\title{
Radionuclide Retention Mechanisms in Secondary Waste-Form Testing: Phase II
}
W Um
RJ Serne
MM Valenta
KE Parker
C-W Chung
G Wang
JS Yang
KJ Cantrell
$\mathrm{MH}$ Engelhard
JH Westsik, Jr.

September 2011

Pacific Northwest

NATIONAL LABORATORY

Proudly Operated by Battelle Since 1965 



\title{
DISCLAIMER
}

This report was prepared as an account of work sponsored by an agency of the United States Government. Neither the United States Government nor any agency thereof, nor Battelle Memorial Institute, nor any of their employees, makes any warranty, express or implied, or assumes any legal liability or responsibility for the accuracy, completeness, or usefulness of any information, apparatus, product, or process disclosed, or represents that its use would not infringe privately owned rights. Reference herein to any specific commercial product, process, or service by trade name, trademark, manufacturer, or otherwise does not necessarily constitute or imply its endorsement, recommendation, or favoring by the United States Government or any agency thereof, or Battelle Memorial Institute. The views and opinions of authors expressed herein do not necessarily state or reflect those of the United States Government or any agency thereof.

\author{
PACIFIC NORTHWEST NATIONAL LABORATORY \\ operated by \\ BATTELLE \\ for the \\ UNITED STATES DEPARTMENT OF ENERGY \\ under Contract DE-AC05-76RL01830
}

Printed in the United States of America

Available to DOE and DOE contractors from the

Office of Scientific and Technical Information,

P.O. Box 62, Oak Ridge, TN 37831-0062;

ph: (865) 576-8401

fax: $(865) 576-5728$

email: reports@adonis.osti.gov

Available to the public from the National Technical Information Service

5301 Shawnee Rd., Alexandria, VA 22312 ph: (800) 553-NTIS (6847)

email: orders@ntis.gov <http://www.ntis.gov/about/form.aspx>

Online ordering: http://www.ntis.gov

This document was printed on recycled paper. 



\title{
Radionuclide Retention Mechanisms in Secondary Waste-Form Testing: Phase II
}

\author{
W Um \\ RJ Serne \\ MM Valenta \\ C-W Chung \\ JS Yang \\ MH Engelhard \\ KE Parker \\ G Wang \\ KJ Cantrell \\ JH Westsik, Jr.
}

September 2011

Prepared for

the U.S. Department of Energy

under Contract DE-AC05-76RL01830

Pacific Northwest National Laboratory

Richland, Washington 99352 



\section{Executive Summary}

This report describes the results from laboratory tests performed at Pacific Northwest National Laboratory (PNNL) for Washington River Protection Solutions (WRPS) to evaluate candidate stabilization technologies that have the potential to successfully treat liquid secondary waste stream effluents produced by the Hanford Tank Waste Treatment and Immobilization Plant (WTP). WRPS is considering the design and construction of a Solidification Treatment Unit (STU) for the Effluent Treatment Facility (ETF) at Hanford. The ETF, a multi-waste, treatment-and-storage unit that has been permitted under the Resource Conservation and Recovery Act (RCRA), can accept dangerous, low-level, and mixed wastewaters for treatment. The STU needs to be operational by 2018 to receive secondary liquid waste generated during operation of the WTP. The STU will provide the additional capacity needed for ETF to process the increased volume of secondary waste expected to be produced by WTP. This report on radionuclide retention mechanisms describes the testing and characterization results that improve understanding of radionuclide retention mechanisms, especially for pertechnetate, ${ }^{99} \mathrm{TcO}_{4}{ }^{-}$in four different waste forms: Cast Stone, DuraLith alkali aluminosilicate geopolymer, encapsulated fluidized bed steam reforming (FBSR) product, and Ceramicrete ${ }^{\circledR}$ phosphate-bonded ceramic. These data and results will be used to fill existing data gaps on the candidate technologies to support a decision-making process that will identify a subset of the candidate waste forms that are most promising and should undergo further performance testing.

The following subtasks are included within the radionuclide retention mechanisms task:

1. Measure the technetium (Tc) speciation/oxidation state in different unleached waste forms.

2. Measure the reductive capacity of each waste form and some of its individual ingredients.

3. Extend EPA Draft 1315 leach testing up to 90 days for Cast Stone and DuraLith specimens used for Phase I.

4. Conduct additional weathering tests using $\mathrm{CO}_{2}(\mathrm{~g})$ or $\mathrm{O}_{2}(\mathrm{~g})$ reactions and subsequent EPA Draft 1315 leaching tests.

5. Conduct pore-structure analysis of waste forms before and after weathering.

6. Conduct flow-through column leach tests using the EPA 1314 method.

7. Extend the contact times used in the EPA Draft 1313 method pH-effects tests of unreacted and weathered waste forms.

Tc speciation calculations using oxidation-reduction potential (Eh)-pH diagrams for the different simulant solutions predict that Tc should be present solely as the oxidized species $\left(\mathrm{TcO}_{4}{ }^{-}\right)$or as some other Tc(VII) oxidation state species, which are more mobile and soluble than reduced Tc species, such as $\mathrm{Tc}(\mathrm{IV}) \mathrm{O}_{2} \cdot 2 \mathrm{H}_{2} \mathrm{O}$. However, the Tc oxidation state in the final solid waste forms determined by $\mathrm{x}$-ray absorption near-edge structure (XANES) spectroscopy varied depending on the type of waste form, the curing (or aging) time, and the amounts and types of reductants used to prepare the waste forms (Cast Stone, DuraLith, and Ceramicrete). The oxidation state of Tc in Cast Stone was most sensitive to the curing (or aging) time after preparation because of the slow dissolution kinetics for the blast furnace slag (BFS). The presence of $\mathrm{Tc}(\mathrm{VII}) \mathrm{O}_{4}{ }^{-}$was almost $85 \%$ to $93 \%$ in Cast Stone that was cured for only 3 days. However, increasing $\mathrm{Tc}(\mathrm{IV})$ contributions from $\mathrm{TcO}_{2} \cdot 2 \mathrm{H}_{2} \mathrm{O}$ and $\mathrm{Tc} /$ sulfur species were found in Cast Stone as the curing time increased to 76 days. Because the reductants (i.e., $\mathrm{SnF}_{2}$ or $\mathrm{SnCl}_{2}$ ) are added 
during the preparation of DuraLith and Ceramicrete, respectively, more Tc(IV) species were found in these cured waste forms, even after short curing times (3 days to 28 days). Reduction of Tc(VII) to Tc(IV) was very fast and complete during the preparation of Ceramicrete. Reduction of almost $100 \%$ of the Tc to Tc(IV) species was observed within 3 days in the Ceramicrete because of the relatively large amount of $\mathrm{SnCl}_{2}(1.2 \mathrm{wt} \%)$ used to prepare that waste form. Because of the low concentration of rhenium (Re) in FBSR waste forms sent to PNNL, x-ray photoelectron spectroscopy (XPS) was not able to determine Re oxidation states in two FBSR samples.

The reductive capacities of dry ingredients and the final cured waste forms were measured using two different methods. The ingredients tested using Ce(IV) as the oxidant showed generally larger reductive capacity values when compared to those measured using the $\mathrm{Cr}(\mathrm{VI})$ method. The difference is caused by the different $\mathrm{pH}$ conditions used in these two reduction capacity methods (i.e., $\mathrm{pH} \approx 1-2$ for the $\mathrm{Ce}(\mathrm{IV}$ ) method and $\mathrm{pH} \approx 7.0$ for the $\mathrm{Cr}(\mathrm{VI})$ method), respectively. Much more of the solids dissolve in the strong acid environment created by the $\mathrm{Ce}(\mathrm{IV})$ method; therefore, more of the reductants are available and measured in the $\mathrm{Ce}(\mathrm{IV})$ than in the $\mathrm{Cr}(\mathrm{VI})$ method. The BFS, sodium sulfide, $\mathrm{SnF}_{2}$, and $\mathrm{SnCl}_{2}$ used as dry ingredients to make various waste forms showed significantly larger measured reductive capacities compared to other ingredients regardless of which method was used. Although the BFS exhibits appreciable reductive capacity, it requires greater amounts of time to fully react (dissolve) and release all its electrons. The reductive capacities for the four different liquid waste simulants at 2-M sodium (Na) concentrations were similar for both methods because there was no need for solids dissolution to release measurable electrons. For the Cast Stone waste forms prepared with varying concentrations of simulant S1, the reductive capacity increased as the concentration of the S1 simulant was increased from 2-M Na to 10-M Na because of a synergistic reaction promoted by the low $\mathrm{pH}$ condition of the Ce(IV) method. The high salt content of the more concentrated simulants promoted more dissolution of the slowly reacting BFS. The FBSR granular product sample exhibited a larger reductive capacity than the FBSR product encapsulated in Geo-7 binder, suggesting that the Geo-7 binder does not have significant reductive properties. The DuraLith geopolymer and Ceramicrete waste forms showed larger reductive capacities than Cast Stone when the Ce(IV) method was used because of the large amounts of the strong reductants $\mathrm{Na}_{2} \mathrm{~S}$ and $\mathrm{SnF}_{2} / \mathrm{SnCl}_{2}$ used to prepare the DuraLith geopolymer and Ceramicrete waste forms, respectively. Based on the measured reductive capacity values, the Ce(IV) method can be used as an upper bound for the waste form reductive capacity because much more solids are dissolved, thus releasing much larger quantities to consume the oxidant. The $\mathrm{Cr}(\mathrm{VI})$ method can be used to estimate primarily the waste form surface-related and readily dissolvable reduction capacity. However, the $\mathrm{Cr}(\mathrm{VI})$ method does not measure the total reduction capacity of the waste form, the long-term reductive capacity afforded by very slowly dissolving solids, or the reductive capacity present in the interior pores and internal locations of the solids.

Pore structure analysis using both nitrogen $\left(\mathrm{N}_{2}\right)$ gas absorption analysis and x-ray microtomography (XMT) techniques showed that Cast Stone is a relatively highly porous material (less dense) compared to other waste forms. Carbonation reactions changed the Cast Stone pore structure, which in turn may correlate with Tc leachability. The porosity and surface area of Cast Stone increased, while the average pore diameter decreased, after short carbonation reaction times (14 days). However, a longer carbonation reaction time (28 days) showed some reversal in the trends observed after 14 days so that there was a decrease in total pore volume and surface area, but an increase in pore diameter. Also, the overall changes in the measured parameters after carbonation still showed a net increase in pore volume and surface area, but a net decrease in average pore diameter with either carbonation time period when 
compared to the uncarbonated Cast Stone. Slightly increased porosity, ranging from $8.6 \%$ to $10.7 \%$ after carbonation using gas absorption analysis, also was measured in the weathered Cast Stone. A similar increased porosity was found in Cast Stone after carbonation (14 days) using the XMT analysis. However, smaller values of porosity were measured by XMT in Cast Stone before and after carbonation (14 days) because of the limited capability of the XMT technique to separate water-filled pore areas from cement solid materials-that is, the XMT was delineating mostly the small volume of air-filled pores and not the total porosity.

The EPA 1314 method (up-flow percolation column leaching test) was used for the Cast Stone and DuraLith geopolymer (Batch \#2) waste forms available from Phase I and for the Geo-7 encapsulated FBSR product recently available from Savannah River National Laboratory. The Tc concentrations leached from the DuraLith geopolymer packed column were slightly higher than the Tc concentrations leached from the Cast Stone packed column. Significantly higher Re concentrations were found in the leachates from the FBSR packed column. The stop-flow technique was also applied to the Cast Stone and DuraLith geopolymer packed columns. When the first effluents were obtained after flow was resumed, the Tc concentrations were significantly higher, which confirms that Tc releases from both Cast Stone and DuraLith were controlled by diffusion processes. Leachate concentrations for RCRA-listed metals from the packed columns were very low, a result that was similar for the Cast Stone and DuraLith waste forms. That is, none of the RCRA-listed metals present in the secondary waste simulants leached out of the Cast Stone or DuraLith in significant concentrations. Concentrations of RCRA-listed metals and major cations (including Re), electrical conductivity, and alkalinity were higher in the effluents from the packed column with FBSR encapsulated with Geo-7 monolith chunks using the EPA 1314 method. These high concentrations may be attributable to the higher concentrations of RCRA metals in the FBSR product that, after encapsulation in Geo-7, was used for the packed column test.

EPA 1315 leach tests for Cast Stone and DuraLith monoliths from the Phase-I project were extended beyond 63 days to 90 days. The leach test results showed that the Tc diffusivity for the DuraLith Batch \#1 and Batch \#2 waste forms at 90 days were a bit higher than that observed for the Cast Stone. There also was a minor decreasing Tc diffusivity trend for the Cast Stone over the entire 90-day leaching period. The decreasing Tc diffusivity trend might be caused by ongoing carbonation reactions - that is, formation of calcium carbonate on the surface and within near-surface micro cracks that might be reducing the porosity of the monolith during the leach testing. The slightly increased Tc diffusivity in the DuraLith waste form near the 90-day leach interval might result from more dissolution of the DuraLith matrix with extended contact with the solution, which is consistent with the increased concentrations of major components sodium (Na), calcium (Ca), aluminum (Al), and silicon (Si) in the leachate after a 90-day leaching period. The XRD and scanning electron microscopy (SEM)/EDS analyses of slices of Cast Stone waste form after 90 days of leaching showed that most of the major XRD peaks for mineral phases, such as ettringite, gypsum, and calcium-aluminum-oxide carbonate hydrate, had disappeared or showed reduced intensity. The calcite peak in the $292-\theta$ region slightly increased in the sliced Cast Stone sample collected at the outermost rim region compared to two other sliced samples collected farther inside the monolith. The XRD patterns of the sliced DuraLith monolith after a 90-day leaching period showed no changes in peak intensity for its major crystalline minerals (quartz and anhydrite), regardless of sample location. Because the chemical composition changes in each waste-form sample after 90-day leaching periods were minor, the SEM/EDS technique unfortunately was not sensitive enough to detect even minor changes in chemical composition as a function of depth from the monolith surface vs. the starting composition of the monoliths. 
The accelerated weathering reactions produced with exposure to elevated $\mathrm{CO}_{2}(\mathrm{~g})$ or $\mathrm{O}_{2}(\mathrm{~g})$ were performed on different waste-form monoliths and powder samples for 14 days. The weathered monoliths then were leached using the EPA Draft 1315 method. The resulting water leachates for the carbonated Cast Stone showed significantly decreased pHs but increased Tc diffusivities for the entire 90-day period when compared to Cast Stone monoliths that were not weathered. The increased Tc diffusivity for Cast Stone after reacting with $\mathrm{CO}_{2}(\mathrm{~g})$ probably resulted from increased porosity as found in pore structure analyses. However, the increased Tc diffusivity in carbonated Cast Stone slowly decreased, and the decreased $\mathrm{pH}$ in effluents also gradually increased as leaching times increased, suggesting that additional calcite precipitation and pore structure changes might continue to affect Tc diffusivity in a different way under long-term leaching conditions. The Cast Stone monolith that was reacted in the enhanced $\mathrm{O}_{2}(\mathrm{~g})$ environment generated leachates with $\mathrm{pH}$ values that were the same as leachates from Cast Stone that were not weathered. However, the Tc diffusivity for the oxidized Cast Stone increased significantly during early leaching times, most likely because $\mathrm{O}_{2}(\mathrm{~g})$ is a strong oxidant that re-oxidized the reduced Tc(IV) species found near the surface of the monolith. Increased Tc diffusivity in oxidized Cast Stone also decreased as the leaching times increased, perhaps because the oxidation rate into the interior was slow compared to the rate near the surface of the monoliths.

The leachate pHs for both the carbonated and oxidized DuraLith monoliths were lower when compared to the leachates from an unweathered DuraLith monolith, but the degree of decrease in $\mathrm{pH}$ after reacting with $\mathrm{CO}_{2}(\mathrm{~g})$ was not as large as that found in carbonated Cast Stone leachates. Further, there was an increase in the Tc diffusivity in the carbonated and the oxidized DuraLith monoliths when compared to unreacted DuraLith, but the degree of increase was small in comparison with the larger increase in Tc diffusivity found for the carbonated Cast Stone monolith versus the unreacted Cast Stone. This finding suggests that the carbonation and oxidation effects for Cast Stone are more significant than for DuraLith waste forms. The initial increase in Tc diffusivity for oxidized DuraLith was also from re-oxidation of Tc present near the surface of the DuraLith monolith. The increased Tc diffusivity in the oxidized DuraLith monolith dropped after 40 days of leaching time and the longer-term Tc diffusivity became similar to that for un-reacted DuraLith waste forms.

The FBSR monolith after reacting with $\mathrm{CO}_{2}(\mathrm{~g})$ or $\mathrm{O}_{2}(\mathrm{~g})$ showed decreasing Re diffusivity as leaching times increased, while the $\mathrm{pH}$ values were similar to those measured in leachates from an unreacted FBSR monolith. The oxidized FBSR leachates also showed $\mathrm{pH}$ values similar to those of unreacted or carbonated FBSR monolith after 10 days of leaching time. This finding indicates that the effects of carbonation and oxidation on the encapsulated FBSR product may decrease Re diffusivity as leaching time increases. In a relative sense, the results from tests using the EPA 1313 method for the Cast Stone, DuraLith, and encapsulated FBSR waste forms after reaction inside a $\mathrm{CO}_{2}$ (g) or $\mathrm{O}_{2}$ (g) chamber showed results similar to those obtained from the EPA 1315 Method. That is, carbonation or oxidation of the Cast Stone and FBSR waste forms showed significant impacts, but carbonation or oxidation of the DuraLith waste forms resulted in smaller impacts. This generalization is based on short-term weathering (only 14 days) followed by relatively short-term leach testing (up to 7 days for the 1313 Method and 30 to 90 days for the 1315 Method leach testing). Based on our observations of continually increasing Tc or Re concentrations in filtrates tested using the EPA 1313 Method for unreacted Cast Stone and DuraLith waste forms, such testing should be extended to longer time periods to determine whether steady-state (constant) concentrations are reached after longer time periods. 


\section{Acknowledgments}

The authors are grateful to Kim Smith, Kris Colosi, Tom May, and Max Melvin at Washington River Protection Solutions, LLC, Richland, Washington, for the project funding and programmatic guidance. We also acknowledge Steven Baum, Keith Geiszler, Cristian Iovin, Igor Kutnyakov, and Dennese Smith in the Geosciences group at PNNL for their analytical and laboratory support. The Tc-X-ray absorption fine structure data collection and analysis support performed by Jeffrey Fitts at Brookhaven National Laboratory and Wayne Lukens at Lawrence Berkeley National Laboratory are greatly appreciated. We would like to acknowledge Cary Counts and Maura Zimmerschied for editing this report. PNNL is a multi-program national laboratory operated by Battelle for the U.S. Department of Energy. 



\section{Acronyms and Abbreviations}

\begin{tabular}{|c|c|}
\hline ANS & American Nuclear Society \\
\hline ANSI & American National Standards Institute \\
\hline ASTM & American Society for Testing and Materials (now known as ASTM International) \\
\hline BET & Brunauer-Emmett-Teller (method) \\
\hline BFS & blast furnace slag \\
\hline $\mathrm{BJH}$ & Barrett, Joyner, and Halenda (method) \\
\hline CCD & charge-coupled device \\
\hline CCS & containerized Cast Stone \\
\hline COC & contaminant(s) of concern \\
\hline CS & Cast Stone \\
\hline C-A-S-H & calcium aluminum silicate hydrate \\
\hline C-S-H & calcium silicate hydrate \\
\hline DIW & deionized water \\
\hline DMR & Denitration and Mineralization Reformer \\
\hline DOE & U.S. Department of Energy \\
\hline DW & Debye-Waller \\
\hline EC & electrical conductivity \\
\hline EDS & energy dispersive $x$-ray spectroscopy \\
\hline Eh & oxidation-reduction potential \\
\hline EPA & U.S. Environmental Protection Agency \\
\hline EQL & estimated quantitation limit \\
\hline ETF & Effluent Treatment Facility \\
\hline EXAFS & extended x-ray absorption fine structure \\
\hline FBSR & Fluidized Bed Steam Reformer \\
\hline HTF & High-Temperature Filter \\
\hline ICP & inductively coupled plasma \\
\hline ICP-MS & inductively coupled plasma mass spectroscopy \\
\hline IDF & Integrated Disposal Facility \\
\hline ILAW & immobilized low-activity waste \\
\hline LAW & low-activity waste \\
\hline LI & leachability index \\
\hline LS & liquid to solid \\
\hline ND & not detected; not determined \\
\hline NSLS & National Synchrotron Light Source \\
\hline PNNL & Pacific Northwest National Laboratory \\
\hline PR & Product Receiver \\
\hline
\end{tabular}


PSD

RCRA

SBS

SEM

SRNL

SSRL

STU

THOR

WRPS

WTP

XAFS

XANES

XPS

XRD

XMT particle-size distribution

Resource Conservation and Recovery Act

submerged-bed scrubber

scanning electron microscopy

Savannah River National Laboratory

Stanford Synchrotron Radiation Laboratory

Solidification Treatment Unit

THermal Organic Reduction

Washington River Protection Solutions

Hanford Tank Waste Treatment and Immobilization Plant

$\mathrm{x}$-ray absorption fine structure

$\mathrm{x}$-ray absorption near-edge structure

$\mathrm{x}$-ray photoelectron spectroscopy

$\mathrm{x}$-ray diffraction

x-ray microtomography 
Terms used by cement chemists:

$\begin{array}{lll}\mathrm{C} & \mathrm{CaO} & \text { calcium oxide, or lime } \\ \mathrm{S} & \mathrm{SiO}_{2} & \text { silicon dioxide, or silica } \\ \mathrm{CH} & \mathrm{Ca}(\mathrm{OH})_{2} & \text { portlandite } \\ \text { A } & \mathrm{Al}_{2} \mathrm{O}_{3} & \text { aluminum oxide, or alumina } \\ \mathrm{F} & \mathrm{Fe}_{2} \mathrm{O}_{3} & \text { iron oxide } \\ \mathrm{T} & \mathrm{TiO}_{2} & \text { titanium dioxide } \\ \mathrm{M} & \mathrm{MgO} & \text { magnesium oxide } \\ \mathrm{K} & \mathrm{K}_{2} \mathrm{O} & \text { potassium oxide } \\ \mathrm{N} & \mathrm{Na}_{2} \mathrm{O} & \text { sodium oxide } \\ \mathrm{H} & \mathrm{H}_{2} \mathrm{O} & \text { water } \\ \bar{C} & \mathrm{CO}_{2} & \text { carbon dioxide } \\ \bar{S} & \mathrm{SO}_{3} & \text { sulfur trioxide } \\ \mathrm{P} & \mathrm{P}_{2} \mathrm{O}_{5} & \text { phosphorus hemi-pentoxide }\end{array}$





\section{Units of Measure}

$\theta$

$\AA$

${ }^{\circ} \mathrm{C}$

$\mathrm{cm}$

g

$\mu$

$\mu \mathrm{m}$

$\mathrm{mS} / \mathrm{cm}$

$\mathrm{M}$

$\mathrm{mL}$

rpm

$\lambda$

wt\% angle of incidence (Bragg angle)

Angstrom $\left(10^{-10} \mathrm{~m}\right.$ or $\left.10^{-1} \mathrm{~nm}\right)$

temperature in degrees Celsius $\left[\mathrm{T}\left({ }^{\circ} \mathrm{C}\right)=\mathrm{T}(\mathrm{K})-273.15\right]$

centimeter

gram

micro (prefix, 10-)

micrometer

millisiemens per centimeter (electrical conductance)

molarity, mol/L

milliliter

revolutions per minute

wavelength

weight percent 



\section{Contents}

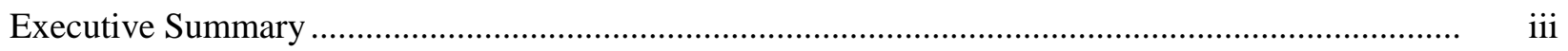

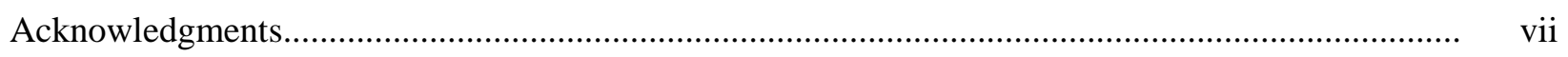

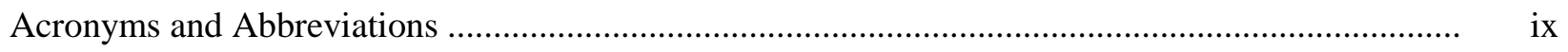

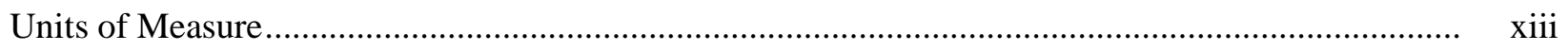

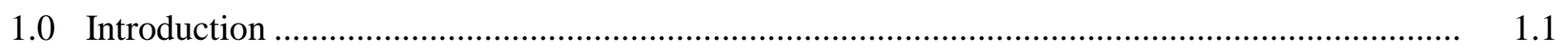

2.0 Secondary Waste Forms and Preparation ........................................................................ 2.1

2.1 Composition of Secondary Waste Simulant................................................................ 2.1

2.2 Cast Stone and Preparation ....................................................................................... 2.3

2.3 DuraLith Alkali-Aluminosilicate Geopolymer and Preparation ....................................... 2.4

2.4 Ceramicrete Phosphate Bonded Ceramic ........................................................................... 2.6

2.5 Fluidized Bed Steam Reformer and Preparation............................................................ 2.7

3.0 Technetium Speciation .................................................................................................

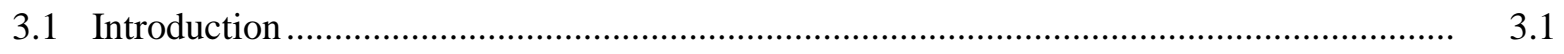

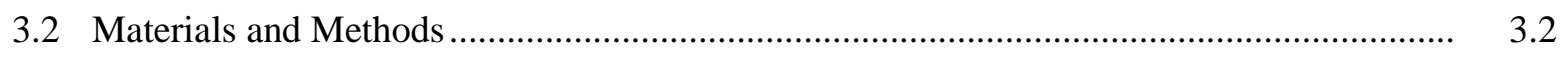

3.2.1 Solution Analysis ............................................................................................ 3.2

3.2.2 Tc Eh-pH Diagram Calculation....................................................................... 3.3

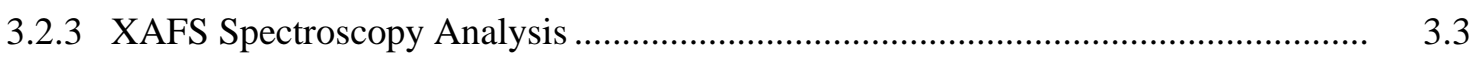

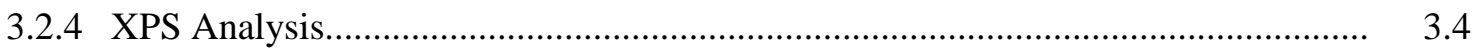

3.3 Results and Discussion............................................................................................ 3.5

3.3.1 Solution pH and Eh Analysis and Technetium Eh-pH Diagram Development ........ 3.5

3.3.2 XAFS Spectroscopy Analysis ......................................................................... 3.6

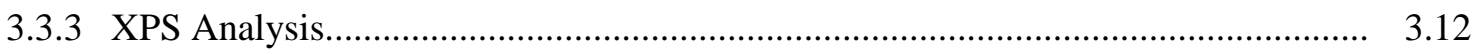

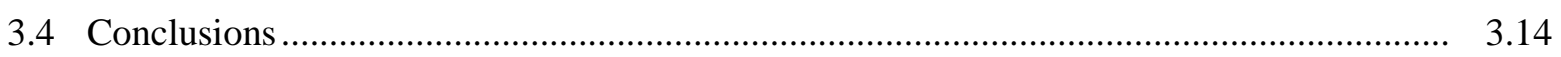

4.0 Reductive Capacity Measurement …...................................................................................

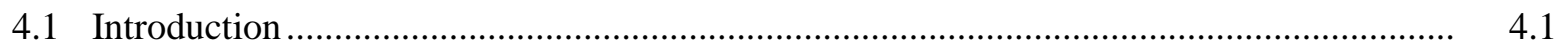

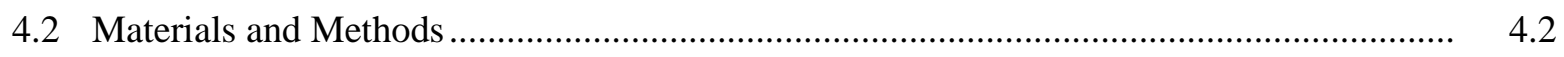

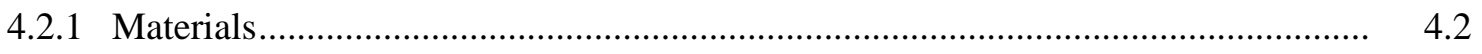

4.2.2 Particle-Size Analysis ....................................................................................... 4.2

4.2.3 Measurement of Reductive Capacity ............................................................... 4.3

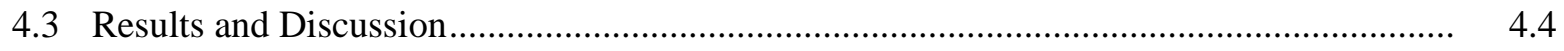

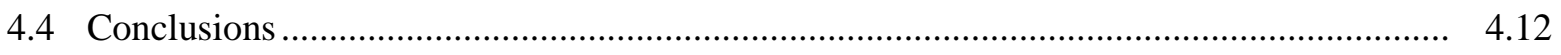

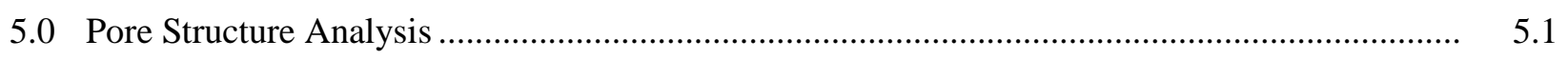

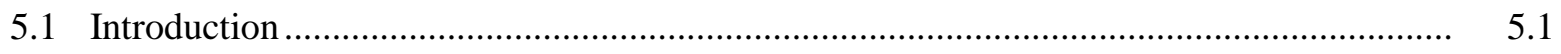

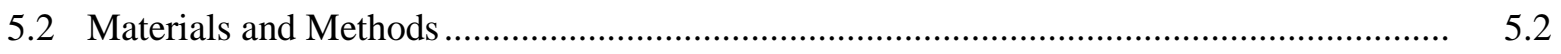

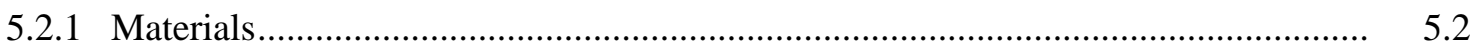

5.2.2 Environmental $\mathrm{CO}_{\mathbf{2}}$ (g) Chamber …........................................................... 5.2 


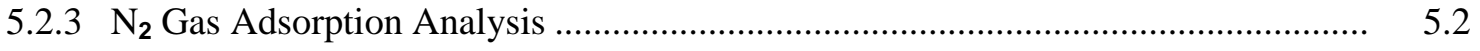

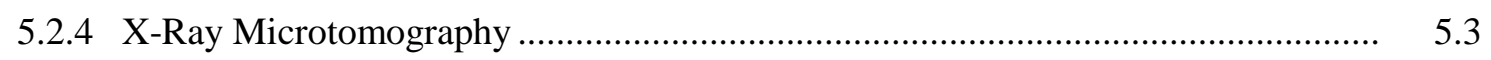

5.3 Results and Discussion.............................................................................................. 5.4

5.3.1 Pore Analysis for Unreacted Waste Forms ........................................................... 5.4

5.3.2 Cast Stone Sample Analysis Before and After Carbonation ................................... 5.5

5.3.3 X-ray Microtomography ................................................................................ 5.14

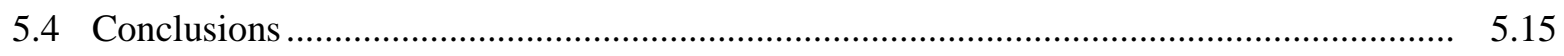

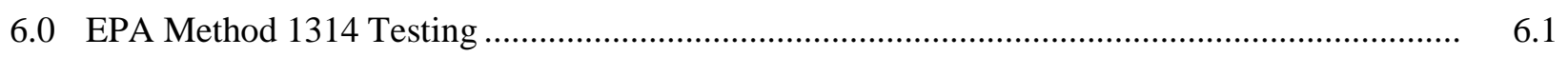

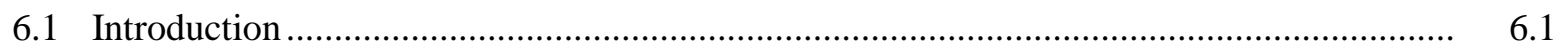

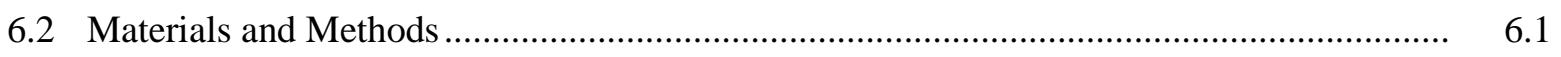

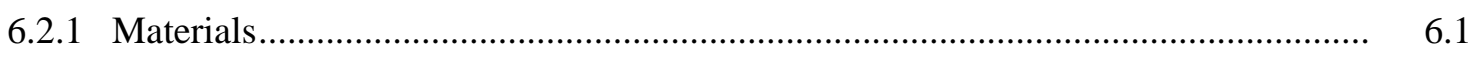

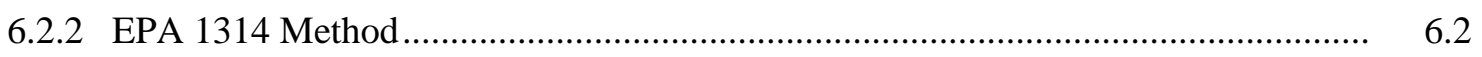

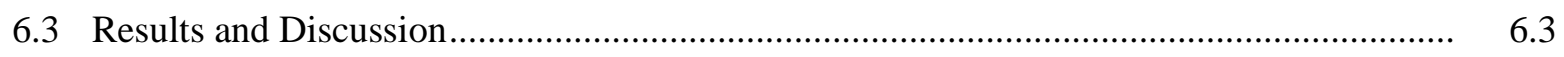

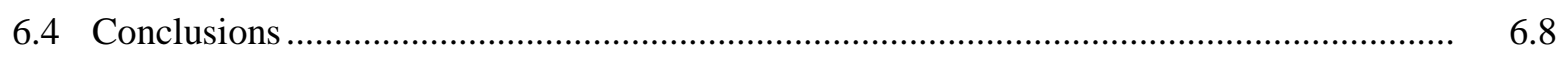

7.0 Extension of EPA Method 1315 on Phase-I Waste Forms ...................................................... 7.1

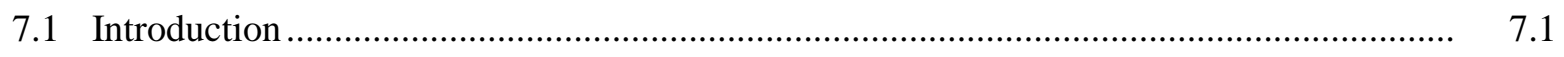

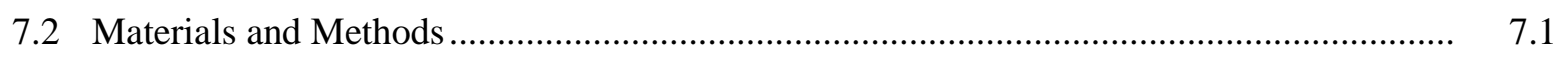

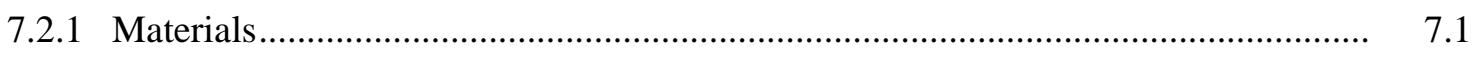

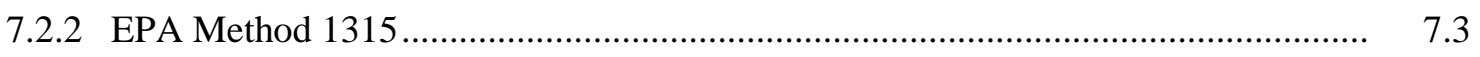

7.2.3 X-Ray Diffraction Analysis.............................................................................. 7.4

7.2.4 Scanning Electron Microscopy and Energy Dispersive Spectrometry..................... 7.4

7.3 Results and Discussion................................................................................................ 7.5

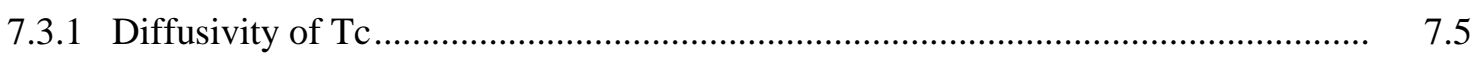

7.3.2 Post-Characterization of 90-Day Leached Waste Form Monoliths.......................... 7.6

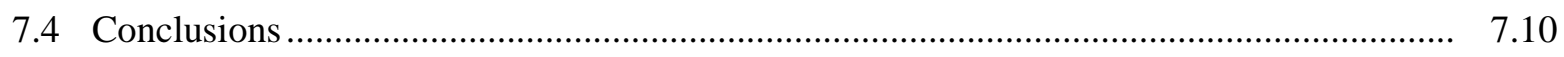

8.0 Oxidation and Carbonation Studies .........................................................................

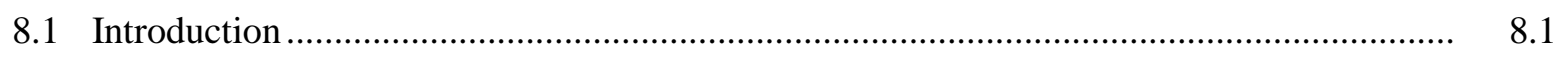

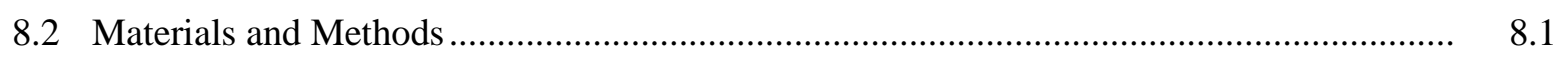

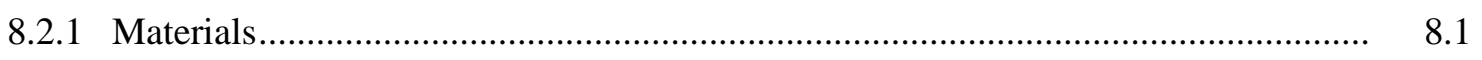

8.2.2 Environmental Atmosphere Chamber ............................................................. 8.2

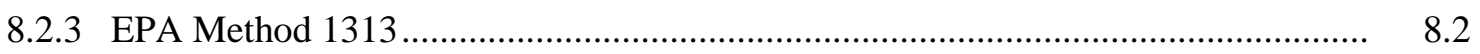

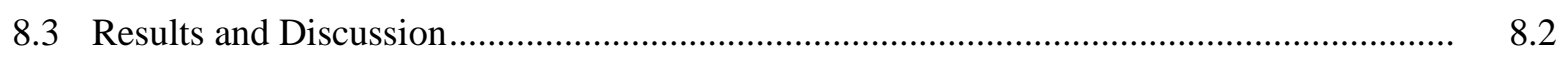

8.3.1 EPA 1315 Method After Weathering ................................................................ 8.2

8.3.2 EPA 1313 Method Analysis ............................................................................... 8.8

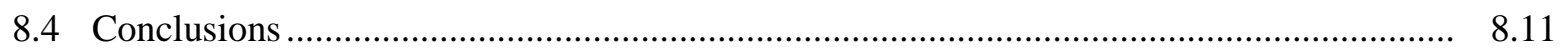

9.0 Summary and Recommendations …............................................................................... 9.1

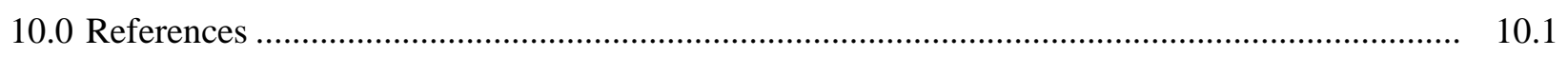

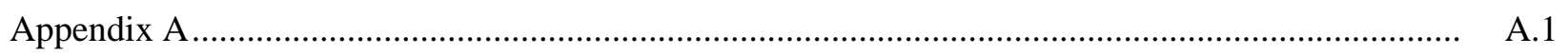




\section{Figures}

3.1 Eh-pH Stability Diagrams for Dominant Technetium Species at $25^{\circ} \mathrm{C}$.................................. 3.6

3.2 Normalized Tc XANES Spectra and Fits for Containerized Cast Stone Samples Prepared with Phase-I Simulant and Simulants S1, S2, S3, and S4....................................... 3.7

3.3 Normalized Tc XANES Spectra and Fits for DuraLith and Ceramicrete Samples................... 3.10

3.4 EXAFS Spectra and their Fourier Transforms for Cast Stone Samples Aged for 60 Days with Tc Concentrations $300 \mu \mathrm{g} / \mathrm{g}$ and $200 \mu \mathrm{g} / \mathrm{g}$

3.5 High Energy Resolution XPS Spectra of the Re 4f Region for Re References

3.6 High Energy Resolution Photoemission Spectra of the Re 4f Region for FBSR Powder and FBSR Milled Monolith Powder

4.1 PSDs of Dry Ingredients Used for Making Cast Stone and Final Cast Stone Samples Prepared with Different Simulants

4.2 PSDs of Dry Ingredients of DuraLith and Geopolymers Prepared with Different Simulants.

4.3 PSDs of FBSR Waste Forms and Dry Ingredients Used for Making Ceramicrete.

4.4 Effect of Reaction Time for the Measurement of Reductive Capacity ....

4.5 Reductive Capacity of Cast Stone Samples Without Tc and Tc-Loaded Cast Stone Samples Using the Ce(IV) and Cr(VI) Methods.

4.6 Relationship Between Estimated and Measured Cast Stone Reductive Capacities

5.1 Adsorption and Desorption Isotherms of Cast Stone, DuraLith, FBSR, and Ceramicrete Waste Forms Before Carbonation Reaction

5.2 $\mathrm{N}_{2}$ (g) Adsorption and Desorption Isotherms of Normal and Carbonated Cast Stone with Different Simulants: Cast Stone Prepared with S1 2-M Na Simulant; Cast Stone Prepared with S1 4-M Na Simulant

5.3 $\mathrm{N}_{2}$ (g) Adsorption and Desorption Isotherms of Normal and Carbonated Cast Stone with Different Simulants: Cast Stone Prepared with S1 8-M Na Simulant; Cast Stone Prepared with S1 10-M Na Simulant.

5.4 Nitrogen Gas Adsorption and Desorption Isotherms of Normal and Carbonated Cast Stone with Different Simulants: Cast Stone Prepared with S1 2M Na Simulant; Cast Stone Prepared with S4 2M Na Simulant

5.5 Surface Area of Normal and Carbonated Cast Stone Specimens Prepared with S1, S2, S3, and S4 2M Na Concentration; S1 2 to 10M Na Concentrations.

5.6 Pore Volume of Normal and Carbonated Cast Stone Specimens Prepared with S1-, S2-, S3-, and S4-2M Na Concentration; S1-2M to S1-10M Na Concentrations

5.7 Average Pore Diameter of Normal and Carbonated Cast Stone Specimens Prepared with S1-, S2-, S3-, and S4-2M Na Concentration; S1-2M to -10M Na Concentrations

5.8 Nitrogen Gas Adsorption/Desorption Isotherms of Normal and Carbonated Cast Stone Monolith Specimens

5.9 Surface Area and Pore Volume of Normal, 14-day Carbonated, and 30-day Carbonated Cast Stone Monolith Specimens.....

5.10 Average Pore Diameter of Normal, 14-day Carbonated, and 30-day Carbonated Cast Stone Monolith Specimens 
5.11 XMT Images of the Cast Stone Monolith after the 14-day Carbonation Period; Cast Stone Monolith with Different Location of Two-Dimensional Section Images

Collected; Two-Dimensional Projection; Vertical Cross-Section; Diagonal

Cross-Section; Distribution of Pores After Removing Gray and White Colored Areas

5.12 Two-Dimensional Computed Tomography Scans for the Cast Stone Monolith Specimen Collected at Different Locations Shown in Figure 5.11a

6.1 Schematic of Column Test Apparatus for the EPA 1314 Method

6.2 The Results of EPA 1314 Testing for Different Waste Forms

6.3 Cumulative Leached Concentrations of RCRA-Listed Metals and Tc and Major Cations from Tests of Cast Stone using the EPA 1314 Method

6.4 Cumulative Leached Concentrations of RCRA Metals with Tc and Major Cations from DuraLith using EPA 1314 Testing

6.5 Cumulative Leached Concentrations of RCRA-Listed Metals with Re and Major Cations from FBSR Using EPA 1314 Testing

7.1 Schematic of Sliced Monolith Samples after Leaching for 90 Days

7.2 Diffusivity of ${ }^{99}$ Tc Measured Using EPA Method 1315 up to 90 Days Reaction

7.3 XRD Spectra of Unreacted Cast Stone and Cast Stone Sliced Samples After Leaching for 90 Days Using EPA 1315 Method; Top-Horizontally Sliced Samples of top-H1, -H2, and-H3 from Top to Bottom; Bottom-Vertically Sliced Samples of Bottom-V1, -V2, -V3, -V4, and -V5 from Right to Left.

7.4 XRD Spectra of Unreacted DuraLith and Sliced DuraLith Samples After Leaching for 90 Days Using the EPA 1315 Method; Top-Horizontally Sliced Samples of top-H1, -H2, and-H3 from Top to Bottom; Bottom-Vertically Sliced Samples of Bottom-V1, -V2, -V3, -V4, and -V5 from Right to Left .

7.5 SEM Images and Elemental Maps of Cast Stone Sliced Top-H1 Sample

7.6 SEM Images and Elemental Map of DuraLith Sliced Top-H2 Sample

8.1 Diffusivity of Tc and Measured pHs for Cast Stone Leachates Before and After Reaction Inside $\mathrm{CO}_{2} / \mathrm{N}_{2}$ or $\mathrm{O}_{2} / \mathrm{N}_{2}$ Chamber Using the EPA 1315 Method.

8.2 Diffusivity of Tc and Measured pHs for DuraLith Before and After Reaction Inside a $\mathrm{CO}_{2} / \mathrm{N}_{2}$ or $\mathrm{O}_{2} / \mathrm{N}_{2}$ Chamber Using the EPA 1315 Method....

8.3 Reacted FBSR Monolith with $\mathrm{CO}_{2} / \mathrm{N}_{2}$ (g) Inside a Chamber and XRD Patterns of Collected Two White Precipitates, White Lumps and White Squares from the Reacted FBSR Surfaces and Reference XRD Pattern of $\mathrm{NaHCO}_{3}$, Nahcolite.

8.4 Diffusivity of Re and Measured pHs for the FBSR Monolith Before and After Reaction Inside a $\mathrm{CO}_{2} / \mathrm{N}_{2}$ or $\mathrm{O}_{2} / \mathrm{N}_{2}$ Chamber Using the EPA 1315 Method

8.5 Concentrations of Leached Tc and Measured pHs for Cast Stone Before and After Reaction Inside a $\mathrm{CO}_{2} / \mathrm{N}_{2}$ or $\mathrm{O}_{2} / \mathrm{N}_{2}$ Chamber Using the EPA 1313 Method as a Function of Time

8.6 Concentrations of Leached Tc and pHs for DuraLith Before and After Reaction Inside a $\mathrm{CO}_{2} / \mathrm{N}_{2}$ or $\mathrm{O}_{2} / \mathrm{N}_{2}$ Chamber Using the EPA 1313 Method as a Function of Time.

8.7 Concentrations of leached Re and Measured pHs for FBSR Monolith Powder Before and After Reaction Inside a $\mathrm{CO}_{2} / \mathrm{N}_{2}$ or $\mathrm{O}_{2} / \mathrm{N}_{2}$ Chamber Using the EPA 1313 Method as Functions of Time... 


\section{Tables}

2.1 Composition of WTP Secondary Waste Simulant ............................................................. 2.2

2.2 Dry Reagent Compositions Used in Cast Stone................................................................... 2.3

2.3 Summary of Important Chemical and Physical Properties of Cast Stone................................. 2.4

2.4 Summary of Important Chemical and Physical Properties of the DuraLith Samples................ 2.5

2.5 Material Specifications and Composition for DuraLith Monoliths ......................................... 2.6

3.1 Solution Analyses of Secondary Waste Simulants ............................................................... 3.5

3.2 The XANES Fit Results for Tc Species in Different Waste Forms ........................................ 3.8

3.3 Best Fit Parameters for Cast Stone Samples from EXAFS Analysis...................................... 3.12

3.4 Atomic Concentration of Surface Composition................................................................... 3.14

4.1 Reductive Capacities of Secondary Waste Forms without Tc and Their Ingredients................ $\quad 4.8$

4.2 Reductive Capacities of ${ }^{99}$ Tc Loaded Secondary Waste Forms .............................................. 4.9

5.1 Surface Area, Pore Volume, and Pore Diameter of Various Waste Forms Before

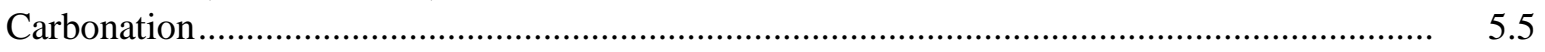

5.2 Surface Area of Cast Stone Obtained from Chunk Specimens ............................................... 5.8

5.3 Pore Volume of Cast Stone Obtained from Chunk Specimens............................................... 5.9

5.4 Pore Diameter Size of Cast Stone Obtained from Chunk Specimens ...................................... 5.10

6.1 pH, EC, Alkalinity, and Tc/Re Concentrations in the EPA Method 1314 Effluents from

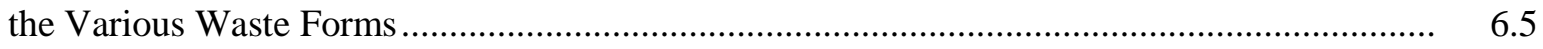

7.1 Material Specifications and Compositions for Cast Stone Monoliths Used in Phase I ............. 7.2

7.2 Material Specifications and Compositions for DuraLith Monoliths....................................... 7.2

7.3 Diffusivity, LI Values, pH, EC, and Alkalinity Results of Waste Forms After Reacting for 90 Days Using EPA 1315 Method .................................................................................... $\quad 7.6$

7.4 The Concentrations of Major Cations in Eluate for Waste Forms from EPA 1315 Method 63 and Leaching for 90 Days ................................................................................ $\quad 7.7$

8.1 Values of pH, EC, Alkalinity, Tc/Re Diffusivity, and Tc/Re LI of Waste Forms Measured by the EPA 1315 Method after $\mathrm{CO}_{2} / \mathrm{N}_{2}$ or $\mathrm{O}_{2} / \mathrm{N}_{2}$ Chamber Reaction ....................................... 8.4

8.2 Values of pH, EC, Alkalinity, Tc/Re Diffusivity, and Tc/Re LI of Waste Forms Measured by the EPA 1313 Method After $\mathrm{CO}_{2} / \mathrm{N}_{2}$ or $\mathrm{O}_{2} / \mathrm{N}_{2}$ Chamber Reactions 



\subsection{Introduction}

Washington River Protection Solutions (WRPS) is proceeding with the design and construction of a Solidification Treatment Unit (STU) to upgrade the Effluent Treatment Facility (ETF) at the U.S. Department of Energy's Hanford Site, which is located in south-central Washington. The ETF, a multi-waste treatment and storage unit permitted under the Resource Conservation and Recovery Act, can accept dangerous and low-level radioactive and mixed wastewaters generated in Washington State for treatment. The STU needs to be operational by 2018 to receive secondary liquid wastes generated during operation of the Hanford Tank Waste Treatment and Immobilization Plant (WTP). Adding the STU to ETF will provide the additional capacity needed for ETF to process the increased volume of secondary wastes expected to be generated by the WTP. Although the current baseline calls for solidification of the ETF evaporator concentrate in a cement-based waste form, an evaluation is being conducted to identify and characterize other candidate stabilization technologies that are mature enough and have the potential for successfully treating the secondary liquid waste stream from the WTP. In addition, the selected technology must be capable of passing the regulatory disposal facility performance requirements for the Integrated Disposal Facility (IDF). Pacific Northwest National Laboratory (PNNL) has been asked by WRPS to conduct Phase II of a secondary waste-form testing program to support the evaluation and selection of waste forms to stabilize and solidify the liquid secondary waste stream from WTP. An optional third phase of testing also is scheduled. This third testing phase will support risk and performance assessments for IDF by evaluating the long-term durability of the selected waste form(s) that will be received at the facility.

A radionuclide retention mechanism subtask of the Phase II Secondary Waste Form Testing Task focuses on developing more fundamental, scientific information that supports the evaluation and selection of a waste form(s) that could be used to immobilize the WTP liquid secondary wastes. Information developed under this subtask will be used to 1) fill existing data gaps regarding the processes that affect and control retention of radionuclides, especially technetium-99 $\left.\left({ }^{99} \mathrm{Tc}\right), 2\right)$ support the decision-making process for selecting the final waste form for the secondary liquid wastes, and 3) facilitate reaching agreement with the Washington State Department of Ecology. Specific tasks and objectives of the radionuclide retention mechanism subtask are described below.

1. Investigate Tc speciation to understand the Tc oxidation state in the final waste form and Tc aqueous species in the prepared secondary-waste simulants used to make the waste forms.

2. Measure the reductive capacity of each final waste form and its dry ingredients as well as the simulant solutions used to prepare different waste forms.

3. Analyze pore structures (porosity and pore volume) that affect Tc leachability in different waste forms and changes in pore structures as a function of aging times with additional $\mathrm{CO}_{2}$ (g) contact.

4. Perform leach testing of waste forms using an up-flow percolation column (U.S. Environmental Protection Agency [EPA] Draft 1314 method) (EPA 2009b) to provide the liquid-solid partitioning of radionuclide and other major ions in a granular solid material as a function of the liquid-to-solid ratio under percolation conditions.

5. Extend the Phase-I EPA Draft 1315 test (EPA 2009c) to a total duration of 90 days to provide more Tc leaching data to advance our understanding of Tc release in a long-term reaction from two waste forms, containerized Cast Stone (CS) and DuraLith alkali aluminosilicate geopolymer. 
6. Conduct additional oxidation and carbonation tests recommended by the review panel for the Phase-I report such as the EPA 1313/1315 methods (EPA 2009a, c) for Cast Stone and DuraLith waste forms after the $\mathrm{O}_{2}$ or $\mathrm{CO}_{2}(\mathrm{~g})$ reaction and EPA 1313 method (EPA 2009a) for each waste form with an extended function of reaction times (up to 7 days).

Each of these experiments is discussed in more detail in a separate chapter in this report. The background and preparation details for each waste form also are described in an introductory chapter. 


\subsection{Secondary Waste Forms and Preparation}

Four different waste forms-Cast Stone, DuraLith, Fluidized Bed Steam Reformer (FBSR), and Ceramicrete phosphate-bonded ceramic (Ceramicrete)—were prepared and tested. Brief background information on different secondary waste simulants, waste forms, and preparation methods are described in this chapter.

\subsection{Composition of Secondary Waste Simulant}

Four simulant compositions representing "typical” WTP secondary waste effluents and realistic ranges of compositions were used in these experiments. The caustic scrubber, which is downstream of the primary low-activity waste (LAW) vitrification off-gas treatment system, is expected to capture volatile iodine (I) and Tc not removed upstream in the process. As part of the secondary off-gas treatment system, the caustic scrubber is downstream of the high-efficiency particulate air (HEPA) filters used for particulate removal, the carbon beds for mercury $(\mathrm{Hg})$ removal, and the selective catalytic reduction beds for oxidizing volatile organic compounds, sulfur oxides, and carbon monoxide as well as for nitrogen oxide reduction. Liquid effluents from the caustic scrubber are returned to the pretreatment plant where they are combined with condensates from the pretreatment evaporator and then sent to the ETF, becoming the source of the secondary wastes requiring treatment. A brief summary of the process used to determine the simulant composition is provided below. For additional details refer to Josephson et al. (2010).

Three simulant compositions were selected to represent secondary waste liquid effluent from the Hanford WTP that will be processed through the ETF for immobilization into a waste form and then disposed of in the IDF. These compositions were used to test candidate waste forms for immobilizing liquid wastes from the immobilized low-activity waste (ILAW) glass melter off-gas treatment caustic scrubber. In addition, a fourth simulant also was used to represent liquid waste streams from the blended caustic scrubber with the submerged bed scrubber (SBS) and the wet electrostatic precipitator. Four simulant compositions used in this task as well as Phase-I simulant compositions shown in Table 2.1 are described below.

- Caustic scrubber median (Simulant 1 or S1). Medians of component values in modeled ILAW melter off-gas caustic scrubber compositions over the duration of the Hanford mission.

- Two compositions of cluster 1 (Simulant 2 or S2) and cluster 2 (Simulant 3 or S3) representing variations in the composition of the ILAW off-gas caustic scrubber secondary waste stream. The two compositions were selected to represent 1 ) a high and low composition of two major components (nitrate and chloride) that are known to negatively impact secondary waste-form performance, and 2) two clusters of waste compositions that account for the variation of all major components in the waste stream. The two "cluster" compositions (S2 and S3) are based on a statistical analysis of the same G2 model set normalized to constant sodium ( $\mathrm{Na}$ ) concentration. In this case, samples from four dates were removed as apparent outliers, and the analysis was conducted on the remaining 237 samples. A cluster analysis of the data showed that the compositions appear to fall into one of two clusters. Further statistical analysis identified the following two compositions. 
1. Composition in Cluster 1 at approximately the $95^{\text {th }}$ percentile of distance between a center composition and each of the 55 compositions in Cluster 1. This is the August 30, 2029, projected composition in the $\mathrm{G} 2$ data set.

2. Composition in Cluster 2 at approximately the $95^{\text {th }}$ percentile of distance between the same center composition and each of the 182 compositions in Cluster 2. This is the 12/9/2027 projected composition in the $\mathrm{G} 2$ data set.

- Mixed caustic and submerged-bed scrubber effluents (Simulant 4 or S4). An operational mode where $10 \%$ of the ILAW submerged-bed scrubber recycle is mixed with the caustic scrubber secondary waste.

- Submerged-bed scrubber effluent. Medians of component values in the ILAW melter off-gas submerged-bed scrubber effluent.

- Phase I simulant. Simulant composition used for Phase-I secondary waste-form testing program. More details can be found in Pierce et al. (2010).

Table 2.1. Composition of WTP Secondary Waste Simulant

\begin{tabular}{|c|c|c|c|c|c|}
\hline $\begin{array}{c}\text { Element } \\
\text { (mole/liter) }\end{array}$ & $\begin{array}{c}\text { S1 } \\
\text { Caustic } \\
\text { Scrubber } \\
\text { Median }\end{array}$ & $\begin{array}{c}\text { S2 } \\
\text { Statistical - } \\
\text { Cluster 1 } \\
3 / 16 / 2038 \\
\end{array}$ & $\begin{array}{c}\text { S3 } \\
\text { Statistical - } \\
\text { Cluster } 2 \\
05 / 28 / 2024 \\
\end{array}$ & $\begin{array}{c}\text { S4 } \\
\text { Caustic Scrubber/ } \\
10 \% \text { of SBS Blend }\end{array}$ & $\begin{array}{c}\text { Phase } 1 \\
\text { Simulant }\end{array}$ \\
\hline $\mathrm{Na}$ & 2 & 2 & 2 & 2 & 2 \\
\hline $\mathrm{Al}(\mathrm{OH})_{3}$ & $1.88 \mathrm{E}-01$ & 2.28E-01 & 1.84E-01 & 8.48E-02 & 0.23 \\
\hline $\mathrm{Si}$ & $3.76 \mathrm{E}-03$ & $4.08 \mathrm{E}-03$ & $1.55 \mathrm{E}-03$ & 2.78E-02 & - \\
\hline K & $1.16 \mathrm{E}-03$ & $1.30 \mathrm{E}-03$ & 4.36E-03 & 5.74E-02 & - \\
\hline $\mathrm{NH}_{4}^{+}$(total) & --- & --- & --- & 8.82E-01 & - \\
\hline $\mathrm{OH}^{-}$ & 7.96E-01 & 8.70E-01 & 4.90E-01 & 2.04E-08 & 1.2 \\
\hline $\mathrm{NO}_{3}^{-}$ & $6.56 \mathrm{E}-01$ & 3.80E-01 & 7.94E-01 & $2.26 \mathrm{E}+00$ & 0.69 \\
\hline $\mathrm{CO}_{3}{ }^{2-}$ & 4.56E-02 & 9.32E-02 & 7.88E-02 & $2.08 \mathrm{E}-02$ & $1.5 \mathrm{E}-6$ \\
\hline $\mathrm{Cl}^{-}$ & $4.50 \mathrm{E}-02$ & 4.34E-02 & 5.82E-02 & 2.08E-02 & - \\
\hline $\mathrm{NO}_{2}^{-}$ & $2.40 \mathrm{E}-02$ & 2.10E-02 & 7.66E-02 & 8.62E-02 & - \\
\hline $\mathrm{PO}_{4}^{-3}$ & 1.37E-02 & $9.70 \mathrm{E}-03$ & $1.21 \mathrm{E}-02$ & 1.02E-02 & 1.7E-2 \\
\hline $\mathrm{SO}_{4}^{-2}$ & 8.82E-03 & 1.16E-02 & 1.03E-02 & 8.72E-02 & $9.7 \mathrm{E}-3$ \\
\hline $\mathrm{F}^{-}$ & $1.11 \mathrm{E}-03$ & $7.50 \mathrm{E}-04$ & 8.84E-04 & 2.04E-08 & - \\
\hline $\mathrm{Cr}$ & 4.06E-04 & 4.06E-04 & 4.06E-04 & 2.18E-03 & 8.43E-3 (1×) \\
\hline $\mathrm{Ag}$ & $1.25 \mathrm{E}-05$ & $1.25 \mathrm{E}-05$ & $1.25 \mathrm{E}-05$ & 4.70E-05 & $\begin{array}{c}2.5 \mathrm{E}-4 \\
(100 \times)^{(\mathrm{a})}\end{array}$ \\
\hline As & $6.96 \mathrm{E}-05$ & 6.96E-05 & 6.96E-05 & 3.22E-05 & - \\
\hline $\mathrm{Cd}$ & 3.14E-06 & 3.14E-06 & 3.14E-06 & 4.32E-05 & 5.0E-5 $(100 \times)$ \\
\hline $\mathrm{Hg}$ & $2.26 \mathrm{E}-05$ & 2.26E-05 & 1.13E-05 & $1.06 \mathrm{E}-05$ & 3.3E-5 (1×) \\
\hline $\mathrm{Pb}$ & $1.80 \mathrm{E}-05$ & $1.80 \mathrm{E}-05$ & $1.80 \mathrm{E}-05$ & 1.66E-05 & 7.9E-4 $(100 \times)$ \\
\hline Tc & 3.62E-05 & 3.62E-05 & 3.62E-05 & 1.12E-03 & \\
\hline${ }^{99} \mathrm{Tc}$ (Ci/Liter) & $6.05 \mathrm{E}-05$ & $6.10 \mathrm{E}-05$ & $6.10 \mathrm{E}-05$ & $1.88 \mathrm{E}-03$ & 1.3E-5 Ci/L \\
\hline I & $9.24 \mathrm{E}-06$ & $9.24 \mathrm{E}-06$ & $9.24 \mathrm{E}-06$ & $1.26 \mathrm{E}-04$ & $2.9 \mathrm{E}-6$ \\
\hline${ }^{129} \mathrm{I}$ (Ci/Liter) & 1.91E-07 & 1.91E-07 & 1.91E-07 & 2.60E-06 & \\
\hline $\mathrm{TOC}^{(\mathrm{b})}$ (as oxalate) & $1.88 \mathrm{E}-01$ & 2.28E-01 & 1.84E-01 & 8.48E-02 & 0.23 \\
\hline
\end{tabular}


Because of the need to increase the analytical sensitivity for some of the metals identified in the Resource Conservation and Recovery Act (RCRA) (namely silver [Ag], arsenic[As], cadmium[Cd], and lead $[\mathrm{Pb}]$ ), the concentrations of these contaminants of concern (COC) were spiked at 10 to 100 times their maximum expected concentration. The concentrations of chromium $(\mathrm{Cr})$ and mercury $(\mathrm{Hg})$ were not increased because the simulant concentration for this COC is sufficient to achieve the analytical sensitivity required to obtain quantitative information from these leach experiments. More details of simulant preparation can be also found in Pierce et al. (2010) and Sundaram et al. (2011).

\subsection{Cast Stone Description and Preparation}

The Cast Stone waste form was developed to solidify the low-activity and secondary waste that will be generated by the operation of the WTP at the Hanford Site (Lockrem 2005; Lockrem et al. 2008). Cast Stone is a waste form that consists of a mixture of Class-F fly ash, Grade-120 blast furnace slag (BFS), and Type-I/II Portland cement. More details on the Cast Stone used in Phases I and II are found in Pierce et al. (2010) and Sundaram et al. (2011), respectively.

Cast Stone has been tested previously to solidify liquid effluents entering the Liquid Effluent Retention Facility, including the WTP off-gas scrubber waste stream, and also has been tested with various getter materials ${ }^{1}$ as a waste form for treating the Basin 43 waste stream of the Liquid Effluent Retention Facility that is concentrated to achieve 28.9\% solids (Cooke et al. 2009). The getters tested with this waste form included bone char, bone ash, bone black, synthetic apatite, iron powder, iron phosphate, tin apatite, and two resins (i.e., Purolite ${ }^{\circledR}$ A530-E and A532-E) (Cooke et al. 2009; Lockrem et al. 2008). The two dry reagent formulations were tested with a LAW simulant at waste loadings ranging from $8.2 \%$ to $24.2 \%$ by weight. The compositions of these two formulations are shown in Table 2.2.

Table 2.2. Dry Reagent Compositions Used in Cast Stone

\begin{tabular}{lcc}
\hline \multicolumn{1}{c}{ Ingredients } & DRF2 (wt\%) & DRF4 (wt\%) \\
\hline Portland Cement Type I, II & 8 & 20 \\
Fly Ash, Class F & 45 & 66 \\
Blast Furnace Slag, Grade 120 & 47 & -- \\
Attapulgite clay & -- & 14 \\
\hline
\end{tabular}

The test results discussed in Lockrem et al. (2008) indicated that Cast Stone made from the DRF2 mix met both the U.S. Nuclear Regulatory Commission (NRC 1991) and the Washington State Administrative Code Land Disposal (WAC 2000) regulatory requirements. This waste form appeared to perform well when subjected to non-regulatory tests such as volume reduction, bleed-water percentage, hydraulic conductivity, thermal transmission, curing-heat evolution, and toxic- and explosive-gas evolution (Lockrem et al. 2008). A summary of important chemical and physical properties of Cast Stone is given in Table 2.3. Based on the demonstrated performance of Cast Stone, this waste form has been included for further evaluation. The PNNL produced Cast Stone used for the retention-mechanism

(1) Getter materials are added to further reduce the mobility of hazardous metals and radionuclides within the waste form. 
experiments discussed in this report had the same percentages of the three dry blend ingredients as the DRF2 formulation but the sources of the ingredients were different.

Table 2.3. Summary of Important Chemical and Physical Properties of Cast Stone

\begin{tabular}{lc}
\hline \multicolumn{1}{c}{ Properties } & $\begin{array}{c}\text { DRF2 } \\
(\text { Cooke et al. 2008) }\end{array}$ \\
\hline Density, g/cm ${ }^{3}$ & $\mathrm{NM}^{(\mathrm{a})}$ \\
Compressive Strength, $\mathrm{MPa}$ & 8.03 to $6.3 \mathrm{MPa}$ \\
Porosity & $\mathrm{NM}$ \\
Surface Area, $\mathrm{m}^{2} / \mathrm{g}$ & $\mathrm{NM}$ \\
ANS 16.1 Leach Index for $\mathrm{Re}^{(\mathrm{b})}$ & 9.5 to 10.4 \\
\hline (a) NM = Not measured. & \\
(b) Reused as a chemical analogue for ${ }^{99} \mathrm{Tc}$. \\
\hline
\end{tabular}

The Cast Stone monoliths were prepared with a procedure described by Pierce et al. (2010). The Portland cement and BFS were obtained from LaFarge North America, Inc. (Herndon, Virginia), and the Class F fly ash was obtained from Lonestar (Seattle, Washington). The dry materials were blended for 5 minutes with a planetary mixer set at low speed. After the dry-solid mixture was homogeneous, the five Tc-spiked simulants, including Phase-I simulant (see Table 2.1) and deionized water (DIW), were added to the blended dry mixture and mixed for 5 minutes to obtain a homogeneous slurry that flowed easily. Three different Tc concentrations (i.e., 100, 200, and $300 \mu \mathrm{g}$-Tc/g of the final solid form) were used to prepare Cast Stone samples with high Tc concentrations in the same Phase-I simulant (see Table 2.1). The target waste loading was approximately $8 \mathrm{wt} \%$ on a dry-weight basis for each Cast Stone-waste simulant combination. An additional four Tc-spiked simulants (S1, S2, S3, and S4) were prepared to make Cast Stone with a Tc concentration of $150 \mu \mathrm{g} / \mathrm{g}$ in the final Cast Stone product. A Tc stock solution with a concentration of $\sim 10,000$ ppm was prepared with either $\mathrm{NaTcO}_{4}$ or $\mathrm{NH}_{4} \mathrm{TcO}_{4}$ as the Tc source, depending on the type of simulant. The Cast Stone monoliths were cast in molds that were $2 \mathrm{in}$. in diameter by $4 \mathrm{in}$. in height $(2.5 \mathrm{~cm}$ by $5.0 \mathrm{~cm})$, which is the same size of Cast Stone samples used in Phases I and II. Additional smaller-sized molds, 1 in. in diameter by 2 in. in height $(2.5 \mathrm{~cm}$ by $5 \mathrm{~cm})$ or $0.28 \mathrm{in}$. in diameter by $2 \mathrm{in}$. in height $(0.7 \mathrm{~cm}$ by $5 \mathrm{~cm})$ also were prepared with either Tc-spiked or nonTc simulant for other tasks described below. The molds were partially filled in the vertical orientation and vibrated until a significant decrease in the release of air bubbles was observed. Then, the molds were filled to capacity with additional wet slurry and vibrated until no air bubbles were observed. The molds were stored in a 100\% relative humidity chamber at room temperature for a curing time of 28 days.

\subsection{DuraLith Alkali-Aluminosilicate Geopolymer Description and Preparation}

Geopolymers, also known as alkali-activated aluminosilicate binders, form through the reaction of aluminosilicate materials, such as clay or fly ash, in a caustic solution. When the reactions proceed at near-ambient temperature, polymerization forms amorphous to semi-crystalline aluminosilicate networks (Perera et al. 2005). Structural integrity and mechanical strength, as determined by slumping and compressive strength, are usually obtained within minutes to hours, depending on the specific materials and processes used. Geopolymers are thought to be composed of a three-dimensional matrix of 
poly(sialate) (i.e., Si-O-Al-O), and/or poly(sialate-siloxo) (i.e., Si-O-Al-O-Si), and/or poly-sialatedisiloxo (i.e., $\mathrm{Si}-\mathrm{Al}-\mathrm{Si}-\mathrm{O}-\mathrm{Si}-\mathrm{O}$ ) compounds. The material is primarily amorphous, with some minor crystalline structure present, again dependent on the source materials. Contaminant distribution studies showed that cesium was concentrated in the amorphous phase, while strontium was present in both the amorphous and crystalline phases (Perera et al. 2005).

A specific geopolymer known as “DuraLith” was included in a study of low-temperature immobilization technologies for Hanford WTP secondary wastes (Russell et al. 2006). DuraLith is composed of three components - an activator, a binder, and an enhancer. The activator is a solution of sodium hydroxide and/or potassium hydroxide with a rapidly dissolving form of silica, such as silica fume (also known as microsilica) or fly ash. The binder is a mixture of meta-kaolinite, BFS, fly ash, or other additives. The binder and activator are the two main components that yield the geopolymer material. The enhancers are essentially getter materials.

The DuraLith prepared with the Hanford secondary waste simulant used during Phase I showed compressive strengths above $22 \mathrm{MPa}$ (3200 psi) before and after irradiation, easily meeting the 3.45-MPa (500 psi) requirement. The material also easily passed the toxicity characteristic leach procedure test for $\mathrm{Cr}, \mathrm{Cd}, \mathrm{Ag}, \mathrm{Hg}$, and $\mathrm{Pb}$ included in the simulant. Details can be found in previously published reports (Russell et al. 2006; Pierce et al. 2010). The important chemical and physical properties of DuraLith are provided in Table 2.4.

Table 2.4. Summary of Important Chemical and Physical Properties of the DuraLith Samples

\begin{tabular}{lc}
\hline \multicolumn{1}{c}{ Property } & $\begin{array}{c}\text { Russell et al. (2006) } \\
\text { Value }\end{array}$ \\
\hline Density, g/cm & 1.76 \\
Compressive Strength, MPa & $29 \pm 8$ \\
Porosity & $\mathrm{NM}^{(\mathrm{a})}$ \\
Surface Area, $\mathrm{m}^{2} / \mathrm{g}$ & $\mathrm{NM}$ \\
ANS 16.1 Leach Index for ${ }^{99} \mathrm{Tc}^{3}$ or $\mathrm{Re}^{(\mathrm{b})}$ & 10.4 \\
\hline
\end{tabular}

(a) $\mathrm{NM}=$ Not measured.

(b) Re was used as a chemical analogue for ${ }^{99} \mathrm{Tc}$.

Additional smaller-sized DuraLith monoliths ( 1 in. in diameter by 2 in. in height) were prepared with four different simulants to achieve a concentration of $150 \mu \mathrm{g}-\mathrm{Tc} / \mathrm{g}$ in the final solid form. The fabrication procedure used for the smaller sized DuraLith monoliths is similar to that used in Phase I and is summarized below.

An activator solution was prepared by mixing each ingredient in the simulant in the order listed in Table 2.5. First, the simulant solution and tin fluoride were added to a $50-\mathrm{mL}$ Teflon ${ }^{\circledR}$ beaker and stirred for 1 hour. Tin (Sn[II]) fluoride was used as a reducing agent for redox-sensitive elements such as Tc. Next, potassium hydroxide $(\mathrm{KOH})$ was added to the Teflon beaker and allowed to mix until the $\mathrm{KOH}$ was fully dissolved. In addition to $\mathrm{KOH}$, sodium hydroxide $(\mathrm{NaOH})$ was slowly added to the mixture until it completely dissolved. Finally, the fumed silica was added slowly to facilitate stirring. The mixture was heated to approximately $50^{\circ} \mathrm{C}$ and stirred overnight. A paper film was placed on top of the Teflon beaker to minimize water evaporation. 
The binder was prepared separately in a 125-mL plastic jar by adding the dry materials in the following order: meta-kaolinite, furnace slag, sand, and sodium sulfide hydrate. These dry materials were hand-mixed for 10 minutes with a plastic scoop, and the mixture then was allowed to stand for 5 minutes.

Table 2.5. Material Specifications and Composition for DuraLith Monoliths

\begin{tabular}{lcc}
\hline \multicolumn{1}{c}{ Material } & Amount Used for 2 Monoliths [g] & Addition Order \\
\hline Simulant & 15.21 & 1 \\
Tin fluoride & 0.06 & 2 \\
Potassium hydroxide & 7.84 & 3 \\
Sodium hydroxide & 0.38 & 3 \\
Fumed silica & 8.83 & 4 \\
Meta-kaolinite & 15.49 & 5 \\
Furnace slag & 10.18 & 5 \\
River sand & 14.47 & 5 \\
Sodium sulfide hydrate & 0.10 & 5 \\
Silver zeolite & 0.38 & 6 \\
\hline
\end{tabular}

The DuraLith paste was prepared by pouring a small amount of activator solution into the blended binder solids and mixing until the activator solution was incorporated into the dry materials. The activator-solution additions were poured slowly into the binder solids and hand mixed with a plastic scoop. This procedure was repeated several times until $32 \mathrm{~g}$ of activator solution had been added. Once well mixed (i.e., until the paste thins out), silver zeolite was sprinkled into the paste and continuously mixed until a smooth and homogeneous paste was achieved (approximately 10 minutes to achieve the desired paste consistency).

Polycarbonate vials (20 mL) with the screw-top mouth cut off were used as molds for casting monoliths ( 1 in. in diameter by $2 \mathrm{in}$. in height). The molds were partially filled in the vertical orientation and vortex vibrated until a significant decrease in the release of air bubbles was observed. Then, the molds were filled to near capacity and vibrated until no air bubbles were observed. The molds were covered with a perforated paper film and allowed to stand for 24 hours at room temperature. The monoliths then were removed from the molds and allowed to air dry for 24 hours. Subsequently, the monoliths were placed into a plastic bag and sealed at room temperature for a total curing time of 28 days.

\subsection{Ceramicrete Phosphate-Bonded Ceramic Description and Preparation}

Ceramicrete or low-temperature-forming phosphate ceramic was developed as part of the U.S. Department of Energy's (DOE’s) Office of Environmental Management program to stabilize and contain volatile contaminants such as Tc and I. This technology has been demonstrated on various waste streams (liquids, fly ashes, debris) and has been shown to retain adequately both radioactive (uranium, Tc, plutonium) and hazardous contaminants ( $\mathrm{Hg}, \mathrm{Pb}, \mathrm{Cr}$, etc.). Ceramicrete is fabricated by an acid/base reaction of calcined magnesium oxide and monopotassium phosphate, which, when mixed with water, forms a slurry that sets into a hard ceramic in a few hours. The process is simple and quite similar to the Cast Stone mixing process. No additional equipment is needed beyond the equipment used to make Cast 
Stone waste forms. Ceramicrete has a strong (as high as 10,000 psi compressive strength), dense matrix, and has the superior capability to bind contaminants, which makes it an excellent candidate for macroencapsulation applications. Equation 2.1 represents the chemical reaction that takes place in Ceramicrete (Singh et al. 1997; Wagh 2004).

$$
\mathrm{MgO}+\mathrm{KH}_{2} \mathrm{PO}_{4}+5 \mathrm{H}_{2} \mathrm{O} \rightarrow \mathrm{MgKPO}_{4} \cdot 6 \mathrm{H}_{2} \mathrm{O}
$$

The resulting $\mathrm{MgKPO}_{4} \cdot 6 \mathrm{H}_{2} \mathrm{O}$ phase is extremely stable and has a solubility product of $2 \times 10^{-11}$ under typical IDF subsurface conditions. Typically, there is no residual water associated with the hardened product; it is bound as water of hydration. Ceramicrete has a unique property of binding to itself. Because of the flexibility of this process, various materials may be added to promote higher strength, resistance to fracturing, and reduced porosity. As much as $80 \mathrm{wt} \%$ of fly ash can be added to the Ceramicrete dry powder mix, and there is no specific particle-size requirement for the fly ash. It has been found that, in addition to the phosphate bonding, there may be silicophosphate bonding occurring that provides the enhanced structural properties (Wagh 2004).

To prepare Ceramicrete monoliths (2 in. by 4 in. or 1 in. by 2 in,), 329 g of S1-2M simulant (Table 2.1) and $30.5 \mathrm{~g}$ of DIW were added to a mixing bowl containing $21.24 \mathrm{~g}$ of tin chloride $\left(\mathrm{SnCl}_{2}\right)$, and then mixed for 4 minutes at low speed with a planetary mixer. Next, $18.27 \mathrm{~g}$ of silver zeolite was added to the bowl and mixed for 3 minutes. In a separate container, $160 \mathrm{~g}$ of magnesium oxide (MgO), $544.14 \mathrm{~g}$ of potassium diphosphate $\left(\mathrm{KH}_{2} \mathrm{PO}_{4}\right)$, and $576.04 \mathrm{~g}$ of Class $\mathrm{C}$ fly ash were dry mixed using a wire whisk. The dry materials were added slowly to the mixing bowl and mixed at medium speed for 20 minutes. During mixing, the sides of the mixing bowl were periodically cleaned with a rubber spatula. When mixing was complete, the resulting paste was poured into molds and vibrated for approximately 1 minute to remove air bubbles. The molds then were covered and set aside to cure for 14 days.

\subsection{Fluidized Bed Steam Reformer Description and Preparation}

Mineralizing steam reforming technology, offered by THOR $^{\circledR}$ (THermal Organic Reduction) Treatment Technologies, is intended to immobilize the high sodium nitrate liquid/radioactive metal waste feed solution into a stable solid at a moderate temperature $\left(625-750^{\circ} \mathrm{C}\right)$ consisting largely of sodium/potassium (K)-alumina-silicate target mineral phases of various structures (Jantzen et al. 2004). The THOR FBSR process has previously been shown to be effective at converting certain low-activity radioactive liquid wastes into insoluble, mineralized solid products capable of immobilizing radioactive and hazardous metal constituents. The mineral phases are formed as a result of the clay (aluminosilicate) additive and are intended to capture and retain (stabilize) the alkali metals ( $\mathrm{Na}, \mathrm{K})$, target radionuclides (Tc, I, and Cs), hazardous metals, and anions (Olson et al. 2004). The major phase found in the bed product is nepheline (a cage-structured sodium aluminosilicate), with minor amounts of corundum (from the alumina starting bed) and combeite (sodium calcium silicate) and trace amounts of sodalite (a cagestructured sodium aluminosilicate).

Two FBSR samples (FBSR powder and FBSR encapsulated monolith with Geo-7 binder) were prepared using rhenium (Re) as a surrogate for radioactive Tc at Savannah River National Laboratory (SRNL) and shipped to and tested at PNNL. The mineralized solid products for WTP secondary-waste tests, ART-P-2A and ART-P-2B were collected at the Denitration and Mineralization Reformer (DMR) discharge via the Product Receiver (PR) and at the High Temperature Filter (HTF) downstream of the 
DMR off-gas port. The ART-P-2A Test, with a duration of about 75 hours, processed 899.56 gal of simulant feed into $1001.1 \mathrm{lb}$ of DMR product and $2766 \mathrm{lb}$ of HTF product, also referred to as fines. Test ART-P-2B processed 323.49 gal of feed in 27 hours, resulting in $334.34 \mathrm{lb}$ of DMR product and 1025.6 lb of fines. Test ART-P-2B was run from 07:30 on May 5, 2008, until 10:29 on May 6, 2008, and generated the FBSR product used in the FBSR secondary waste-form monoliths supplied for PNNL screening activities. Based on examination of the operating conditions and the results of the Product Consistency Tests, the ideal WTP secondary-waste test FBSR product was determined to be the one from test ART-P2-B with a DMR product-to-fines ratio (PR/HTF) of 0.33. Therefore, the FBSR product (or FBSR powder sample) was collected from WTP secondary-waste simulant test ART-P-2B, and the reformer product was screened $(<1.0 \mathrm{~mm})$ and blended in a PR/HTF ratio of 0.33 . The test FBSR monoliths (2-in.-diameter by 4-in.-long cylindrical monolithic forms) also were prepared by mixing the FBSR solids with a geopolymer binder. The geopolymer (amorphous to semi-crystalline, threedimensional silicoaluminate materials) mineral polymers resulted from the mixing of clay or fly ash with sodium silicate and/or sodium hydroxide. Formulation of the monoliths and waste-form testing were performed at SRNL, and it was determined that the best WTP secondary-waste form encapsulating geopolymer formulation was that associated with sample "GEO-7.” This binder formulation used fly ash instead of the heat-treated metakaolin clay, and test monoliths were prepared with an FBSR product waste loading of $65.2 \%$. More details regarding those two samples can be found in Pires et al. (2011). One of the FBSR monolith samples was crushed and used for this radionuclide retention task. 


\subsection{Technetium Speciation}

\subsection{Introduction}

Technetium-99, a radioactive fission product of ${ }^{235} \mathrm{U}$ fuel, has been released into the environment as the result of nuclear weapons testing and radioactive waste disposal. The highly soluble and oxidized pertechnetate oxyanion, $\mathrm{Tc}(\mathrm{VII}) \mathrm{O}_{4}^{-}$, does not sorb onto sediments, so $\mathrm{TcO}_{4}{ }^{-}$migrates at nearly the same velocity as groundwater under common subsurface conditions (i.e., at $\mathrm{pH}$ levels close to neutral or slightly alkaline and under suboxic conditions). Under reducing conditions, Tc can precipitate as $\mathrm{Tc}(\mathrm{IV}) \mathrm{O}_{2} \cdot 2 \mathrm{H}_{2} \mathrm{O}$, sorb to mineral phases, and be retained in different natural environments and engineered waste forms. A component of past strategies has been to use reducing agents to transform Tc(VII) into the less mobile $\mathrm{Tc}(\mathrm{IV})$ species. When manifested as the hydrated oxide $\left(\mathrm{TcO}_{2} \cdot n \mathrm{H}_{2} \mathrm{O}\right)$, sulfide $\left(\mathrm{TcS}_{2}\right)$, or as a co-precipitate with iron (oxy)hydroxides, the solubility and mobility of Tc are very low. However, the re-oxidation of $\mathrm{Tc}(\mathrm{IV})$ by changing conditions, such as contact with atmospheric oxygen, $\mathrm{O}_{2}$ (g), can result in a subsequent release of Tc into the environment, leading to the prediction of high Tc release rates in cement waste forms (Shuh et al. 2000) and scenarios in which $\mathrm{O}_{2}$ is present in the subsurface for many performance assessments (Gilliam et al. 1990; Smith and Walton 1993; Lukens et al. 2005). Because Tc leachability from waste forms is closely related with the Tc speciation or oxidation state in both the simulant and the final solid waste forms, the identity of Tc species is important to understand its retention mechanisms in the final waste form. Both an oxidation-reduction potential (Eh)-pH diagram calculation and spectroscopic techniques such as x-ray absorption fine structure (XAFS) spectroscopy and x-ray photoelectron spectroscopy (XPS) were used to investigate Tc (or Re) species and its binding mechanism in different waste forms prepared with various simulants.

The Eh and $\mathrm{pH}$ conditions and associated complexation reactions are key parameters for understanding the solubility and chemical behavior of Tc in solution. To show the effect of these parameters on the geochemistry of the contaminant of interest (especially for Tc), the distributions of dominant aqueous Tc species and potential solubility controls for Tc were calculated as functions of $\mathrm{pH}$ and Eh using computer-modeling-based equilibrium thermodynamic principles. The theory behind the calculation of Eh-pH predominance diagrams is well documented by Garrels and Christ (1965), Langmuir (1997), Nordstrom and Munoz (1985), and others.

XAFS is a short-range order technique (approximately $4 \AA$ to $6 \AA$ from the absorber) that provides unique information about the local structural environment for the absorbing element in most materials except hydrogen in any type of phase (crystals, amorphous solids, liquids, gases, or mineral-water interfaces), even at low concentration levels (approximately $1 \mathrm{ppm}$ to $10 \mathrm{ppm}$ ). Because XAFS is element-selective and can provide molecular-level coordination information about the oxidation state, element identity, and bonding information (coordination numbers and interatomic distance between the central absorbing element and the nearest neighboring elements), it complements information from other spectroscopic methods to increase our understanding of the binding and leaching mechanisms of Tc in waste forms. In XAFS, x-ray photon energy is used to eject a photoelectron from the core shell of an atom in the target material at the time of $\mathrm{x}$-ray absorption. X-ray absorption occurs when an X-ray photon travels through matter. The intensity of the incident $x$-ray photon decreases by passing through the material, and the absorption coefficient is determined by the thickness of the material and the difference between intensities of incident and transmitted x-rays. As the energy of the photon increases, the absorption coefficient generally decreases until the incident energy reaches the threshold energy, at which 
the absorption coefficient rises abruptly. The threshold energy is the minimum energy required to eject an electron from a core shell of the atomic orbital in the material. This sharp increment in the absorption coefficient is attributed to the photoelectron ejection and is referred to as the absorption "edge." The absorption coefficient as a function of incident photon energy is used for XAFS analysis. The photoelectron emitted by x-ray absorption is partially backscattered by the neighboring atoms before the ejection occurs (Teo 1986). Multiple scattering of ejected photoelectrons normally occurs in x-ray absorption near-edge structure (XANES) spectroscopy, while a single scattering usually occurs in extended x-ray absorption fine structure (EXAFS) spectroscopy. Both XANES and EXAFS spectroscopies probe only the local environment because of the low energy of photoelectrons at a short range. Oxidation state and site symmetry information can be obtained from XANES analysis, while molecular-level information on the coordination environment (coordination number and bonding distance) can be acquired from EXAFS analysis.

In this study, XPS was also used to obtain oxidation state information for Re used as a surrogate for Tc in the FBSR waste form. The XPS technique is based on the photoelectric effect. When materials are illuminated with $\mathrm{x}$-rays energetic enough to eject electrons from inner or valence shells, the difference between the incoming photon energy and electron binding energy is converted to kinetic energy in the escaping photoelectron. Binding energies for different elements and orbitals can be determined either experimentally or from single-atom models. The kinetic energy of the ejected electrons gives information about the binding energies of electrons involved and the oxidation state of the specific element, as well as dissolution, precipitation, and weathering reactions at surfaces (Biino and Grönig 1998; Hochella 1988, 1990). Because XPS is a surface-sensitive technique, only the outermost surface layers, between $10 \AA$ and $50 \AA$, of solids can be examined. A wide-energy-range "survey" scan can be used to identify the elements present in a sample, but it is not used to quantify the elemental composition because it lacks resolution; instead, narrow scans are used for this purpose. A chemical shift is defined as the difference in binding energy between a particular line and the binding energy for the same line in a reference compound. By means of chemical shifts, one can often distinguish between two different oxidation states of an element in a given sample or between different coordination environments. With XPS, one can obtain at least semi-quantitative estimates of the relative abundances of the elements present on the surface of a sample. To obtain reliable quantitative information, narrow scans of the regions corresponding to the peaks of interest must be collected using small energy steps.

\subsection{Materials and Methods}

\subsubsection{Solution Analysis ( $\mathrm{pH}$ and Eh measurements)}

After spiking with Tc, the simulant solutions S1, S2, S3, and S4 (Table 2.1) were measured for $\mathrm{pH}$ and Eh before they were used to make waste forms. The $\mathrm{pH}$ levels of the solution samples (in both the starting simulants and the final leach test effluents described in later sections) were measured with a solidstate $\mathrm{pH}$ electrode and a $\mathrm{pH}$ meter (Hanna, Model HI 4521). Before taking the measurement, the $\mathrm{pH}$ probe was calibrated with National Bureau of Standards buffers $(\mathrm{pH}=2.00,4.00,7.00,10.00$, and/or 12.00 at $25^{\circ} \mathrm{C}$ ). The precision of the $\mathrm{pH}$ measurement was $\pm 0.1 \mathrm{pH}$ units. An Eh probe (Hanna, Model 3131B) was used to measure the Eh of the starting simulants and leachate solutions. The Eh probe was calibrated with $\mathrm{pH}$ buffer solutions ( $\mathrm{pH}=4.00$ and 7.00 at $25^{\circ} \mathrm{C}$ ) mixed with $0.5 \mathrm{~g}$ of quinhydrone. The Eh values discussed in this report are the measured Eh values corrected using Equation (3.1). 


$$
\text { Eh }(\text { corrected })=\text { Eh }(\text { measured })+208 m V
$$

The $\mathrm{pH}$ and Eh measurements were conducted on duplicate aliquots, and average values are reported in this report.

\subsubsection{Tc Eh-pH Diagram Calculation}

Eh-pH diagrams for Tc in the different simulants were calculated at $25^{\circ} \mathrm{C}(298 \mathrm{~K})$ and 1 atm pressure using Version 8.0.9 of the The Geochemist's Workbench software package (Bethke and Yeakel 2009) and the expanded thermodynamic database file "thermo.com.V8.R6+.dat" provided with the software package. The thermodynamic database originally was developed at Lawrence Livermore National Laboratory for use with the EQ3/6 geochemical model software.

Each Eh-pH diagram contains dashed black lines from coordinates (Eh $1.2 \mathrm{~V}, \mathrm{pH}$ 0) to (Eh $0.4 \mathrm{~V}$, $\mathrm{pH}$ 14) and from (Eh $0.0 \mathrm{~V}, \mathrm{pH} 0$ ) to (Eh -0.8 V, pH 14) that represent the Eh-pH boundaries for the dissociation of water to its gaseous components at $25^{\circ} \mathrm{C}$ and 1 atm pressure. At Eh-pH values above the upper black dashed line, water breaks down to $\mathrm{O}_{2}$. At Eh-pH values below the lower black dashed line, water breaks down to form hydrogen gas. The redox conditions for essentially all environmental systems occur in the region within these two water-stability limits.

\subsubsection{XAFS Spectroscopy Analysis}

Each batch of waste-form samples prepared with different simulants was characterized to determine the Tc oxidation state (Tc[VII] vs. Tc[IV]) and near-neighbors using XAFS. For Cast Stone, three samples of Cast Stone monolith (1-in. diameter by 2-in. height) were prepared at three different Tc concentrations for the one simulant type designated Phase I (see Table 2.1 for simulant information) with target final concentrations of $100 \mu \mathrm{g} / \mathrm{g}, 200 \mu \mathrm{g} / \mathrm{g}$, and $300 \mu \mathrm{g} / \mathrm{g}$ to identify the most appropriate Tc concentration to use in experiments that investigate the impacts of different curing times ( 3 days and 28 days). In addition, four Cast Stone monoliths (1-in. diameter by 2-in. height) with a final concentration $150 \mu \mathrm{g}$-Tc/g were prepared with each of the four different simulants (S1, S2, S3, and S4) shown in Table 2.1. For DuraLith samples, four different monoliths (1-in. diameter by 2-in. height) with a concentration of $150 \mu \mathrm{g}-\mathrm{Tc} / \mathrm{g}$ were prepared (one for each of the four different simulants). The DuraLith waste forms were cured 28 days before XAFS data collection. For Ceramicrete, only one monolith (1 in. diameter by $2 \mathrm{in.} \mathrm{height)} \mathrm{with} \mathrm{a} \mathrm{final} \mathrm{concentration} \mathrm{of} 150 \mu \mathrm{g}$-Tc/g solid was prepared with simulant 1 (S1) and cured for only 3 days before XAFS data collection because of a time conflict.

Each waste-form monolith was crushed into chunks with a hammer, and the chunks then were ground using a ball mill to make powder samples, which were mounted on Teflon sample holders and sealed with Kapton ${ }^{\circledR}$ tape. At least one monolith of each waste form that was prepared with each of the Tc concentrations and each of the different simulants has been archived for future analysis. XAFS data collection was conducted at one of the synchrotron radiation facilities- the National Synchrotron Light Source (NSLS) at Brookhaven National Laboratory or the Stanford Synchrotron Radiation Laboratory (SSRL). The XAFS spectroscopy data were collected at NSLS beamline X11A. A Si(111) double crystal monochromator detuned by $10 \%$ was used to scan energy across the molybdenum (Mo) and Tc K edges. A Mo foil was used as an internal energy calibration standard by scanning across the Mo K edge in 1-eV steps $( \pm 50 \mathrm{eV})$ at the start of each Tc energy scan. The center of the first inflection point of the 
Mo foil spectrum was assigned to 20,000 eV. Tc K-edge spectra were recorded by integrating for 3 seconds at 1-eV steps from $50 \mathrm{eV}$ below the edge to $300 \mathrm{eV}$ above the edge (Tc threshold energy $\mathrm{E}_{0}$ was assigned to 21,044 eV). Tc fluorescence spectra were acquired with a 13-element, solid-state germanium (Ge) detector (Canberra) set with the single-channel analyzer gated on the Tc K-alpha fluorescence emission line. At least two or more scans were used to collect spectra for each sample. Additional XAFS spectroscopy data were collected at SSRL beamlines 11-2 or 4-1 in fluorescence mode using a 30-element Ge detector with a 0.2-mm aluminum (Al) filter (i.e., two sheets of $\mathrm{Al}$ cut from soda cans). A Si(220) double-flat-crystal monochromator was used, and the energy was calibrated by using the first inflection point of the Tc K-edge spectrum of the Tc(VII) standard defined as $21.044 \mathrm{keV}$. The Tc solid standards $\left(\mathrm{KTcO}_{4}, \mathrm{NaTcO}_{4}, \mathrm{TcO}_{4}{ }^{-}\right.$adsorbed on Reillex ${ }^{\mathrm{TM}} \mathrm{HPQ}$ resin, and $\left.\mathrm{TcO}_{2} \cdot 2 \mathrm{H}_{2} \mathrm{O}\right)$ were also collected in transmission mode at room temperature using a 7-element (NSLS) or 13-element (SSRL) Ge detector. XAFS spectrum processing (i.e., calibration, alignment, background subtraction, normalization, and averaging) was performed with Athena software using the software IFEFFIT (Newville 2001) and ATHENA/ARTEMIS (Ravel and Newville 2005) after correction for detector dead time. Data resolution for the waste form solids closely matched the resolution for the reference solids' spectra, so neither the reference spectra nor the waste form sample data were convolved with a broadening function. The XANES spectra for the Tc waste form samples were fit with a linear combination of the XANES spectra using $\mathrm{TcO}_{4}{ }^{-}$adsorbed on Reillex HPQ resin as the Tc(VII) standard spectrum and both $\mathrm{TcO}_{2} \cdot 2 \mathrm{H}_{2} \mathrm{O}$ and $\mathrm{Tc}_{2} \mathrm{~S}_{7}$ in grout as the standard spectra for $\mathrm{Tc}(\mathrm{IV})$ (Lukens et al. 2002; Shuh et al. 2000). In all cases, for the best model, an F-test was performed on each scattering shell: if the probability of $\mathrm{F}[\mathrm{p}(\mathrm{F})]^{1}$ is less than 0.05 , the addition of that shell improves the fit to greater than $2 \sigma$ (Debye-Waller factor), and that shell was considered to be observed in the experiment.

All EXAFS spectra were fitted in R space by Fourier transformation of the $\chi(\mathrm{k})$ data. The backscattering phase and amplitude information for individual neighboring atoms were determined using the theoretical EXAFS modeling code FEFF7 (Rehr et al. 1991) based on the model for Tc standards previously reported (Shuh et al. 2000; Lukens et al. 2002, 2005). The amplitude reduction factor $\left(\mathrm{S}_{0}{ }^{2}\right)$ was fixed at 1.0 for all the EXAFS fits. The $\Delta \mathrm{E}_{\mathrm{o}}$ parameter was allowed to vary during fitting, but was constrained to be the same for all scattering shells for a given fit.

\subsubsection{XPS Analysis}

Two FBSR samples (FBSR powder and FBSR encapsulated with Geo-7 geopolymer, to form a monolith) and six Re standards were used for XPS analysis to determine Re oxidation state and chemical composition in the surfaces of the two solids. The six Re standards include $\mathrm{Re}(0)$ metal, $\mathrm{Re}(\mathrm{III}) \mathrm{Cl}_{3}$, $\mathrm{Re}(\mathrm{IV}) \mathrm{O}_{2}, \mathrm{Re}(\mathrm{V}) \mathrm{Cl}_{5}, \mathrm{Re}(\mathrm{VI}) \mathrm{O}_{3}$, and $\mathrm{Re}(\mathrm{VII})_{2} \mathrm{O}_{7}$. The two FBSR samples were ground to prepare powder samples for XPS analysis at the Environmental Molecular Sciences Laboratory (EMSL) located at PNNL. The XPS powder samples were pressed onto clean double-sided Nichiban tape supported on the underside by a 1-cm by 3-cm flat silicon (Si) wafer. The other side of the tape was pressed onto the sample holder before placing it into the XPS vacuum introduction system. The vacuum system was pumped to $<1 \times 10^{-6}$ Torr using a turbomolecular pumping system before introducing the sample assembly into the main ultra-high-vacuum system. The main vacuum system pressure is maintained at $<5 \times 10^{-9}$ Torr during analysis and pumped with a series of sputter ion pumps. The XPS measurements were performed with a Physical Electronics Quantera scanning x-ray microprobe. This system uses a focused monochromatic Al

\footnotetext{
${ }^{1} \mathrm{~F}$ is described in Table 3.3 and $\mathrm{p}(\mathrm{F})$ is described in Table 3.2
} 
K $\alpha$ x-ray (1486.7 eV) source for excitation and a spherical section analyzer. The instrument has a 32-element multichannel detection system. A 100-W x-ray beam focused to a diameter of $100 \mu \mathrm{m}$ was rastered over a 1.4-mm by $0.1-\mathrm{mm}$ rectangle on the sample. The $\mathrm{x}$-ray beam is incident normal to the sample, and the photoelectron detector is at $45^{\circ}$ off normal. Spectra were collected with a pass energy of $69.0 \mathrm{eV}$ with a step size of $0.125 \mathrm{eV}$. For the $\mathrm{Ag} 3 \mathrm{~d} 5 / 2$ line, these conditions produced a full width at half maximum of $0.91 \mathrm{eV}$. The FBSR-based samples experienced variable degrees of charging. Low-energy electrons at $\sim 1 \mathrm{eV}, 20 \mu \mathrm{A}$, and low-energy argon ions were used to minimize this charging. The position and intensity of the carbon $1 \mathrm{~s}$ peak at $284.8 \mathrm{eV}$ were used as references. The XPS data collection and analysis were done with SmartSoft-XPS V2.0.4.1 (ULVAC-PHI Inc. 2009) and MultiPak Version 8.2B (ULVAC-PHI Inc.), respectively.

\subsection{Results and Discussion}

\subsubsection{Solution $\mathrm{pH}$ and Eh Analysis and Technetium Eh-pH Diagram Development}

The measured $\mathrm{pH}$ and Eh values for the five different simulants and DIW are given in Table 3.1. Similarly high $\mathrm{pH}$ values of around 13.0 were measured for most of the simulants except S4, which was prepared to simulate a mixed caustic-scrubber solution and submerged-bed-scrubber solution. The corrected Eh values for four simulants (S1, S2, S3, and Phase I) also showed similar values ranging between $140 \mathrm{mV}$ and $160 \mathrm{mV}$, but a much higher Eh value $(300 \mathrm{mV})$ was found in Simulant 4. Comparing this to the Eh values measured for DIW and other simulants, the relatively higher Eh value found in S4 indicates that S4 contains fewer reductive chemicals (or exists at a more oxidative condition) than other simulants.

Table 3.1. Solution Analyses (pH and Eh) of Secondary Waste Simulants

\begin{tabular}{|c|c|c|c|c|c|}
\hline Analysis & $\begin{array}{c}\text { S1 } \\
\text { Caustic Scrubber } \\
\text { Median }\end{array}$ & $\begin{array}{c}\text { S2 } \\
\text { Statistical - } \\
\text { Cluster 1 } \\
3 / 16 / 2038\end{array}$ & $\begin{array}{c}\text { S3 } \\
\text { Statistical - } \\
\text { Cluster } 2 \\
05 / 28 / 2024\end{array}$ & $\begin{array}{c}\text { S4 } \\
\text { Caustic Scrubber/ } \\
\text { 10\% SBS Blend }\end{array}$ & $\begin{array}{c}\text { Phase } 1 \\
\text { Simulant }\end{array}$ \\
\hline $\mathrm{pH}$ & 13.3 & 13.3 & 13.1 & 8.94 & 13.3 \\
\hline $\mathrm{Eh}_{\text {corrected }}(\mathrm{mV})$ & $142.6 \pm 3.4$ & $153.6 \pm 0.7$ & $161.4 \pm 2.5$ & $304.7 \pm 4.5$ & $147.8 \pm 1.9$ \\
\hline
\end{tabular}

The results of aqueous Tc speciation and solubility calculations are presented graphically as Eh-pH diagrams for each of the different simulants. The diagrams were constructed assuming the S1, S2, S3, and S4 caustic scrubber compositions provided in Table 2.1. The diagrams show the stability fields for the dominant technetium species at $25^{\circ} \mathrm{C}$. Calculating these diagrams typically requires the assumption that the system is at equilibrium; however, in this case, equilibrium was not allowed for both the nitrogen (N) and carbon (C) systems because $\mathrm{NO}_{3}{ }^{-}, \mathrm{NO}_{2}{ }^{-}$, and $\mathrm{NH}_{4}{ }^{+}$occasionally occur simultaneously in the waste streams for the $\mathrm{N}$ system, and carbonate and oxalate occur simultaneously for the $\mathrm{C}$ system in all the waste streams. To allow this disequilibrium, the following redox couples were decoupled: $\mathrm{NO}_{3}{ }^{-} / \mathrm{NO}_{2}{ }^{-}$, $\mathrm{NO}_{2}{ }^{-} / \mathrm{NH}_{4}{ }^{+}$, and oxalate/ $\mathrm{HCO}_{3}{ }^{-}$. Decoupling of these redox couples is justified because it is not expected that they will equilibrate in the time frame that it will take to fabricate the waste forms. The Eh-pH diagrams of Tc in the four simulants (S1, S2, S3, and S4) are shown in Figure 3.1, and they are very 
similar to each other. Minor differences in the distribution of Tc species $\left(\mathrm{TcO}^{2+}\right.$ and $\left.\mathrm{TcO}_{2} \cdot 2 \mathrm{H}_{2} \mathrm{O}\right)$ can be found only at low pH conditions. The Eh-pH diagram of Tc in the Phase-I simulant also is similar to that of S1 (Pierce et al. 2010). Based on the measured $\mathrm{Eh}$ and the $\mathrm{pH}$ values for the four different simulants, the dominant aqueous Tc species was $\mathrm{TcO}_{4}{ }^{-}$in all four of the simulants.
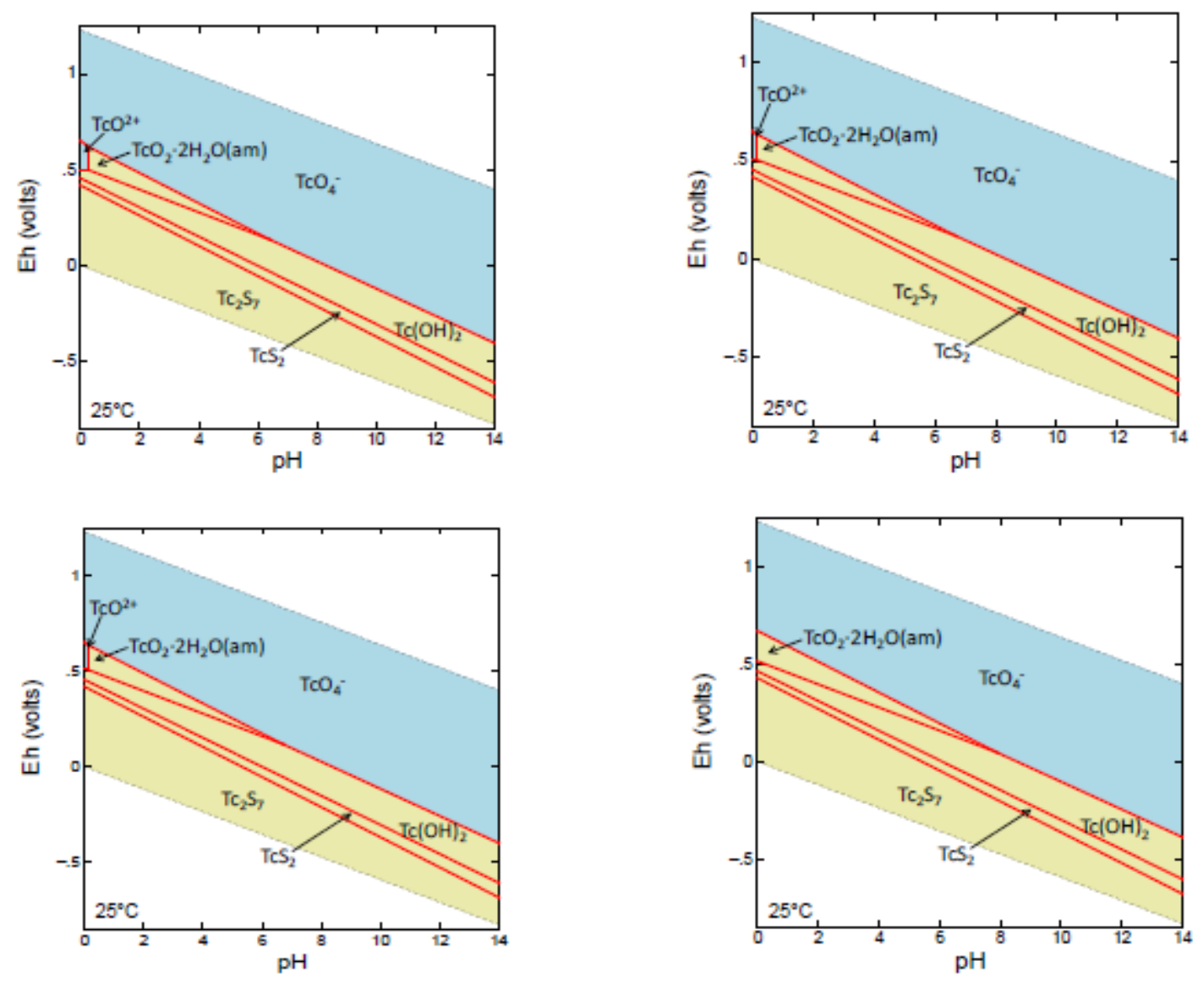

Figure 3.1. Eh-pH Stability Diagrams for Dominant Technetium Species at $25^{\circ} \mathrm{C}$. Top left: Median S1 Caustic Scrubber Simulant; top right: S2 Caustic Scrubber Cluster 1 Simulant; bottom left: S3 Caustic Scrubber Cluster 2 Simulant; bottom right: Median S4 Caustic Scrubber/ 10\% SBS Blend Simulant. (See Table 2.1 for simulant compositions). The blue shading represents aqueous Tc species, while the yellow-green shading represents solid phase.

\subsubsection{XAFS Spectroscopy Analysis}

The XANES spectra of Tc standards $\left[\mathrm{TcO}_{4}{ }^{-}\right.$adsorbed on Reillex-HPQ resin for Tc(VII) and $\mathrm{TcO}_{2} \cdot 2 \mathrm{H}_{2} \mathrm{O}$ for $\left.\mathrm{Tc}(\mathrm{IV})\right]$ and Tc waste-form samples are shown in Figure 3.2 and Figure 3.3. The spectrum of the $\mathrm{TcO}_{4}{ }^{-}$(VII) standard is characterized by a strong pre-edge feature because of the $1 \mathrm{~s}$ to $4 \mathrm{~d}$ transition, which is allowed for the tetrahedral $\mathrm{TcO}_{4}{ }^{-}$anion. The XANES spectrum for the Tc(IV) standard $\left(\mathrm{TcO}_{2} \cdot 2 \mathrm{H}_{2} \mathrm{O}\right)$ is very different and is characteristic of $\mathrm{Tc}(\mathrm{IV})$ coordinated by six oxygen atoms in an octahedral geometry. In addition, the absorption edge of $\mathrm{TcO}_{2} \cdot 2 \mathrm{H}_{2} \mathrm{O}$ is about $5.5 \mathrm{eV}$ lower in energy than the absorption edge of $\mathrm{TcO}_{4}{ }^{-}$. The oxidation state of Tc in the waste-form samples was determined by fitting their XANES spectra using the spectra of $\mathrm{TcO}_{4}{ }^{-}$adsorbed on Reillex-HPQ resin for $\mathrm{Tc}(\mathrm{VII})$ and both $\mathrm{TcO}_{2} \cdot 2 \mathrm{H}_{2} \mathrm{O}$ and $\mathrm{Tc}_{2} \mathrm{~S}_{7}$ in grout as standard spectra for Tc(IV) (Lukens et al. 2005). 

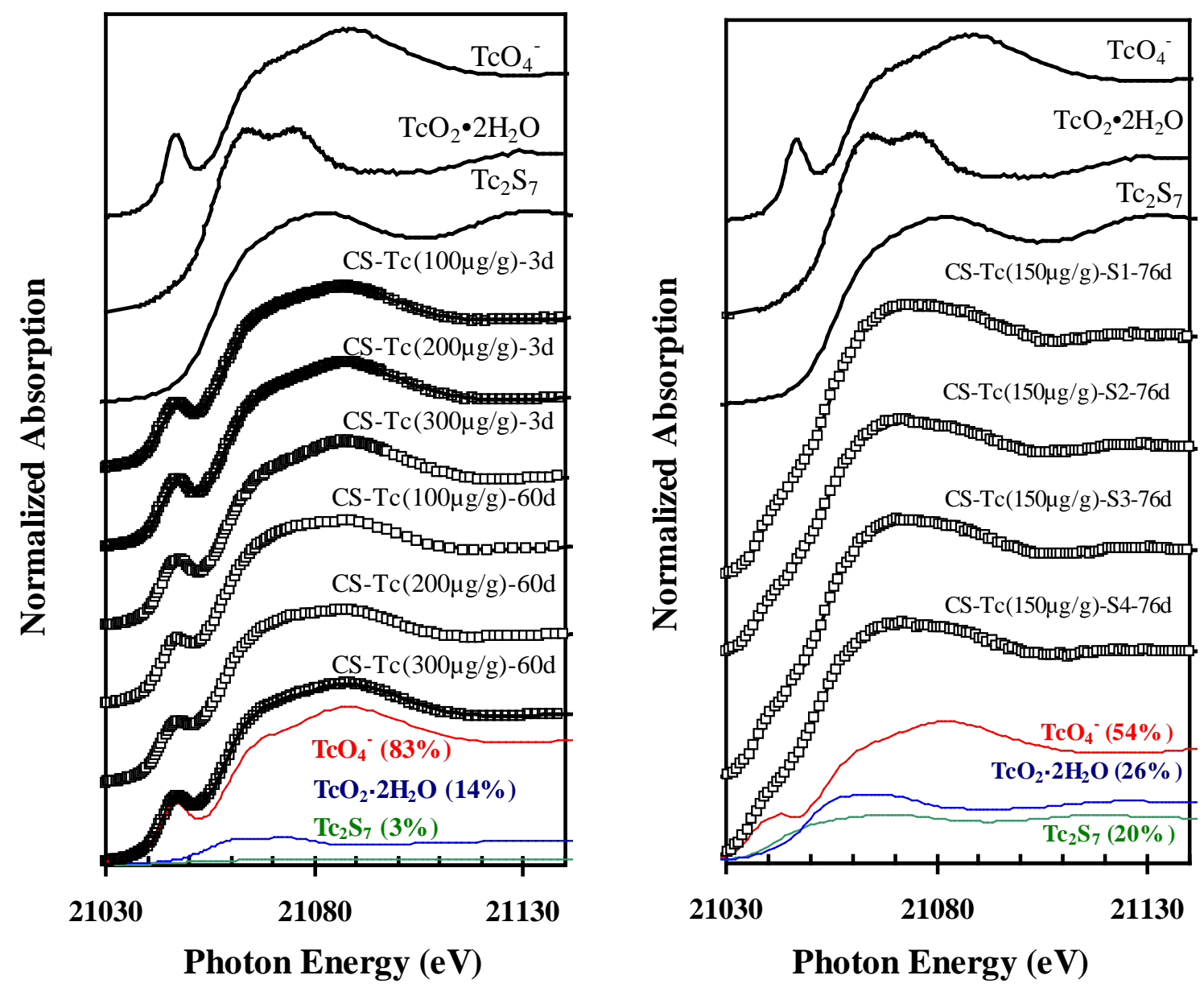

Figure 3.2. Normalized Tc XANES Spectra and Fits for Containerized Cast Stone (CCS) Samples Prepared with Phase-I Simulant (left) and Simulants S1, S2, S3, and S4 (right). Data are represented by symbols, and the fit is represented by the solid black line. The contributions of each Tc species and their percentages are shown with different colors for CS-Tc(300 $\mu \mathrm{g} / \mathrm{g})-60 \mathrm{~d}(\mathrm{left})$ and CS-Tc(150 $\mu \mathrm{g} / \mathrm{g})-\mathrm{S} 4-76 \mathrm{~d}($ right $)$.

The XANES spectra for Tc in CCS prepared with different Tc concentrations $(100 \mu \mathrm{g} / \mathrm{g}, 200 \mu \mathrm{g} / \mathrm{g}$, and $300 \mu \mathrm{g} / \mathrm{g}$ ) in the Phase-I simulant are given in the left pane of Figure 3.2 with the best fits. Using a linear combination model in which three Tc species $\left(\mathrm{TcO}_{4}{ }^{-}, \mathrm{TcO}_{2} \cdot 2 \mathrm{H}_{2} \mathrm{O}\right.$, and $\left.\mathrm{Tc}_{2} \mathrm{~S}_{7}\right)$ are considered to be plausible, the summation of spectra contributions from these three Tc forms matched the measured Tc XANES spectra well. The XANES fit results and contribution of each of the three different Tc species are provided in Table 3.2. For the $\mathrm{TcO}_{2} \cdot 2 \mathrm{H}_{2} \mathrm{O}$ and $\mathrm{TcO}_{4}{ }^{-}$components, the $\mathrm{p}(\mathrm{F})$ is $<<0.05$, so both of these components are definitely present in all samples. The contribution of the $\mathrm{Tc}_{2} \mathrm{~S}_{7}$ species increased as the reaction (curing) time increased from 3 days to 60 days. However, because the $p(F)$ is greater than 0.05 for the $\mathrm{Tc}_{2} \mathrm{~S}_{7}$ component for the Cast Stone samples stored for 60 days, we are not convinced that this species is actually present in these samples. At best, it appears that, if this species is present, its contribution is small when compared to the overall species distribution. 
Table 3.2. The XANES Fit Results for Tc Species in Different Waste Forms

\begin{tabular}{|c|c|c|c|c|c|c|c|c|c|c|}
\hline Samples & $\begin{array}{c}\text { Tc conc. } \\
(\mu \mathrm{g} / \mathrm{g})\end{array}$ & $\begin{array}{c}\text { Time } \\
\text { (days) }^{(\mathrm{a})}\end{array}$ & $\begin{array}{l}\text { Fraction } \\
\mathrm{Tc}_{2} \mathrm{~S}_{7}{ }^{\text {(b) }}\end{array}$ & $\mathrm{p}(\mathrm{F})^{(\mathrm{c})}$ & $\begin{array}{l}\text { Fraction } \\
\mathrm{TcO}_{2} \cdot \\
2 \mathrm{H}_{2} \mathrm{O}\end{array}$ & $\mathrm{p}(\mathrm{F})^{(\mathrm{c})}$ & $\begin{array}{c}\text { Fraction } \\
\mathrm{TcO}_{4}^{-}\end{array}$ & $\mathrm{p}(\mathrm{F})^{(\mathrm{c})}$ & R-factor ${ }^{(\mathrm{d})}$ & Simulants \\
\hline $\begin{array}{l}\text { CS-100-3d } \\
\text { (CCS) }\end{array}$ & 100 & 3 & 0.0 & NC & $\begin{array}{l}0.153 \\
(8)\end{array}$ & $1 \mathrm{E}-6$ & $\begin{array}{l}0.847 \\
(8)\end{array}$ & $1 \mathrm{E}-6$ & 0.006 & $\begin{array}{c}\text { Phase I } \\
\text { simulant }\end{array}$ \\
\hline $\begin{array}{l}\text { CS-200-3d } \\
\text { (CCS) }\end{array}$ & 200 & 3 & 0.0 & NC & $\begin{array}{c}0.102 \\
(7)\end{array}$ & $1 \mathrm{E}-6$ & $\begin{array}{c}0.898 \\
(8)\end{array}$ & $1 \mathrm{E}-6$ & 0.006 & $\begin{array}{c}\text { Phase I } \\
\text { simulant }\end{array}$ \\
\hline $\begin{array}{l}\text { CS-300-3d } \\
\text { (Cast Stone) }\end{array}$ & 300 & 3 & 0.0 & NC & $\begin{array}{l}0.075 \\
(6)\end{array}$ & $1 \mathrm{E}-6$ & $\begin{array}{c}0.925 \\
(6)\end{array}$ & $1 \mathrm{E}-6$ & 0.005 & $\begin{array}{c}\text { Phase I } \\
\text { simulant }\end{array}$ \\
\hline $\begin{array}{l}\text { CS-100-60d } \\
\text { (Cast Stone) }\end{array}$ & 100 & 60 & $\begin{array}{l}0.03 \\
(2)\end{array}$ & 0.4 & $\begin{array}{l}0.21 \\
(2)\end{array}$ & $3 E-5$ & $\begin{array}{l}0.76 \\
(1)\end{array}$ & $2 \mathrm{E}-9$ & 0.008 & $\begin{array}{c}\text { Phase I } \\
\text { simulant }\end{array}$ \\
\hline $\begin{array}{l}\text { CS-200-60d } \\
\text { (Cast Stone) }\end{array}$ & 200 & 60 & $\begin{array}{l}0.05 \\
(2)\end{array}$ & 0.1 & $\begin{array}{l}0.20 \\
(2)\end{array}$ & $3 E-5$ & $\begin{array}{l}0.75 \\
(1)\end{array}$ & 7E-10 & 0.008 & $\begin{array}{c}\text { Phase I } \\
\text { simulant }\end{array}$ \\
\hline $\begin{array}{l}\text { CS-300-60d } \\
\text { (Cast Stone) }\end{array}$ & 300 & 60 & $\begin{array}{l}0.03 \\
(2)\end{array}$ & 0.3 & $\begin{array}{l}0.14 \\
(2)\end{array}$ & $1 \mathrm{E}-4$ & $\begin{array}{l}0.83 \\
(1)\end{array}$ & $1 \mathrm{E}-10$ & 0.007 & $\begin{array}{c}\text { Phase I } \\
\text { simulant }\end{array}$ \\
\hline $\begin{array}{l}\text { CS-150-S1-76d } \\
\text { (Cast Stone) }\end{array}$ & 150 & 76 & $\begin{array}{c}0.22 \\
(4)\end{array}$ & $1 \mathrm{E}-4$ & $\begin{array}{l}0.26 \\
(3)\end{array}$ & $1 \mathrm{E}-4$ & $\begin{array}{l}0.53 \\
(2)\end{array}$ & $1 \mathrm{E}-4$ & 0.005 & S1 \\
\hline $\begin{array}{l}\text { CS-150-S2-76d } \\
\text { (Cast Stone) }\end{array}$ & 150 & 76 & $\begin{array}{l}0.22 \\
(5)\end{array}$ & 0.002 & $\begin{array}{l}0.30 \\
(4)\end{array}$ & $1 \mathrm{E}-4$ & $\begin{array}{l}0.48 \\
(3)\end{array}$ & $1 \mathrm{E}-4$ & 0.006 & S2 \\
\hline $\begin{array}{l}\text { CS-150-S3-76d } \\
\text { (Cast Stone) }\end{array}$ & 150 & 76 & $\begin{array}{c}0.21 \\
(4)\end{array}$ & 0.001 & $\begin{array}{c}0.27 \\
(3)\end{array}$ & $1 \mathrm{E}-4$ & $\begin{array}{c}0.52 \\
(2)\end{array}$ & $1 \mathrm{E}-4$ & 0.006 & S3 \\
\hline $\begin{array}{l}\text { CS-150-S4-76d } \\
\text { (Cast Stone) }\end{array}$ & 150 & 76 & $\begin{array}{l}0.20 \\
(4)\end{array}$ & 0.001 & $\begin{array}{l}0.26 \\
(3)\end{array}$ & $1 \mathrm{E}-4$ & $\begin{array}{l}0.54 \\
(2)\end{array}$ & $1 \mathrm{E}-4$ & 0.005 & S4 \\
\hline $\begin{array}{l}\text { G-150-S1-76d } \\
\text { (DuraLith) }\end{array}$ & 150 & 76 & $\begin{array}{l}0.14 \\
(3)\end{array}$ & $1 \mathrm{E}-4$ & $\begin{array}{l}0.06 \\
(2)\end{array}$ & 0.062 & $\begin{array}{l}0.79 \\
(1)\end{array}$ & $1 \mathrm{E}-4$ & 0.006 & S1 \\
\hline $\begin{array}{l}\text { G-150-S2-76d } \\
\text { (DuraLith) }\end{array}$ & 150 & 76 & $\begin{array}{l}0.08 \\
(3)\end{array}$ & 0.019 & $\begin{array}{l}0.07 \\
(3)\end{array}$ & 0.047 & $\begin{array}{l}0.85 \\
(2)\end{array}$ & $1 \mathrm{E}-4$ & 0.007 & S2 \\
\hline $\begin{array}{l}\text { G-150-S3-76d } \\
\text { (DuraLith) }\end{array}$ & 150 & 76 & $\begin{array}{l}0.13 \\
(3)\end{array}$ & 0.002 & $\begin{array}{l}0.07 \\
(3)\end{array}$ & 0.059 & $\begin{array}{l}0.80 \\
(2)\end{array}$ & $1 \mathrm{E}-4$ & 0.005 & S3 \\
\hline $\begin{array}{l}\text { G-150-S4-76d } \\
\text { (DuraLith) }\end{array}$ & 150 & 76 & $\begin{array}{l}0.29 \\
(4)\end{array}$ & $1 \mathrm{E}-4$ & $\begin{array}{c}0.09 \\
(3)\end{array}$ & 0.033 & $\begin{array}{l}0.62 \\
(2)\end{array}$ & $1 \mathrm{E}-4$ & 0.006 & S4 \\
\hline $\begin{array}{l}\text { Ceramicrete- } \\
\text { 150-S1-3d }\end{array}$ & 150 & 3 & $\begin{array}{l}0.1 \\
(2) \\
\end{array}$ & 1.0 & $\begin{array}{l}0.9 \\
(1)\end{array}$ & $1 \mathrm{E}-4$ & $\begin{array}{c}0.00 \\
(7)\end{array}$ & 1.0 & 0.009 & $\mathrm{~S} 1$ \\
\hline
\end{tabular}

(a) Time indicates "total curing time” between sample preparation and XAFS data collection in units of days.

(b) These values represent the fraction of the total Tc assumed to be present as the designated species. The sum of all species is 1.0. The number in parentheses is the standard deviation in the same units as the last digit in the number ([e.g., 0.17(1) is 0.17 with a standard deviation of 0.01 .

(c) $\mathrm{p}(\mathrm{F})$ is the probability that the improvement to the fit result including this component is due to random error. If $\mathrm{p}(\mathrm{F})<0.05$, the component can be considered to be present. NC indicates "not conducted," because the other two possible Tc species significantly contribute to the fits, so adding the third species is not necessary.

(d) The R-factor is described by $\left[\Sigma\left(\mathrm{y}_{\text {obs }}-\mathrm{y}_{\text {calc }}\right)^{2} / \Sigma \mathrm{y}_{\text {obs }}{ }^{2}\right]^{1 / 2}$, where the sum is over all data. If the R-factor is $<0.05$, the fit result is acceptable.

The intensity of the pre-edge peak present around 21,047 eV also decreased as the curing time (slow continued hydration reaction) increased. In addition, absorption peaks around 21,065 eV moved to relatively lower energy regions for the Cast Stone samples cured for 60 days compared to those cured for 3 days, indicating a greater contribution from $\mathrm{Tc}(\mathrm{IV})$ species as the curing time increased. For the $\mathrm{TcO}_{2} \cdot 2 \mathrm{H}_{2} \mathrm{O}$ and $\mathrm{TcO}_{4}{ }^{-}$components, the $\mathrm{p}(\mathrm{F})$ is $<<0.05$, so both of these components are definitely present in all samples. There is no difference in Tc speciation, especially for Tc(VII) between Cast Stone samples with Tc concentrations of 100 and $200 \mu \mathrm{g} / \mathrm{g}$, no matter what the reaction time was. However, because of the relatively higher initial Tc(VII) concentration present in the waste simulant, Cast Stone samples prepared with the highest Tc concentration (i.e., $300 \mu \mathrm{g} / \mathrm{g}$ ) showed much higher Tc(VII) 
contributions in the samples cured for both 3 days and 60 days. This observation implies that there is a finite limit to the capability of the ingredients in the Cast Stone dry ingredients or the minerals formed during hydration to reduce the Tc(VII) originally present in the waste simulant.

The XANES spectra of Tc-Cast Stone prepared with a final Tc concentration of $150 \mu \mathrm{g} / \mathrm{g}$ in the four different simulants along with the best fits (Figure 3.2, right pane) showed slightly different contributions from the various model Tc species (Table 3.2). The pre-edge peak, typical of Tc(VII) species, essentially disappeared in these samples (Figure 3.2, right). Although a small, weak hump can still be found in lowenergy regions between 21,040 eV and 21,050 eV, there appear to be increased contributions of $\mathrm{TC}_{2} \mathrm{~S}_{7}$ species (20\% to 22\%) in the Tc-Cast Stone samples after 76 days reaction compared to other Tc-Cast Stone samples (0\% to 3\%) reacted from 3 days to 60 days (Table 3.2). Even though the $\mathrm{TcO}_{2} \cdot 2 \mathrm{H}_{2} \mathrm{O}$ contribution also increased as the reaction time increased, the increase in the $\mathrm{TcO}_{2} \cdot 2 \mathrm{H}_{2} \mathrm{O}$ contribution after 76 days was relatively minor compared to the increase in the $\mathrm{Tc}_{2} \mathrm{~S}_{7}$ contribution. The increase in the $\mathrm{Tc}_{2} \mathrm{~S}_{7}$ and $\mathrm{TcO}_{2} \cdot 2 \mathrm{H}_{2} \mathrm{O}$ contributions as the reaction time increases is considered to result from more-dissolved concentrations of sulfide and other reductants like ferrous iron from the BFS used in preparing Cast Stone. Accordingly, the contribution of $\mathrm{TcO}_{4}{ }^{-}$species in Cast Stone decreased from between 75\% and 90\% (based only on $100 \mu \mathrm{g} / \mathrm{g}$ and $200 \mu \mathrm{g} / \mathrm{g}$ Tc concentration solids cured for 3 days and 60 days) to between $48 \%$ and $54 \%$ after curing for 76 days regardless of what simulant was used. The types and percentages of the three types of Tc species found in the Cast Stone and the time evolution in the Tc species showed no differences for the four different simulants used to prepare the Tc-Cast Stone waste forms.

Shuh et al. (2002) reported that increasing contributions of $\mathrm{Tc}_{2} \mathrm{~S}_{7}$ and $\mathrm{TcO}_{2} \cdot 2 \mathrm{H}_{2} \mathrm{O}$ species were found only in cement waste forms that were completely sealed and not allowed to be exposed to $\mathrm{O}_{2}$ sources for 9 months after preparation. However, re-oxidation of these reduced Tc(IV) species was found to occur in cement waste forms that were not sealed. Such samples, when exposed to air, showed increasing contributions of the oxidized $\mathrm{TcO}_{4}{ }^{-}$species up to 25 months after preparation because of $\mathrm{O}_{2}$ diffusion into the porous cement waste forms. Shuh and his co-workers concluded that the presence or absence of nitrate/nitrite during cement waste-form preparation had no effect on the Tc speciation or reduction/reoxidation processes. Oxygen was the only oxidant that effectively impacted the Tc speciation such that $\mathrm{Tc}(\mathrm{IV})$ was converted to Tc(VII). Based on their results and the results presented in this report, we recommend that more long-term aging studies be performed to quantify the evolution of Tc species in Cast Stone.

The Tc-XANES spectra and the best fits for Tc-DuraLith are shown in the left pane of Figure 3.3. The XANES spectra for the DuraLith samples showed a pre-edge peak at low energy regions, although it is not sharp. The pre-edge peaks indicate a contribution of $\mathrm{TcO}_{4}^{-}$species in DuraLith, ranging from 62\% to $85 \%$. Relatively lower contribution of the $\mathrm{TcO}_{4}{ }^{-}$species (62\%) was found in the DuraLith prepared with the S4 simulant (Table 3.2 and Figure 3.3, right). However, as pointed out by Shuh et al. (2000), the minor fluctuations in the values of Tc species contributions also can be caused by heterogeneous distribution of Tc species in waste-form samples. There was a higher contribution of Tc(IV) species in the DuraLith samples than found in Cast Stone samples analyzed after curing for 60 days, even though the curing time for the DuraLith was just 28 days (Table 3.2). The higher contribution of Tc(IV) species is attributed to adding two strong reductants to the DuraLith mix, $\mathrm{Na}_{2} \mathrm{~S}$ and $\mathrm{SnF}_{2}$ (see previous section for DuraLith preparation and Table 2.5). Adding significant masses of these reductants while preparing the DuraLith waste forms effectively enhanced Tc(VII) reduction to Tc(IV). 

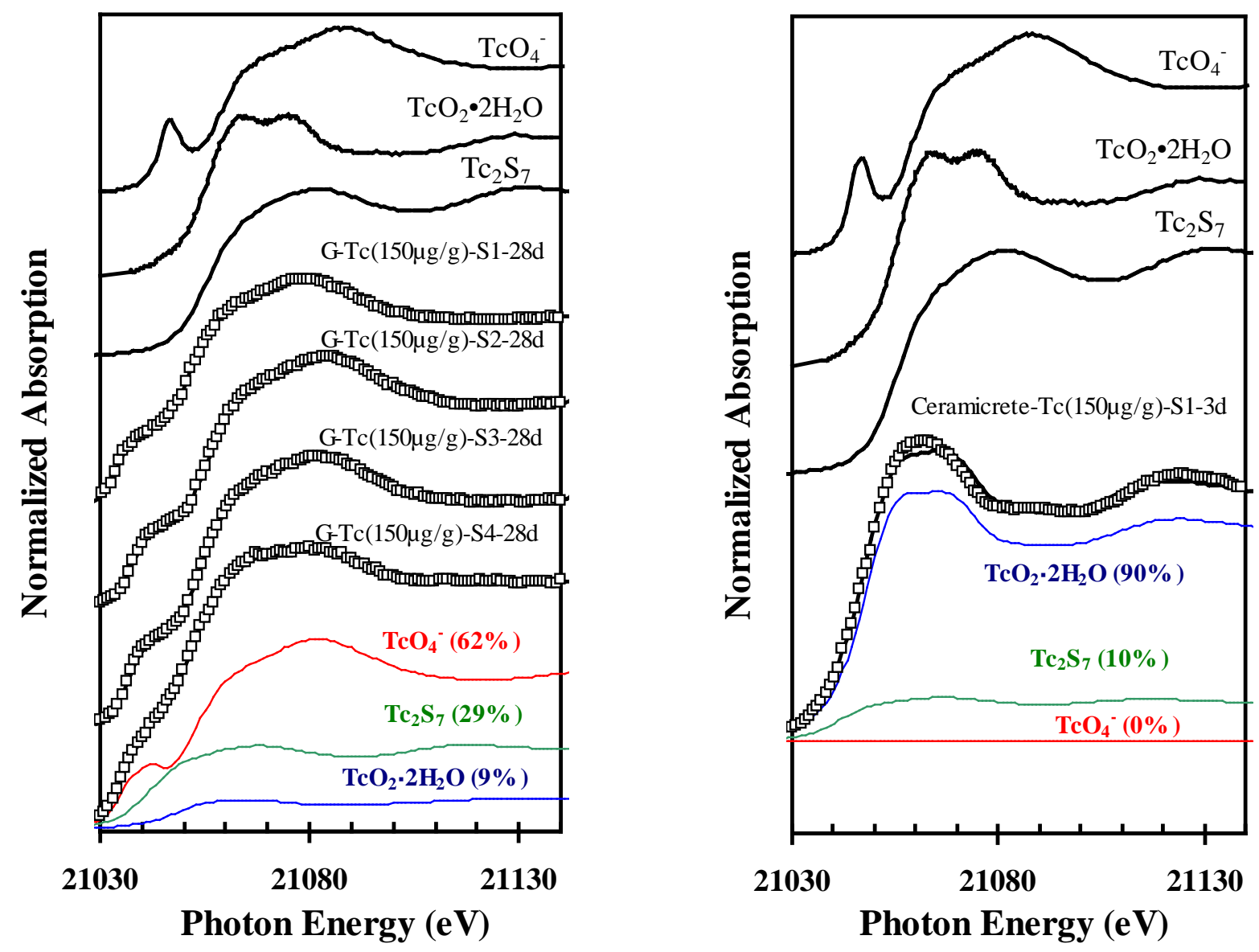

Figure 3.3. Normalized Tc XANES Spectra and Fits for DuraLith (left) and Ceramicrete (right) Samples. "G” indicates DuraLith geopolymer waste form samples prepared with $150 \mu \mathrm{g} / \mathrm{g}$ Tc concentration in four different simulants (left). Data are represented by symbols, and the fit is represented by the solid black line. The contributions of each Tc species and the percentages are shown with different colors for G-Tc(150 $\mu \mathrm{g} / \mathrm{g})-\mathrm{S} 4-28 \mathrm{~d}(\mathrm{left})$ and Ceramicrete-Tc(150 $\mu \mathrm{g} / \mathrm{g})-\mathrm{S} 1-3 \mathrm{~d}$ (right).

Tc XANES spectra for the Ceramicrete sample were fit well using only two Tc components, $\mathrm{TcO}_{2} \cdot 2 \mathrm{H}_{2} \mathrm{O}$ and $\mathrm{Tc}_{2} \mathrm{~S}_{7}$. However, because the $\mathrm{p}(\mathrm{F})$ value of the $\mathrm{Tc}_{2} \mathrm{~S}_{7}$ spectrum is higher than 0.05 (Table 3.2), the presence of $\mathrm{Tc}_{2} \mathrm{~S}_{7}$ species is not certain. Another reduced Tc species related to $\mathrm{Sn}$ (II) can be a possible candidate to contribute reduced $\mathrm{Tc}(\mathrm{IV})$ instead of the $\mathrm{Tc}_{2} \mathrm{~S}_{7}$ because no $\mathrm{Na}_{2} \mathrm{~S}$ is used in Ceramicrete preparation. During the XANES data-fitting process, the contribution of $\mathrm{TcO}_{4}{ }^{-}$species also was included, but there was no contribution observed from $\mathrm{TcO}_{4}{ }^{-}$species. All the initial $\mathrm{Tc}(\mathrm{VII})$ species were reduced to $\mathrm{Tc}(\mathrm{VI})$ in the Ceramicrete waste form, even though the curing time was just 3 days after preparation. The complete and rapid Tc reduction from Tc(VII) to Tc(IV) in Ceramicrete resulted from adding large amounts of the reductant, $\mathrm{SnCl}_{2}$, in preparing Ceramicrete. The amount of $\mathrm{SnCl}_{2}$ used in preparing the Ceramicrete was $1.2 \mathrm{wt} \%$ (see previous section for Ceramicrete preparation), which is about five times higher than the combination of $\mathrm{SnF}_{2}(0.08 \mathrm{wt} \%)$ and $\mathrm{Na}_{2} \mathrm{~S}(0.14 \mathrm{wt} \%)$ added for preparing DuraLith waste forms. 
Because of the limited availability of synchrotron beam time, the EXAFS spectra were collected and analyzed only for Cast Stone samples prepared with $200 \mu \mathrm{g} / \mathrm{g}$ and $300 \mu \mathrm{g} / \mathrm{g}$ of Tc concentrations using Phase-I simulant and aged 60 days (samples CS-Tc-200 $\mu \mathrm{g} / \mathrm{g}-60 \mathrm{~d}$ and CS-300 $\mu \mathrm{g} / \mathrm{g}-60 \mathrm{~d}$ ). The EXAFS spectra and the best fits are shown in Figure 3.4, and fitting parameters are given in Table 3.3. The best fit for the CS-300 $\mu \mathrm{g} / \mathrm{g}-60 \mathrm{~d}$ sample was obtained for a structure with four oxygen atoms at $\sim 1.7 \AA$ from the Tc atom. Because the amplitude of the EXAFS spectrum is a function of both the number of neighbors and the Debye-Waller (DW) parameter, the contribution from the Tc(IV) $\mathrm{O}_{2} \cdot 2 \mathrm{H}_{2} \mathrm{O}$ also can be mostly accounted for by increasing the DW parameter of the four oxygen atoms at $\sim 1.7 \AA$. However, because the contribution from $\mathrm{TcO}_{2} \cdot 2 \mathrm{H}_{2} \mathrm{O}$ in the CS-300 $\mu \mathrm{g} / \mathrm{g}$-60d sample is low ( $14 \%$ in Table 3.2), no additional oxygen scattering was observed in this sample. However, the best fit for the CS-Tc-200 $\mu \mathrm{g} / \mathrm{g}-60 \mathrm{~d}$ sample includes a contribution from oxygen neighbors at $2.0 \AA$. This fit was significantly constrained, with the number of oxygen neighbors determined by the number of oxygen neighbors at $1.7 \AA$, and only one DW parameter was used, which was applied to both sets of oxygen neighbors.
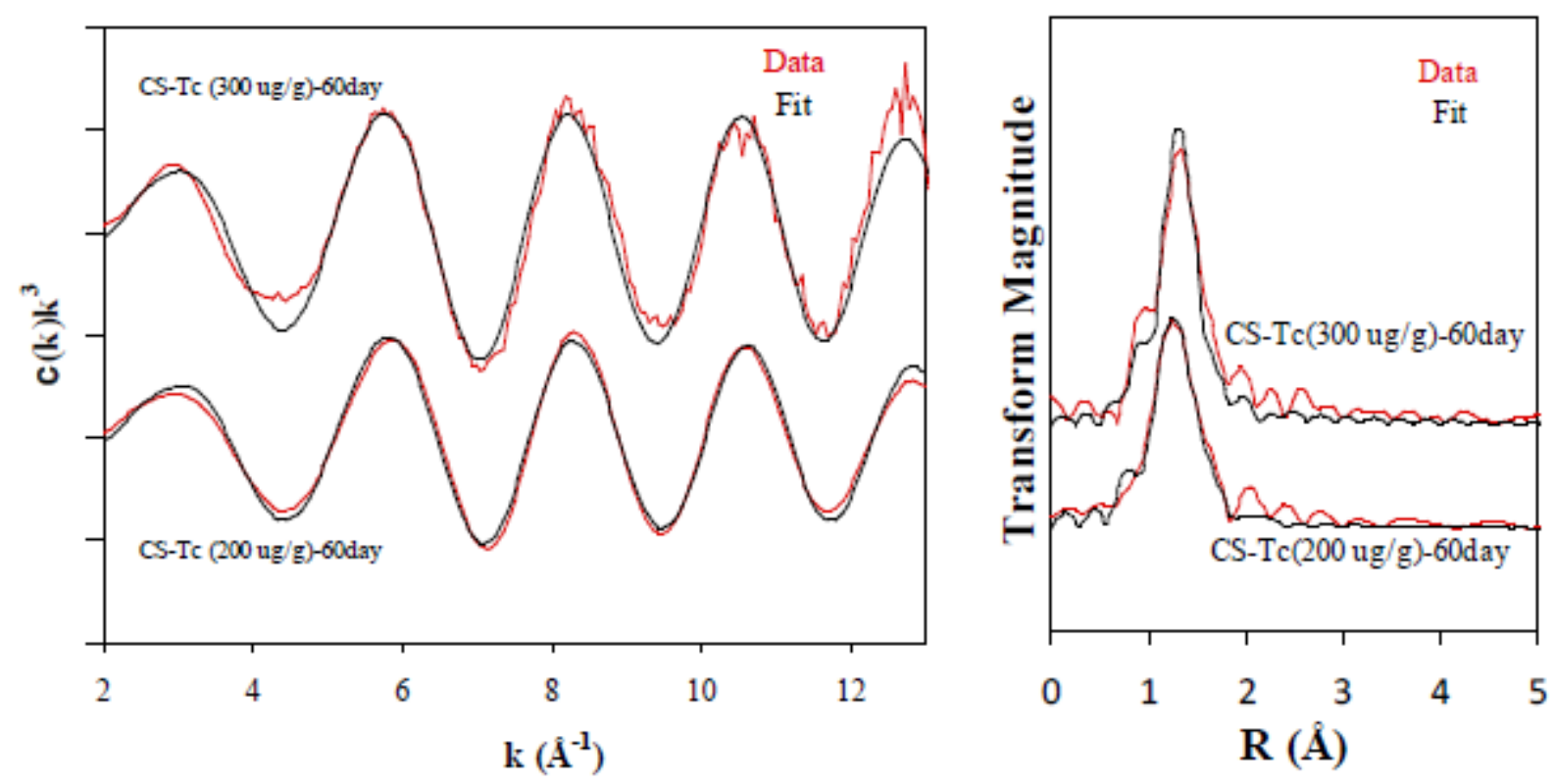

Figure 3.4. EXAFS Spectra (left) and their Fourier Transforms (right) for Cast Stone Samples Aged for 60 Days with Tc Concentrations $300 \mu \mathrm{g} / \mathrm{g}$ and $200 \mu \mathrm{g} / \mathrm{g}$. The measured data and the fits are shown in red and black, respectively.

When compared to the Tc speciation determined using XANES, the EXAFS data and analysis are both less sensitive and less accurate for coordination number information. From the XANES fitting, the CS-300 $\mu \mathrm{g} / \mathrm{g}-60 \mathrm{~d}$ sample contains 14\% of Tc(IV) species; however, scattering from oxygen atoms at $2 \AA$, because of the Tc(IV) species, was not observed in the EXAFS spectrum and analysis. Based on the XANES analysis, the CS-Tc-200 $\mu \mathrm{g} / \mathrm{g}$-60d sample contains about 20\% Tc(IV); however, the EXAFS fit indicates a Tc(IV) content of only $10 \%$. 
Table 3.3. Best Fit Parameters for Cast Stone Samples from EXAFS Analysis

\begin{tabular}{ccccccc}
\hline Samples & $\begin{array}{c}\text { Neighboring } \\
\text { Atoms }\end{array}$ & $\begin{array}{c}\text { CN of } \\
\text { Neighbors }^{(\mathrm{c})}\end{array}$ & $\begin{array}{c}\text { Interatomic } \\
\text { Distance }(\AA)\end{array}$ & $\sigma^{2}\left(\AA^{2}\right)^{(\mathrm{a})}$ & $\mathrm{F}(\mathrm{p})^{(\mathrm{b})}$ & $\mathrm{R}^{(\mathrm{c})}$ \\
\hline CS-200-60d & $\mathrm{O}$ & $3.6(2)^{(\mathrm{e})}$ & $1.71(1)$ & $0.0024(3)$ & 0.017 & 0.009 \\
(Cast Stone) $^{(\mathrm{d})}$ & $\mathrm{O}$ & $0.6(3)$ & $2.07(1)$ & $0.0024(3)$ & 0.056 & \\
CS-300-60d $\left.^{(\text {Cast Stone) }}\right)^{(\mathrm{f})}$ & $\mathrm{O}$ & 4 & $1.71(5)$ & $0.0032(6)$ & 0.02 & 0.03 \\
\hline
\end{tabular}

(a) Debye-Waller factor

(b) $\mathrm{F}(\mathrm{p})$ is the significance of the improvement to the fit created by adding an additional set of atoms. If the p-value is less than 0.05 , the additional atoms have significantly improved the fit and can be considered "observed" in the EXAFS experiment.

(c) Goodness-of-fit parameter (R-factor) is described by $\left[\Sigma\left(\mathrm{y}_{\mathrm{obs}}-\mathrm{y}_{\text {calc }}\right)^{2} / \Sigma \mathrm{y}_{\text {obs }}{ }^{2}\right]^{1 / 2}$, where the sum is over all data.

(d) Fit range: $2<\mathrm{k}<12$ and $0.8<\mathrm{R}<2$ for $\mathrm{CS}-200-60 \mathrm{~d}$ sample; $\mathrm{CN}=$ coordination number; $\mathrm{S}_{0}{ }^{2}=0.9$; energy $\operatorname{shift}\left(\Delta \mathrm{E}_{0}\right)=$ $-5(3)$ eV; F-test $[\mathrm{p}(\mathrm{F})]$.

(e) The number in parentheses is the standard deviation in the same units as the last digit in the number [e.g., 0.17(1) is 0.17 with a standard deviation of 0.01$]$.

(f) Fit range: $3<\mathrm{k}<13$ and $0.6<\mathrm{R}<1.8$ for $\mathrm{CS}-300-60 \mathrm{~d}$ sample; $\mathrm{S}_{0}{ }^{2}=0.9, \Delta \mathrm{E}_{0}=-3(2) \mathrm{eV}$.

\subsubsection{XPS Analysis}

The binding energies of six Re standards are shown in Figure 3.5 and can be clearly distinguishable between the range of $40 \mathrm{eV}$ and $50 \mathrm{eV}$. The binding-energy information is representative of the chemical state of the element and can provide valuable information regarding oxidation state and coordination environment. A higher binding energy is observed in higher oxidation state elements, which is consistent with the $\mathrm{Re}(\mathrm{VII})$ standard (i.e., $46.9 \mathrm{eV}$ ) compared to $\mathrm{Re}(0)$ metal (i.e., $40.2 \mathrm{eV}$ ) binding energy for the $\operatorname{Re} 4 f_{7 / 2}$ line (Figure 3.5). The binding energies of the Re standards chosen are 40.2, 43.6, 43.8, 44.0, 46.2, and $46.9 \mathrm{eV}$ for the $\operatorname{Re} 4 \mathrm{f}_{7 / 2}$ line of $\operatorname{Re}(0), \operatorname{Re}(\mathrm{III}), \operatorname{Re}(\mathrm{IV}), \operatorname{Re}(\mathrm{V}), \operatorname{Re}(\mathrm{VI})$, and $\operatorname{Re}(\mathrm{VII})$, respectively. The two $\operatorname{Re} 4 f_{7 / 2}$ and $R_{4} 4 f_{5 / 2}$ lines are separated by $\sim 2.4 \mathrm{eV}$, and should always have the same intensity ratio for each valence state. However, the XPS spectra collected for two FBSR samples (FBSR powdered product and FBSR milled powder from the FBSR encapsulated with Geo-7 binder) did not show high enough signal-to-noise ratios to determine the Re oxidation states (Figure 3.6). Any significant Re lines were not detected above the background in these two FBSR samples. The poor-quality spectrum of each FBSR sample is attributed to the low Re concentration spiked into the waste forms compared to the detection limit of XPS for elemental Re; the detection limit using XPS is generally about 0.1 atom percent. Depending on the elemental sensitivity factor (Re being above average), the Re concentration of $300 \mathrm{ppm}$ in FBSR samples is around 0.03 atom percent, which is below the XPS detection limit. The peak found in two FBSR samples at about $50 \mathrm{eV}$ is not considered to be from Re because of potential overlapping lines from other elements present in this relatively low binding energy range (0 to $100 \mathrm{eV})$. Trace amounts of $\mathrm{P}$ and I were found in the FBSR powder sample, and the XPS spectra for these constituents are provided in Appendix A-1. 


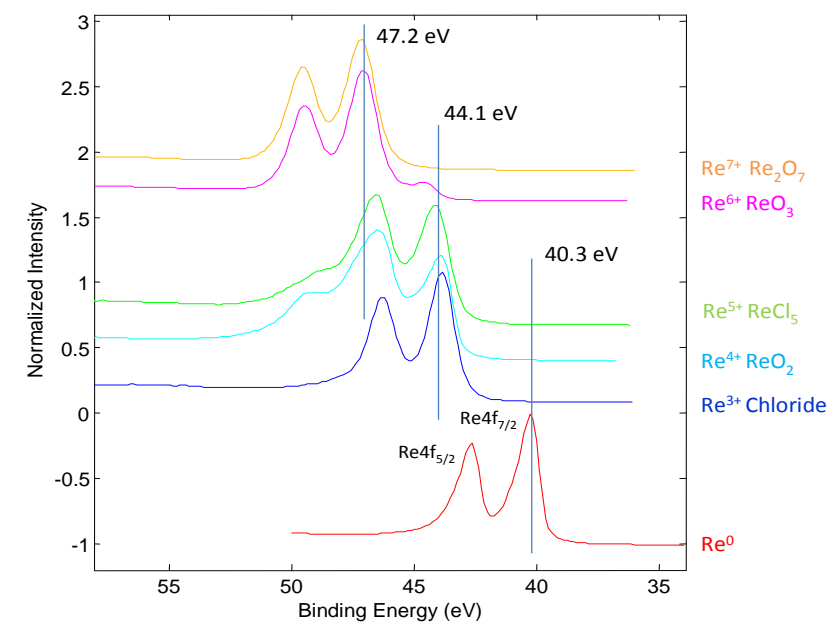

Figure 3.5. High Energy Resolution XPS Spectra of the Re 4f Region for Re References

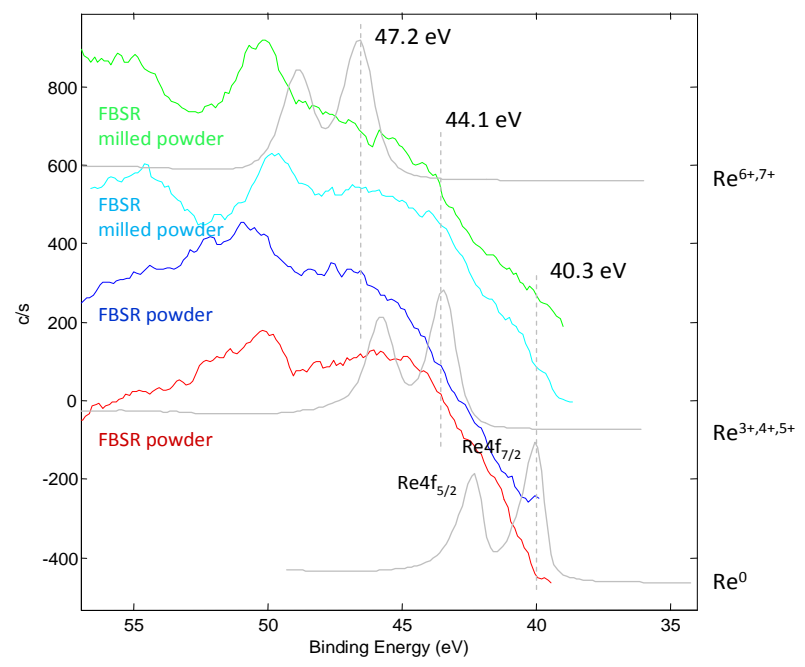

Figure 3.6. High Energy Resolution Photoemission Spectra of the Re 4f Region for FBSR Powder and FBSR Milled Monolith Powder

For each FBSR sample, a broad survey spectrum was collected, in the 0 to $1100 \mathrm{eV}$ energy range, with a high-sensitivity but low-resolution data-collection mode ( $1 \mathrm{eV} / \mathrm{step})$. The survey scan was then followed by narrower scans, typically 20 to $30 \mathrm{eV}$, with lower sensitivity but higher resolution ( $0.065 \mathrm{eV} / \mathrm{step})$ for the elements of interest. These elements typically included the major cations anticipated or observed in the sample, including $\mathrm{Si}, \mathrm{Al}, \mathrm{Na}, \mathrm{K}, \mathrm{Ca}, \mathrm{Mg}, \mathrm{Fe}, \mathrm{Mn}$, and the anion oxygen (O). The calculations of atomic concentration of surface composition are listed in Table 3.4. The surface composition of the samples is reported as a percentage of atomic concentration, based on the number of atoms present, as opposed to percentage composition by weight, as is often done. It should be emphasized that all analyses are semi-quantitative, performed without the use of reference standards. The software, however, accounts for different efficiencies of photoelectrons having different binding energies. An analytical error of approximately $10 \%$ to $20 \%$ is typically expected in this XPS analysis. As expected, $\mathrm{O}, \mathrm{Na}, \mathrm{Si}$, and $\mathrm{Al}$ were the most abundant elements at the surfaces of two FBSR samples. Potassium also 
was present only in the FBSR milled powder sample, which was FBSR encapsulated in Geo-7 that was milled to form a powder sample. Trace amounts of P, Ti, I, and Cs were also found in an FBSR-only powder sample (not from an FBSR monolith). Calcium and Fe were not detectable in either of the two samples. The atomic percentages of $\mathrm{O}, \mathrm{Na}$, $\mathrm{Si}$, and $\mathrm{Al}$ averaged around $52 \%, 17 \%, 12 \%$, and $8 \%$, respectively, accounting for approximately $89 \%$ of the sample, which is close to the final amounts of aluminosilicate minerals found in the FBSR process.

Table 3.4. Atomic Concentration of Surface Composition

\begin{tabular}{|c|c|c|c|c|c|c|c|c|c|c|}
\hline Samples & $\begin{array}{l}\mathrm{C} \\
1 \mathrm{~s} \\
\end{array}$ & $\begin{array}{l}\mathrm{O} \\
1 \mathrm{~s} \\
\end{array}$ & $\begin{array}{l}\mathrm{Na} \\
1 \mathrm{~s} \\
\end{array}$ & $\begin{array}{l}\mathrm{Al} \\
2 \mathrm{p}\end{array}$ & $\begin{array}{l}\mathrm{Si} \\
2 \mathrm{p}\end{array}$ & $\begin{array}{l}\mathrm{P} \\
2 \mathrm{p} \\
\end{array}$ & $\begin{array}{c}\mathrm{K} \\
2 \mathrm{p} 3 \\
\end{array}$ & $\begin{array}{c}\mathrm{Ti} \\
2 \mathrm{p} 3 \\
\end{array}$ & $\begin{array}{c}\mathrm{I} \\
3 \mathrm{~d} 5 \\
\end{array}$ & $\begin{array}{c}\mathrm{Cs} \\
3 \mathrm{~d} 5 \\
\end{array}$ \\
\hline FBSR Powder & 13.0 & 50.3 & 16.0 & 9.6 & 10.0 & 0.77 & 0.00 & 0.23 & 0.02 & 0.13 \\
\hline $\begin{array}{l}\text { FBSR Powder } \\
\text { FBSR Milled }\end{array}$ & 7.3 & 51.7 & 18.8 & 10.2 & 10.6 & 0.95 & 0.00 & 0.27 & 0.02 & 0.15 \\
\hline $\begin{array}{l}\text { Monolith } \\
\text { FBSR Milled }\end{array}$ & 13.2 & 51.6 & 15.0 & 6.4 & 13.3 & 0.06 & 0.31 & 0.07 & 0.00 & 0.03 \\
\hline Monolith & 6.7 & 55.9 & 17.1 & 6.6 & 12.9 & 0.14 & 0.47 & 0.11 & 0.00 & 0.06 \\
\hline
\end{tabular}

\subsection{Conclusions}

The technetium speciation and oxidation state were estimated both in the simulant solutions with Eh-pH diagram calculations and in the actual solid waste forms with XAFS and XPS techniques. Although the initial Tc species and oxidation states in the four different simulants were estimated to be solely $\mathrm{TcO}_{4}{ }^{-}$or the $\mathrm{Tc}$ (VII) oxidation state, the Tc species in the final solid waste forms varied depending on the types of waste forms prepared and the curing (or storage) times. The oxidation state (or species) of Tc in Cast Stone was controlled more by the curing (or storage) time after preparation because of the slow dissolution kinetics for the BFS that was added as one of the dry ingredients. Pertechnetate, $\mathrm{TcO}_{4}{ }^{-}(\mathrm{VII})$, was present in almost $100 \%$ of the Cast Stone samples cured for 3 days. Then, as the curing time increased up to 76 days, increasing $\mathrm{Tc}(\mathrm{IV})$ contributions from $\mathrm{TcO}_{2} \cdot 2 \mathrm{H}_{2} \mathrm{O}$ and $\mathrm{Tc}_{2} \mathrm{~S}_{7}$ species were observed. Because the reductants, $\mathrm{SnF}_{2}$ or $\mathrm{SnCl}_{2}$, are added in the preparation of DuraLith and Ceramicrete, respectively, more contributions from Tc(IV) species were found in both the DuraLith and Ceramicrete waste forms, even in samples that underwent a short curing period (i.e., 3 days to 28 days). The reduction of Tc(VII) was very rapid and complete; almost $100 \%$ of the $\mathrm{Tc}(\mathrm{IV})$ species was reduced within 3 days in the Ceramicrete. The large amount of $\mathrm{SnCl}_{2}$ used in the Ceramicrete is the reason Tc(VII) reduction is rapid and complete. Even though the EXAFS sample collection and analyses were limited, the results provided supplementary data and similar results to the XANES analysis. Because of the low concentration of Re in the FBSR samples, we were not able to use XPS to determine Re oxidation states in two FBSR samples; however, the surface compositions of these FBSR samples determined by XPS analysis indicated that the solids had similar chemical compositions. 


\subsection{Reductive Capacity Measurement}

\subsection{Introduction}

Low-temperature waste solidification processes commonly use reductants that are inherently present in the dry blend or are added to improve the retention of redox-sensitive metal/metalloid and radioactive contaminants such as $\mathrm{Cr}$, Se, ${ }^{129} \mathrm{I}$, ${ }^{99} \mathrm{Tc}$, and ${ }^{238} \mathrm{U}$ in the solid waste forms. These redox-sensitive contaminants are generally much less soluble when present in their reduced valence states in solutions or solids. Their capability to adsorb or co-precipitate with solidification compounds and soils/sediments is much better in the reduced forms than in the oxidized forms. Thus, when chemically reduced, the mobility of these contaminants is significantly decreased in subsurface environments. Therefore, measuring the reductive capacity of waste forms, as well as the dry ingredients used to make waste forms, is a key task needed to project the long-term performance of the waste forms after they are placed in the subsurface environment. Shallow land-burial repositories typically have partially water-saturated, mildlyoxidizing, and near-neutral $\mathrm{pH}$ conditions. The influx of $\mathrm{O}_{2}$-saturated fresh pore waters and $\mathrm{O}_{2}$ in the air that partially fills the unsaturated pores will over time push the redox status of the repository toward oxidizing conditions by consuming any reducing agents present in the waste forms and other materials. The weathering of the emplaced waste forms and the time required for the natural environmental oxidizing conditions to consume any reducing agents can be estimated by measuring the reducing capacity (i.e., meq of electrons $/ \mathrm{kg}$ of material) of the emplaced materials.

At least two widely used measurement techniques have been described in the literature for determining reductive capacity (also called reductant capacity) in materials such as fly ash, BFS, and native sediments, etc. (Angus and Glasser 1985; Lee and Batchelor 2003). Simply stated, both procedures define reductive/reductant capacity as the amount of an oxidant that can be reduced by a testing material when sufficient time is given that the reaction proceeds to its maximum extent or equilibrium condition. The technique described by Angus and Glasser (1985) uses cerium (IV) as the oxidant, while the technique described by Lee and Batchelor (2003) uses Cr(VI) as the oxidant. Because there are significant differences [a factor of $~ 22$, with the Ce(IV)-based technique yielding the larger value; see Kaplan et al. (2005)] in the measured reducing capacity of materials such as BFS, which is a commonly used material in low-temperature waste form dry blends, both procedures are recommended for measuring the reductive capacity of waste forms and the individual dry ingredients used to create the waste forms. A representative sample of the raw materials and the Cast Stone, DuraLith, FBSR, and Ceramicrete final waste forms (prepared as described in Section 2.0 with each of the four simulant compositions) were analyzed to determine their reductive capacity.

Until the scientific community achieves consensus on the most realistic measurement procedure for determining the reductive capacity of waste forms and their ingredient materials, both of the procedures identified above for measuring reductive capacity should be used to provide more data to cover the entire range of waste forms. If the observed values differ significantly, they can be used to perform bounding calculations on the length of time that redox-sensitive contaminants are predicted to remain in their less mobile states. 


\subsection{Materials and Methods}

\subsubsection{Materials}

Four different waste forms (Cast Stone, DuraLith, FBSR, and Ceramicrete) prepared with or without Tc using different simulant compositions, as well as dry ingredients, were tested for reductive capacity measurements. For the Cast Stone waste form, eight different simulants were spiked with Tc or spiked with Re as a surrogate for Tc. The eight liquid simulants were the same simulants as used in the Cast Stone Phase-II tests (S1-2, -4, -6, -8, and -10 M Na; S2-2 M Na; S3-2 M Na; and S4-2 M Na), which are described in detail in Sundaram et al. (2011). Simulant S1 solutions with 4, 6, 8, and $10 \mathrm{M}$ Na were prepared with increased amounts (multiplied by 2, 3, 4, and 5) of each constituent found in the S1-2 M Na simulant (Table 2.1) to make the target simulants. The other four simulant compositions (S1-2 M Na, S2-2 M Na, S3-2 M Na, and S4-2 M Na) are the same as simulants S1, S2, S3, and S4 described in Table 2.1. Dry ingredients to make the Cast Stone samples include BFS, fly ash (Type F), and Portland cement (Type I/II). Both Tc-spiked and Re-spiked Cast Stone samples were prepared to measure reductive capacity.

Both Tc-free and Tc-spiked DuraLith waste forms were prepared with the four different simulants (S1, S2, S3, and S4) and measured for reductive capacity. Each of the dry ingredients used in preparing DuraLith (i.e., fumed silica, meta-kaolinite, river sand, silver zeolite, BFS, sodium sulfide hydrate $\left[\mathrm{Na}_{2} \mathrm{~S} \cdot 9 \mathrm{H}_{2} \mathrm{O}\right]$, and $\mathrm{SnF}_{2}$ ) also were analyzed to obtain their individual reductive capacities. The two FBSR samples, namely FBSR powder product and FBSR encapsulated in Geo-7 geopolymer binder followed by milling to a powder, also were tested for reductive capacity. For the Ceramicrete waste form, only S1 simulant with Tc was prepared. This Ceramicrete final waste form and all its dry ingredients $\left(\mathrm{SnCl}_{2}\right.$, fly ash [Type C], silver zeolite, $\mathrm{MgO}$, and $\left.\mathrm{KH}_{2} \mathrm{PO}_{4}\right)$ were also analyzed for reductive capacity.

\subsubsection{Particle-Size Analysis}

From a practical standpoint, the measurement of the reduction capacity of the starting dry materials and final waste forms is sensitive to their grain-size distribution, because particle size affects the rate at which the redox reactions occur in the test solutions. Therefore, all the dry materials and final waste forms were ground to less than a 1.0-mm size fraction and sieved before reductive capacity measurements. Particle-size characterization was done with a Mastersizer 2000 (Malvern Instruments, Inc., Southborough, Massachusetts) particle-size analyzer with a Hydro G wet dispersion accessory (equipped with a continuously variable and independent pump, stirrer, and ultrasound). The Mastersizer has a nominal size measurement range of $0.02 \mu \mathrm{m}$ to $2000 \mu \mathrm{m}$. The actual range is dependent on the accessory used as well as the properties of the solids being analyzed. When coupled with the Hydro G wet dispersion accessory, the nominal measuring range is $0.02 \mu \mathrm{m}$ to $2000 \mu \mathrm{m}$ (also dependent on material density). A performance check of the particle-size analyzer was performed with a particle-size standard traceable to the National Institute of Standards and Technology before any particle-size analysis was undertaken.

Small aliquots of the samples ( 0.2 to $1 \mathrm{~g}$ for dry powders) were diluted in degassed DIW in the Hydro $G$ dispersion unit with the pump and stirrer speeds set at $2500 \mathrm{rpm}$ and $1000 \mathrm{rpm}$, respectively, for 60 seconds before making the particle-size measurements. The total volume of the dispersion unit was $\sim 800 \mathrm{~mL}$. Appropriate dilutions were determined by the amount of light passing through the diluted 
material (obscuration), which was measured by the particle-size analyzer. Samples were analyzed on the same aliquot, initially without sonication and then during sonication $(100 \%, 20 \mathrm{~W})$ after an initial sonication period of 60 seconds. Duplicate samples were measured to confirm the mixing and subsampling technique to make sure that a representative particle-size distribution (PSD) of the material could be obtained.

\subsubsection{Measurement of Reductive Capacity}

The Ce(IV) method for measuring reductive capacity described by Kaplan et al. (2005) and Augus and Glasser (1985) was slightly modified. Generally, two different concentrations of $\mathrm{Ce}(\mathrm{IV})$ stock solution (10 mM and $40 \mathrm{mM}$ ) were prepared in $10 \% \mathrm{H}_{2} \mathrm{SO}_{4}$ solution with $\left(\mathrm{NH}_{4}\right)_{4} \mathrm{Ce}\left(\mathrm{SO}_{4}\right)_{4} \cdot 2 \mathrm{H}_{2} \mathrm{O}$ (SigmaAldrich). Based on results of preliminary tests, if the reductive capacity of the sample was higher than $100 \mathrm{meq} / \mathrm{kg}$, the $40-\mathrm{mM}$ Ce(IV) stock solution was used. For samples with less than $100 \mathrm{meq} / \mathrm{kg}$ reductive capacity, the $10-\mathrm{mM} \mathrm{Ce}(\mathrm{IV})$ stock solution was used. The procedure then used $0.5 \mathrm{~g}$ of secondary-waste forms or their individual dry ingredients mixed with $15 \mathrm{~mL}$ of the appropriate Ce(IV) stock solution in a $20-\mathrm{mL}$ vial. Immediately after mixing, the vial was tightly capped and placed on a platform shaker to mix completely at room temperature $\left(23 \pm 2^{\circ} \mathrm{C}\right)$ for 1 day. To determine the effect of mixing time, the reaction time also was varied between 1 hour and 7 days for certain samples (BFS and Cast Stone) to test for kinetic effects before measuring others. The solution was then filtered with a $0.45-\mu \mathrm{m}$ syringe filter (Whatman) after the target reaction time. After mixing, $0.05 \mathrm{~mL}$ of Ferroine solution $[0.025 \mathrm{M} \mathrm{Fe} \text { (o-phenanthroline })_{3}{ }^{2+}$, Fluka] was reacted with $5 \mathrm{~mL}$ of the filtrate, and the final solution was titrated using a Metrohm titrator that dispensed $20 \mathrm{mM}$ of ammonium ferrous sulfate prepared in $4 \% \mathrm{H}_{2} \mathrm{SO}_{4}$ solution until the solution developed and retained a lilac color. Before the measurement of reductive capacities, the concentration of ammonium ferrous sulfate solution was initially calibrated with standard Ce(IV) solution (1 M, Sigma-Aldrich). The reduction capacity was calculated by determining the difference between the oxidizing equivalent in Ce(IV) solution [meq $\mathrm{Ce}(\mathrm{IV})$ ] and the reducing equivalent of Fe(II) needed to neutralize excess Ce(IV) after reaction with the sample [meq $\mathrm{Fe}(\mathrm{II})]$. The final reductive capacity per gram was calculated by dividing the reductive capacity (meq) by the mass of sample (g).

The Cr(VI) reduction capacity procedure developed by Lee et al. (2003) also was modified. The $\mathrm{Cr}(\mathrm{VI})$ stock solutions (10 mM or $30 \mathrm{mM}$ ) were prepared with $\mathrm{K}_{2} \mathrm{CrO}_{4}$ (Sigma-Aldrich) in $10-\mathrm{mM}$ $\mathrm{NaHCO}_{3}$ solutions. The $\mathrm{Cr}(\mathrm{VI})$ solutions were then purged with $\mathrm{N}_{2}$ gas for 2 hours, and the stock solution then was introduced into an anoxic chamber (Coy Laboratory Products Inc.) containing a mixed gas atmosphere $\left(4 \% \mathrm{H}_{2}\right.$ and $96 \% \mathrm{~N}_{2}$ ). One-gram samples of the waste form or dry ingredients were placed in 20-mL quartz vials and then introduced into the anoxic chamber. The sample vial and $\mathrm{Cr}(\mathrm{VI})$ stock solution were kept in the anoxic chamber for 2 days to allow any air present in the containers to diffuse out before use. After the 2-day air-purging period, $10 \mathrm{~mL}$ of the $\mathrm{Cr}(\mathrm{VI})$ stock solution was mixed into the sample vial, and the $\mathrm{pH}$ of the suspension was adjusted to $7 \pm 1$ by adding a 1-M $\mathrm{NaOH}$ or 1- $\mathrm{M} \mathrm{H}_{2} \mathrm{SO}_{4}$ solution. The vials were tightly capped, removed from the chamber, placed on a platform shaker, and allowed to mix at room temperature $\left(23 \pm 2^{\circ} \mathrm{C}\right)$ for 7 days. To determine the effect of shaking time, some of the test vials with BFS and Cast Stone samples were allowed to shake for varying times, ranging from 1 hour to 7 days. After mixing, the vial was transferred back into the anoxic chamber, and $0.142 \mathrm{~g}$ of sodium sulfate was added. The vials were re-sealed, removed from the chamber, and shaken on the platform shaker for one more day; this was done to remove any potentially adsorbed $\operatorname{Cr}(\mathrm{VI})$ from the materials being tested so that the final $\mathrm{Cr}$ measurement in solution truly reflected all the $\mathrm{Cr}(\mathrm{VI})$ that 
was reduced and precipitated as $\mathrm{Cr}(\mathrm{III})$. The final supernatant was filtered with a $0.45-\mu \mathrm{m}$ syringe filter, and the concentration of $\mathrm{Cr}(\mathrm{VI})$ in the final filtrate was determined by a titration method. One $\mathrm{mL}$ of the filtrate was mixed with $1 \mathrm{~mL}$ of the $\mathrm{H}_{2} \mathrm{SO}_{4}$ solution (1:1 ratio), and $0.05 \mathrm{~mL}$ of Ferroine solution was added as used for Ce(IV) method. The solution was titrated with $20 \mathrm{mM}$ or $10 \mathrm{mM}$ ammonium ferrous sulfate solution, which was prepared in $4 \% \mathrm{H}_{2} \mathrm{SO}_{4}$ solution, until the solution became and remained lilac in color. The final reductive capacity was calculated by determining the difference between the oxidizing equivalents in $\mathrm{Cr}(\mathrm{VI})$ and the reducing equivalents of $\mathrm{Fe}(\mathrm{II})$ as described above.

\subsection{Results and Discussion}

The reduction capacities of the waste forms and their individual dry ingredients were measured by using either the redox pairs of $\mathrm{Ce}(\mathrm{IV}) / \mathrm{Ce}(\mathrm{III})$ or $\mathrm{Cr}(\mathrm{VI}) / \mathrm{Cr}$ (III) with back titration of excess oxidant with $\mathrm{Fe}(\mathrm{II}) / \mathrm{Fe}(\mathrm{III})$. In both the $\mathrm{Ce}(\mathrm{IV})$ and $\mathrm{Cr}(\mathrm{VI})$ methods, the test materials reach an end point of the following reactions for measurement:

$$
\begin{gathered}
\mathrm{Fe}(\mathrm{II})+\mathrm{Ce}(\mathrm{IV}) \rightarrow \mathrm{Fe}(\mathrm{III})+\mathrm{Ce}(\mathrm{III}) \\
3 \mathrm{Fe}(\mathrm{II})+\mathrm{Cr}(\mathrm{VI}) \rightarrow 3 \mathrm{Fe}(\mathrm{III})+\mathrm{Cr}(\mathrm{III})
\end{gathered}
$$

The amounts of $\mathrm{Ce}(\mathrm{IV})$ and $\mathrm{Cr}(\mathrm{VI})$ consumed by the solid materials are used to quantify the reductive capacities. Measuring the reductive capacity of porous materials involves diffusion of oxidants [Ce(IV) or $\mathrm{Cr}(\mathrm{VI})]$ into the pores present in the sample materials. In the Ce(IV) method, a strong acid (10\% sulfuric acid) is used to facilitate the dissolution of the solid materials so that the oxidant can easily contact the smaller dissolving particles or the reduced solutes generated from the dissolution process. However, in the $\mathrm{Cr}(\mathrm{VI})$ method, because $10-\mathrm{mM}$ carbonate buffer solution is used to adjust the $\mathrm{pH}$ to around 7.0, there is little solid dissolution, and the particle-size reduction and the contact between the $\mathrm{Cr}(\mathrm{VI})$ oxidant and reduced species within the solids may not be complete. In this case, the PSD of the porous material is also a sensitive factor in measuring reductive capacity.

The measured PSDs of the powdered waste forms and their individual ingredients used in the reductive capacity analyses are shown in Figure 4.1, Figure 4.2, and Figure 4.3. The PSD of fly ash (Type F) was a little bit wider than those of the cement and BFS samples, which both had a narrow range centered around $20 \mu \mathrm{m}$ (Figure 4.1) because the cement and BFS materials were ground and milled before use. The Cast Stone samples showed a bimodal PSD around $40 \mu \mathrm{m}$ and $400 \mu \mathrm{m}$, except for the Cast Stone prepared with S1-2M simulant (Figure 4.1). PSDs of the DuraLith dry ingredients and the DuraLith waste form prepared with the four different simulants are shown in Figure 4.2. Metakaolinite, fumed silica, and BFS have narrow PSDs with an average particle size less than $20 \mu \mathrm{m}$ (Figure 4.2). River sand has a wide PSD with a bimodal distribution between 60 and $1100 \mu \mathrm{m}$. Silver zeolite has a narrow PSD and larger average particle size $(257 \mu \mathrm{m})$. However, because zeolite is a highly porous material with very small internal pores, the diffusion of oxidants $\mathrm{Ce}(\mathrm{IV})$ or $\mathrm{Cr}(\mathrm{VI})$ inside these pores could be limited. The DuraLith sample (S1-2M) also shows a narrow and unimodal PSD. The PSDs of DuraLith samples made with the four simulants were similar to each other. The PSDs of the two FBSR samples and the dry ingredients used to prepare Ceramicrete are shown in Figure 4.3. The two FBSR samples show very similar PSD results with an average size between $50 \mu \mathrm{m}$ and $70 \mu \mathrm{m}$. Type-C fly ash 
showed a wider PSD range than MnO, but the PSD of Type-C fly ash, which ranged from $0.2 \mu \mathrm{m}$ to $100 \mu \mathrm{m}$ (Figure 4.3), is narrower than that of Type-F fly ash, which ranged from $0.1 \mu \mathrm{m}$ and $1000 \mu \mathrm{m}$ (Figure 4.1).
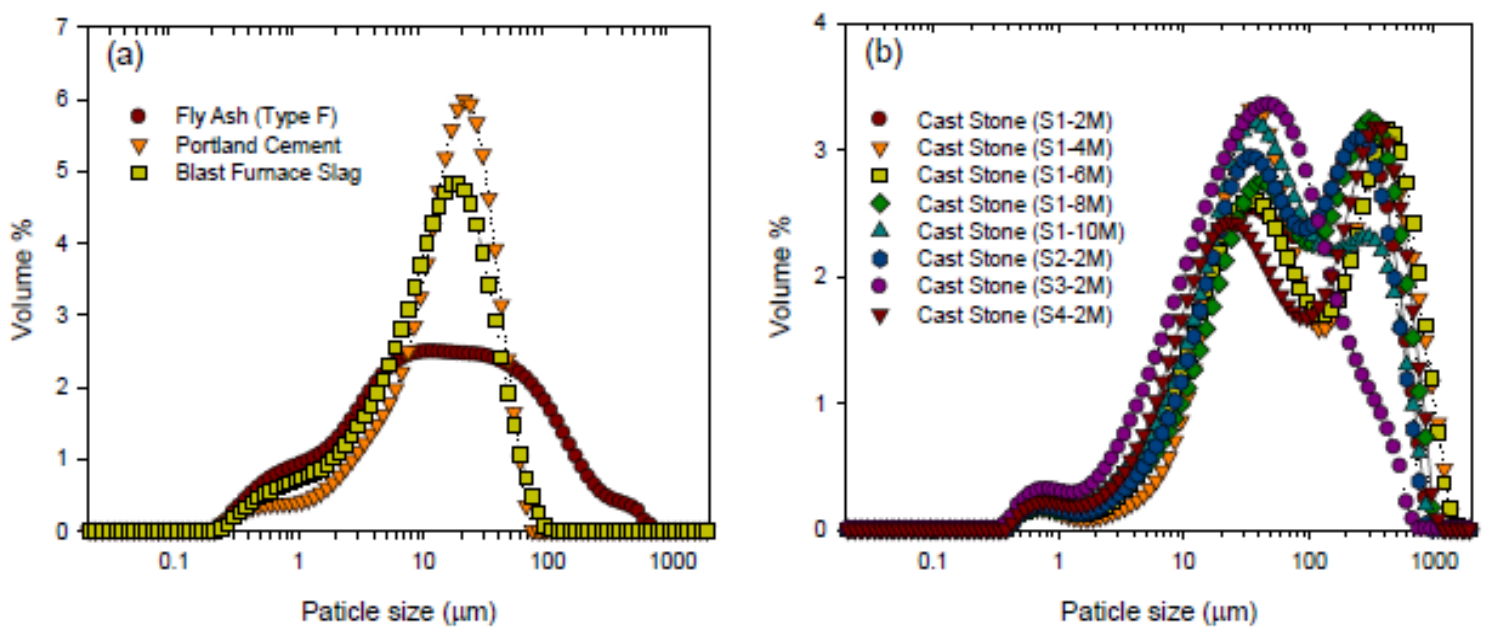

Figure 4.1. PSDs of (a) Dry Ingredients Used for Making Cast Stone and (b) Final Cast Stone Samples Prepared with Different Simulants
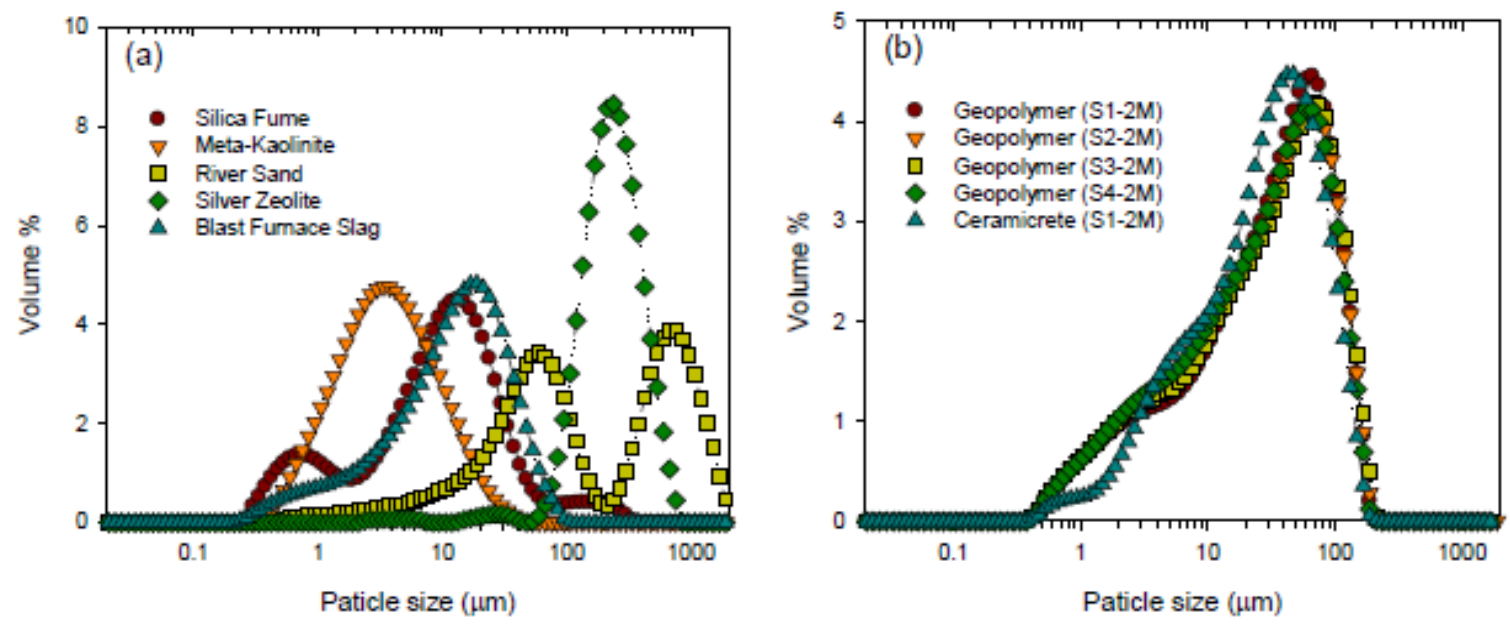

Figure 4.2. PSDs of (a) Dry Ingredients of DuraLith and (b) Geopolymers Prepared with Different Simulants 

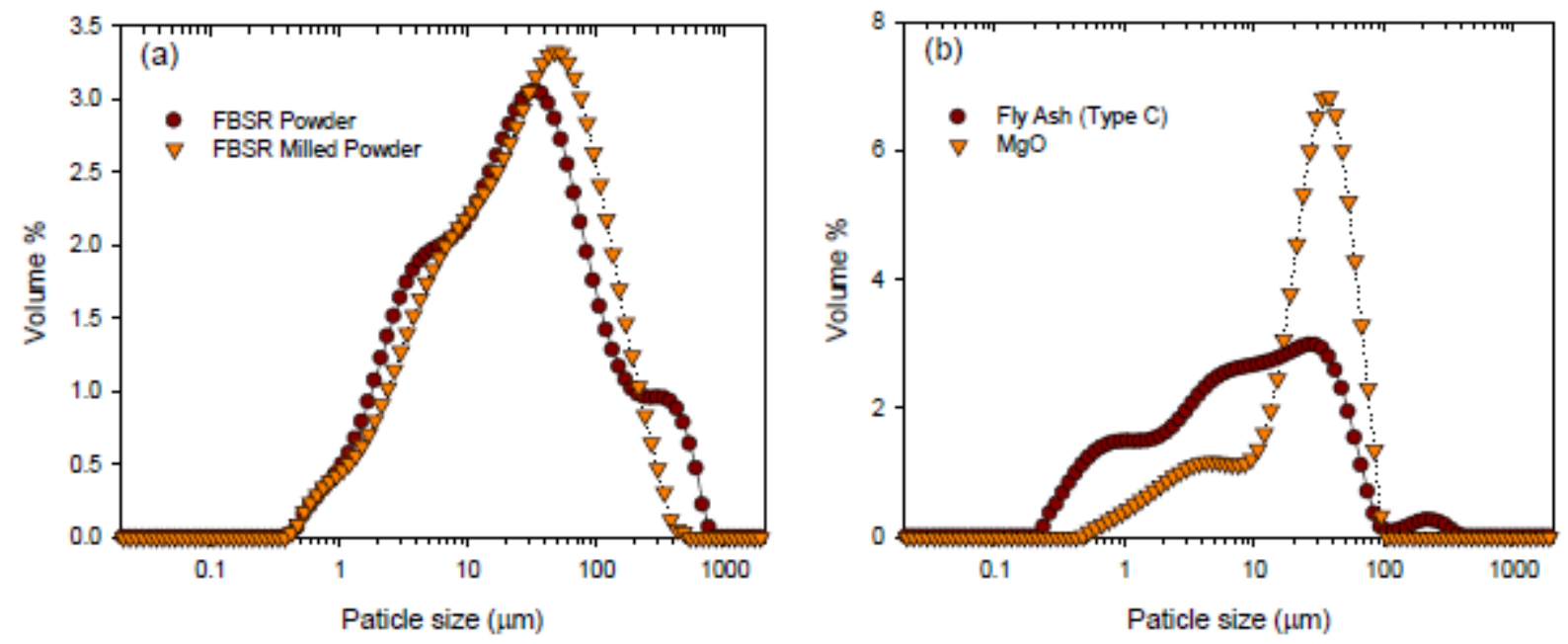

Figure 4.3. PSDs of (a) FBSR Waste Forms and (b) Dry Ingredients Used for Making Ceramicrete

The effects of contact time between the oxidizing reagent and solids were evaluated for BFS and Cast Stone samples using both the Ce(IV) and Cr(VI) methods to determine the optimal reaction time for measuring reductive capacity, and the results are given in Figure 4.4. Kaplan et al. (2005) and Augus and Glasser (1985) used a 1-hour reaction time to measure the reductive capacity of slag using the Ce(IV) method. As shown in Figure 4.4, it takes at least 1 or 2 days to reach reductive capacity equilibrium in our tests for the BFS and Cast Stone. Roberts and Kaplan (2009) also mentioned that an hour of mixing the Ce(IV) solution with solid samples is sufficient time to allow Ce(IV) to diffuse completely using the Augus and Glasser (1985) method. However, according to our results, at least a 1- or 2-day reaction time is needed to measure complete reductive capacity of all the solid materials using the Ce(IV) method. Using the $\mathrm{Cr}(\mathrm{VI})$ method, it took at least 4 days for the measured reductive capacity values to reach equilibrium. Our results are consistent with previous results reported by Lee and Batchelor (2003). They reported that at least 4 days were needed to reach equilibrium in the measurement of reductive capacity for iron oxides using the $\mathrm{Cr}(\mathrm{VI})$ method. Because the $\mathrm{Ce}(\mathrm{IV})$ method uses $10 \%$ sulfuric acid, and the $\mathrm{pH}$ in Ce(IV) stock solution is between 0 and 1 , the Ce(IV) method measures almost all the reductive capacity of the solid sample that can be dissolved within a relatively short reaction period (i.e., 1 to 2 days). However, because the $\mathrm{Cr}(\mathrm{VI})$ method uses $10-\mathrm{mM} \mathrm{NaHCO}_{3}$ solution, and the $\mathrm{pH}$ is adjusted to around 7.0, the $\mathrm{Cr}(\mathrm{VI})$ method measures only the surface reductive capacity of the sample, and it requires more than 4 days to reach equilibrium or to attain a constant value for the reductive capacity. These kinetic effects and the limited accessibility of internal reductants in solid particles with the oxidizing reagent lead to differences between the reductive capacities measured using the two methods. In secondary waste forms, because Tc may be uniformly distributed and can react with reductive materials present in each waste form following the reaction, $\mathrm{Tc}(\mathrm{VII}) \mathrm{O}_{4}{ }^{-}+3 \mathrm{e}^{-}+4 \mathrm{H}^{+} \rightarrow \mathrm{Tc}(\mathrm{IV}) \mathrm{O}_{2} \cdot 2 \mathrm{H}_{2} \mathrm{O}$, the reductive capacity measured by the $\mathrm{Ce}(\mathrm{IV})$ method is expected to be more useful for predicting the longterm leaching of Tc from secondary waste forms. 


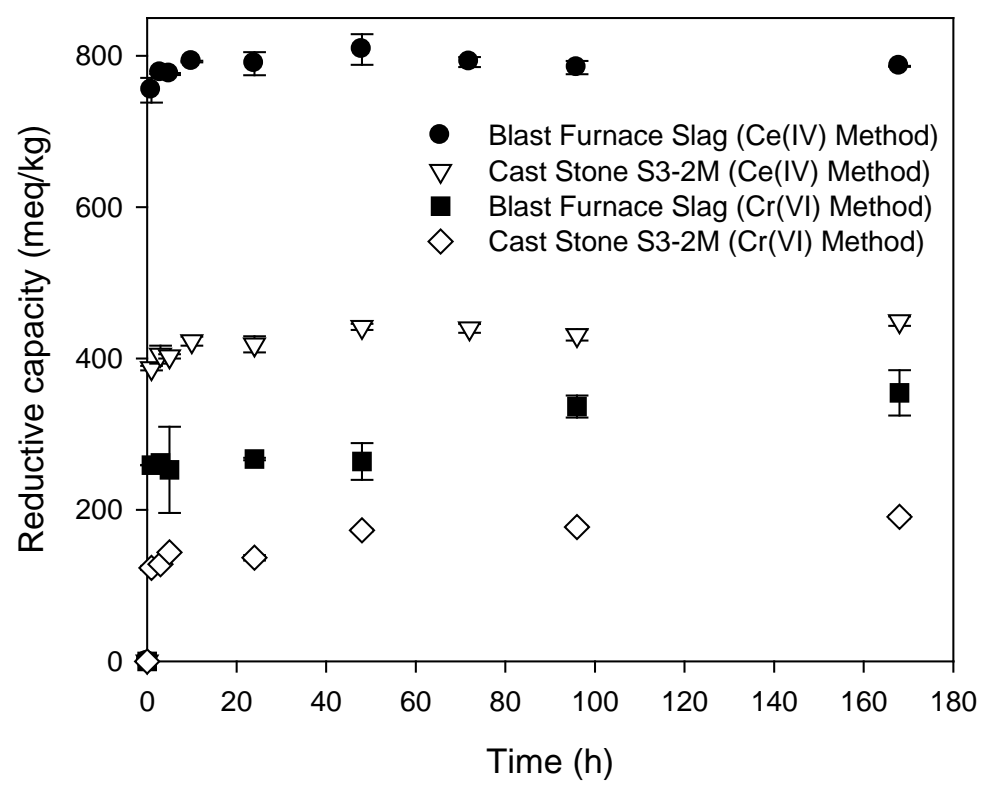

Figure 4.4. Effect of Reaction Time for the Measurement of Reductive Capacity

The reductive capacity of different secondary waste forms prepared without Tc and their dry ingredients was measured with both methods, and the results are given in Table 4.1. Different waste forms with Tc-spiked simulants were also used to test the reductive capacity, and the results are shown in Table 4.2. The dry blend ingredients with the largest reductive capacity are BFS, tin chloride, tin fluoride, and sodium sulfide. The reductive capacity of our particular BFS was $799 \mathrm{meq} / \mathrm{kg}$ when the Ce(IV) method was used. This value is slightly lower than the reported value of $820 \mathrm{meq} / \mathrm{kg}$ (Lukens et al. 2005; Roberts and Kaplan 2009) for the BFS used at Savannah River to produce Saltstone. The reductive capacity of BFS measured with the $\mathrm{Cr}(\mathrm{VI})$ method was $346 \mathrm{meq} / \mathrm{kg}$, which is noticeably lower than the $799 \mathrm{meq} / \mathrm{kg}$ value determined with the Ce(IV) method. However, the different values from these two methods are readily explained by the kinetic effects of contact time and the effects of different solid dissolution rates at different $\mathrm{pH}$ conditions. The BFS contains both ferrous ion and sulfides that are strong reductants and precipitating agents for Tc. Both Fe(II) and S(II) are reductants once they dissolve, and they can effectively reduce contaminants such as ${ }^{99}$ Tc that may be present in the pore water within the waste form to form more stable species such as Tc(IV) in the secondary waste form. However, only ferrous-iron oxides in the BFS can be measured with the Cr(VI) method (Lee and Batchelor 2003; Lukens et al. 2005), while all reducing materials, including sulfur compounds and iron oxides in the BFS, can be measured when the Ce(IV) method is used.

Both tin fluoride and tin chloride, used for making DuraLith and Ceramicrete waste forms, respectively, also have very large reductive capacities. The measured reductive capacity (8700 to $12,000 \mathrm{meq} / \mathrm{kg}$ ) for tin compounds using the two methods was similar to their theoretically calculated reductive capacities, 12,764 and 10,549 meq/kg for tin chloride and tin fluoride, respectively. Tin chloride, an ingredient of Ceramicrete, and tin fluoride, an ingredient of DuraLith, are strong reducing agents that have a standard reduction potential of $\mathrm{E}_{\mathrm{o}}[\mathrm{Sn}(\mathrm{IV}) / \mathrm{Sn}(\mathrm{II})]=+0.15 \mathrm{~V}$. The tin (Sn) components can oxidize to $\mathrm{Sn}(\mathrm{IV})$ with oxygen contact or redox-sensitive contaminants. When the alkaline $\mathrm{pH}$ condition is maintained and the $\mathrm{Sn}(\mathrm{II})$ solution is added, $\mathrm{Sn}(\mathrm{II})$ oxide $\left(\mathrm{SnO} \cdot \mathrm{H}_{2} \mathrm{O}\right)$ precipitates and then dissolves to form stannite salt $\left[\mathrm{NaSn}(\mathrm{OH})_{3}\right]$ with excess base. Most of the secondary waste forms 
considered in this project use large amounts of caustic ingredients so that Sn(II) solutions can convert to the stannite salt, which serves as a continuous source of reducing agent in the final solid waste form.

Table 4.1. Reductive Capacities of Secondary Waste Forms without Tc and Their Ingredients

\begin{tabular}{|c|c|c|c|}
\hline Materials & Simulants & $\begin{array}{l}\text { Reductive Capacity } \\
\text { (Ce(IV) method) } \\
\text { (meq/kg) }\end{array}$ & $\begin{array}{l}\text { Reductive Capacity } \\
\text { (Cr(VI) method) } \\
\text { (meq/kg) }\end{array}$ \\
\hline \multicolumn{4}{|l|}{ Cast Stone Ingredients } \\
\hline Blast Furnace Slag & & $798.7 \pm 14.2$ & $345.6 \pm 21.9$ \\
\hline Fly Ash (Type F) & & $77.3 \pm 1.3$ & $2.0 \pm 0.4$ \\
\hline Portland Cement & & $79.0 \pm 33.0$ & $35.2 \pm 2.9$ \\
\hline \multicolumn{4}{|l|}{ Cast Stone Variants } \\
\hline Cast Stone S1-2M & S1 (2-M Na) & $398.7 \pm 3.2$ & $185.4 \pm 7.6$ \\
\hline Cast Stone S1-4M & S1 (4-M Na) & $442.0 \pm 3.4$ & $181.9 \pm 8.2$ \\
\hline Cast Stone S1-6M & S1 (6-M Na) & $485.3 \pm 5.7$ & $192.8 \pm 1.7$ \\
\hline Cast Stone S1-8M & S1 (8-M Na) & $540.0 \pm 1.9$ & $189.1 \pm 1.4$ \\
\hline Cast Stone S1-10M & S1 (10-M Na) & $595.6 \pm 2.0$ & $179.0 \pm 2.8$ \\
\hline Cast Stone S2-2M & S2 (2-M Na) & $401.7 \pm 4.6$ & $184.4 \pm 3.9$ \\
\hline Cast Stone S3-2M & S3 (2-M Na) & $449.6 \pm 1.4$ & $199.8 \pm 7.3$ \\
\hline Cast Stone S4-2M & S4 (2-M Na) & $461.1 \pm 12.6$ & $212.4 \pm 2.0$ \\
\hline \multicolumn{4}{|l|}{ DuraLith Ingredients } \\
\hline Silica Fume & & $300.6 \pm 6.7$ & $22.5 \pm 2.6$ \\
\hline Meta-Kaolinite & & $0.4 \pm 0.0$ & $0.3 \pm 0.2$ \\
\hline River Sand & & $1.6 \pm 1.2$ & $1.0 \pm 0.8$ \\
\hline Silver Zeolite & & $47.7 \pm 6.2$ & $1,129.0 \pm 52.4$ \\
\hline Blast Furnace Slag & & $798.7 \pm 14.2$ & $435.9 \pm 8.1$ \\
\hline Sodium Sulfide Hydrate & & $8,210.8 \pm 287.9$ & $31,049.9 \pm 1158$ \\
\hline Tin Fluoride & & $12,194.3 \pm 120.3$ & $8,652.1 \pm 715.5$ \\
\hline \multicolumn{4}{|l|}{ DuraLith Geopolymer } \\
\hline DuraLith S1-2M & $\mathrm{S} 1(2 \mathrm{M} \mathrm{Na})$ & $456.9 \pm 3.1$ & $128.2 \pm 2.4$ \\
\hline DuraLith S2-2M & $\mathrm{S} 2(2 \mathrm{M} \mathrm{Na})$ & $458.2 \pm 3.1$ & $114.3 \pm 0.7$ \\
\hline DuraLith S3-2M & S3 (2M Na) & $464.9 \pm 2.9$ & $134.4 \pm 2.5$ \\
\hline DuraLith S4-2M & S4 (2M Na) & $411.7 \pm 2.6$ & $115.6 \pm 0.6$ \\
\hline \multicolumn{4}{|l|}{ Ceramicrete Ingredients } \\
\hline Tin Chloride & & $10,038.8 \pm 98.3$ & $11,315.2 \pm 613.2$ \\
\hline Fly ash (Type C) & & $84.1 \pm 4.1$ & $27.0 \pm 1.7$ \\
\hline Silver Zeolite & & $47.7 \pm 6.2$ & $1,129.0 \pm 52.4$ \\
\hline $\mathrm{MgO}$ & & $281.6 \pm 0.0$ & $199.5 \pm 12.2$ \\
\hline $\mathrm{KH}_{2} \mathrm{PO}_{4}$ & & $18.1 \pm 0.7$ & $10.6 \pm 0.7$ \\
\hline \multicolumn{4}{|l|}{ FBSR } \\
\hline FBSR Powder & & $2,823.2 \pm 45.0$ & $21.7 \pm 2.5$ \\
\hline FBSR Milled Powder & & $914.9 \pm 8.1$ & $16.4 \pm 5.4$ \\
\hline \multicolumn{4}{|l|}{ Simulants } \\
\hline Simulant 1 & $\mathrm{~S} 1$ (2M Na) & $366.4 \pm 19.8$ & $218.2 \pm 6.0$ \\
\hline Simulant 2 & $\mathrm{~S} 2(2 \mathrm{M} \mathrm{Na})$ & $450.0 \pm 1.2$ & $229.5 \pm 3.3$ \\
\hline Simulant 3 & S3 (2M Na) & $441.9 \pm 8.1$ & $325.6 \pm 13.4$ \\
\hline Simulant 4 & S4 (2M Na) & $281.1 \pm 2.3$ & $289.8 \pm 4.3$ \\
\hline
\end{tabular}


When dissolved in water, sodium sulfide, an ingredient of DuraLith, produces HS, which promotes the formation of many metal sulfide precipitates. Liu et al. $(2008,2009)$ reported that the reaction between sulfide and $\mathrm{TcO}_{4}{ }^{-}$in $\mathrm{pH} 9$ aqueous solution under anaerobic conditions produces $\mathrm{Tc}_{2} \mathrm{~S}_{7}$ according to the reaction $2 \mathrm{TcO}_{4}{ }^{-}+7 \mathrm{HS}^{-}+\mathrm{H}_{2} \mathrm{O} \rightarrow \mathrm{Tc}_{2} \mathrm{~S}_{7}+9 \mathrm{OH}^{-}$. Note that the sulfur in this compound is a mix of polysulfides such that each sulfur is not -2 charged. Also, $\mathrm{Na}_{2} \mathrm{~S}$ can oxidize to $\mathrm{Na}_{2} \mathrm{~S}_{2} \mathrm{O}_{3}$, which can react with $\mathrm{TcO}_{4}{ }^{-}$and reduce the $\mathrm{Tc}$ (VII) to form $\mathrm{TcO}_{2}$, such as $2 \mathrm{NaTcO}_{4}+3 \mathrm{Na}_{2} \mathrm{SO}_{3}+5 \mathrm{H}_{2} \mathrm{O} \rightarrow 2 \mathrm{TcO}_{2} \cdot 2 \mathrm{H}_{2} \mathrm{O}+$ $3 \mathrm{Na}_{2} \mathrm{SO}_{4}+2 \mathrm{NaOH}$ (Lukens et al. 2005). Therefore, $\mathrm{Na}_{2} \mathrm{~S}$ can be used as an oxygen scavenger and can be used to make an anoxic condition in the secondary waste form to improve Tc retention as reduced Tc(IV) forms. The measured reductive capacities of $\mathrm{Na}_{2} \mathrm{~S}$ varied significantly from $8200 \mathrm{meq} / \mathrm{kg}$ to $31,000 \mathrm{meq} / \mathrm{kg}$, depending on the method used. Higher reductive capacities found in $\mathrm{Na}_{2} \mathrm{~S}$ and $\mathrm{SnF}_{2} / \mathrm{SnCl}_{2}$ are also consistent with Tc speciation results reported in Section 3, which shows higher percentages of reduced Tc(IV) species in DuraLith and Ceramicrete waste forms, even though their curing (aging) times after preparation were relatively short compared to that of Cast Stone (Table 3.2). Even though the BFS used to make Cast Stone also showed significant reductive capacity, the magnitude of the reductive capacity of the BFS material is not as large as the reductive capacity for $\mathrm{Na}_{2} \mathrm{~S}$ and $\mathrm{SnF}_{2} / \mathrm{SnCl}_{2}$ on a mass basis.

Table 4.2. Reductive Capacities of ${ }^{99}$ Tc Loaded Secondary Waste Forms

\begin{tabular}{llcc}
\hline \multicolumn{1}{c}{ Materials } & Simulants & $\begin{array}{c}\text { Reductive Capacity } \\
\text { (Ce(IV) method) } \\
\text { (meq/kg) }\end{array}$ & $\begin{array}{c}\text { Reductive Capacity } \\
\text { (Cr(VI) method) } \\
\text { (meq/kg) }\end{array}$ \\
\hline${ }^{99}$ Tc-Loaded Cast Stone & & & $212.5 \pm 7.7$ \\
\hline${ }^{99}$ Tc-Loaded Cast Stone S1-2M & S1 (2-M Na) & $379.4 \pm 5.6$ & $209.6 \pm 6.5$ \\
${ }^{99}$ Tc-Loaded Cast Stone S1-4M & S1 (4-M Na) & $445.3 \pm 13.0$ & $215.7 \pm 13.1$ \\
${ }^{99}$ Tc-Loaded Cast Stone S1-6M & S1 (6-M Na) & $495.6 \pm 2.0$ & $219.3 \pm 9.9$ \\
${ }^{99}$ Tc-Loaded Cast Stone S1-8M & S1 (8-M Na) & $556.7 \pm 3.2$ & $205.0 \pm 14.8$ \\
${ }^{99}$ Tc-Loaded Cast Stone S1-10M & S1 (10-M Na) & $528.3 \pm 2.6$ & $203.7 \pm 25.1$ \\
${ }^{99}$ Tc-Loaded Cast Stone S2-2M & S2 (2-M Na) & $402.5 \pm 3.3$ & $211.1 \pm 13.6$ \\
${ }^{99}$ Tc-Loaded Cast Stone S3-2M & S3 (2-M Na) & $500.4 \pm 5.2$ & $116.9 \pm 12.9$ \\
${ }^{99}$ Tc-Loaded Cast Stone S4-2M & S4 (2-M Na) & $423.7 \pm 8.6$ & $105.1 \pm 7.6$ \\
\hline${ }^{99}$ Tc-Loaded DuraLith & & & $131.2 \pm 5.7$ \\
\hline${ }^{99}$ Tc-Loaded DuraLith S1-2M & S1 (2-M Na) & $581.9 \pm 10.5$ & $126.5 \pm 5.2$ \\
${ }^{99}$ Tc-Loaded DuraLith S2-2M & S2 (2-M Na) & $536.6 \pm 8.9$ & $167.6 \pm 2.8$ \\
${ }^{99}$ Tc-Loaded DuraLith S3-2M & S3 (2-M Na) & $561.9 \pm 17.9$ & \\
${ }^{99}$ Tc-Loaded DuraLith S4-2M & S4 (2-M Na) & $540.0 \pm 18.1$ & \\
\hline${ }^{99}$ Tc-Loaded Ceramicrete & & & \\
\hline${ }^{99}$ Tc-Loaded Ceramicrete S1-2M & S1 (2-M Na) & $943.5 \pm 2.4$ & \\
\hline
\end{tabular}

Other dry ingredients had reductive capacities less than $100 \mathrm{meq} / \mathrm{kg}$, except silver zeolite [i.e., $1100 \mathrm{meq} / \mathrm{kg}$ using the $\mathrm{Cr}(\mathrm{VI})$ method] and fumed silica [i.e., $300 \mathrm{meq} / \mathrm{kg}$ using the Ce(IV) method]. However, the silica fume (or fumed silica) used in our work has a minor fraction of elemental silicon that can produce $\mathrm{H}_{2}(\mathrm{~g})$ when it dissolves. Upon dissolution, it forms silicate ion at the low $\mathrm{pH}$ value used in the $\mathrm{Ce}(\mathrm{IV})$ method, and the $\mathrm{H}_{2}$ (g) oxidizes to water and consumes some of the oxidant, $\mathrm{Ce}(\mathrm{IV})$. The low reductive capacity for fumed silica, $23 \mathrm{meq} / \mathrm{kg}$ measured with the $\mathrm{Cr}(\mathrm{VI})$ method, occurs because the 
$\mathrm{Cr}(\mathrm{VI})$ method is performed at a $\mathrm{pH}$ of 7, and very little silicon is dissolved to generate $\mathrm{H}_{2}(\mathrm{~g})$. The measured reductive capacity values usually showed higher values for the Ce(IV) method than for the $\mathrm{Cr}(\mathrm{VI})$ method, except for three samples, sodium sulfide, silver zeolite, and tin chloride. The reason for the higher measured reductive capacity for the $\mathrm{Cr}(\mathrm{VI})$ method is not clearly understood. However, some interaction or chemical reaction between $\mathrm{Ag}$ and $\mathrm{Cr}(\mathrm{VI})$ may be possible to form very stable silver chromate $\left(\mathrm{Ag}_{2} \mathrm{CrO}_{4}\right.$ with very low solubility of $1.2 \times 10^{-12} \mathrm{~mol} / \mathrm{mL}$ in $\left.\mathrm{H}_{2} \mathrm{O}\right)$, which removes all the excess unused $\mathrm{Cr}(\mathrm{VI})$, thus leading to inflated reductive capacity values upon back titration.

The measured reductive capacity values of the four different simulants were similar, ranging from 220 to $450 \mathrm{meq} / \mathrm{kg}$. Simulant 4 (S4) does have a slightly lower reductive capacity from the Ce(IV) method, which agrees well with the Eh results for different simulants shown in Table 3.1. The highest Eh value was found in the S4 simulant, which is indicative of a lower reductive capacity.

The results of measured reductive capacities for Cast Stone samples made with different simulants with or without Tc spikes are shown in Figure 4.5. When $\mathrm{Cr}(\mathrm{VI})$ was used as an oxidant, the reductive capacity of the Cast Stone without Tc was first measured in both oxic and anoxic environments, and the results were very similar regardless of simulant types used or the oxygen conditions. Effects of oxygen (an additional but uncontrolled oxidizing reagent) during the measurement of the reductive capacity using the $\mathrm{Cr}(\mathrm{VI})$ method were negligible. Therefore, Cast Stone samples with Tc-spiked simulants were measured without using the anoxic chamber. The results showed slightly higher values than those of Cast Stone samples prepared without Tc and measured in either oxic (no chamber used) or anoxic (chamber was used) environments. However, the differences in reductive capacity values among the three Cast Stone samples are within their error ranges, indicating that the reductive capacities can be considered to be the same. The measured reductive capacities of Cast Stone samples from the Ce(IV) method also showed similar results, irrespective of different simulant types used (S1, S2, S3, and S4). However, higher reductive capacity values were found as the concentration of S1 (from S1-2M to S1-10M) was used to prepare the Cast Stone samples. The increasing reductive capacity measured in Cast Stone containing the increasing simulant concentrations might be related to the reactions that occur in the Cast Stone as it hydrates and transforms from slurry to a hardened paste. The progressively higher salt and alkaline concentrations in the S1 simulant solution as it was concentrated from 2-M to $10-\mathrm{M} \mathrm{Na}$ normalized may dissolve more reducing materials present in Cast Stone dry ingredients, especially the BFS. The higher amount of dissolved reducing agents in the evolving Cast Stone pore water is then readily titrated by the acidic Ce(IV) oxidizing reagents, thus leading to the larger reduction capacity value. A similar increase in reductive capacity in the Cast Stone solids made with varying concentrations of the S1 simulant was not observed when using the $\mathrm{Cr}(\mathrm{VI})$ method. This perhaps is caused by the fact that the $\mathrm{Cr}(\mathrm{VI})$ method is performed at $\mathrm{pH}$ values near 7.0, and fewer of the dry ingredients with reducing capacity are dissolved or reacted during the hydration process.

The measured reductive capacities of Cast Stone samples prepared without Tc were compared with the reductive capacities estimated by summing values of the independently measured reductive capacity for each dry ingredient multiplied by its weight percent in the Cast Stone formulation. The comparison is shown in Figure 4.6, where a higher reductive capacity is measured in the cured Cast Stone solids than is calculated from the sum of the reductive capacities of the individual dry ingredients, which indicates that increase in the reductive capacity originated from the curing (or aging) process in Cast Stone. The timedependent nature of the Cast Stone reductive capacity could be the cause of the varying contributions of $\mathrm{Tc}(\mathrm{IV}) / \mathrm{Tc}(\mathrm{VII})$ species as a function of different aging times observed and discussed in the previous Tc speciation section (Table 3.2). 


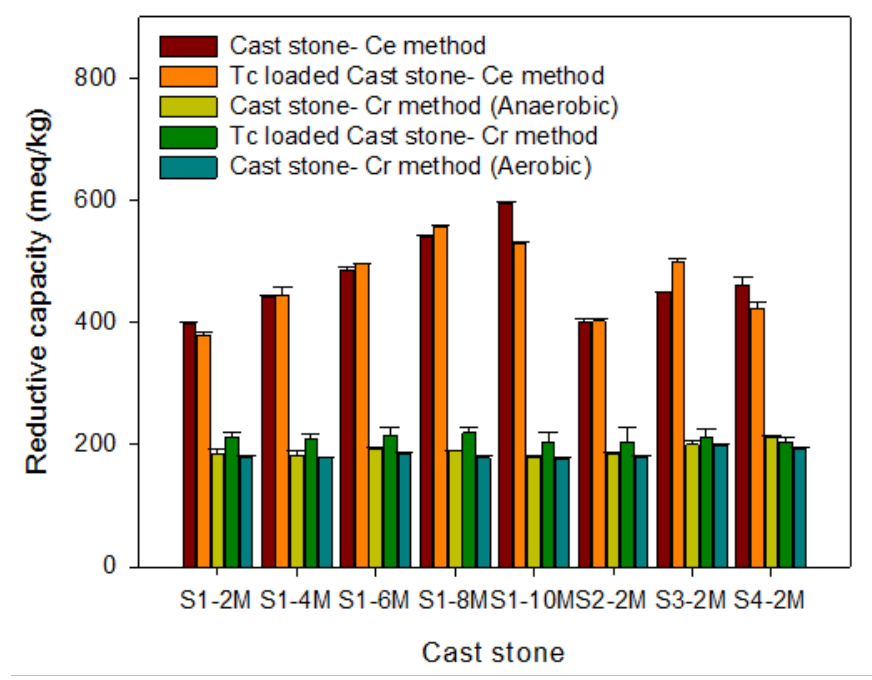

Figure 4.5. Reductive Capacity of Cast Stone Samples Without Tc and Tc-Loaded Cast Stone Samples Using the $\mathrm{Ce}(\mathrm{IV})$ and $\mathrm{Cr}(\mathrm{VI})$ Methods. For the $\mathrm{Cr}(\mathrm{VI})$ method, the reductive capacity was measured under both anoxic and oxic environments for Cast Stone samples prepared without Tc. Other reductive capacities were conducted only in an aerobic environment.

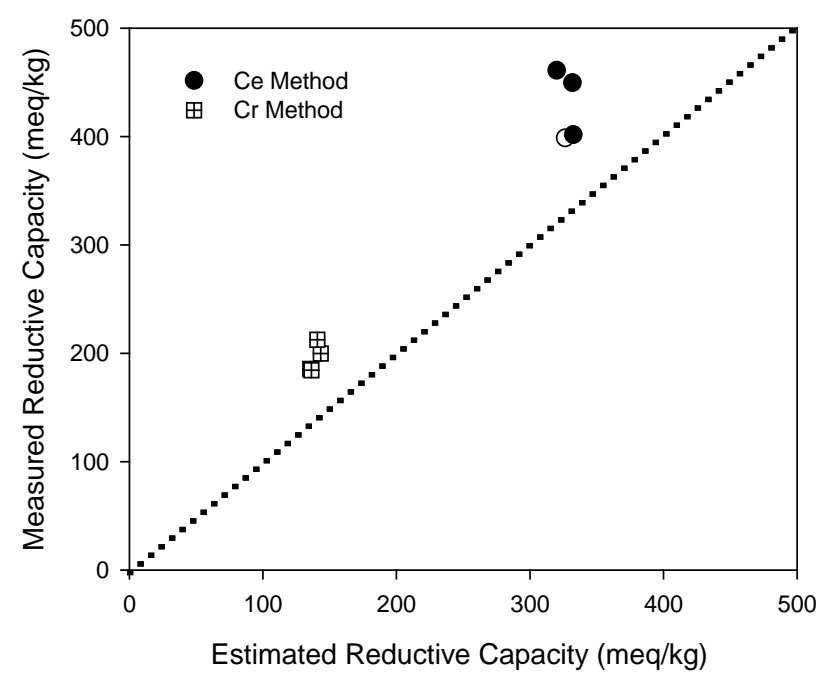

Figure 4.6. Relationship Between Estimated and Measured Cast Stone Reductive Capacities. The measured values are the symbols, and the dotted line indicates a 1:1 correlation between measured and calculated reductive capacity values.

The two FBSR solids also showed high reductive capacities when measured with the Ce(IV) method (900 meq $/ \mathrm{kg}$ to $2800 \mathrm{meq} / \mathrm{kg}$ ). The reductive capacities of FBSR powder and FBSR milled powder (prepared as monolith with Geo-7 binder) by the Ce(IV) method were much higher than the reductive capacities measured by the $\mathrm{Cr}(\mathrm{VI})$ method (16 meq/kg to $22 \mathrm{meq} / \mathrm{kg}$ ), most probably because of the nature of the FBSR compounds and the different $\mathrm{pH}$ conditions for the two methods. The FBSR process involves slowly adding and atomizing liquid waste in a bed of particles in an upward-flowing 
reducing-gas mixture that destroys nitrate and nitrites present in the waste feed under the highly reducing environment (Olson et al. 2004). Cabonaceous reductants, such as sugar and CO, are introduced into the reducing-gas reactor as a reformer to create the reducing conditions. Therefore, reduced materials, such as coal, sulfide-containing secondary minerals, etc., are present in the FBSR product. Major mineral phases in the FBSR product are nosean, nepheline, sodalite, and corundum (Jantzen 2003). Some of these minerals can accommodate sulfate or sulfide, depending on the redox environment in the steam reforming process (Jantzen 2003). Organic substances in the FBSR product generate low reductive capacity values when measured with the $\mathrm{Cr}(\mathrm{VI})$ method because the dissolution rate of these organics is very slow in the neutral $\mathrm{pH}$ conditions used in the $\mathrm{Cr}(\mathrm{VI})$ method (Lee and Batchelor 2003). With 10\% sulfuric acid used in the $\mathrm{Ce}(\mathrm{IV})$ method, most of the organic and inorganic materials are completely dissolved. Also, the FBSR major minerals are feldspathoids and zeolite minerals, which have highly porous cage structures. At neutral $\mathrm{pH}$ conditions, these minerals are considered to be stable so that there is little reaction when the $\mathrm{Cr}(\mathrm{VI})$ method is used to measure their reductive capacity. In the Ce(IV) method performed at very low $\mathrm{pH}$ levels, these zeolite minerals were partially dissolved and could be inflating the measured reductive capacities.

DuraLith and Ceramicrete waste form samples with Tc also showed higher reductive capacities than the Cast Stone samples because of the higher masses of highly reactive reductants used to prepare these waste forms.

\subsection{Conclusions}

The reductive capacities of dry ingredients used to prepare each waste form and the four waste forms - Cast Stone, DuraLith, FBSR, and Ceramicrete-prepared using different liquid waste simulants with or without Tc were measured with two methods that use different oxidants [i.e., Ce(IV) and $\mathrm{Cr}(\mathrm{VI})$ ]. To minimize particle-size effects, all the solids tested were crushed to a less-than 1-mm size fraction. The measured reductive capacity values were generally larger when using the Ce(IV) method compared to those obtained when the $\mathrm{Cr}(\mathrm{VI})$ method was used. The difference is probably caused by the different $\mathrm{pH}$ conditions used in these two methods. The materials with the largest measured reductive capacities are $\mathrm{BFS}$, sodium sulfide, and $\mathrm{SnF}_{2} / \mathrm{SnCl}_{2}$ used as starting ingredients to make various waste forms. Sodium sulfide and $\mathrm{SnF}_{2} / \mathrm{SnCl}_{2}$ exhibit significantly larger reductive capacities compared to all other ingredients. Although the BFS exhibits appreciable reductive capacity, it requires greater amounts of time to fully react (dissolve) and release all its electrons.

The reductive capacities for the four different simulants at 2-M Na concentrations were similar, but again, the values differed depending on method used. The simulant S4 did exhibit a slightly lower reductive capacity value compared to the other three simulants (S1, S2, and S3). However, the minor differences in reductive capacity for the various simulants did not contribute any significant differences in the overall reductive capacity measured in the final waste forms because the volume or weight percent of the simulant was not high $(<10 \mathrm{wt} \%)$ in the final waste forms. The overall reductive capacities of the different waste forms were also not influenced by whether the simulant did or did not contain Tc. For the Cast Stone waste forms prepared with varying concentrations of simulant S1, there was a trend in the measured reductive capacities as measured with the Ce(IV) method. When the Ce(IV) method was used, the reductive capacity increased as the concentration of the S1 simulant was increased from 2-M to 10-M Na. The increase in reductive capacity with concentration of S1 simulant was attributed to a 
synergistic reaction promoted by the low $\mathrm{pH}$ used in the Ce(IV) method, with the high salt content of the simulants promoting more dissolution of the slowly reacting BFS.

The FBSR powder sample exhibited a larger reductive capacity than the FBSR milled powder material prepared from the FBSR product encapsulated in Geo-7 binder. This finding suggests that the Geo-7 binder itself does not have significant reductive properties and simply diluted the reductive properties of the FBSR product, or alternatively the Geo-7 coating over the FBSR grains protected the grains long enough in the acidic Ce(IV) slurry that the total reductive capacity of the FBSR product was not measured.

The DuraLith and Ceramicrete waste forms showed significantly larger reductive capacities than Cast Stone because of the large amounts of the strong reductants sodium sulfide and $\mathrm{SnF}_{2} / \mathrm{SnCl}_{2}$ used in waste form preparation. Based on the measured reductive capacity values for most of the materials, including individual dry ingredients and final waste forms using the two different methods, the reaction time and the solution $\mathrm{pH}$ condition are the critical parameters that influence the measured reductive capacity. Because the Ce(IV) method uses the low-pH condition that dissolves much more of the solids being tested, thus releasing much larger quantities to consume the oxidant, we postulate that the Ce(IV) method can be used to determine an upper bound of the reductive capacity for these waste forms. The $\mathrm{Cr}(\mathrm{VI})$ method can be also used to estimate primarily the waste form surface-related and readily dissolvable reduction capacity. The $\mathrm{Cr}(\mathrm{VI})$ method does not measure the total reduction capacity of the waste form, the long-term reductive capacity afforded by very slowly dissolving solids, or the reducing capacity present in the interior pores and internal locations of the solids, especially for waste forms with very small pore throats and micro- and nano-sized pore structures. 



\subsection{Pore Structure Analysis}

\subsection{Introduction}

Changes in the physical properties of the waste forms, namely pore structure parameters such as porosity, pore diameter, pore throat size and shape, pore connectivity, total pore volume, and pore size distribution, can have a significant effect on the transport of water, gas, and solutes into and out of the waste forms during physical and chemical weathering processes. The mass transfer of contaminants from the solid phase to the waste-form pore water, and subsequently out of the solid waste form, is directly related to the number and size distribution of pores as well as the microstructure (i.e., the pore tortuosity and connectivity) of the waste form. Because permeability (or diffusivity) and porosity are controlled by pore aperture size (or pore diameter), pore volume, and pore distribution, it is important to have some indication of how these characteristics change in the waste form during weathering. Knowledge of changes in these key parameters can be used to develop predictive models that estimate diffusivity or permeability of contaminants from waste forms for long-term performance assessment.

It is known that dissolution or precipitation of amorphous/crystalline phases within waste forms alters their pore structure and controls the transport of contaminants out of waste forms (Cai et al. 2009). One very important precipitate is calcite, which is formed as a result of carbonation reactions in cement and other high-alkalinity waste forms. Calcite precipitation and the related calcium leaching process on the surface and within micropores in waste forms can significantly affect the microstructure by changing the size, number, volume, and distribution of pores within these high-alkalinity waste forms. To account for these changes, measurements of the pore structure and surface area before and after carbonation weathering reactions were conducted using gas-adsorption Brunauer-Emmett-Teller (BET)/Barret-JoynerHalenda (BJH) methods (Brunauer et al. 1938, Barrett et al. 1951) and x-ray microtomography (XMT). The BJH gas adsorption analysis is not able to measure all the pores present in the solid waste forms. Many of the unconnected or isolated nanopores in the waste forms cannot be filled with the adsorbing gas in the time frame of the measurements. Thus gas adsorption analysis underestimates total porosity of the waste forms.

Testing with the Hg-porosimetry and helium pycnometry methods, which are more standard methods of measuring porosity, was also initially planned; however, because of limited availability and time constraints, this test has not been performed to date.

Because contaminant transport or diffusion processes through porous materials, including the waste forms used in this task (Cast Stone, DuraLith, FBSR, and Ceramicrete), are closely related to the specific surface area and the pore structure changes of the contaminant-hosting materials, these physical characteristics should be determined to increase our understating of the long-term leachability of contaminants, especially Tc, out of the four candidate waste forms. 


\subsection{Materials and Methods}

\subsubsection{Materials}

All the chunk samples used in the pore structure determinations were obtained from the previously prepared Cast Stone and DuraLith samples in Phases I/II that were not consumed previously. An additional small-diameter Cast Stone monolith [0.28 in. $(0.7 \mathrm{~cm})$ in diameter by 2 in. $(5 \mathrm{~cm})$ in height] was prepared and characterized using both gas absorption and XMT for pore structure changes before and after carbonation weathering reactions. The DuraLith (Batch \#2) sample that was characterized for pore structure analysis was an unused sample from Batch \#2 of Phase I (Pierce et al. 2010). The FBSR sample that was characterized was the FBSR Geo-7 binder-encapsulated sample provided by SRNL that was crushed to make the chunk samples (i.e., without being reduced to a powder in a ball mill). The Ceramicrete sample was freshly prepared with the recipe described in Section 2.4. The waste form samples were crushed to form chunks (less than $2 \mathrm{~cm}$ in diameter) that were used for BET gas adsorption analysis before and after $\mathrm{CO}_{2}(\mathrm{~g})$ reaction in environmental chamber.

\subsubsection{Environmental $\mathrm{CO}_{2}(\mathrm{~g})$ Chamber}

An environmental humidity chamber was configured to allow the atmosphere composition to be controlled. $\mathrm{A} \mathrm{CO}_{2}$ (g) chamber was made by modifying a polycarbonate vacuum desiccator. A hole was drilled $\sim 2.5 \mathrm{~cm}$ below the O-ring seal in the base of the desiccator, and a Swagelok bulkhead with neoprene gaskets was installed. A piece of Teflon tubing was installed on the inside of the bulkhead fitting, run through a hole in the desiccator plate, and placed into approximately $800 \mathrm{~mL}$ of DIW. A 0-60 $\mathrm{mL} / \mathrm{min}$ flow meter was connected to the outside portion of the bulkhead fitting to control the gas flow. After the waste form chunk samples were added to the desiccator and the two halves were taped together, a mixture of $5 \% \mathrm{CO}_{2}$ and $95 \% \mathrm{~N}_{2}$ was used to increase carbonation weathering reactions in the waste form samples. The gas mixture was metered into the modified desiccator and then flowed out the stopcock to be exhausted into a fume hood. The reaction time inside the $\mathrm{CO}_{2}(\mathrm{~g})$ chamber varied from 7 days to 30 days.

\subsection{3 $\quad \mathrm{N}_{2}$ Gas Adsorption Analysis}

Surface areas of chunk waste form samples were determined with a Micrometrics Surface Area Analyzer (Model 2020, Micrometrics Instrument Corp., Norcross, Georgia). The approach is based on the multi-point BET adsorption equation using $\mathrm{N}_{2}$. Briefly, an air-dried waste form chunk sample that provides at least $10 \mathrm{~m}^{2}$ of total surface area is placed in a surface area flask and out-gassed for a minimum of 3 hours at $150^{\circ} \mathrm{C}$ and at $3-\mu \mathrm{m} \mathrm{Hg}$ vacuum. The out-gassing temperature was chosen to minimize surface structure alterations in the waste forms. During this time, physically sorbed water and volatile organics were removed. To determine dryness, the vacuum pumps were isolated, and if a vacuum change of less than 2- $\mu \mathrm{m} \mathrm{Hg}$ in 5 minutes occurred, the sample was considered clean and dry. After out-gassing, the adsorption of nitrogen determines the surface area of the waste form's surface.

The specific surface area is the amount of available surface area per unit weight of the solid. Porous waste forms contain residual pore water from liquid wastes that were solidified. The waste forms that have higher specific surface areas can adsorb more solute species and, thus, can reduce contaminant 
leachability. The surface areas of solid samples are usually measured at liquid nitrogen temperature (approximately $77 \mathrm{~K}$ ). The BET method is well known and quantifies surface area according to the following relationship:

$$
\frac{\mathrm{P}}{\mathrm{V}_{\mathrm{a}}\left(\mathrm{P}_{\mathrm{o}}-\mathrm{P}\right)}=\frac{1}{\mathrm{~V}_{\mathrm{m}} \mathrm{C}}+\frac{\mathrm{C}-1}{\mathrm{~V}_{\mathrm{m}} \mathrm{C}}\left(\frac{\mathrm{P}}{\mathrm{P}_{\mathrm{o}}}\right)
$$

where $\quad \mathrm{V}_{\mathrm{a}}=$ the quantity of gas adsorbed at pressure $\mathrm{P}$

$\mathrm{V}_{\mathrm{m}}=$ the quantity of gas adsorbed to form a complete monolayer

$\mathrm{P}_{\mathrm{o}}=$ the saturation pressure of the gas

$\mathrm{C}=$ the BET constant.

The values of $\mathrm{V}_{\mathrm{m}}$ and $\mathrm{C}$ are determined by a regression line on the adsorption isotherm raw data plotted as $\mathrm{P} / \mathrm{V}_{\mathrm{a}}\left(\mathrm{P}_{\mathrm{o}}-\mathrm{P}\right)$ vs. $\mathrm{P} / \mathrm{P}_{\mathrm{o}}$. The specific surface area of a solid is determined by the following relationship:

$$
\text { Area }=\frac{\mathrm{V}_{\mathrm{m}}}{22414} \mathrm{a}_{\mathrm{m}} \mathrm{N}_{\mathrm{A}} 10^{-20}
$$

where $\mathrm{a}_{\mathrm{m}}$ is the average area occupied by a single adsorbate molecule, and $\mathrm{N}_{\mathrm{A}}$ is Avogadro's number (Gregg and Sing 1982; Webb and Orr 1997).

Pore information, including average pore diameter and pore volume (or area) distribution as a function of pore diameter, can also be obtained from the complete adsorption isotherm with the BJH method (Barrett et al. 1951). As $\mathrm{N}_{2}$ is added or removed from the pores using equal step changes in relative pressure, the pressure change represents the pore volume in that step change. The pore radius can be calculated with a thickness relationship. Assuming that the pore is a right circular cylinder, the volume of the pore can then be calculated.

\subsubsection{X-Ray Microtomography}

Tomography characterization was performed by Brookhaven colleagues at NSLS Beamline X2B. The beamline provides monoenergetic beams of x-rays from about $11 \mathrm{keV}$ to $35 \mathrm{keV}$. The $\mathrm{x}$-rays passing through the sample produce light when they interact with a CsI scintillation detector. The transmitted light image is recorded with a charge-coupled device (CCD) camera with 1340 pixels in the horizontal direction. The number of pixels in the vertical direction is determined by the intensity profile of the incident $\mathrm{X}$-ray beam, which usually is set for about 500 pixels. The pixel size in terms of the sample dimension can be changed by using different magnifying lenses that form an enlarged image on the CCD camera. The present work used pixel sizes of $4 \mu \mathrm{m}$ and $8 \mu \mathrm{m}$. Exposure times for the CCD camera varied, but were in the range from 1.5 seconds to 2.0 seconds. The data analysis was carried out using ImageJ software. ${ }^{1}$ The reconstructed images of a two-dimensional, cross-sectional slice were also obtained using Clemex Vision image analysis software (Clemex Technologies, Longueuil, Quebec, Canada). The manual gray threshold with calibration of each phase to the pixel number ranges was programmed and used for each slice to separate each phase (air, water, or solid) and assign three bitplane colors.

\footnotetext{
${ }^{1}$ http://rsbweb.nih.gov/ij/
} 


\subsection{Results and Discussion}

\subsubsection{Pore Analysis for Unreacted Waste Forms}

The $\mathrm{N}_{2}$ (g) gas adsorption and desorption isotherms for the four waste forms (Cast Stone, DuraLith, and Ceramicrete monolith prepared with simulant 1 [S1-2M] and Geo-7 encapsulated FBSR product) before $\mathrm{CO}_{2}(\mathrm{~g})$ reaction are presented in Figure 5.1. As shown in Figure 5.1, Cast Stone prepared with S1 simulant showed the largest adsorbed $\mathrm{N}_{2}(\mathrm{~g})$ volume, indicative of relatively high porosity. The DuraLith showed slightly smaller adsorbed $\mathrm{N}_{2}$ (g) volume than Cast Stone, the FBSR waste form adsorbed- $\mathrm{N}_{2}(\mathrm{~g})$ volume was lower than either the Cast Stone or DuraLith, and the Ceramicrete sample showed the smallest adsorbed gas volume. This indicates that the overall porosity of Cast Stone is probably higher than the porosity of FBSR, DuraLith, and Ceramicrete.

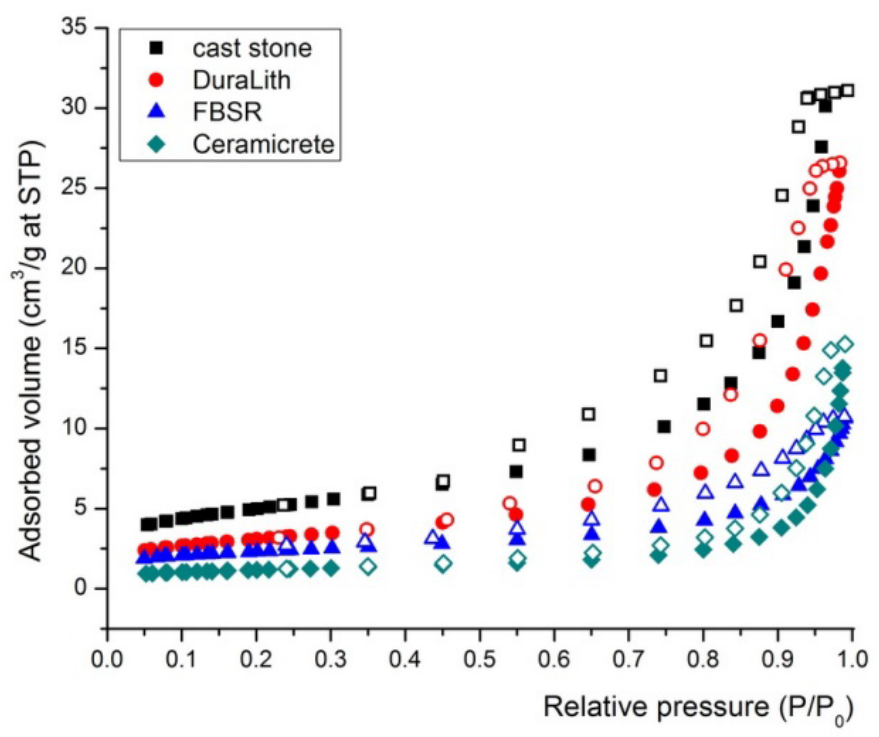

Figure 5.1. Adsorption and Desorption Isotherms of Cast Stone, DuraLith, FBSR, and Ceramicrete Waste Forms Before Carbonation Reaction. Closed and open symbols represent adsorption and desorption, respectively.

As shown in Table 5.1, the specific surface areas of Cast Stone, DuraLith, Geo-7 encapsulated FBSR, and Ceramicrete are $17.68 \mathrm{~m}^{2} / \mathrm{g}, 11.00 \mathrm{~m}^{2} / \mathrm{g}, 8.307 \mathrm{~m}^{2} / \mathrm{g}$, and $4.107 \mathrm{~m}^{2} / \mathrm{g}$, respectively. The surface area of Cast Stone is about three times higher than that of Ceramicrete. The difference in surface area between DuraLith and Cast Stone is also quite large, about $6 \mathrm{~m}^{2} / \mathrm{g}$. However, the difference in pore volume (generally referred to as porosity of the material) between Cast Stone and DuraLith is not as large as the difference in specific surface area. Because the average pore diameter of the DuraLith $(13.71 \mathrm{~nm})$ is larger than that of Cast Stone $(10.88 \mathrm{~nm})$, much smaller sized pores are present in Cast Stone. Smaller sized pores are associated with the larger surface area in Cast Stone than in the DuraLith sample. The Geo-7 encapsulated FBSR exhibits smaller surface area, porosity, and average pore diameter, and therefore this material originally contains fewer pores compared to Cast Stone and DuraLith, indicating that it is a more compact and dense material. Even though Ceramicrete also is a dense material, its larger measured pore diameter and smaller surface area compared to others probably resulted from several minor cracks created when it cured. 
Table 5.1. Surface Area, Pore Volume, and Pore Diameter of Various Waste Forms Before Carbonation

\begin{tabular}{lcccc}
\hline \multicolumn{1}{c}{ Waste Forms } & Cast Stone & FBSR Monolith & \\
& $\mathrm{S} 1$ & DuraLith & $\begin{array}{c}\text { Ceramicrete } \\
\text { (Geo-7 binder) }\end{array}$ & Cer $\left.\mathrm{m}^{2} / \mathrm{g}\right)$ \\
Surface area $\left(\mathrm{cm}^{3} / \mathrm{g}\right)$ & 17.68 & 11.00 & 8.307 & 4.107 \\
Pore volume & 0.04809 & 0.03779 & 0.01548 & 0.01912 \\
Average pore diameter $(\mathrm{nm})$ & 10.88 & 13.74 & 7.454 & 18.62 \\
\hline
\end{tabular}

\subsubsection{Cast Stone Sample Analysis Before and After Carbonation}

\subsubsection{Cast Stone Chunk Samples}

Chunk-sized samples of Cast Stone that were prepared with different S1 simulant concentrations (S1-2, 4, 6, 8, and 10-M Na) and the four different simulants at 2-M Na compositions (S1, S2, S3, and S4) were characterized before and after carbonation treatment using the $\mathrm{CO}_{2}$ chamber. The results of $\mathrm{N}_{2}(\mathrm{~g})$ adsorption and desorption isotherms for normal (before carbonation) and post-carbonation Cast Stone specimens are presented in Figure 5.2 and Figure 5.3. For all the samples, the $\mathrm{N}_{2}$ (g) adsorption isotherm showed less adsorbed volume of $\mathrm{N}_{2}(\mathrm{~g})$ at each pressure level than the adsorbed volume of $\mathrm{N}_{2}(\mathrm{~g})$ in the desorption isotherm. This is because some of the adsorbed $\mathrm{N}_{2}(\mathrm{~g})$ is not removed from the micro-pore structures during the desorption process. This hysteresis event is commonly observed for porous solids with very small-sized pore structures.
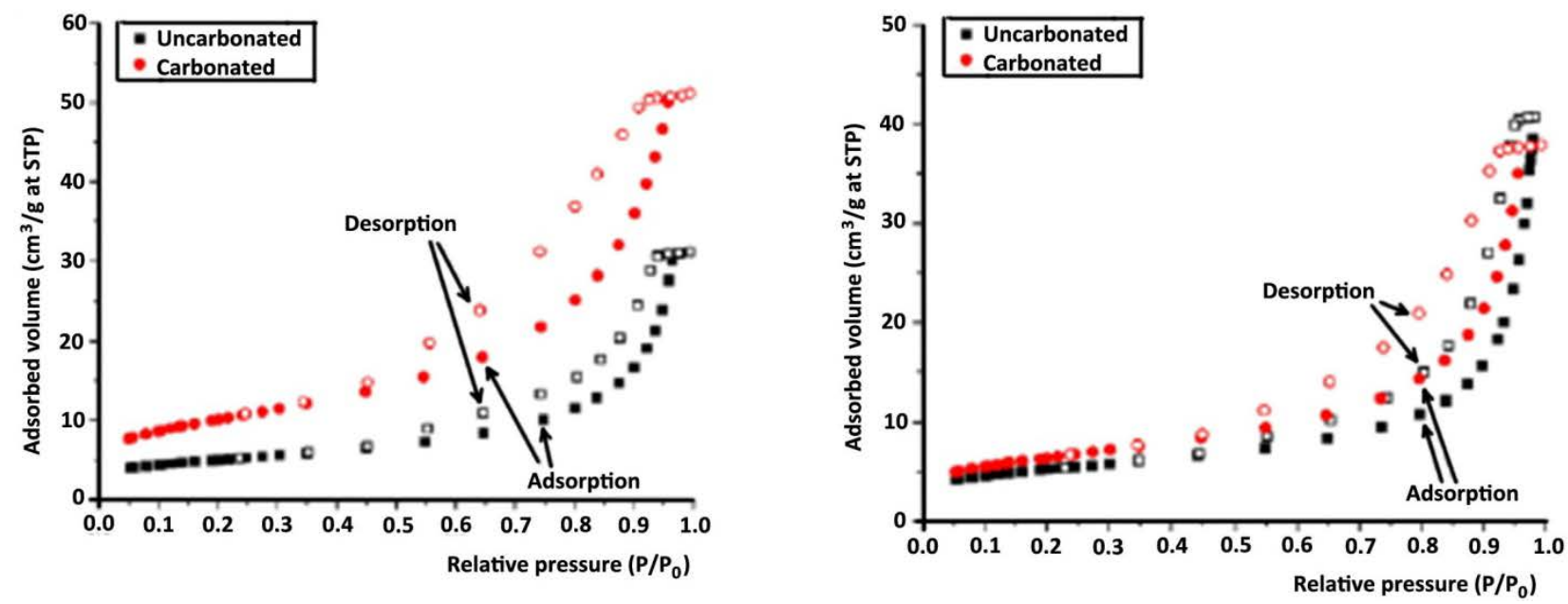

Figure 5.2. $\mathrm{N}_{2}(\mathrm{~g})$ Adsorption and Desorption Isotherms of Normal (uncarbonated) and Carbonated Cast Stone with Different Simulants: (left) Cast Stone Prepared with S1 2-M Na Simulant; (right) Cast Stone Prepared with S1 4-M Na Simulant. Closed and open symbols represent adsorption and desorption, respectively. 

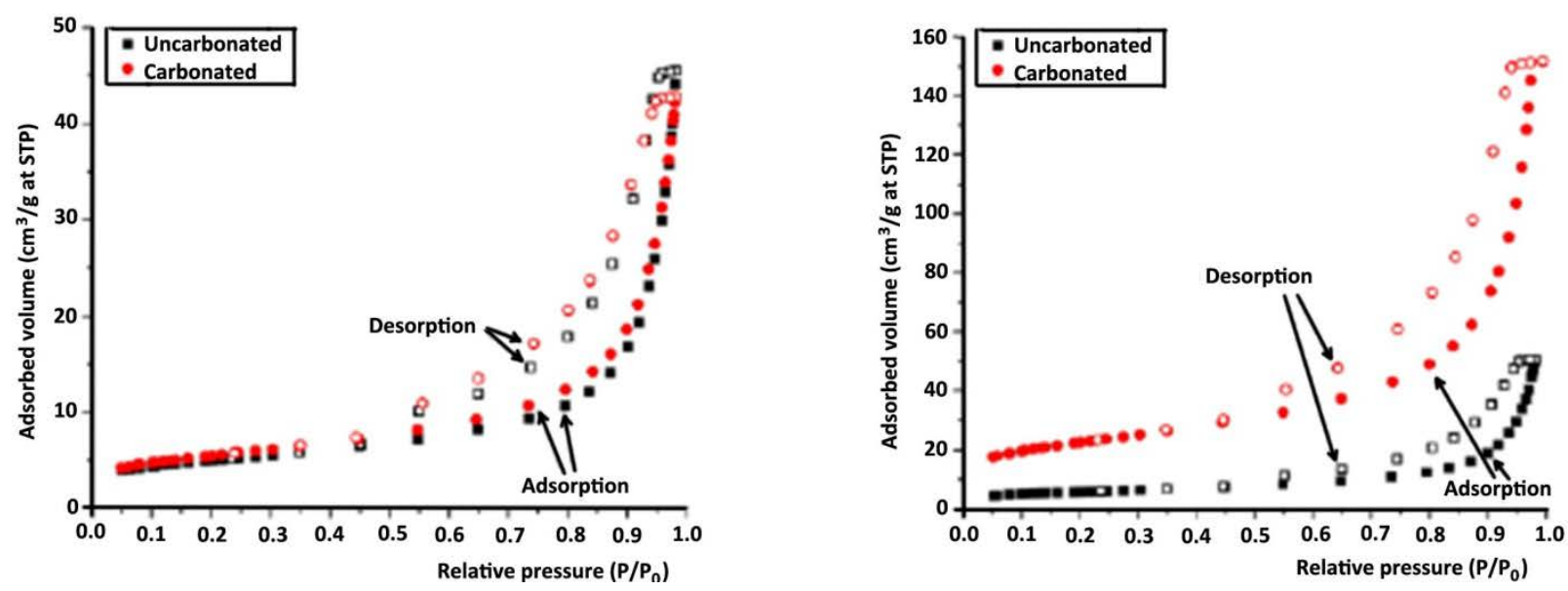

Figure 5.3. $\mathrm{N}_{2}$ (g) Adsorption and Desorption Isotherms of Normal (uncarbonated) and Carbonated Cast Stone with Different Simulants: (left) Cast Stone Prepared with S1 8-M Na Simulant; (right) Cast Stone Prepared with S1 10-M Na Simulant. Closed and open symbols represent adsorption and desorption, respectively. Note: the data for S1 6M is so similar to the date for S1 8M that is not shown.

After surface analysis measurements for the normal (before carbonation) Cast Stone chunk samples, the same specimens were exposed to $\mathrm{CO}_{2}(\mathrm{~g})$ in the environmental chamber for 14 days, where the enhanced carbonation reaction occurred. The $\mathrm{N}_{2}(\mathrm{~g})$ isotherm results for the carbonated Cast Stone chunk specimens are also presented in Figure 5.2 and Figure 5.3. The adsorption and desorption isotherms for the carbonated specimens are located at the higher position, which indicates that more surface area and pore volume have been generated during the carbonation process. This is a clear indication that carbonation affects the pore structure of the Cast Stone. It is also evident from Figure 5.2 and Figure 5.3 that the degree of difference in adsorption and desorption isotherms before and after carbonation decreased as the concentrations of S1 simulant increased from 2-M to 8-M Na. However, large differences in the adsorption/desorption isotherms before and after carbonation were found again in the Cast Stone specimen prepared with S1 10-M Na (Figure 5.3, right). A possible reason for the large difference could be the higher water content used to make the Cast Stone of the S1 10-M Na specimen (to resolve workability issues). The use of more water in the formulation increased the porosity of the cured Cast Stone-S1-10M Na waste form. Isotherms for Cast Stone made with S1-6M Na simulant are not shown in Figure 5.2 because they are similar to Cast Stone prepared with S1-8M Na simulant.

Slight differences in gas adsorption/desorption isotherms were found among Cast Stone specimens prepared with 2-M Na simulants S1, S2, S3, and S4 before carbonate treatment, and only the S1 and S4 data are shown in Figure 5.4. The small differences are most likely caused by the differences in the chemical compositions of waste simulant solutions between the S1, S2, S3, and S4 liquids that affect the hydration of Cast Stone. In all four cases, the carbonated Cast Stone showed higher adsorbed $\mathrm{N}_{2}(\mathrm{~g})$ volumes after carbonation than the uncarbonated (before carbonation) Cast Stone specimens (see Figure 5.4 for two of the simulants). In addition, for simulant S4, there was significant generation of $\mathrm{NH}_{3}$ gas during the Cast Stone production, which increased the porosity of the hardened S4 Cast Stone waste forms. 

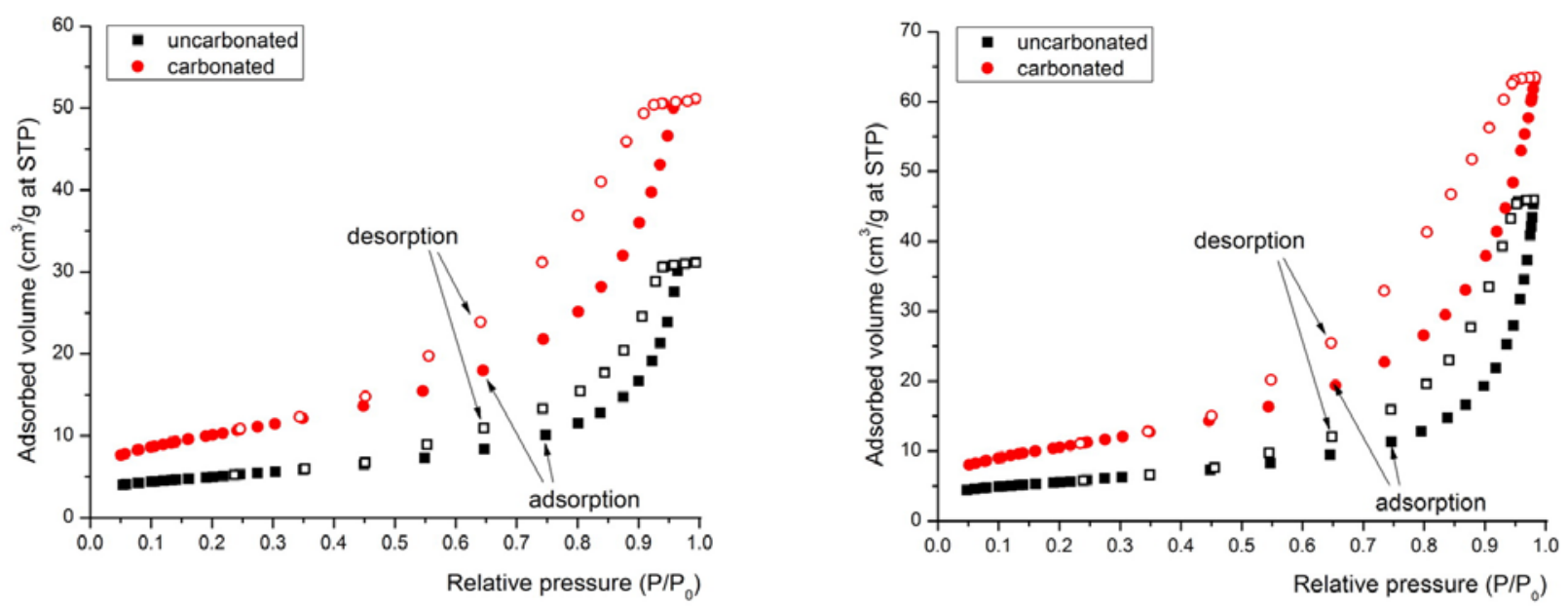

Figure 5.4. Nitrogen Gas Adsorption and Desorption Isotherms of Normal (uncarbonated) and Carbonated Cast Stone with Different Simulants: (left) Cast Stone Prepared with S1 2M Na Simulant; (right) Cast Stone Prepared with S4 2M Na Simulant

The surface areas of Cast Stone specimens made with the four different simulants based on 2-M Na (S1, S2, S3, and S4) and S1 simulant with varying Na concentrations (S1-2, -4, -6, -8, and -10M Na) before and after carbonation are presented in Figure 5.5 and Table 5.2. For the 2-M Na concentration basis, all the 14-day carbonated specimens showed higher surface areas (16.31 to $21.45 \mathrm{~m}^{2} / \mathrm{g}$ higher) than the waste form specimens before carbonation. The largest difference before and after carbonation was observed in the Cast Stone made with S3-2M Na, and the smallest difference was observed in the Cast Stone made with S2-2M Na. However, these differences between S1 and S3 Cast Stone before and after carbonation are within the uncertainty range of the surface-area measurements. Thus, for the Cast Stone specimens made with the four different 2-M-based Na simulants, the increase in surface areas after carbonation is evident no matter what types of simulants were used to prepare different Cast Stone samples. The relative differences in surface area before and after carbonation decreased further as the concentration of the S1 simulant solution increased up to 8-M Na (Figure 5.5, right). The difference in surface area before and after carbonation for the S1-2M Na specimen was $18.57 \mathrm{~m}^{2} / \mathrm{g}$, while the differences become smaller as the concentration increases to the $\mathrm{S1-8M}$ Na specimen $\left(1.92 \mathrm{~m}^{2} / \mathrm{g}\right)$. The surface area differences before and after carbonation for the Cast Stone specimens made with S1-10M Na simulant showed a completely different trend wherein a large change was observed $\left(20.06 \mathrm{~m}^{2} / \mathrm{g}\right.$ before carbonation and $79.87 \mathrm{~m}^{2} / \mathrm{g}$ after carbonation). The large change in surface area for the S1-10M Cast Stone is similar to the large change in the adsorbed $\mathrm{N}_{2}(\mathrm{~g})$ volume shown in Figure 5.3, right. At this time we have no mechanistic explanation for the significant increase in surface area for this Cast Stone-S1-10M combination after carbonation. 

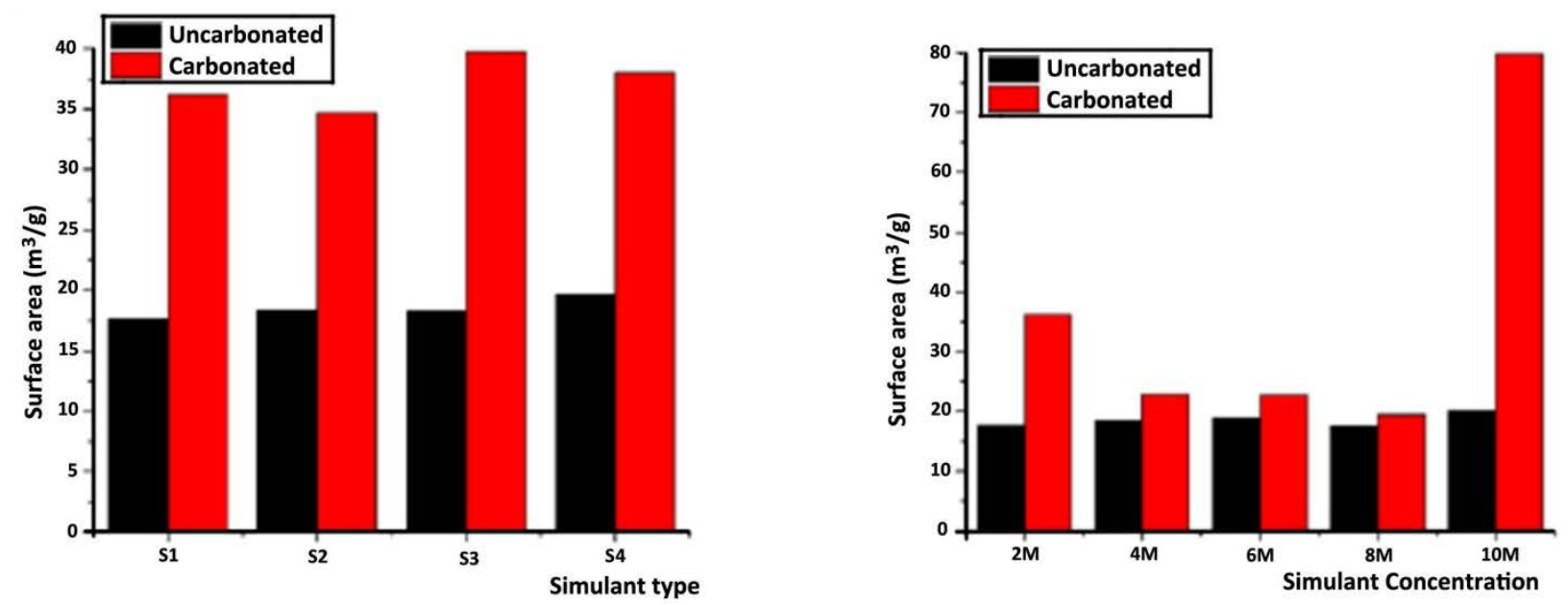

Figure 5.5. Surface Area of Normal (uncarbonated) and Carbonated Cast Stone Specimens Prepared with (left) S1, S2, S3, and S4 2M Na Concentration; (right) S1 2 to 10M Na Concentrations

Table 5.2. Surface Area $\left(\mathrm{m}^{2} / \mathrm{g}\right)$ of Cast Stone Obtained from Chunk Specimens

\begin{tabular}{|c|c|c|c|c|c|c|c|c|}
\hline & \multicolumn{2}{|c|}{ S1 } & \multicolumn{2}{|c|}{$\mathrm{S} 2$} & \multicolumn{2}{|c|}{ S3 } & \multicolumn{2}{|c|}{ S4 } \\
\hline & Normal & Carbonated & Normal & Carbonated & Normal & Carbonated & Normal & Carbonated \\
\hline $2 \mathrm{M}$ & 17.68 & $\begin{array}{c}36.25 \\
(18.57)^{(a)}\end{array}$ & 18.38 & $\begin{array}{c}34.69 \\
(16.31)^{\mathrm{a}}\end{array}$ & 18.32 & $\begin{array}{c}39.78 \\
(21.46)^{a}\end{array}$ & 19.66 & $\begin{array}{c}38.04 \\
(18.38)^{\mathrm{a}}\end{array}$ \\
\hline $4 \mathrm{M}$ & 18.42 & $\begin{array}{l}22.74 \\
(4.32)\end{array}$ & - & - & - & - & - & - \\
\hline $6 \mathrm{M}$ & 19.04 & $\begin{array}{l}22.66 \\
(3.62)\end{array}$ & - & - & - & - & - & - \\
\hline $8 \mathrm{M}$ & 17.55 & $\begin{array}{l}19.47 \\
(1.92)\end{array}$ & - & - & - & - & - & - \\
\hline $10 \mathrm{M}$ & 20.06 & $\begin{array}{c}79.87 \\
(59.81)\end{array}$ & - & - & - & - & - & - \\
\hline (a) & $\begin{array}{l}\text { iges bet } \\
\text { mns. }\end{array}$ & n normal (u & onated & carbonate & nples a & wn in par & ses in $c$ & nated \\
\hline
\end{tabular}

The specific pore volumes of the Cast Stone specimens are presented in Figure 5.6 and Table 5.3. The pore volumes for all the Cast Stone specimens increased after 14 days of exposure in the $\mathrm{CO}_{2}(\mathrm{~g})$ environmental chamber. With various 2-M Na specimens, the increase in pore volume ranges from $0.048 \mathrm{~cm}^{3} / \mathrm{g}$ (S2-2M Na) to $0.065 \mathrm{~cm}^{3} / \mathrm{g}$ (S4-2M Na) for Cast Stone before carbonation, which is consistent with the highest Tc leachability found in Cast Stone prepared in the S4 simulant (Sundaram et al. 2011). For the carbonated Cast Stone specimens, pore volumes also increased from $0.079 \mathrm{~cm}^{3} / \mathrm{g}$ in Cast Stone (S1) to $0.094 \mathrm{~cm}^{3} / \mathrm{g}$ in Cast Stone (S4). A similar trend was observed with the increase in the waste simulant concentration, although the results from pore volume data were not as consistent as the surface area data shown in Figure 5.5. At various S1 concentration levels, the increase in the pore volume varies from $0.048 \mathrm{~cm}^{3} / \mathrm{g}(\mathrm{S} 1-2 \mathrm{M} \mathrm{Na})$ to $0.071 \mathrm{~cm}^{3} / \mathrm{g}$ (S1-10M Na) before carbonation. The increasing pore volume as simulant concentration increased agreed well with increasing Tc leachability as the simulant concentration increased in Cast Stone preparation (Sundaram et al. 2011). The largest pore volume increase after carbonation was found in Cast Stone with S1-10M Na simulant, consistent with the large increases in the adsorbed $\mathrm{N}_{2}(\mathrm{~g})$ isotherms and surface area results discussed earlier. 

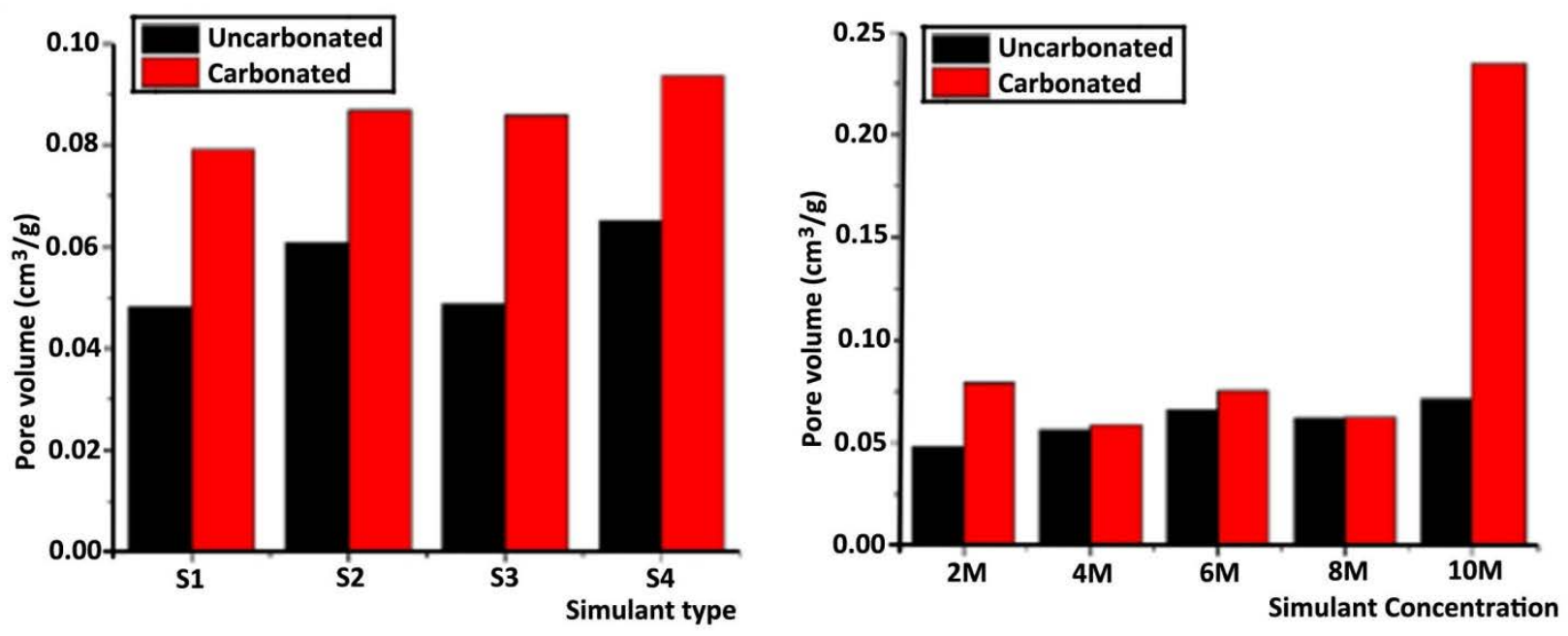

Figure 5.6. Pore Volume of Normal (uncarbonated) and Carbonated Cast Stone Specimens Prepared with (left) S1-, S2-, S3-, and S4-2M Na Concentration; (right) S1-2M to S1-10M Na Concentrations

Table 5.3. Pore Volume $\left(\mathrm{cm}^{3} / \mathrm{g}\right)$ of Cast Stone Obtained from Chunk Specimens

\begin{tabular}{|c|c|c|c|c|c|c|c|c|}
\hline & \multicolumn{2}{|c|}{ S1 } & \multicolumn{2}{|c|}{$\mathrm{S} 2$} & \multicolumn{2}{|c|}{ S3 } & \multicolumn{2}{|c|}{ S4 } \\
\hline & Normal & Carbonated & Normal & Carbonated & Normal & Carbonated & Normal & Carbonated \\
\hline $2 \mathrm{M}$ & 0.04809 & $\begin{array}{c}0.07914 \\
(0.03105)^{(a)}\end{array}$ & 0.06089 & $\begin{array}{c}0.08692 \\
(0.02603)^{(a)}\end{array}$ & 0.04891 & $\begin{array}{c}0.08588 \\
(0.03697)^{(a)}\end{array}$ & 0.06518 & $\begin{array}{c}0.0937 \\
(0.02852)^{(a)}\end{array}$ \\
\hline $4 \mathrm{M}$ & 0.05625 & $\begin{array}{c}0.05856 \\
(0.00231)^{(a)}\end{array}$ & - & - & - & - & - & - \\
\hline $6 \mathrm{M}$ & 0.06612 & $\begin{array}{c}0.07532 \\
(0.00920)^{(a)}\end{array}$ & - & - & - & - & - & - \\
\hline $8 \mathrm{M}$ & 0.06183 & $\begin{array}{c}0.06228 \\
(0.00045)^{(a)}\end{array}$ & - & - & - & - & - & - \\
\hline $10 \mathrm{M}$ & 0.07126 & $\begin{array}{c}0.23462 \\
(0.16336)^{(a)}\end{array}$ & - & - & - & - & - & - \\
\hline
\end{tabular}

(a) Changes between normal (uncarbonated) and carbonated samples are shown in parentheses in carbonated columns.

The average pore diameter of each Cast Stone specimen before and after carbonation is presented in Figure 5.7 and Table 5.4. The average diameter of the pores decreased when the specimens were carbonated. The average pore diameter of the Cast Stone specimens made with various 2-M Na simulants showed smaller average pore diameters after carbonation; the decreases ranged from $2.044 \mathrm{~nm}$ to $3.406 \mathrm{~nm}$. The largest reduction in average pore diameter was observed for the Cast Stone specimen made with S4-2M Na, and the smallest difference was observed for the Cast Stone specimen made with S3-2M Na (Table 5.4). The average pore diameters of Cast Stone specimens prepared with the S1 simulant with different Na concentrations also decreased after carbonation regardless of waste simulant concentration. The differences in average pore diameter before and after carbonation seem to decrease as the concentration of the simulant S1 solution increases, but the trend was not consistent, showing the minimum at 6-M Na and the maximum at 10-M Na (Table 5.4). 

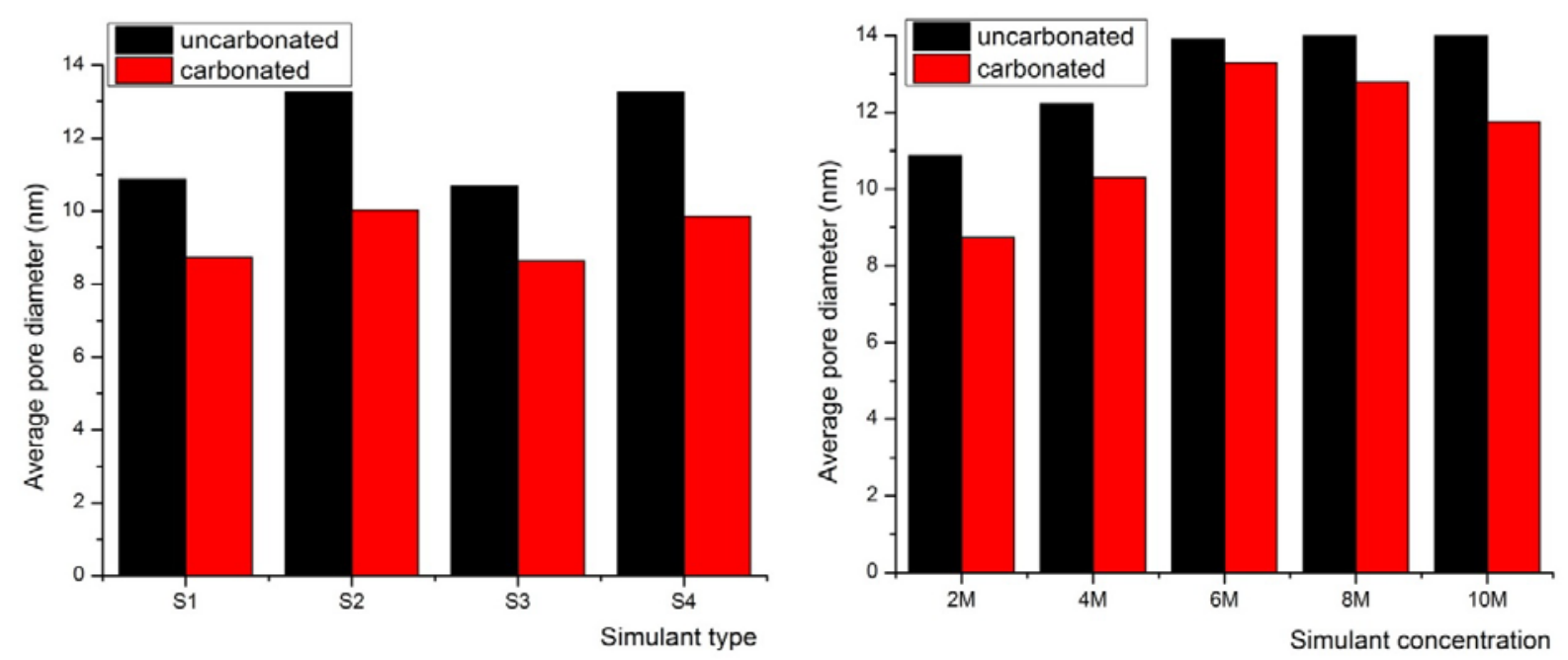

Figure 5.7. Average Pore Diameter of Normal and Carbonated Cast Stone Specimens Prepared with (left) S1-, S2-, S3-, and S4-2M Na Concentration; (right) S1-2M to -10M Na Concentrations

Table 5.4. Pore Diameter Size (nm) of Cast Stone Obtained from Chunk Specimens

\begin{tabular}{|c|c|c|c|c|c|c|c|c|}
\hline & \multicolumn{2}{|r|}{ S1 } & \multicolumn{2}{|r|}{ S2 } & \multicolumn{2}{|r|}{ S3 } & \multicolumn{2}{|r|}{ S4 } \\
\hline & Normal & Carbonated & Normal & Carbonated & Normal & Carbonated & Normal & Carbonated \\
\hline $2 \mathrm{M}$ & 10.88 & $\begin{array}{c}8.733 \\
(-2.148)^{(a)}\end{array}$ & 13.25 & $\begin{array}{c}10.02 \\
(-3.23)^{\mathrm{a}}\end{array}$ & 10.68 & $\begin{array}{c}8.636 \\
(-2.044)^{(a)}\end{array}$ & 13.26 & $\begin{array}{c}9.854 \\
(-3.404)^{(a)}\end{array}$ \\
\hline $4 \mathrm{M}$ & 12.22 & $\begin{array}{c}10.30 \\
(-1.920)^{(a)}\end{array}$ & - & - & - & - & - & - \\
\hline $6 \mathrm{M}$ & 13.89 & $\begin{array}{c}13.30 \\
(-0.598)^{(a)}\end{array}$ & - & - & - & - & - & - \\
\hline $8 \mathrm{M}$ & 14.09 & $\begin{array}{c}12.80 \\
(-1.297)^{(\mathrm{a})}\end{array}$ & - & - & - & - & - & - \\
\hline $10 \mathrm{M}$ & 14.21 & $\begin{array}{c}11.75 \\
(-2.46)^{(a)}\end{array}$ & - & - & - & - & - & - \\
\hline
\end{tabular}

(a) Changes between normal (uncarbonated) and carbonated samples are shown in parentheses in "Carbonated” columns. Negative sign indicates decrease after carbonation.

A possible mechanism that is controlling the change in the pore structure of Cast Stone chunks during carbonation is the formation of calcite in the capillary pores. The $\mathrm{Ca}^{2+}$ ion is supplied by dissolution of $\mathrm{Ca}(\mathrm{OH})_{2}$ (portlandite or $\mathrm{CH}$ ), which is formed during the hydration reactions of the dry blend. Other cementitious solids (calcium silicate hydrate [C-S-H] and calcium aluminum silicate hydrate [C-A-S-H]) can also supply ample concentrations of $\mathrm{Ca}^{2+}$ ions to the Cast Stone pore water. The $\mathrm{CO}_{2}(\mathrm{~g})$ is continually supplied by diffusion of air and/or bicarbonate/carbonate ions in percolating recharge waters into the subsurface. Carbonation reactions are well described below in equations.

$$
\begin{gathered}
\mathrm{CO}_{2}(\mathrm{~g})+\mathrm{H}_{2} \mathrm{O}=\mathrm{H}_{2} \mathrm{CO}_{3} \text { (carbonic acid) } \\
\mathrm{H}_{2} \mathrm{CO}_{3}=\mathrm{HCO}_{3}^{-}+\mathrm{H}^{+} \text {(dissociation of carbonic acid to bicarbonate) }
\end{gathered}
$$




$$
\begin{gathered}
\mathrm{HCO}_{3}{ }^{-}=\mathrm{CO}_{3}{ }^{2-}+\mathrm{H}^{+} \text {(dissociation of bicarbonate to carbonate at high } \mathrm{pH} \text { ) } \\
\mathrm{Ca}^{2+}+\mathrm{CO}_{3}{ }^{2-}=\mathrm{CaCO}_{3} \text { (s) (calcite precipitation) }
\end{gathered}
$$

Because cementitious materials contain near-saturation water conditions even after the slurry hardens, $\mathrm{CO}_{2}$ (g) will be dissolved in the pore water to form $\mathrm{H}_{2} \mathrm{CO}_{3}$ (carbonic acid), and the $\mathrm{H}_{2} \mathrm{CO}_{3}$ will dissociate into $\mathrm{HCO}_{3}{ }^{-}$and $\mathrm{CO}_{3}{ }^{2-}$ at the high $\mathrm{pH}$ of cement pore water $(\mathrm{pH} \approx 12-13)$. The $\mathrm{Ca}^{2+}$ ion will be dissolved from the crystalline portlandite or the amorphous $\mathrm{C}-\mathrm{S}-\mathrm{H}$ phases by contact with the carbonic acid and will react with $\mathrm{CO}_{3}{ }^{2-}$ to form $\mathrm{CaCO}_{3}(\mathrm{~s})$. During this reaction, the $\mathrm{pH}$ of cement pore water will drop from 12 to around 9 to 10 , and the $\mathrm{Ca}^{2+}$ ion can be depleted from the cement. The stability of the $\mathrm{Ca}^{2+}$ ion in the C-S-H or C-A-S-H structure depends on the level of $\mathrm{Ca}^{2+}$ concentration in the pore solution. When carbonation occurs in the hydrated cement paste or normal concrete, the $\mathrm{Ca}^{2+}$ in the pore solution is consumed first, and then additional $\mathrm{Ca}^{2+}$ in $\mathrm{CH}$ is leached out to protect the stability of $\mathrm{Ca}^{2+}$ in C-S-H or C-A-S-H. The structural integrity of C-S-H or C-A-S-H is not so much affected by the sacrificial role of $\mathrm{CH}$ in the microstructure. In addition, although the calcite formation will increase the surface area (calcite crystals form in the capillary pores and reduce pore size), it may also decrease pore connectivity and reduce permeability, which will delay further carbonation reactions. Therefore, with Portland cement paste, it is known that the production of calcite actually decreases the permeability of the material by reducing pore volumes and pore diameters. The carbonation reaction front moves toward the inside of the cement very slowly because of the reduction in the permeability, so Portland cement normally takes 20 years or more to fully carbonate. In this case, the surface area may increase because of a newly formed microstructure of calcite, while the pore volume and the pore diameter will decrease by the formation of calcite within the larger pores that generally allow more rapid $\mathrm{CO}_{2}$ (g) diffusion.

However, it should be also noted that there is no sacrificial role from $\mathrm{CH}$ in the Cast Stone. Considering the constituents of Cast Stone (8\% cement, $45 \%$ fly ash, and $47 \%$ slag), the amount of calcium hydroxide generated during the hydration of cement will be limited. It is very likely that all the $\mathrm{CH}$ produced is used up for the pozzolanic reaction of fly ash and slag. Although there is some $\mathrm{CaO}$ content in the slag and fly ash that can produce some $\mathrm{CH}$ during hydration, the quantity is not believed to be adequate to maintain the $\mathrm{CH}$ at a high enough level to protect the $\mathrm{C}-\mathrm{S}-\mathrm{H}$ or $\mathrm{C}-\mathrm{A}-\mathrm{S}-\mathrm{H}$ phases because of their pozzolanic activity (Sundaram et al. 2011). The assumption that all CH is exhausted in the Cast Stone formulations is supported by the fact that no $\mathrm{CH}$ was observed in hydrated Cast Stone specimens that were characterized for mineralogy (Sundaram et al. 2011). The stability of $\mathrm{Ca}^{2+}$ in C-S-H or C-A-S-H in Cast Stone is therefore weaker, and $\mathrm{Ca}^{2+}$ will leach out more easily compared to concrete prepared with normal Portland cement, and therefore the degradation of C-S-H or C-A-S-H can occur during Cast Stone carbonation. This process can create the additional pore space in the microstructure, causing increases in the permeability. However, the formation of calcite in Cast Stone during its carbonation can still partially fill the larger sized pores and reduce the average pore size as observed herein. But a weaker microstructure associated with the depletion of $\mathrm{Ca}^{2+}$ in $\mathrm{C}-\mathrm{S}-\mathrm{H}$ or C-A-S-H may allow more $\mathrm{CO}_{2}(\mathrm{~g})$ ingress and increase the damage associated with further carbonation, which will cause more depletion of $\mathrm{Ca}^{2+}$ in C-S-H or C-A-S-H. Therefore, it is very likely that the surface area, pore volume, and average pore diameter will change, as was found for the Cast Stone chunks subjected to accelerated carbonation. From the results discussed and graphically presented above, it is clear that the surface area and pore volume increased while the average pore diameter decreased when Cast Stone chunks were carbonated up to 14 days. Therefore, it can be concluded that the degradation of the 
microstructure is associated with the 14-day carbonation process. Because there is no sacrificial $\mathrm{CH}$ in Cast Stone, the only way to prevent such degradation would be to produce denser and stronger microstructures to minimize $\mathrm{CO}_{2}(\mathrm{~g})$ attack.

\subsubsection{Cast Stone (0.28-in. diameter by 2-in. height cylindrical monolith specimens)}

A cylindrical Cast Stone monolith $(0.28$-in. [0.7-cm] diameter by 2-in. [5-cm] height) prepared with S1-2M Na simulant was also tested for pore structure analysis with the gas adsorption method. The reason for preparing the small-diameter monolith and characterizing it for pore structure change was to verify the results for the Cast Stone chunk specimens presented above and to provide more reliable results for waste forms in a shape that is likely to be similar to the proposed waste form.

The $\mathrm{N}_{2}$ (g) adsorption and desorption isotherms for the Cast Stone monolith specimen before and after carbonation (14 days and 30 days) are presented in Figure 5.8. The two carbonation periods were conducted on the same Cast Stone monolith specimen. Trends similar to those found for the chunk Cast Stone specimens were observed for the Cast Stone monolith specimen after carbonation for 14 days. The gas adsorption isotherms of the Cast Stone monolith after 14 days of carbonation are found above the uncarbonated specimen isotherms in Figure 5.8, indicating that more $\mathrm{N}_{2}(\mathrm{~g})$ was adsorbed, which in turn indicates increased pore volumes after carbonation for 14 days. However, after 30 days of carbonation, the Cast Stone monolith gas isotherms are located between the isotherms of the uncarbonated and the 14-day carbonated Cast Stone monolith specimens, indicating reduced pore volume as the carbonation reaction increased from 14 days to 30 days.

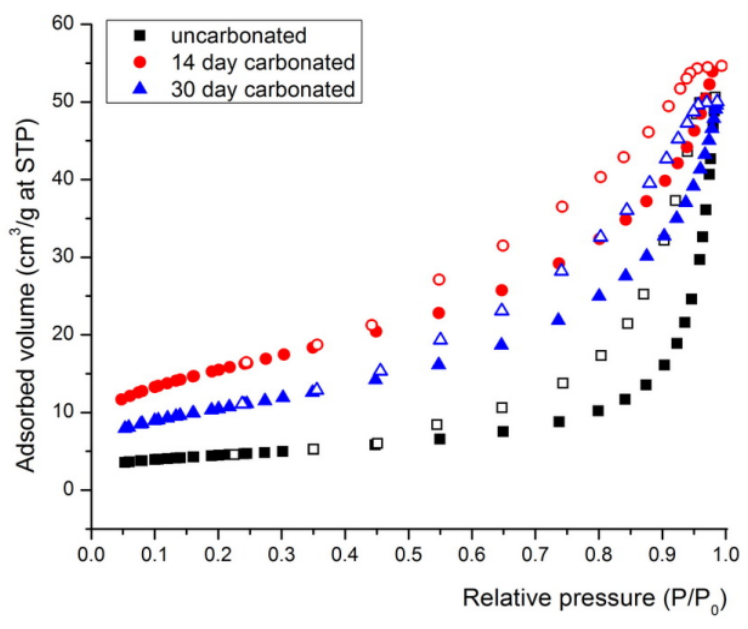

Figure 5.8. Nitrogen Gas Adsorption/Desorption Isotherms of Normal and Carbonated (14 days and 30 days) Cast Stone Monolith Specimens. Closed and open symbols represent adsorption and desorption, respectively.

Figure 5.9 and Figure 5.10 show that the Cast Stone monolith followed trends similar to the Cast Stone chunk specimens up to 14 days of carbonation. The monolith surface area and pore volume increased (Figure 5.9), while average pore diameter decreased (Figure 5.10) with up to 14 days of carbonation. The results from Figure 5.8 and Figure 5.10 agree with the trends observed for the chunk specimens, that the carbonation process affects the microstructure of Cast Stone. However, when carbonation reactions are continued up to 30 days, the surface area and pore volume in the Cast Stone 
monolith decreased somewhat in comparison to the values after 14 days of carbonation, while the average pore diameter after 30 days of carbonation increased somewhat. However, the 30-day carbonated average pore diameter is still less than the average diameter for the uncarbonated Cast Stone monolith. These changes and reversal in trends as the carbonation time was extended from 14 days to 30 days may have been caused by the decreasing release of dissolved $\mathrm{Ca}^{2+}$ ions as the carbonation reaction time increased.
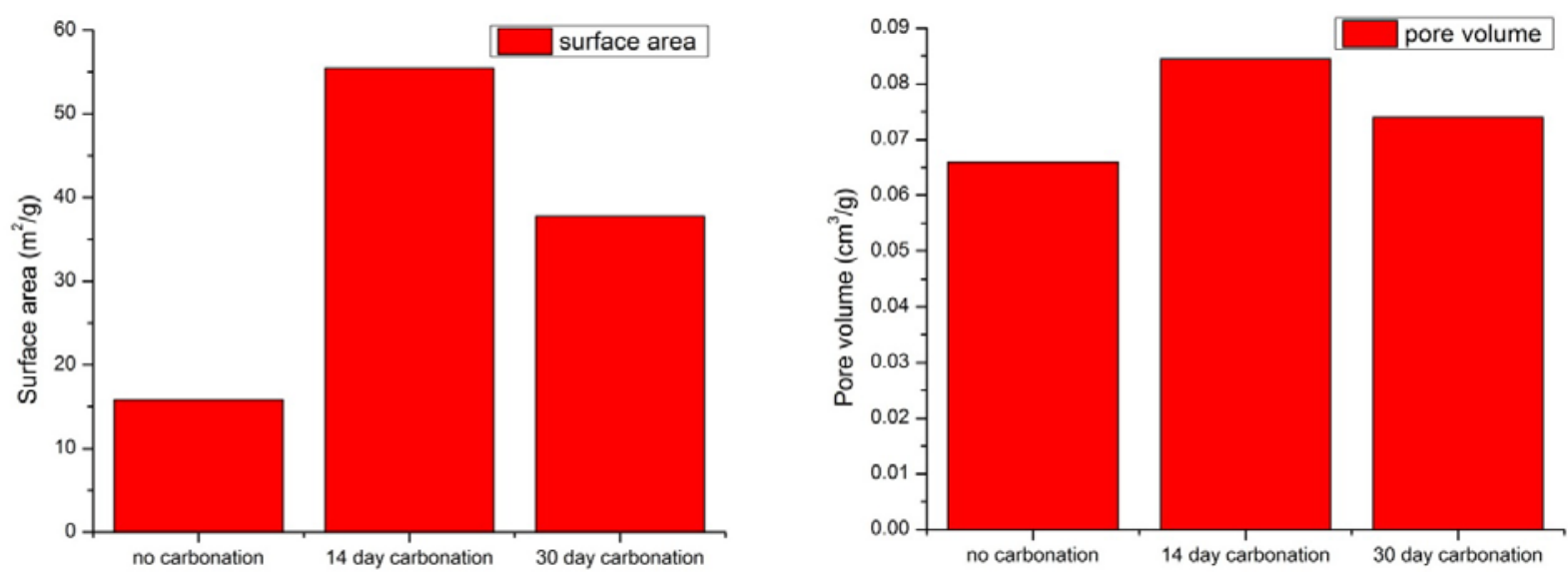

Figure 5.9. Surface Area (left) and Pore Volume (right) of Normal (uncarbonated), 14-day Carbonated, and 30-day Carbonated Cast Stone Monolith Specimens

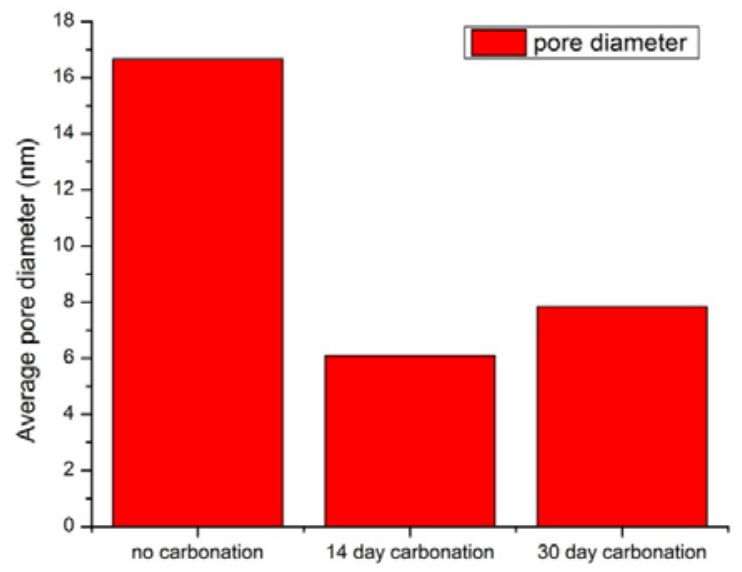

Figure 5.10. Average Pore Diameter of Normal (uncarbonated), 14-day Carbonated, and 30-day Carbonated Cast Stone Monolith Specimens

Initially during the early carbonation process, $\mathrm{Ca}^{2+}$ is released from dissolution of solid C-S-H or C-A-S-H, which increases the Cast Stone porosity but with further carbonation calcite starts to precipitate inside the Cast Stone and refills some of the empty pore space. Based on the changes in gas adsorption results, these two competing reactions, dissolution of C-S-H/C-A-S-H and precipitation of calcite, are occurring simultaneously, with the former reaction dominating during early enhanced carbonation and the latter reaction dominating later in the carbonation time period. The changes in pore diameter are more difficult to interpret. It appears that the dissolution of C-S-H/C-A-S-H gel in the early carbonation causes the internal pore structure of the Cast Stone to form smaller sized pores, but with more carbonation the average pore diameters increase, suggesting that perhaps calcite precipitation forms smaller, more dense solid particles that fill pore volume but allow average pore diameters to increase. 
The porosity of the Cast Stone monolith was calculated semi-quantitatively based on pore volumes measured by gas adsorption analysis and the calculated total volume of the monolith. Because the total mass of the Cast Stone monolith used for gas adsorption analysis is determined for each gas adsorption analysis (2.2449 $\mathrm{g}$ for uncarbonated, and $2.4751 \mathrm{~g}$ and $2.4799 \mathrm{~g}$ for 14-day and 30-day carbonated samples, respectively) and the total volume of Cast Stone monolith specimen can be determined, the porosity based on the measured pore volume of Cast Stone monolith per total volume of monolith sample could be calculated. The calculated porosity for specimens before carbonation is $8.64 \%$. The calculated porosity increased to $12.2 \%$ after the 14 -day carbonation period and decreased to $10.7 \%$ after the 30 -day carbonation period. However, because pore volume analysis as measured by nitrogen gas adsorption underestimates the total porosity of the waste form, the calculated porosities of $8.64 \%$ to $12.2 \%$ are not the actual total porosity of Cast Stone but rather represent the percentage of the smaller-sized voids that can be filled with a monolayer of adsorbed $\mathrm{N}_{2}$ and the more connected voids.

\subsubsection{X-ray Microtomography}

XMT images were collected for the small sized Cast Stone monolith prepared using the S1-2M Na simulant to provide additional information to increase our understanding of pore structure changes in Cast Stone after carbonation. The XMT images and analyses for the Cast Stone monolith were done before and after the 14-day carbonation period. Two-dimensional XMT images of the Cast Stone monolith are shown in Figure 5.11. Because light constituents like air and water do not absorb x-rays, they show up in the images as black or dark-gray colored areas compared to relatively heavy constituents in the Cast Stone monolith specimen, which show up as lighter colors. The XMT images show a heterogeneous distribution of air-filled pores (black spots) in both two-dimensional projections and cross-section images. The distribution of air-filled pores can be more easily visualized by removing other gray and white colored areas (Figure 5.11e). Most of the air-filled pores are isolated with poor connectivity, and they seem to result from air bubbles entrapped during Cast Stone preparation.

The porosity was also determined by examining the histograms of attenuation coefficients of the measured XMT slice data. Small areas of the pore structures and solid sample were examined to estimate an appropriate point for obtaining the relative abundances of pores and solids. The porosity is the value found for pore space divided by the total of pore space and solid space measured in three dimensions. The present results are based on examining 100 tomographic, two-dimensional sections stacked up around the location labeled 334 shown in Figure 5.11a. These stacked slices correspond to a thickness (height) of $0.4 \mathrm{~mm}$ for the Cast Stone monolith before carbonation and $0.8 \mathrm{~mm}$ for analysis of the Cast Stone monolith after 14 days of carbonation. The measured porosity is about $3.1 \%$ before carbonation and $4.0 \%$ after the 14-day carbonation period. The slight increase in porosity after the 14-day carbonation period is consistent with the increased pore volumes after the 14-day carbonation found by the $\mathrm{N}_{2}$ (g) adsorption analysis (Figure 5.9). However, the accuracy of the present XMT measurements is not sufficient to draw any conclusions about changes caused by carbonation reactions because of the heterogeneous distribution of pores, the limited areas used for porosity calculations, and the inability to segregate gray areas representing only water-filled pores. Because XMT porosity calculation used only air-filled pores responsible for black spots in the images, the measured porosity of about $3.0 \%$ to $4.0 \%$ for the Cast Stone monolith using XMT is lower than the calculated porosity changes (between $8.6 \%$ and $12.0 \%$ using gas adsorption analysis). Additional two-dimensional slice images collected at different locations of the Cast Stone monolith specimen are shown in Figure 5.12. The measured effective porosity based on limited areas of interrogation ranged from $0.79 \%$ to $2.64 \%$, depending on locations at which the two-dimensional 
images were collected. There are also water-filled pores as indicated by the gray-colored areas in the collected XMT images. However, it is not easy to separate these water-filled pore areas from coexisting cement solid materials because of the similar x-ray absorption coefficients of most of the light elements (Al and $\mathrm{Si}$ ) in Cast Stone.
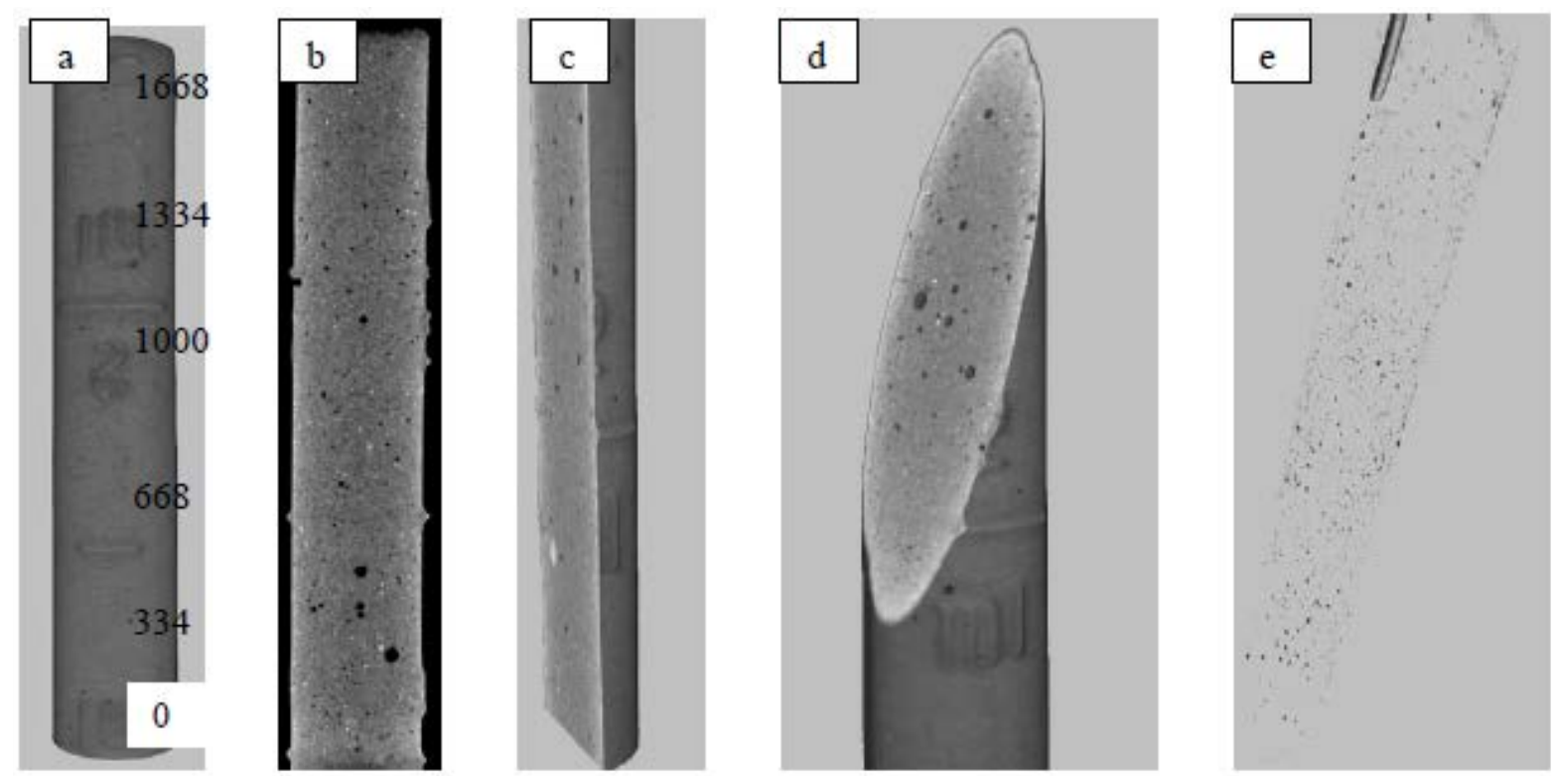

Figure 5.11. XMT Images of the Cast Stone Monolith after the 14-day Carbonation Period; (a) Cast Stone Monolith with Different Location of Two-Dimensional Section Images Collected;

(b) Two-Dimensional Projection; (c) Vertical Cross-Section; (d) Diagonal Cross-Section;

(e) Distribution of Pores After Removing Gray and White Colored Areas

\subsection{Conclusions}

Pore structure analysis was characterized with both $\mathrm{N}_{2}$ (g) adsorption analysis and XMT techniques, and the results show that Cast Stone is a relatively highly porous material (less dense) compared to other waste forms studied in this project. Detailed characterization of Cast Stone chunks and one monolith indicate that carbonation reactions can change the Cast Stone pore structure, which in turn may correlate with Tc leachability. Short (14-day) carbonation reaction times for Cast Stone samples causes pore volume and surface area increases, while the average pore diameter decreases. However, a longer (30-day) carbonation reaction time shows some reversal in the trends observed after 14 days so that there is a decrease in pore volume and surface area, but an increase in pore diameter. However, the overall change in the measured parameters still shows a net increase in pore volume and surface area and a net decrease in average pore diameter with either carbonation time period when compared to the uncarbonated Cast Stone. Longer-term carbonation investigations are required to evaluate the overall effects on Cast Stone physical properties as well as on other waste forms. Slightly increased Cast Stone porosity (3.1\% to 4.0\%) was also found with XMT analysis after 14 days of carbonation. This finding was consistent with the observed increased pore volume using gas adsorption analysis on the Cast Stone monolith after 14 days of carbonation. Based on the changes in pore volumes measured using gas adsorption analysis, the measured porosity was changed from $8.6 \%$ to $10.7 \%$ or $12.0 \%$ after carbonation depending on the length of time the enhanced carbonation was applied. The difference in porosity values measured using the two different methods illustrates the limited capability of the currently used XMT 
system to separate water-filled pores represented by gray-colored areas from cement solid materials, also depicted as a slightly different shade of gray. Neither measurement method yielded a true estimate of the total porosity of the Cast Stone waste forms studied, which is estimated to be closer to 30 to 40 volume percent.

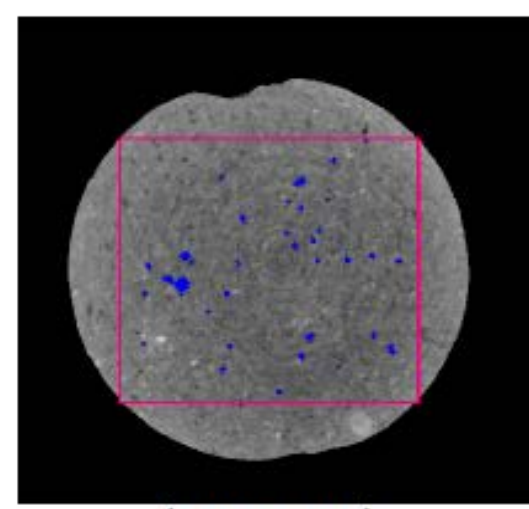

$(1668,1.39 \%)$

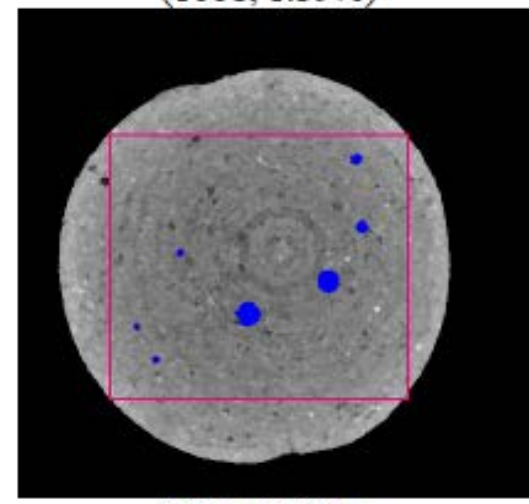

$(668,1.52 \%)$

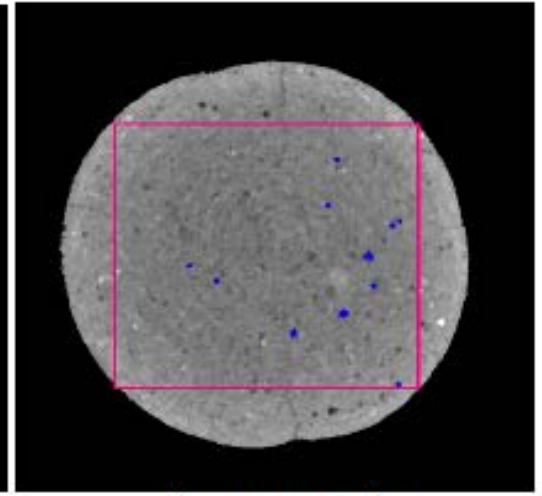

$(1334,0.44 \%)$

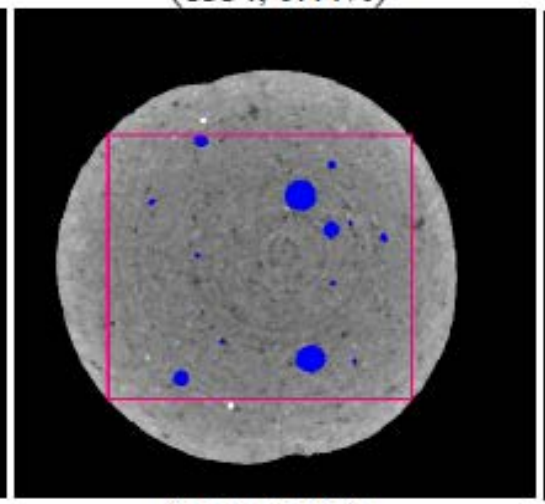

$(334,2.64 \%)$

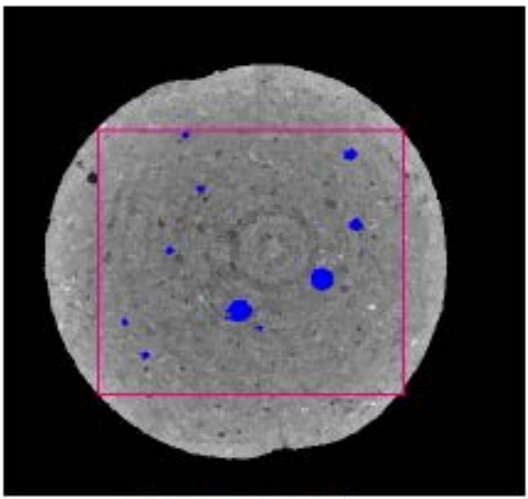

$(1000,1.69 \%)$

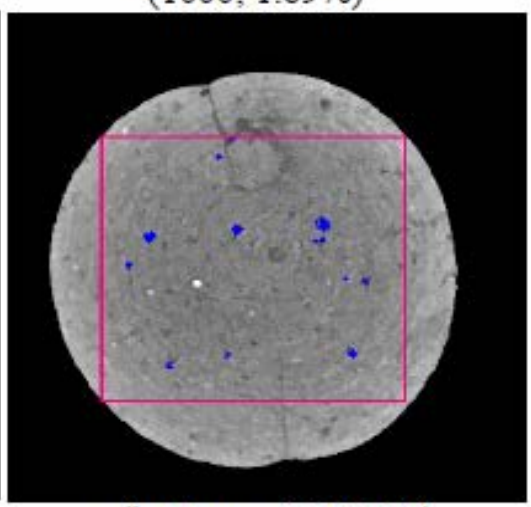

(bottom or $0,0.79 \%$ )

Figure 5.12. Two-Dimensional Computed Tomography Scans for the Cast Stone Monolith Specimen Collected at Different Locations Shown in Figure 5.11a. Digitized images are shown with different colors (blue for black spots) in a limited square field area $\left(25.42 \mathrm{~mm}^{2}\right)$. The calculated porosities based on the areas of the blue spots in a limited square area are also shown next to location information.

Two-dimensional XMT images did show the locations and distribution of pores inside the Cast Stone monolith and suggested that air-filled pores originate from entrapped air bubbles during the Cast Stone preparation process. Furthermore, the air-filled pores are not well connected. However, the water-filled pores, depicted as light gray-colored areas, are well connected and should be closely related with leachability (or diffusivity) of radionuclides constrained in the waste form. Therefore, more studies to reveal the relation between pore structure changes and leachability (or diffusivity) of target radioactive contaminants are needed. These studies should focus on providing more data that could be used to develop predictive models for waste form degradation and Tc leachability, which in turn would allow long-term performance assessment of the IDF repository. 


\subsection{EPA Method 1314 Testing}

\subsection{Introduction}

Selecting specific test methods to evaluate the release of key contaminants from the candidate waste forms was based on the following goals: 1) to rapidly assess material performance, 2) to provide some indication of the dominant release mechanisms for specific COCs, 3) to evaluate the strengths and weaknesses of a variety of waste forms (placing all waste forms on a level playing field), and 4) to gain regulatory acceptance by using test methods approved by the regulatory community. Although these goals focus on the use of standard methods, the test methods need to be augmented with the specialized characterization techniques such as those discussed in Sections 3 and 5 above. To elucidate mechanisms, a key activity is to use detailed waste form characterization both before and after leaching in combination with the leach results themselves to identify processes affecting the release of COCs from the waste forms. One goal is to correlate the measured leachate solution chemistry with changes in the solid waste forms that occur during the immersion in the leachants. This integrated approach is expected to provide insights needed to effectively evaluate what mechanisms are controlling the performance of each of the candidate waste forms and to support decisions for further testing in the ongoing and iterative secondary waste form testing program.

Four test methods were chosen for screening each waste form. In Phase I, three of the EPA test methods - 1313, 1315, and 1316 (EPA 2009a, c, d) —-were used to examine different aspects of material performance. These methods are currently undergoing EPA approval and are expected to be used in place of the Toxicity Characteristic Leaching Procedure method currently used to evaluate the leach performance of waste forms. As part of Phase II, EPA test methods 1313, 1315, and 1316 were also used in the Cast Stone Formulation Task (Sundaram et al. 2011). These three tests rely on batch contact between solutions and the waste forms so they cannot provide any data for flow-through conditions. Therefore, we also employed a fourth method-EPA 1314—as part of this radionuclide retention mechanism task. The results obtained from the EPA 1314 flow-through test provide additional data that quantifies the amount of Tc that leaches out of the candidate waste forms. The EPA 1314 method collects release data as a function of liquid-solid ratio using an upflow percolation column. The results from tests using this 1314 method are expected to provide detailed information on the kinetic and perhaps equilibrium reactions as well as the amounts and release behaviors of key COCs. This information will provide insights into the processes and mechanisms that control element release from each candidate waste form.

\subsection{Materials and Methods}

\subsubsection{Materials}

Waste form particle-size reduction was conducted by crushing and sieving the particles through a 1-mm sieve. The EPA 1314 method (EPA 2009b) recommends that the maximum particle size of the solid should be equal to or less than $1 / 20$ of the column diameter. Chromatographic Kontes ${ }^{\circledR}$ glass columns with a $2.54-\mathrm{cm}$ inner diameter and a $15.0-\mathrm{cm}$ length were used. All the $<1-\mathrm{mm}$ sieved waste forms were oven dried for 48 hours before being packed in the columns. 


\subsubsection{EPA 1314 Method}

The EPA 1314 method (EPA 2009b) is a column leach test that contacts granular material with DIW under saturated flow-through conditions. A schematic of the column test apparatus is shown in Figure 6.1. A layer of 20-to-30 mesh washed quartz sand approximately 1- to 1.5-cm thick was placed on the bottom of each column before introducing the $<1$-mm waste form particles. Then, at the top of the packed granular waste form sample, another layer of washed quartz sand was placed in the approximately 1- to 1.5-cm gap between the top of the sample and the top end cap to fill any void space below the top end cap. The actual bed length of the crushed waste form was about $12.0 \mathrm{~cm}$ of the $15.0-\mathrm{cm}$ height of the glass column. At each step in the column filling process, the total mass of the column and contents was recorded. A syringe pump was used to maintain a constant flow rate of $0.75 \pm 0.25 \mathrm{LS} /$ day (liquid-to-solid [LS] ratio/day). After packing the column, a DIW solution was initially introduced into the column, and stopped when the solution reached the top of the column to allow the column to equilibrate for 24 hours. After the 24-hour equilibration period, the pump was restarted, and the start time was recorded. At each of nine pre-determined leaching intervals to represent nine different liquid-to-solid ratios of $0.2,0.5,1.0$, 1.5, 2.0., 4.5, 5.0, 9.5, and 10.0 (mL/g-dry), the leaching solution was collected, and its mass was recorded. However, because a constant flow rate cannot be readily maintained (because of pump inefficiency, back pressure, dead space lag times and the inability to program automatic sample collectors to vary the collection schedule correctly), the desired effluent collection times do not always occur as planned; thus, the resultant LS ratios based on the volume of eluant collected at different times sometimes may vary from the nine LS ratios mentioned above. The leachate solutions collected from these packedcolumn tests were analyzed to determine the 1) $\mathrm{pH}, 2$ ) electrical conductivity (EC), 3) alkalinity, and 4) concentrations of major cations, RCRA metals, and radioactive Tc (or Re used as a surrogate for Tc in the FBSR waste form) using the analytical methods noted in previous sections and in Phase I (Pierce et al. 2010). The column tests were also subjected to the stop-flow technique for some time periods to monitor the difference between $\mathrm{COC}$ release mechanisms, namely equilibrium reactions and diffusion-controlled release processes.

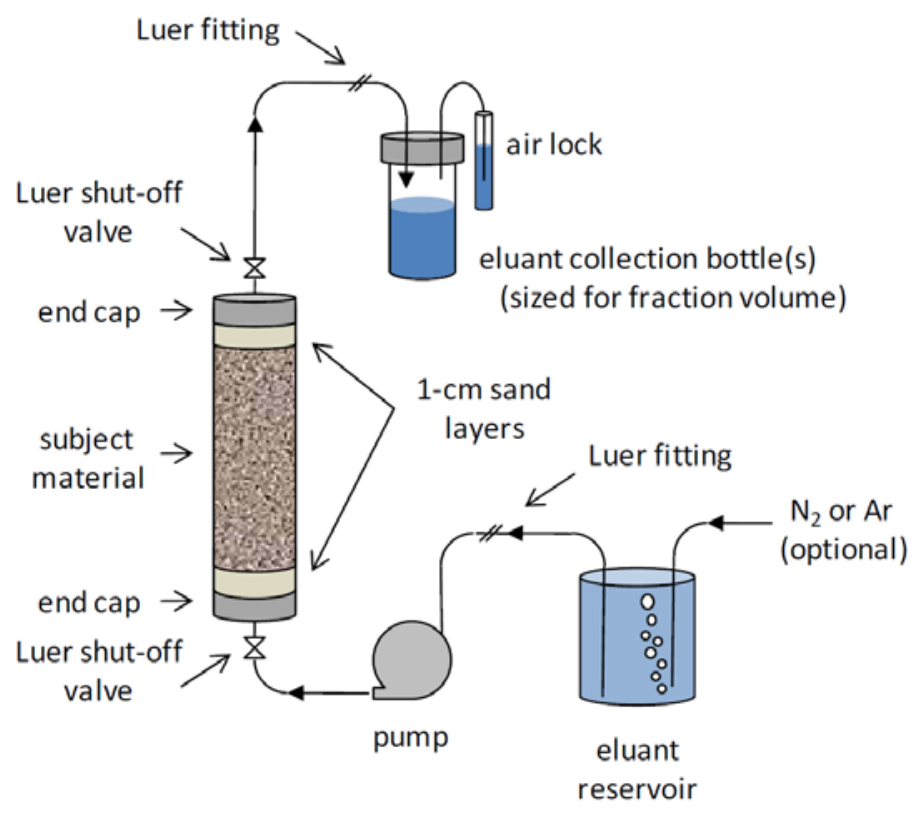

Figure 6.1. Schematic of Column Test Apparatus for the EPA 1314 Method 


\subsection{Results and Discussion}

The Tc or Re concentrations in the effluents of the EPA 1314 column tests were converted to $\mu \mathrm{g}-\mathrm{Tc} / \mathrm{g}$ of dry solid waste form. For comparison, the results for the columns packed with granular Cast Stone, DuraLith (Batch \#2), and FBSR monolith are shown in Figure 6.2. Measured pH, EC, alkalinity, and Tc (or Re) concentrations are also provided in Table 6.1. Concentrations of Tc $(\mu \mathrm{g} / \mathrm{L}$ ) in the effluents from both the Cast Stone and DuraLith waste forms decreased with time (increasing LS ratio leaching time). Slightly higher Tc concentrations were found in the leachates from the DuraLith than from the Cast Stone, which is consistent with the relatively higher Tc diffusivity from DuraLith than from Cast Stone observed in the Phase-I EPA 1315 test and from results of additional EPA 1315 tests up to 90 days described in the next section of this report (Section 7). However, the Tc concentrations that leached out of both the Cast Stone and DuraLith did not follow the linear relation between the cumulative LS ratio (mL/g-dry) and the cumulative concentration of leached Tc $(\mu \mathrm{g} / \mathrm{g})$ that would be found if solubility reactions were the controlling process. A solubility control would manifest itself as a line with a slope of 1.0 (Figure 6.2, left). Even though the cumulative LS ratio increased, no linearly increasing Tc concentrations relative to slope 1.0 were found for Tc release in either the Cast Stone or DuraLith, indicating that diffusion processes are dominant in Tc release from both waste forms. Much higher Re concentrations were observed in the EPA 1314 leachates from the FBSR monolith waste form than from the Cast Stone and DuraLith waste form leachates (Figure 6.2, left). The cumulative mass of Re leached from the FBSR waste form appears to be more related to dissolution of the FBSR matrix solids, at least at low cumulative LS ratio values up to 4 , because the data do fit a linear relation with a slope of 1.0 up to a cumulative LS ratio of 4. The appearance of a solubility-controlled trend for the release of Re at low cumulative LS ratio values is consistent with the much higher values of EC, alkalinity, and major cations measured in FBSR column effluents compared to those for Cast Stone and DuraLith (Table 6.1). All the measured major cations in the column effluents for each waste form can be found in Appendix A-2.

Results from tests using the stop-flow technique during the flow-through EPA 1314 column tests showed that increased amounts of Tc were present in the effluents of both Cast Stone and DuraLith waste forms in the first leach collected immediately after restarting the pump (Figure 6.2, right). The Tc concentration in the effluent from the DuraLith packed column immediately after restarting the flow was much higher than for the Cast Stone effluent because there was a longer stop-flow (or stagnant) period for the DuraLith (47 days) compared to the Cast Stone (16 days). Higher Tc concentrations found in the DuraLith samples collected immediately after restarting the pump indicated that Tc concentration in the effluent did not reach equilibrium (a constant concentration) at the flow rate used in EPA 1314 testing. When a diffusion process rather than a solubility process controls leachable solute concentrations, the longer the stop-flow time period, the more time there is for Tc concentrations to increase by diffusion from the packed particles into the pore water. The increased mass of Tc that diffused from the solid waste form was detected in the first couple of effluent samples collected immediately after restarting the pump. The relatively shorter stagnant period allowed in the packed Cast Stone column did not allow as much Tc to diffuse from the Cast Stone chunks into the pore water, so that the Tc concentration in the effluent sample collected immediately after restarting the pump after the 16-day stop-flow period was not appreciably different from the concentration in the effluent sample collected just before the stop-flow. However, the time at which the flow through the Cast Stone packed column was stopped was a longer cumulative time interval or leaching cycle than that for DuraLith. This longer cumulative leaching period for the Cast Stone column allowed more of the initially sequestered Tc mass to be leached out before the stop-flow started. Also, the early column effluents suggest that Tc is released from the DuraLith at a 
faster rate than from the Cast Stone (see left-hand figure); thus, allowing more time for the stop-flow condition in the DuraLith column test should promote larger masses of Tc to accumulate in the stagnant pore water to be flushed out as the flow is reinitiated.
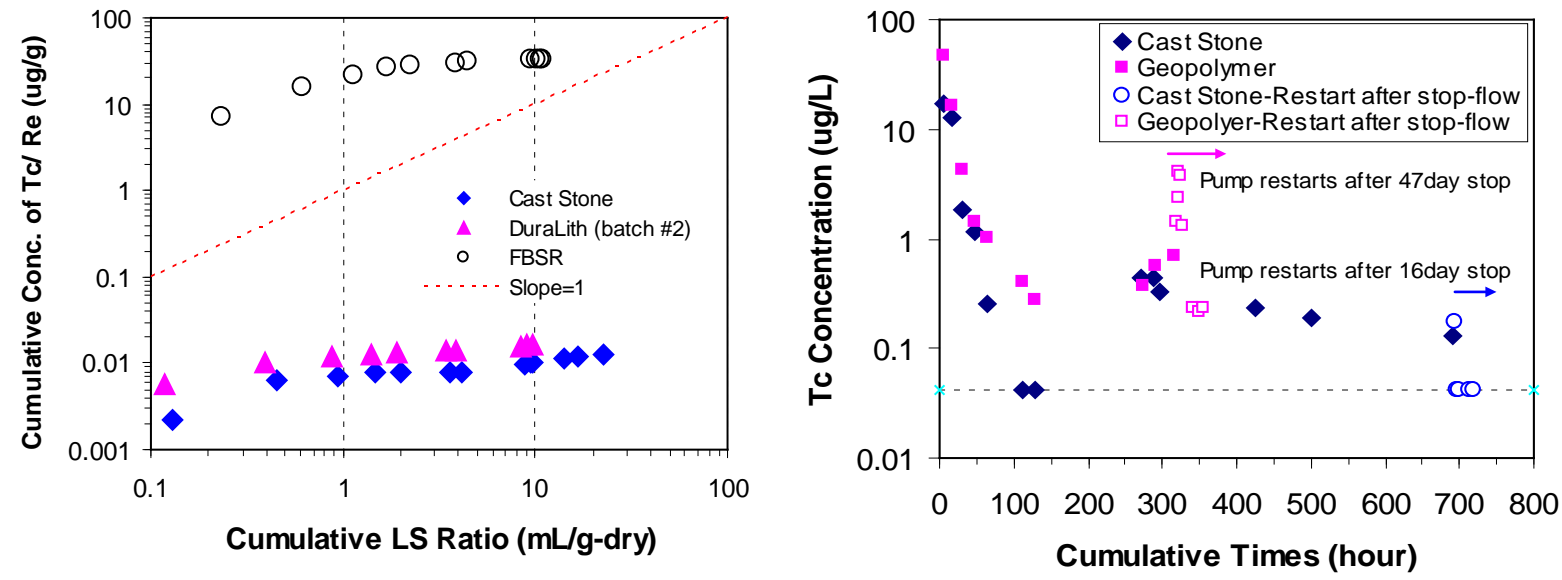

Figure 6.2. The Results of EPA 1314 Testing for Different Waste Forms. (Left) Cumulative release of Tc or Re from EPA 1314 using Cast Stone, DuraLith, and FBSR. Dotted red line represents solubility control with a slope of 1.0. (Right) Measured Tc concentrations in effluents with an additional stop-flow period as a function of cumulative time. Arrows with different colors represent the time at which the pump was restarted after a 16-day stop-flow in Cast Stone (blue) and a 47-day stop-flow in DuraLith (pink), respectively. The dashed blue line (right) indicates an estimated quantitation limit (EQL) of $0.041 \mu \mathrm{g} / \mathrm{L}$ for Tc concentration measured by inductively coupled plasma mass spectroscopy (ICP-MS).

The column effluent initial $\mathrm{pH}$ values were similar (i.e., 12.7 to 13.0) for all three waste forms (see Table 6.1). There were slight decreases in the effluent $\mathrm{pH}$ and $\mathrm{EC}$ values in all three waste forms as the solids were leached with more DIW (increasing LS ratios). The alkalinity concentrations did not show a monotonic decrease with leach time, at least in the early time periods. Much higher values of alkalinity were found in the DuraLith effluents than in the Cast Stone effluents because of different chemical compositions of the dry ingredients used to make these waste forms. Both Cast Stone and DuraLith effluents showed an initial increase in alkalinity up to an LS ratio of 2.0, and then the effluent alkalinities started to decrease at larger values of LS ratio. However, the alkalinity in Cast Stone effluent after the 7.5 LS ratio abruptly increased again, which is well matched by an increased cumulative Ca concentration (Figure 6.3, right). The abrupt increase in alkalinity and Ca concentration in Cast Stone may result from additional dissolution of calcium carbonate minerals that were formed initially when the Cast Stone was prepared.

The Method 1314 effluent from the column packed with FBSR showed a much higher initial alkalinity than the values for effluents from the other two waste forms. Alkalinity values for the FBSR effluents measured at early stages (or low cumulative LS ratios up to 1.0) were two to three orders of magnitude higher than those for Cast Stone and DuraLith, indicating that the Geo-7 encapsulated FBSR waste form dissolved much faster and more constantly in the DIW waste solution. The more dramatic decrease in alkalinity from 149,000 mg/L to $569 \mathrm{mg} / \mathrm{L}$ as $\mathrm{CaCO}_{3}$ in $\mathrm{FBSR}$ was exhausted compared to the drop in alkalinity for the DuraLith (from $3790 \mathrm{mg} / \mathrm{L}$ to $1920 \mathrm{mg} / \mathrm{L}$ as $\mathrm{CaCO}_{3}$ was depleted) at 
a cumulative LS ratio of about 7(Table 6.1) also suggests that most of the FBSR dissolution occurred during the early stages (i.e., when the cumulative LS ratio was still relatively low).

Table 6.1. pH, EC, Alkalinity, and Tc/Re Concentrations in the EPA Method 1314 Effluents from the Various Waste Forms

\begin{tabular}{|c|c|c|c|c|c|c|c|}
\hline $\begin{array}{c}\text { Waste } \\
\text { Forms with } \\
\text { Reactions }\end{array}$ & $\begin{array}{c}\text { Cumulative } \\
\text { LS Ratio }\end{array}$ & pH & $\begin{array}{c}\mathrm{EC} \\
(\mathrm{mS} / \mathrm{cm})\end{array}$ & $\begin{array}{c}\text { Tc Conc. } \\
(\mu \mathrm{g} / \mathrm{L})\end{array}$ & $\begin{array}{l}\text { Alkalinity } \\
\text { (mg/L as } \\
\left.\mathrm{CaCO}_{3}\right)\end{array}$ & $\begin{array}{c}\text { Cumulative } \\
\text { Release of Tc } \\
\text { or } \operatorname{Re}(\mu \mathrm{g} / \mathrm{g})\end{array}$ & $\begin{array}{l}\text { Cumulative } \\
\text { Release of Tc } \\
\text { or } \operatorname{Re}(\%)^{(b)}\end{array}$ \\
\hline \multirow{13}{*}{ Cast Stone } & 0.129 & 12.7 & $\mathrm{NM}^{(\mathrm{a})}$ & 17.2 & NM & 0.00222 & 1.13 \\
\hline & 0.452 & 12.8 & 38.2 & 12.9 & 27.9 & 0.00639 & 3.25 \\
\hline & 0.943 & 12.7 & 23.6 & 1.86 & 33.0 & 0.00730 & 3.71 \\
\hline & 1.47 & 12.6 & 16.6 & 1.14 & 63.5 & 0.00789 & 4.01 \\
\hline & 2.01 & 12.5 & 10.7 & 0.258 & 51.5 & 0.00804 & 4.09 \\
\hline & 3.60 & 12.3 & 7.17 & 0.0425 & 58.4 & 0.00810 & 4.12 \\
\hline & 4.13 & 11.9 & 2.37 & 0.0151 & 57.9 & 0.00811 & 4.12 \\
\hline & 8.89 & 11.8 & 1.89 & 0.432 & 53.5 & 0.0102 & 5.17 \\
\hline & 9.43 & 11.6 & 1.00 & 0.432 & 44.9 & 0.0104 & 5.29 \\
\hline & 9.70 & 8.70 & NM & 0.335 & 159 & 0.0105 & 5.33 \\
\hline & 14.0 & 11.8 & 1.63 & 0.236 & 83.1 & 0.0115 & 5.85 \\
\hline & 16.6 & 11.7 & 1.76 & 0.189 & 405 & 0.0120 & 6.10 \\
\hline & 22.9 & 11.7 & 1.77 & 0.129 & 430 & 0.0128 & 6.51 \\
\hline \multirow{11}{*}{$\begin{array}{l}\text { DuraLith } \\
\text { Batch \#2 }\end{array}$} & 0.119 & 12.8 & 20.2 & 46.9 & NM & 0.00558 & 2.15 \\
\hline & 0.392 & 12.2 & 26.8 & 16.1 & 3790 & 0.00997 & 3.84 \\
\hline & 0.884 & 12.4 & 20.7 & 4.24 & 4490 & 0.0121 & 4.64 \\
\hline & 1.39 & 12.4 & 16.8 & 1.43 & 4410 & 0.0128 & 4.92 \\
\hline & 1.89 & 12.3 & 15.7 & 1.02 & 4260 & 0.0133 & 5.12 \\
\hline & 3.40 & 12.0 & 12.8 & 0.405 & 3410 & 0.0139 & 5.35 \\
\hline & 3.90 & 12.3 & 9.48 & 0.283 & 2750 & 0.0140 & 5.41 \\
\hline & 8.43 & 12.1 & 6.53 & 0.369 & 2130 & 0.0157 & 6.05 \\
\hline & 8.98 & 12.0 & 5.02 & 0.577 & 3030 & 0.0160 & 6.17 \\
\hline & 9.78 & 11.9 & 3.40 & 0.690 & 1920 & 0.0166 & 6.39 \\
\hline & & & & $\begin{array}{l}\text { Re conc. } \\
(\mu \mathrm{g} / \mathrm{L})\end{array}$ & & & \\
\hline \multirow{11}{*}{$\begin{array}{c}\text { FBSR } \\
\text { Monolith }\end{array}$} & 0.233 & 13.0 & NM & 31200 & 149000 & 7.27 & 2.82 \\
\hline & 0.617 & 12.9 & 76.0 & 22800 & 92200 & 16.0 & 6.21 \\
\hline & 1.13 & 12.8 & 58.0 & 11800 & 47700 & 22.1 & 8.57 \\
\hline & 1.69 & 12.7 & 43.5 & 7350 & 33000 & 26.2 & 10.2 \\
\hline & 2.26 & 12.5 & 20.3 & 2550 & 10600 & 27.7 & 10.7 \\
\hline & 3.91 & 12.4 & 10.2 & 1400 & 4770 & 30.0 & 11.6 \\
\hline & 4.46 & 12.2 & 5.75 & 918 & 2790 & 30.5 & 11.8 \\
\hline & 9.40 & 11.7 & 2.36 & 544 & 990 & 33.2 & 12.9 \\
\hline & 10.1 & 11.6 & 1.46 & $<350$ & 569 & 33.4 & 13.0 \\
\hline & 10.6 & 11.4 & 1.18 & $<350$ & 467 & 33.6 & 13.0 \\
\hline & 11.0 & 11.4 & 1.06 & $<350$ & 441 & 33.7 & 13.1 \\
\hline
\end{tabular}

(a) $\mathrm{NM}=$ not measured.

(b) Cumulative release of Tc or Re $=$ [cumulative concentrations of Tc or Re ( $\mu \mathrm{g} / \mathrm{g}$-dry solid)/initial concentration $\left(\mathrm{C}_{\mathrm{o}}\right)$ of Tc or Re $(\mu \mathrm{g} / \mathrm{g}$-dry solid $\left.)\right] \times 100$. 
Cumulative release percentage of Tc or Re was also determined using the starting concentration of Tc or Re in the oven-dried Cast Stone, DuraLith Batch \#2, and Geo-7 encapsulated FBSR waste forms (Table 6.1). Even though the Tc release rate is low, the cumulative Tc release percentages in Cast Stone and DuraLith showed a slowly increasing trend similar to the trend in the cumulative releases of cations from these waste forms (see figures below). However, the cumulative Re release percentage for the Geo-7 encapsulated FBSR showed an early increase and reached a plateau after the cumulative LS ratio reached 9.0, which is also similar to the trends found for cations released from the FBSR waste form. The Geo-7 encapsulated FBSR waste form showed a higher cumulative Re release percentage (13.0\%) before the cumulative LS ratio reached 10.0 compared to the cumulative Tc release percentages $(5.33 \%$ and 6.39\%) found in Cast Stone and DuraLith waste forms (Table 6.1).

The cumulative release concentrations ( $\mu \mathrm{g} / \mathrm{g}$-dry of waste form) for RCRA-listed metals and major cations in the EPA 1314 method effluents from the Cast Stone column are shown in Figure 6.3. Many RCRA-listed metals' cumulative concentration trends were similar to that of Tc, in which the process is diffusion-controlled. However, the cumulative concentration values for $\mathrm{Cr}$ and As showed a more linear relationship, especially at low cumulative LS ratios (up to 4 to 5 cumulative LS ratio), indicating the possibility of dissolution-controlled release for these three metals at an early leaching stage. The cumulative concentrations of $\mathrm{Cd}$ and $\mathrm{Pb}$ releases were very similar to that of Tc in the Cast Stone effluents as a function of releasing time. The major cations showed significantly larger cumulative concentrations leached compared to those of RCRA metals in Cast Stone (Figure 6.3, right) as would be expected for components that are present at much higher concentrations in Cast Stone waste forms. The leaching for most major cations matched well a linear trend with a slope of 1.0 up to 4.0 cumulative LS ratio, and the cumulative concentrations for $\mathrm{Al}, \mathrm{K}$, and Si releases showed linear relationships with slopes of 1.0 up to 10 cumulative LS ratio. There was an abrupt increased concentration of the leached Ca after a cumulative LS ratio of 4.0, indicating additional dissolution of calcium carbonate minerals in Cast Stone at this time. Total S concentration was also plotted, and cumulative S releases seemed to be controlled by a diffusion process.
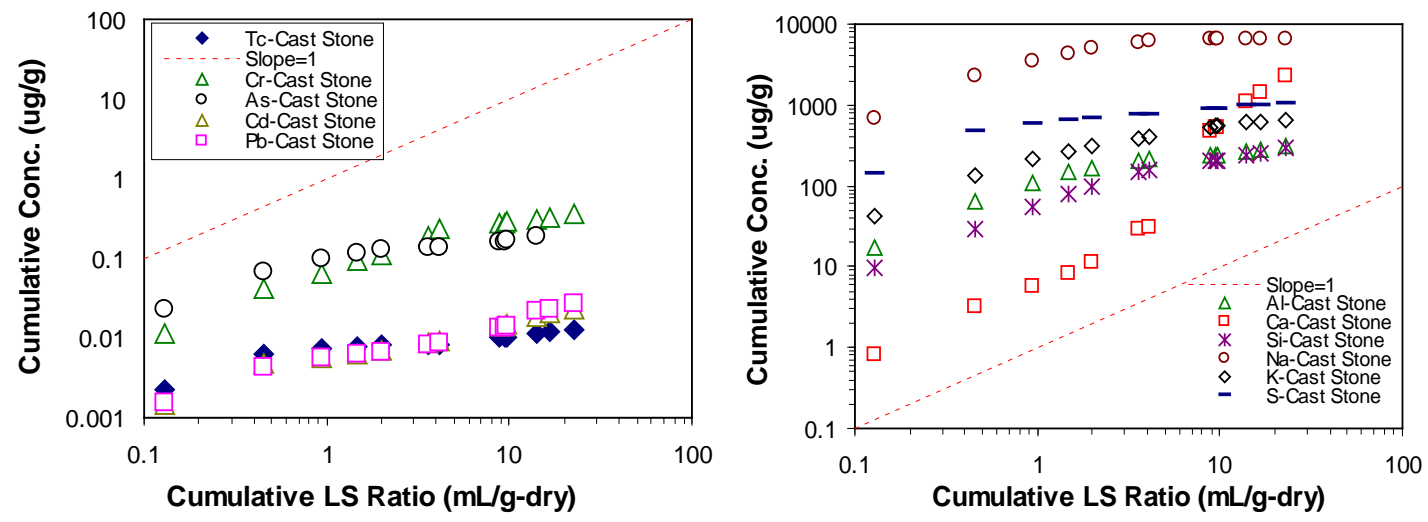

Figure 6.3. Cumulative Leached Concentrations of RCRA-Listed Metals and Tc (left) and Major Cations (right) from Tests of Cast Stone using the EPA 1314 Method. Dashed red lines represent solubility control with a slope of 1.0.

Similarly, there were higher cumulative concentrations of major cations compared to RCRA-listed metal concentrations leached from the DuraLith (Batch \#2) using the EPA 1314 method (Figure 6.4). The 
cumulative concentrations of most metals leached from the DuraLith showed gradual increases with time that appear to be diffusion controlled (most not solubility controlled), but the cumulative concentrations leached from the DuraLith were still lower than those that leached from Cast Stone (Figure 6.3 and Figure 6.4), except for the ${ }^{99} \mathrm{Tc}$ as shown in Figure 6.2.

Concentrations of $\mathrm{K}$ and Na that leached from DuraLith using the EPA 1314 method (Figure 6.4, right) show a linear relation with a slope of $~ 1.0$, suggesting that these major cations may be solubility controlled. Both $\mathrm{Al}$ and Si releases showed continuously increasing cumulative concentrations leached with a slope larger than 1.0 as the cumulative LS ratio increased, indicating continuous rapid dissolution of the DuraLith and release of its two major elements, Si and Al. The cumulative concentrations of Ca seemed to slowly increase but with linear slope less than 1.0 with increasing cumulative LS ratio values, because calcium is a minor component and diffusion is becoming the dominant process controlling $\mathrm{Ca}$ release as the leaching increases in the DuraLith. Cumulative $S$ release from the DuraLith appears to be controlled more by a diffusion process.
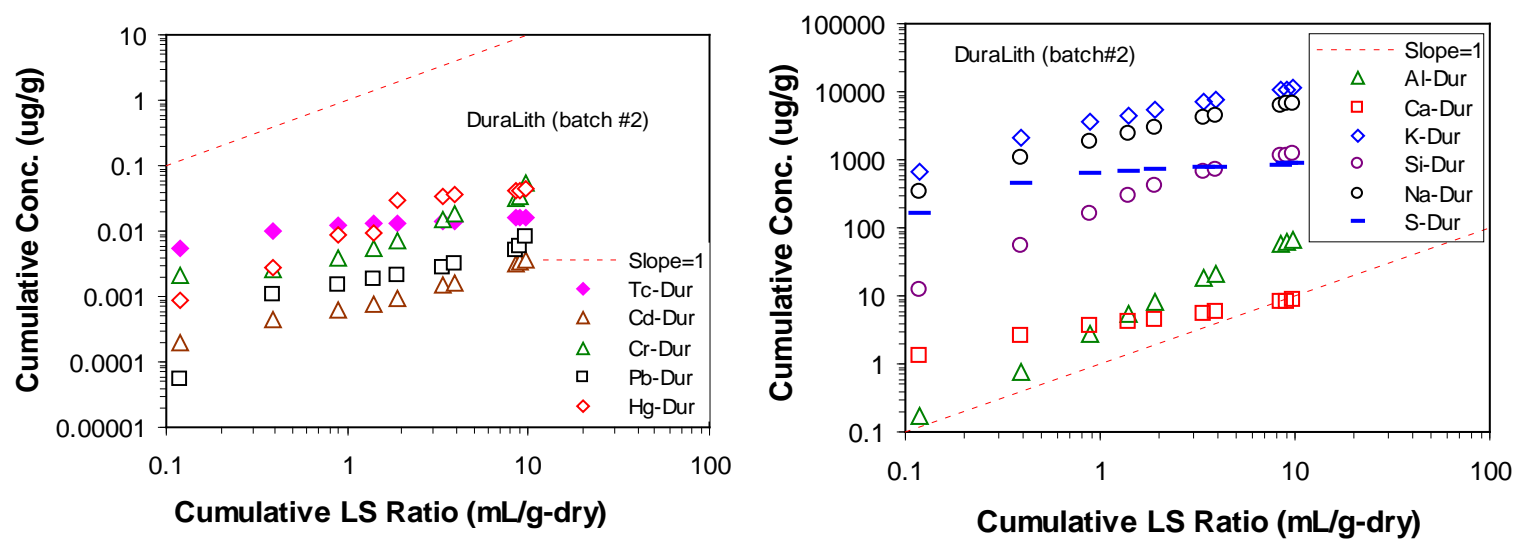

Figure 6.4. Cumulative Leached Concentrations of RCRA Metals with Tc (left) and Major Cations (right) from DuraLith (Batch \#2) using EPA 1314 Testing. Dashed red line represents solubility control with a slope of 1.0 .

The cumulative concentrations of RCRA-listed metals and major cations present in the Geo-7 encapsulated FBSR EPA 1314 method effluents showed different trends from those in Cast Stone and DuraLith (Figure 6.5). Much higher cumulative concentration releases for RCRA-listed metals were found for the effluents from the column packed with FBSR monolith chunks (Figure 6.5, left) compared to those for Cast Stone and DuraLith (Figure 6.3 and Figure 6.4). Also, the slowing trend in RCRA-listed metal concentrations with increasing cumulative LS ratio is very similar to that for the major cations and Re cumulative leached concentrations found in the Geo-7 encapsulated FBSR column leachates (Figure 6.5, right). Higher concentrations of the RCRA metals are expected because of the higher concentrations in the waste simulant used to prepare the FBSR product. Because leaching trends of cumulative concentrations for RCRA-listed metals, Re, and the major cations are all similar, at least for early leaching times ( $<3$ cumulative LS ratio), the release mechanisms from the FBSR waste form are also similar and are expected to be controlled by solubility, especially at early leaching times. The observed higher cumulative concentrations of $\mathrm{Na}$ and Re also agreed well with the very high measured EC and alkalinity in FBSR waste form (Table 6.1). 

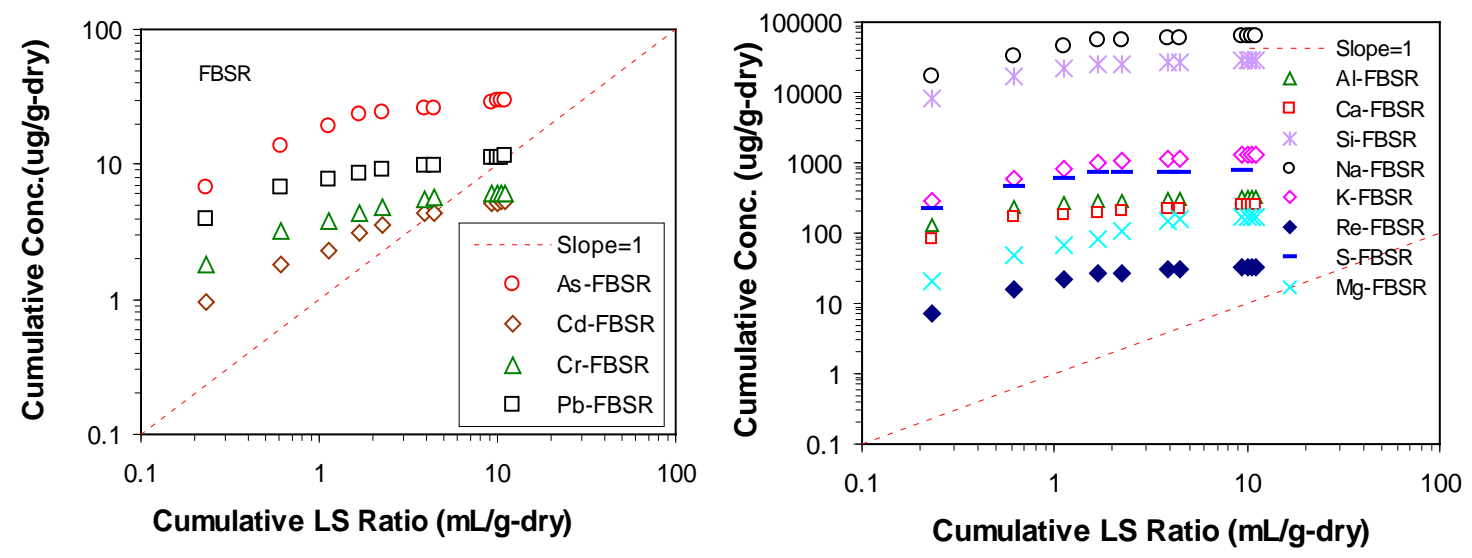

Figure 6.5. Cumulative Leached Concentrations of RCRA-Listed Metals with Re (left) and Major Cations (right) from FBSR Using EPA 1314 Testing. Dashed red line represents solubility control with a slope of 1.0 .

\subsection{Conclusions}

The EPA 1314 method was used to test leaching behavior of target contaminants (Re or Tc) and select RCRA-listed metals and major cations from different waste forms with an upflow percolation column. The leaching behavior of Tc was similar in both Cast Stone and DuraLith (Batch \#2) that was crushed to chunks and packed in the columns in accordance with the EPA 1314 testing procedure. The slightly larger amount of Tc leached from the DuraLith in comparison to Cast Stone is consistent with the higher Tc diffusivity found in EPA 1315 tests conducted in Phase I (Pierce et al. 2010). The observed larger cumulative concentrations of Re leached from the Geo-7 encapsulated FBSR chunks using the EPA 1314 method also agreed well with the Re diffusivity results found in the independent FBSR testing (Pires et al. 2011). The stop-flow technique applied to both the Cast Stone and DuraLith EPA 1314 column tests suggests that Tc release from both Cast Stone and DuraLith is controlled by slow diffusion processes because there were larger Tc concentrations in effluents collected right after restarting the flow. Different Tc concentrations detected in effluents collected right after restarting the flow in the two waste form columns were attributed to different stagnant (or stop-flow) periods and different total leaching times for these two waste forms.

Cumulative leached concentrations of RCRA-listed metals are higher than or similar to the leached cumulative concentrations of Tc in the Cast Stone (see Figure 6.3) and lower than the cumulative concentrations of Tc leached from the DuraLith (Figure 6.4). The cumulative concentrations of major cations leached from Cast Stone and DuraLith during EPA 1314 testing were much higher than for the Tc and RCRA-listed metals, and more importantly showed a close relationship to dissolution of the host matrix. Continuously increasing cumulative concentrations leached with a slope greater than 1.0 as the cumulative LS ratio value increased were found for $\mathrm{Ca}$ in the Cast Stone samples and for $\mathrm{Si}$ and $\mathrm{Al}$ in the DuraLith. These increasing rates with slopes higher than 1.0 for the $\mathrm{Ca}, \mathrm{Al}$, and Si leaching behavior resulted from the dissolution of two separate phases in each waste form material as the cumulative LS ratio value (time) increased. That is, the Ca in the Cast Stone is a major component present in several different compounds that leach at different rates, and similarly, the Si and $\mathrm{Al}$ in the DuraLith geopolymer are present in phases with different dissolution rates. 
Concentrations of RCRA-listed metals and major cations in the Geo-7 encapsulated FBSR waste form leachates collected with the EPA 1314 method were high in comparison with the other two waste forms. This is expected because of the higher concentrations of the RCRA metals in the simulant used for the FBSR product. The observed high cumulative concentration values as functions of cumulative LS ratio value (time) agree well with the high EC and alkalinity concentrations found in the leachates. Higher Re leachate concentration could also be due to high initial Re concentration used in preparation of FBSR

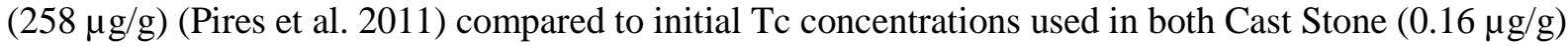
and DuraLith waste forms $(0.30 \mu \mathrm{g} / \mathrm{g}$ for Batch \#1 and $0.23 \mu \mathrm{g} / \mathrm{g}$ for Batch \#2) (Pierce et al 2010). 



\subsection{Extension of EPA Method 1315 on Phase-I Waste Forms}

\subsection{Introduction}

The leachability or diffusivity of Tc is one of the criteria used to down-select among the waste form candidates. Although the EPA 1315 test requires conducting the batch leaching test up to 63 days, continued leachate collection after 63 days was performed to provide more data to aid in understanding the long-term leaching behavior of Tc from two waste forms used in Phase I screening testing.

Following the completion of the Phase-I secondary waste form testing program, the EPA 1315 leach test experiment for the Cast Stone and DuraLith monolith waste forms, the waste forms were put back into leachate solution and reacted for an additional 30 days of leaching. The total cumulative leaching period was extended from the initial 63 days prescribed by EPA 1315 method to 90 days total.

Subsequent to the completion of the 90-day reaction, post-test characterization of the weathered samples was performed to gain insight into the processes responsible for the observed decreasing diffusivity values with time that were measured in Phase I (see Pierce et al. 2010). The results from the Phase-I test suggested that calcite precipitation related with carbonation may be the mechanism responsible for the observed decreases in Tc diffusivity values, especially for the longer reacted Cast Stone samples. To evaluate this possible mechanism, one cylindrical monolith sample after a 90-day reaction period for each waste form type was sliced vertically into two equal halves with a tile saw without using water. One half was used for additional vertical sectioning, and the other half was used for additional horizontal sectioning to obtain both vertical and horizontal profiles of alteration phases that may have formed. The vertical and horizontal sections of the 90-day reacted waste forms were analyzed with bulk x-ray diffraction (XRD) and scanning electron microscopy (SEM) analyses to identify 1) chemical gradients within the monolith and 2) mineralogical changes from precipitation of other constituents in specific locations in the monoliths, if there are any.

\subsection{Materials and Methods}

\subsubsection{Materials}

Monolith waste forms (2-in. diameter by 4-in. height) of Cast Stone and DuraLith used for Phase-I screening testing of secondary waste forms were used for this extension of the EPA 1315 method. Two replicate Cast Stone and two replicates of each DuraLith monolith from Batches 1 and 2 were used in this extended leach test. After a cumulative 90-days leaching, one reacted monolith waste form of each type was sliced with a tile saw inside a glove bag and used for post-leaching solid phase characterization. A top-half hemisphere of each waste form monolith was again sliced into three horizontal samples (numbered 1, 2, and 3) from top to bottom. Another bottom-half hemisphere of each waste form monolith was further sliced into bottom-vertical samples 1 to 5 or 6 from right to left. A schematic of the sliced monolith samples after leaching for 90 days is shown in Figure 7.1.

The composition of the Cast Stone from Phase I is listed in Table 7.1 and includes a mix of common Portland Type I/II cement with Class F fly ash and Grade 100 BFS. More details can be also found in Pierce et al. (2010). 


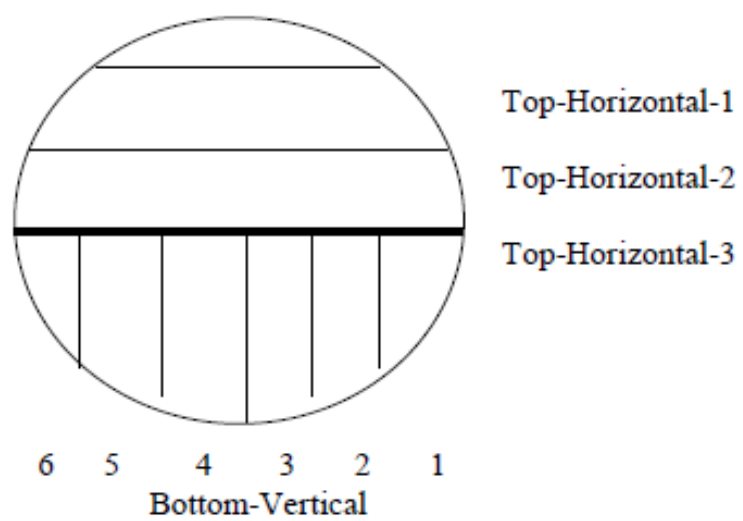

Figure 7.1. Schematic of Sliced Monolith Samples after Leaching for 90 Days

Table 7.1. Material Specifications and Compositions for Cast Stone Monoliths Used in Phase I

\begin{tabular}{ccc}
\hline Material & Specification & Amount Used (g) per Monolith \\
\hline Simulant-Phase I ${ }^{(\mathrm{a})}$ & & 96.7 \\
Cement & Portland Cement, Type I/II ${ }^{(\text {b) }}$ & 76.82 \\
Fly Ash & Class F & 431.95 \\
BFS & Type 100 & 451.21 \\
DIW & & 276.7 \\
\hline
\end{tabular}

(a) Phase-I simulant composition can be found in Table 2.1.

(b) Type I is more general-purpose Portland cement whereas Type II is general-purpose Portland cement that has better sulfate resistance. Therefore, the general properties of these two cements are similar. If the cement conforms to both Type I and II, the cement company may write their product as either Type I, Type II, or Type I/II. It solely depends on their commercial purpose. Cast Stone is produced using cement conforming both Type I and II; therefore, either Type I or II can be used to produce Cast Stone (Sundaram et al. 2011).

The DuraLith monoliths were prepared for Phase I from a recipe provided by Dr. Weiliang Gong from the Catholic University of America. The composition is listed in Table 7.2. The mixing process is similar to that described previously in Section 2.3. More details can be also found in Pierce et al. (2010).

Table 7.2. Material Specifications and Compositions for DuraLith Monoliths

\begin{tabular}{lccc}
\hline \multicolumn{1}{c}{ Material } & Addition Order & Batch \#1 & Batch \#2 \\
Amount Used (g) & Amount Used (g) \\
\hline Simulant-Phase I ${ }^{(\mathrm{a})}$ & 1 & 798.5 & 399.25 \\
Tin fluoride & 2 & 3.0 & 1.5 \\
Potassium hydroxide & 3 & 411.4 & 205.7 \\
Sodium hydroxide & 3 & 20.1 & 10.05 \\
Fumed silica & 4 & 463.8 & 231.9 \\
Meta-kaolinite & 5 & 813.3 & 406.7 \\
Furnace slag & 5 & 534.2 & 267.1 \\
Sand & 5 & 759.5 & 379.8 \\
Sodium sulfide hydrate & 5 & 5.0 & 2.5 \\
Silver zeolite & 6 & 20.0 & 10.0 \\
\hline
\end{tabular}

(a) Phase-I simulant composition can be found in Table 2.1. 


\subsubsection{EPA Method 1315}

The EPA 1315 method (EPA 2009c) is a 63-day semi-dynamic leach test that consists of submerging a monolithic sample (with a fixed geometry) in water at a fixed liquid volume-to-solid surface area ratio and sampling at fixed periods of time (EPA 2009c). The cumulative leaching time was extended from 63 days up to 90 days, and the data collected at 90 days were also used to calculate diffusivity values in this report. The geometric surface area used in this EPA 1315 method is calculated based on the cylindrical dimensions of the sample. At each of the nine pre-determined leaching intervals, the sample mass is recorded, and the leaching solution is changed. This method is similar to American National Standards Institute/American Nuclear Society (ANSI/ANS)-16.1, but the leaching intervals are modified, and the process of mass transfer can be interpreted by more complex release models that account for physical retention of the porous medium and chemical retention at the pore wall through geochemical speciation modeling.

The cylindrical monolith sample (2-in. diameter by 4-in. height) was placed into the center of a leaching vessel and mixed with DIW to maintain a solid-to-solution ratio of $9 \pm 1 \mathrm{~mL}$ of eluant per $\mathrm{cm}^{2}$ of sample. The sample stand and holder were used to maximize contact area of the sample with the leaching solution. Between the sampling/replacement intervals, the experimental vessels were covered with a lid. The leaching intervals used for these experiments were 2 hours and 1, 2, 7, 14, 28, 42, 49, and 63 days, with an additional 90 days. Samples collected during these intervals were used to measure $\mathrm{pH}$, EC, and redox potential. Before chemical analyses, the samples were also filtered with a $0.45-\mu \mathrm{m}$ syringe filter.

The observed diffusivity for each constituent was calculated with the analytical solution, Equation 7.1, for simple radial diffusion from a cylinder into an infinite bath as presented by Crank (1986).

$$
D_{i}=\pi\left[\frac{M_{t_{i}}}{2 \rho C_{o}\left(\sqrt{t_{i}}-\sqrt{t_{i-1}}\right)}\right]^{2}
$$

where $\quad \mathrm{D}_{i}=$ observed diffusivity of the constituent for leaching interval $i\left[\mathrm{~m}^{2} / \mathrm{s}\right]$

$\mathrm{M}_{t i}=$ mass released during leaching interval $i\left[\mathrm{mg} / \mathrm{m}^{2}\right]$

$\mathrm{t}_{i}=$ cumulative contact time after leaching interval $i[\mathrm{~s}]$

$\mathrm{t}_{i-1}=$ cumulative contact time after leaching interval $i-1[\mathrm{~s}]$

$\mathrm{C}_{0}=$ initial leachable content $(\mathrm{mg} / \mathrm{Kg})$

$\rho \quad$ sample density $\left(\mathrm{Kg}-/ \mathrm{m}^{3}\right)$.

The mean observed diffusivity for each constituent can be determined by taking the average of the interval observed diffusivity with the standard deviation. A leachability index (LI) can then be calculated as the negative logarithm of the observed diffusivity in $\mathrm{cm}^{2} / \mathrm{s}$ as shown in Equation 7.2. A low diffusivity means a larger LI.

$$
L I=-\log \left(\frac{D_{\text {effective }}}{\mathrm{cm}^{2} \mathrm{~s}}\right)
$$

All leachate solutions collected from the additional EPA 1315 method tests were monitored for $\mathrm{pH}$, EC, alkalinity, major anions, major cations, Tc, and RCRA-listed metals. The $\mathrm{pH}$ of the solution samples 
was measured with a solid-state pH electrode and a pH meter (Hanna, Model HI 4521). Before measurement, the $\mathrm{pH}$ probe was calibrated with National Institute of Standards and Technology (NIST)traceable buffers $\left(\mathrm{pH}=2.0,4.0,7.0,10.0\right.$, and/or 12.0 at $\left.25^{\circ} \mathrm{C}\right)$. The precision of the $\mathrm{pH}$ measurement was $\pm 0.1 \mathrm{pH}$ units. A Pharmacia Biotech conductivity sensor was used to measure the EC of leachate solutions. The sensor was calibrated with a range of freshly prepared potassium chloride standard solutions, ranging from $0.001 \mathrm{M}$ to $1.0 \mathrm{M}$. Approximately $2 \mathrm{~mL}$ to $3 \mathrm{~mL}$ of filtered leachate was used to measure the conductivity. Alkalinity $\left(\mathrm{mg} / \mathrm{L}\right.$ as $\left.\mathrm{CaCO}_{3}\right)$ was measured with a standard acid titration method (total alkalinity at $\mathrm{pH}=4.5$ ). The alkalinity procedure is equivalent to the U.S. Geological Survey method in the National Field Manual for the Collection of Water-Quality Data (USGS 2004). The concentrations of nitrate $\left(\mathrm{NO}_{3}{ }^{-}\right)$, phosphate $\left(\mathrm{PO}_{4}{ }^{-3}\right)$, and sulfate $\left(\mathrm{SO}_{4}{ }^{-2}\right)$ in the leachate solutions were determined using ion chromatography with a Dionex AS17 column. This methodology is based on EPA Method 300.0A (EPA 1984) with the exception of using the gradient elution of $\mathrm{NaOH}$. Microwaveassisted, strong-acid digestions were conducted with 16- $\mathrm{M} \mathrm{HNO}_{3}$ ( 17 wt\%), $12 \mathrm{M} \mathrm{HCl}$ (7 wt\%), $32 \mathrm{M} \mathrm{HF}$ (3.3 wt\%), and DIW (72.7\%). About $0.5 \mathrm{~g}$ of $\mathrm{H}_{3} \mathrm{BO}_{3}$ was added to the acid leachate later before analysis for total Tc concentration and other major cations. The concentration of major cations was performed with inductively coupled plasma optical emission spectroscopy (ICP-OES) using high-purity calibration standards to generate calibration curves and verify continuing calibration during the analysis run. Because of the differences in the leachate cation concentrations, a number of dilutions, ranging from 100 to 1.01 times, were used to obtain measurable concentrations of the cations of interest. Details of this method are found in EPA Method 6010B (EPA 2000a). Inductively coupled plasma mass spectrometry (ICP-MS) was used to measure RCRA-listed metal concentrations, including I, Hg, and ${ }^{99} \mathrm{Tc}$. These measurements were performed following the PNNL-AGG-415 method (PNNL 1998), which is similar to EPA Method 6020 (EPA 2000b).

\subsubsection{X-Ray Diffraction Analysis}

The phase compositions and changes in the waste forms after the 90-day EPA 1315 test were determined using XRD. For the XRD analysis, aliquots from the aforementioned slices of each waste form after the 90-day sample collection were ground in a mortar and pestle. Small amounts of acetone were added to mitigate heat created during the grinding process. Dry powdered specimens were packed into sample holders, and then each sample holder was placed in the Panalytical MPD system. X-ray powder diffraction patterns were recorded with $\mathrm{Cu} \mathrm{K}_{\alpha}$ radiation with a Panalytical MPD system operated at $40 \mathrm{kV}$ and $45 \mathrm{~mA}$. Scans were measured between 5 and 80 degrees $2 \theta$ using a variable divergent slit and post-diffraction graphite monochromator. Crystalline compounds were identified by comparing them with patterns in the International Center for Diffraction Data (ICDD) (Newtown ICDD database using the JADE diffraction software [Materials Data Incorporated, California]).

\subsubsection{Scanning Electron Microscopy and Energy Dispersive Spectrometry}

Powdered samples from selected slices from each 90-day leached waste form were also mounted with double-sided carbon tape attached to an aluminum stub. After being mounted, the side of the specimen was coated with silver paint to ensure good transmission of electrons. The sample was sputter coated with palladium in a vacuum to improve the conductivity of the samples and the quality of the SEM images and the energy dispersive x-ray spectroscopy (EDS) signal. A JEOL 5900 SEM was used to provide images of these samples. Mostly secondary electron images were obtained, and some backscattered electron images were recorded if necessary. EDS was used to determine the chemical 
compositions of observed features for different sliced samples prepared at different locations. A Metek EDS System was used to collect EDS spectra for qualitative elemental analysis.

\subsection{Results and Discussion}

\subsubsection{Diffusivity (or leachability index) of Tc}

The Tc diffusivity coefficient after leaching for 90 days was calculated and is shown along with previous Tc diffusivities in Figure 7.2. The calculated diffusivity after leaching for 90 days was in line with previous results for diffusivity calculated up to 63 days. Consistent with previous results, the Cast Stone showed a lower Tc diffusivity at 90 days than both the DuraLith waste forms studied in Phase I (Batches 1 and 2). While the Tc diffusivity after 90 days for Cast Stone was lower than the value after 63 days of leaching, both DuraLith monoliths showed slightly increased Tc diffusivity values after 90 days compared to values after 63 days (Table 7.3). The lower Tc diffusivity found for the Cast Stone after 90 days may be the result of continued carbonation reactions or increasing reduction of $\mathrm{Tc}(\mathrm{VII})$ to Tc(IV) species caused by the continued slow dissolution of the BFS reductant present in the Cast Stone. The slow dissolution of BFS and continued reduction of Tc was discussed previously in Section 3. The reason for the slight increase in Tc diffusivity in both DuraLith samples after reacting for 90 days is not clear now; however, it may be related to stability issues for DuraLith monoliths immersed in water for prolonged exposure times. Even for shorter leaching times, small particles (debris) were also found in the Phase-I DuraLith leach tests as reported in Pierce et al. (2010).

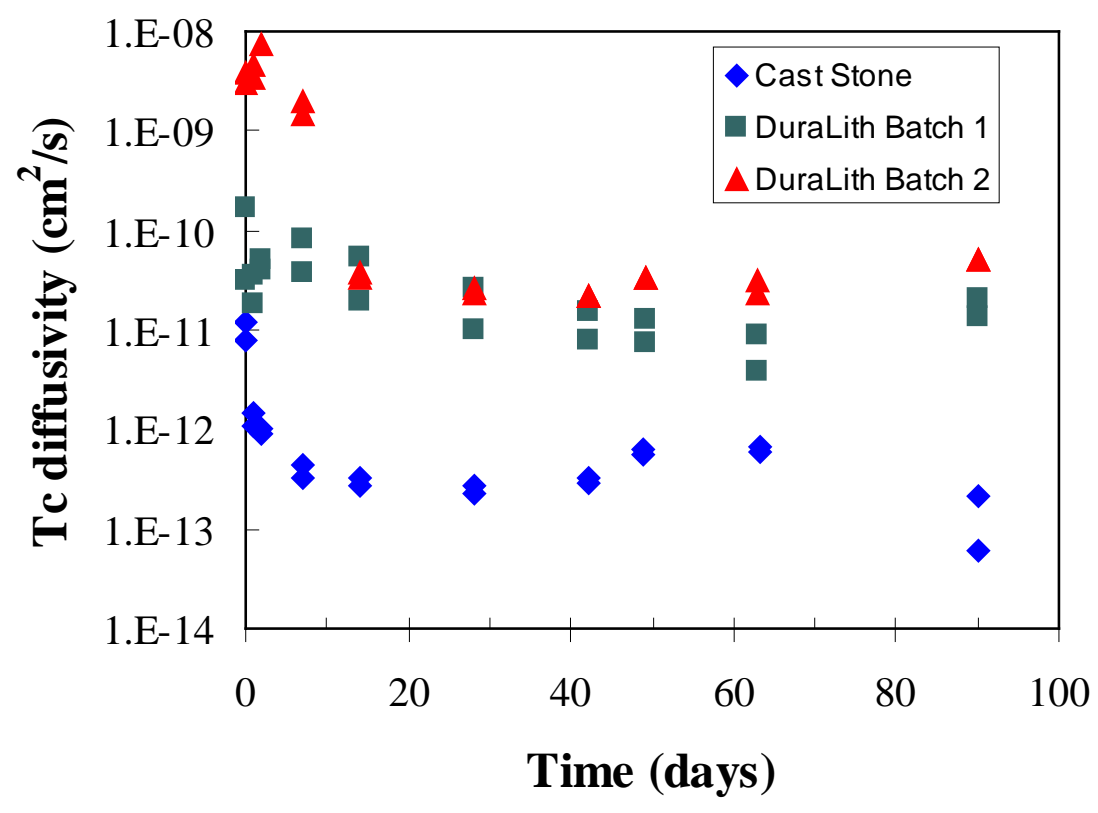

Figure 7.2. Diffusivity of ${ }^{99}$ Tc Measured Using EPA Method 1315 up to 90 Days Reaction 
Table 7.3. Diffusivity, LI Values, pH, EC, and Alkalinity Results of Waste Forms After Reacting for 90 Days Using EPA 1315 Method

\begin{tabular}{cccccc}
\hline & $\begin{array}{c}\text { Tc } \\
\text { Diffusivity } \\
\left(\mathrm{cm}^{2} / \mathrm{s}\right)\end{array}$ & $\begin{array}{c}\text { Tc } \\
\text { LI }\end{array}$ & $\mathrm{pH}$ & $\begin{array}{c}\mathrm{EC} \\
(\mathrm{mS} / \mathrm{cm})\end{array}$ & $\begin{array}{c}\text { Alkalinity (mg/L } \\
\text { as CaCO }\end{array}$ \\
\hline Cast Stone & $2.11 \mathrm{E}-13$ & 12.7 & 10.9 & 0.204 & 69.4 \\
& $<6.13 \mathrm{E}-14^{(\mathrm{a})}$ & 13.2 & 11.1 & 0.242 & 83.1 \\
DuraLith & $1.34 \mathrm{E}-11$ & 10.9 & 11.8 & 1.480 & 369.0 \\
Batch \#1 & $2.00 \mathrm{E}-11$ & 10.7 & 11.8 & 1.480 & 388.0 \\
DuraLith & $4.93 \mathrm{E}-11$ & 10.3 & 11.8 & 1.140 & 315.0 \\
Batch \#2 & $5.05 \mathrm{E}-11$ & 10.3 & 11.7 & 1.150 & 316.0 \\
\hline
\end{tabular}

(a) Sample EQL for Tc $(0.00414 \mu \mathrm{g} / \mathrm{L})$ was used to calculate diffusivity (in table with $<$ ).

Other 90-day leachate results, including $\mathrm{pH}$, most cations, most anions, and RCRA-listed metals, all fall within the range of previous leachate results (see the results for these analyses in Pierce et al. 2010). However, there was a slight increase in concentrations for some of the analytes, but these slight increases still fell within the range of values found for some leachates during the 90-day leach test. The most noticeable increases in the 90-day leachates were the alkalinity for DuraLith Batches 1 and 2 (315.0 to $388.0 \mathrm{mg} / \mathrm{L}$ as $\mathrm{CaCO}_{3}$ ) from those (135.4 to $210.4 \mathrm{mg} / \mathrm{L}$ as $\mathrm{CaCO}_{3}$ ) in the 63-day leachates (Pierce et al. 2010). Both DuraLith leachates displayed an increase in alkalinity concentration at the 90-day interval. Also, slightly increased EC values were found in the 90-day leachates for DuraLith Batches 1 and 2 (1.14 to $1.48 \mathrm{mS} / \mathrm{cm}$ ) compared to those found in the 63-day leachates $(0.740$ to $0.893 \mathrm{mS} / \mathrm{cm}$ ) (see Pierce et al. 2010), while the EC values decreased from (0.295 to $0.335 \mathrm{mS} / \mathrm{cm})$ in the 63-day leachates for Cast Stone to 0.204 to $0.242 \mathrm{mS} / \mathrm{cm}$ in the 90 -day leachates. All three waste forms showed increases in $\mathrm{Na}, \mathrm{Al}, \mathrm{K}$, $\mathrm{Mg}$, and Si concentrations as well as $\mathrm{NO}_{3}{ }^{-}$concentrations in the 90-day leachate (Table 7.4). These slight increases for the leachate concentrations of these analytes are likely caused by the increased leach duration. Samples in previous leach intervals were immersed in water for a maximum of 14 days before the leach solution was renewed, whereas the monoliths were immersed in leach solution for a total of 27 days before the 90-day leachate was collected. Although the Ca concentration increased in both DuraLith monoliths after 90-days leaching, Cast Stone showed decreased Ca concentrations after leaching for 90 days. The Cast Stone leachates in previous Phase-I (Pierce et al. 2010) EPA 1315 tests showed that Ca concentrations increased gradually up to 28 days leaching, but then decreased for leachates collected after 42 days of cumulative leaching. This finding indicates that less calcium was dissolving from the Cast Stone as the leaching time increased. No RCRA-listed metals were detected in the 90-day leachates from any of the three waste forms, which is similar to the non-detects found in the 63-day leachates.

\subsubsection{Post-Characterization of 90-Day Leached Waste Form Monoliths}

The XRD patterns collected for the sliced Cast Stone and DuraLith (Batch \#2) samples after leaching for 90 days using EPA Method 1315 are compared with the XRD patterns for the unreacted initial Cast Stone and DuraLith waste forms in Figure 7.3 and Figure 7.4, respectively. 
Table 7.4. The Concentrations of Major Cations in Eluate for Waste Forms from EPA 1315 Method 63 and Leaching for 90 Days

\begin{tabular}{|c|c|c|c|c|c|c|c|c|c|}
\hline Waste Form & $\begin{array}{l}\text { Cumul. } \\
\text { Leach } \\
\text { Time } \\
\text { (Days) } \\
\end{array}$ & $\begin{array}{c}\mathrm{Na} \\
(\mu \mathrm{g} / \mathrm{L})\end{array}$ & $\begin{array}{c}\mathrm{Ca} \\
(\mu \mathrm{g} / \mathrm{L})\end{array}$ & $\begin{array}{c}\mathrm{K} \\
(\mu \mathrm{g} / \mathrm{L})\end{array}$ & $\begin{array}{c}\mathrm{Al} \\
(\mu \mathrm{g} / \mathrm{L})\end{array}$ & $\begin{array}{c}\mathrm{Mg} \\
(\mu \mathrm{g} / \mathrm{L}) \\
\end{array}$ & $\begin{array}{c}\mathrm{Si} \\
(\mu \mathrm{g} / \mathrm{L})\end{array}$ & $\begin{array}{c}\mathrm{S} \\
(\mu \mathrm{g} / \mathrm{L})\end{array}$ & $\begin{array}{c}\mathrm{Fe} \\
(\mu \mathrm{g} / \mathrm{L})\end{array}$ \\
\hline \multirow{4}{*}{$\begin{array}{l}\text { Cast Stone } \\
\text { (2 replicates) }\end{array}$} & 63 & $8.5 \mathrm{E}+00$ & $2.4 \mathrm{E}+01$ & ND & $2.6 \mathrm{E}+00$ & 6.3E-02 & $6.0 \mathrm{E}+00$ & $1.4 \mathrm{E}+00$ & ND \\
\hline & 63 & $8.0 \mathrm{E}+00$ & $2.3 \mathrm{E}+01$ & ND & $2.7 \mathrm{E}+00$ & 6.3E-02 & $6.3 \mathrm{E}+00$ & $1.2 \mathrm{E}+00$ & ND \\
\hline & 90 & $2.4 \mathrm{E}+01$ & $4.9 \mathrm{E}+00$ & $1.8 \mathrm{E}+00$ & $3.0 \mathrm{E}+00$ & 9.7E-02 & $7.4 \mathrm{E}+00$ & ND & ND \\
\hline & 90 & $2.4 \mathrm{E}+01$ & $8.8 \mathrm{E}+00$ & $2.0 \mathrm{E}+00$ & $3.1 \mathrm{E}+00$ & $1.1 \mathrm{E}-01$ & $7.5 \mathrm{E}+00$ & ND & ND \\
\hline \multirow{4}{*}{$\begin{array}{l}\text { DuraLith } \\
\text { Batch \#1 } \\
\text { (2 replicates) }\end{array}$} & 63 & $4.4 \mathrm{E}+01$ & 1.5E-01 & $8.1 \mathrm{E}+01$ & $7.6 \mathrm{E}+00$ & 2.0E-01 & $1.9 \mathrm{E}+01$ & $2.9 \mathrm{E}+01$ & 6.6E-02 \\
\hline & 63 & $4.6 \mathrm{E}+01$ & $1.2 \mathrm{E}-01$ & $8.6 \mathrm{E}+01$ & $7.9 \mathrm{E}+00$ & $2.1 \mathrm{E}-01$ & $1.9 \mathrm{E}+01$ & $2.9 \mathrm{E}+01$ & 7.0E-02 \\
\hline & 90 & $8.4 \mathrm{E}+01$ & 3.1E-01 & $1.7 \mathrm{E}+02$ & $1.3 \mathrm{E}+01$ & 9.7E-02 & $2.6 \mathrm{E}+01$ & $5.1 \mathrm{E}+01$ & $5.2 \mathrm{E}-02$ \\
\hline & 90 & $8.7 \mathrm{E}+01$ & 3.0E-01 & $1.8 \mathrm{E}+02$ & $1.3 \mathrm{E}+01$ & $1.1 \mathrm{E}-01$ & $2.5 \mathrm{E}+01$ & $5.5 \mathrm{E}+01$ & ND \\
\hline \multirow{4}{*}{$\begin{array}{l}\text { DuraLith } \\
\text { Batch \#2 } \\
\text { (2 replicates) }\end{array}$} & 63 & $4.4 \mathrm{E}+01$ & ND & $8.1 \mathrm{E}+01$ & $9.6 \mathrm{E}+00$ & 3.4E-01 & $1.9 \mathrm{E}+01$ & $2.9 \mathrm{E}+01$ & 6.6E-02 \\
\hline & 63 & $4.6 \mathrm{E}+01$ & ND & $8.6 \mathrm{E}+01$ & $9.8 \mathrm{E}+00$ & 3.6E-01 & $1.9 \mathrm{E}+01$ & $2.9 \mathrm{E}+01$ & 7.0E-02 \\
\hline & 90 & $7.8 \mathrm{E}+01$ & 2.9E-01 & $1.4 \mathrm{E}+02$ & $1.1 \mathrm{E}+01$ & 3.2E-01 & $2.5 \mathrm{E}+01$ & $2.6 \mathrm{E}+01$ & 7.3E-02 \\
\hline & 90 & $7.8 \mathrm{E}+01$ & 2.8E-01 & $1.4 \mathrm{E}+02$ & $1.1 \mathrm{E}+01$ & 3.2E-01 & $2.4 \mathrm{E}+01$ & $3.8 \mathrm{E}+01$ & 7.1E-02 \\
\hline
\end{tabular}
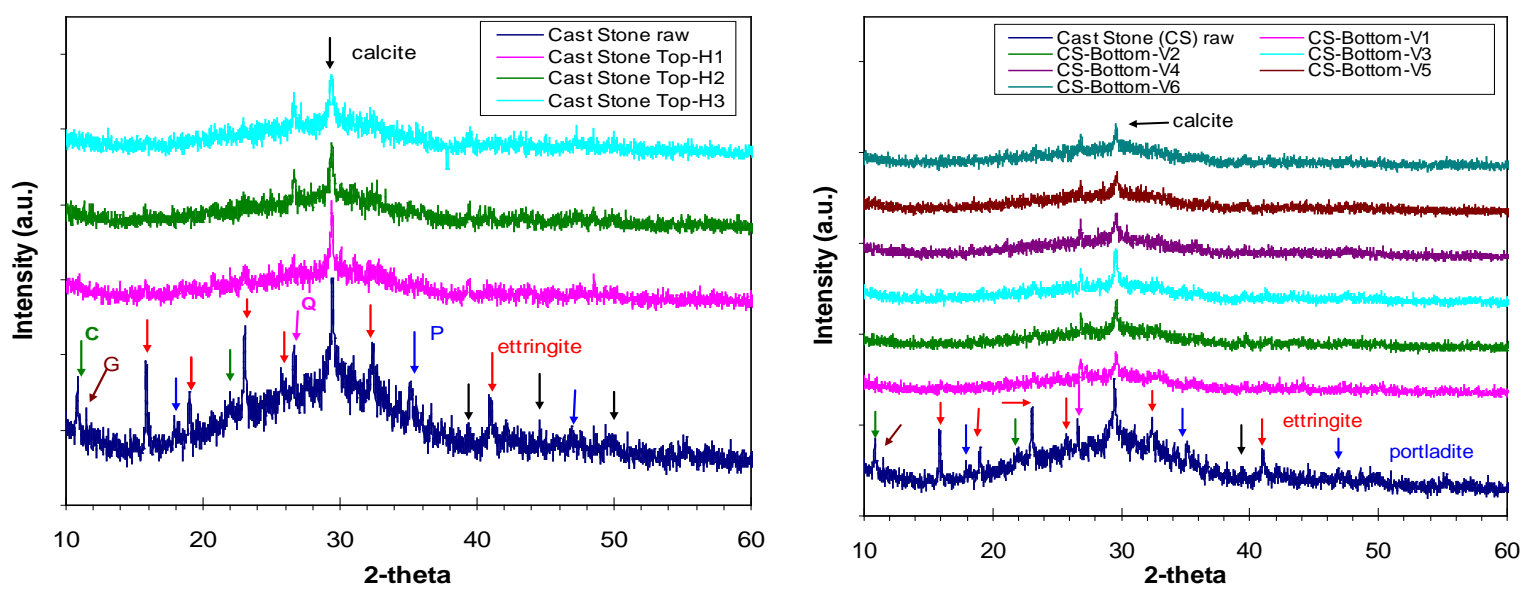

Figure 7.3. XRD Spectra of Unreacted Cast Stone and Cast Stone Sliced Samples After Leaching for 90 Days Using EPA 1315 Method; (left) Top-Horizontally Sliced Samples of top-H1, -H2, and-H3 from Top to Bottom; (right) Bottom-Vertically Sliced Samples of Bottom-V1, -V2, -V3, -V4, and -V5 from Right to Left. Arrows with different colors indicate major minerals: calcite (black), ettringite (red), P (portlandite [blue]), C (calcium aluminum oxide carbonate hydrate [green]), Q (quartz [pink]), and G (gypsum [brown]). 

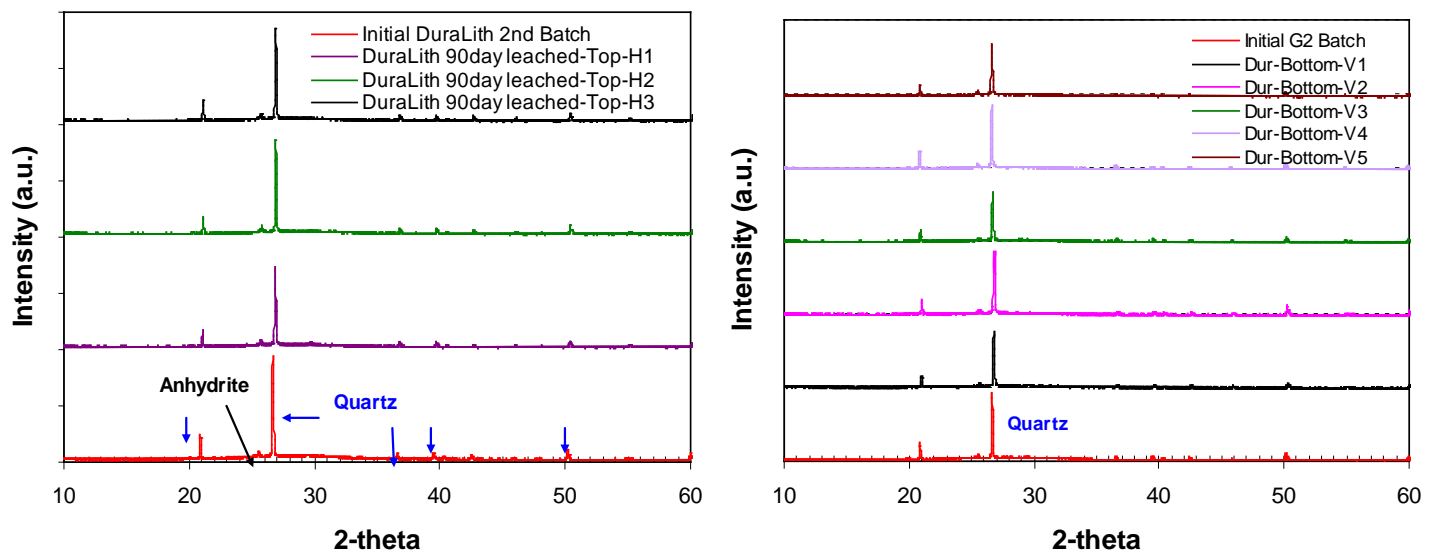

Figure 7.4. XRD Spectra of Unreacted DuraLith (Batch \#2) and Sliced DuraLith (Dur) Samples After Leaching for 90 Days Using the EPA 1315 Method; (left) Top-Horizontally Sliced Samples of top-H1, -H2, and-H3 from Top to Bottom; (right) Bottom-Vertically Sliced Samples of Bottom-V1, -V2, -V3, -V4, and -V5 from Right to Left. Arrows with different colors indicate major minerals, quartz (blue), and anhydrite (black).

Most of the major peaks in the unleached Cast Stone XRD pattern were identified as ettringite, gypsum, Ca aluminum oxide carbonate hydrate, and portlandite. Based on the absence of or reduced intensities in 90-day leached Cast Stone samples (Figure 7.3), these minerals disappeared or showed reduced amounts after leaching. The major peak for calcite found at the 29 2- $\theta$ region was not diminished in horizontally sliced samples. Even though the Top-H1 sliced sample was collected at the outermost rim area where one might expect maximum leaching/dissolution, it showed relatively higher intensity for the calcite peak at the $292-\theta$ region than the intensities for the other two Top-horizontally sliced Cast Stone samples (Figure 7.3, left). The top-H1 sliced sample also showed relatively lower intensity of the quartz peak than the other two horizontally sliced samples, indicating that more dissolution occurred at the most outer rim of the Cast Stone monoliths when immersed in DIW during the EPA 1315 test. An increased intensity of the calcite peak in the top-H1 sample that was prepared at the outermost rim area may result from additional calcite precipitation due to the enhanced carbonation reaction with increased exposure to the atmosphere at the outermost rim area before the monolith slicing activity. However, the changes in calcite and quartz peaks in these samples collected at different locations are very subtle so that more quantitative analyses for chemical composition changes are required to provide supplementary data. Aside for the calcite and quartz peak intensities differences, very similar XRD patterns and peak intensities were collected for the three top-horizontally sliced Cast Stone samples, and most of the major XRD peaks from other mineral phases disappeared in the leached solids, except the peaks for calcite at the $292-\theta$ and quartz at the $272-\theta$ regions.

The vertically sliced samples from the bottom half of the Cast Stone monolith after leaching for 90 days using the EPA 1315 test showed very similar XRD patterns no matter where they were collected. Most of the major mineral phases present in the unleached Cast Stone disappeared, but there are still visible peaks for calcite and quartz in most of the vertically sliced samples (Figure 7.3, right). A slightly higher intensity of the calcite peak at $292-\theta$ was found in the bottom-V3 sample, which was collected near the center compared to other sliced samples. The intensity of quartz XRD peaks at the $272-\theta$ region was unchanged no matter where the samples were collected, indicating that uniform dissolution was occurring in those vertically sliced samples because of similar contact areas of the sliced samples exposed to solution. 
The XRD patterns of both horizontally and vertically sliced DuraLith Batch \#2 samples after leaching for 90 days using the EPA 1315 method were the same as those of the unreacted initial DuraLith waste form (Figure 7.4). Two major minerals, quartz and anhydrite $\left(\mathrm{CaSO}_{4}\right)$, showed no changes in peak intensity regardless of the location in the sliced monolith, indicating that no significant mineralogical changes occurred in the DuraLith even after leaching for 90 days.

Analysis by SEM/EDS for the same sliced Cast Stone and DuraLith (Batch \#2) samples as used for XRD analysis provided chemical composition and morphology data. Figure 7.5 shows SEM images and elemental mapping of major elements in the Cast Stone top-H1 slice. As found in the Phase I report, the major elements in Cast Stone are $\mathrm{Ca}, \mathrm{Al}$, and $\mathrm{Si}$, and there is still unhydrated fly ash (spherical shaped particles) present after 90 days of leaching. Similar SEM images and elemental information were collected for other Cast Stone slices. However, because there were only minor changes in the Cast Stone bulk chemistry after leaching for 90 days, the EDS data for chemical composition did not show any noticeable changes in both horizontally and vertically sliced Cast Stone samples collected at different locations.

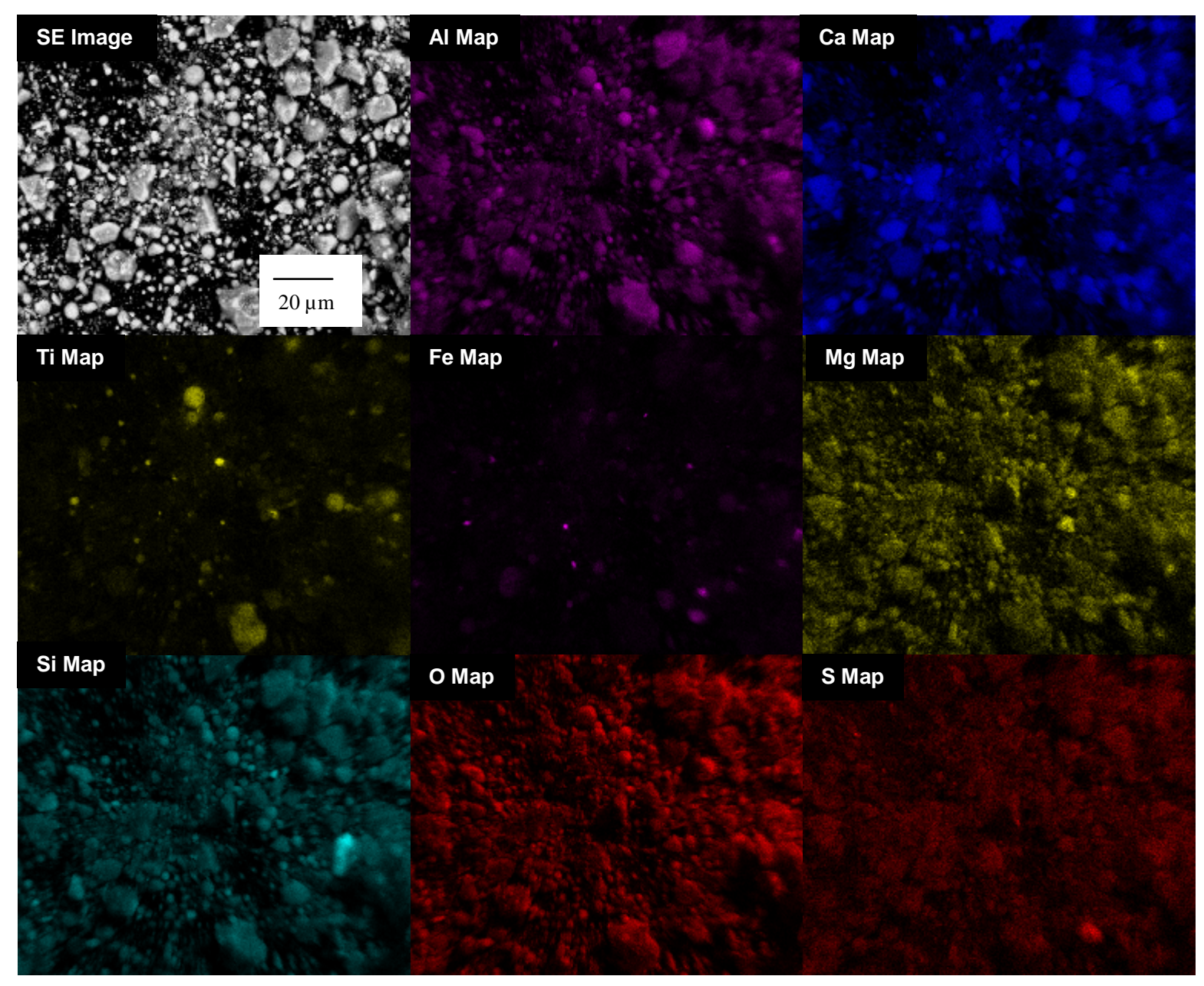

Figure 7.5. SEM Images and Elemental Maps of Cast Stone Sliced Top-H1 Sample 
The SEM image and elemental maps for DuraLith (Batch \#2) sliced at the top-H2 sample after leaching for 90 days are shown in Figure 7.6. The images show the presence of fine-grained material with a few larger particles. The EDS spectra of the larger particles indicate high amounts of $\mathrm{Al}, \mathrm{Ca}, \mathrm{K}$, iron, $\mathrm{Si}$, and titanium (Ti) with minor amounts of $\mathrm{Ag}, \mathrm{Cu}, \mathrm{Mg}$, and sulfur (S). As described above for the sliced Cast Stone, generally very similar SEM images were obtained for the sliced DuraLith samples, even though they were collected at different locations and after leaching for 90 days using the EPA 1315 method. The EDS results also showed very similar chemical compositions for each of the sliced DuraLith samples no matter where they were collected. More SEM elemental maps and EDS data are found in Appendix A-3. It appears that the chemical changes in the 90-day leached waste forms are so slight that the SEM/EDS images are most useful for showing particle morphologies as opposed to chemical changes.

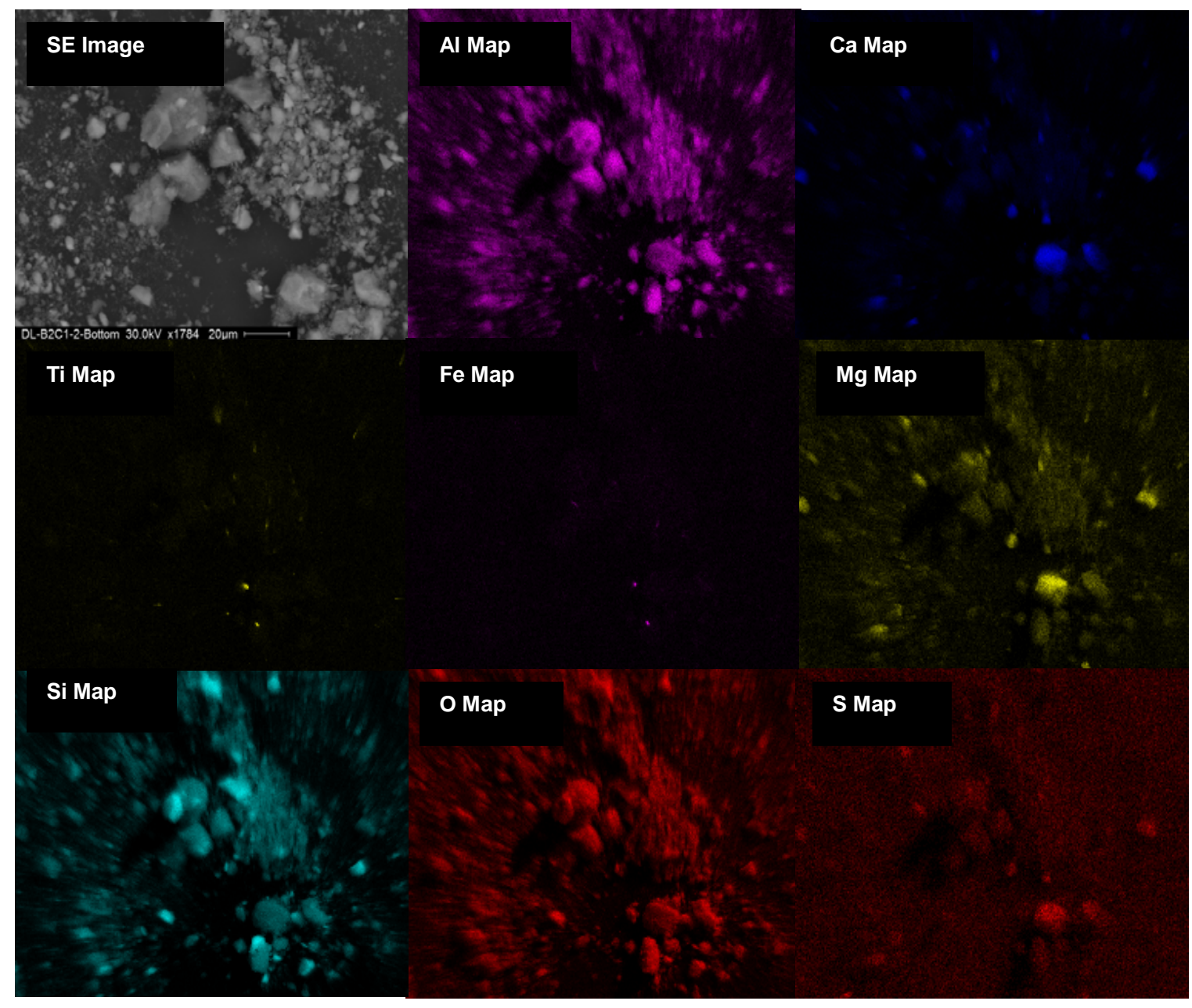

Figure 7.6. SEM Images and Elemental Map of DuraLith (Batch \#2) Sliced Top-H2 Sample

\subsection{Conclusions}

EPA 1315 method leachates collected after 90 days showed that Tc diffusivity (or LI) for Cast Stone followed a general trend of slowly decreasing Tc diffusivity. The minor decrease in Tc diffusivity in Cast Stone after leaching for 90 days is attributed to continuous carbonation reaction and/or slow continued dissolution of the BFS reductant that allows continued reduction of pore water-borne Tc(VII) to Tc(IV), 
which is the less soluble Tc species. However, the Tc diffusivity for DuraLith Batches \#1 and 2 waste forms after 90 days of leaching increased a little bit. The slightly increased Tc diffusivity in the DuraLith waste forms after 90 days of leaching may result from continued "congruent” dissolution of the DuraLith waste form with extended contact time with solution, which is consistent with the observed increased concentrations of major elements like $\mathrm{Na}, \mathrm{Ca}, \mathrm{Al}$, and $\mathrm{Si}$ in the DuraLith leachate after 90 days. Because there were no observable differences in the elemental maps of unleached and 90-day leached DuraLith, the dissolution process must be "congruent," which means that all elements leach proportionately to their initial concentration in the waste form. Otherwise, we should have seen differences in the element maps before and after leaching.

No RCRA-listed metals were detected in the leachates from both Cast Stone and DuraLith waste forms after 90 days of leaching using the EPA 1315 method. Post characterization of the 90-day leached waste forms was conducted using XRD and SEM/EDS analyses after preparing the sliced samples either horizontally or vertically. The XRD analysis showed that most of the major peaks of mineral phases present in the unleached Cast Stone, such as ettringite, gypsum, and calcium-aluminum-oxide carbonate hydrate, disappeared or showed reduced intensity after 90 days of leaching. However, the XRD peaks from quartz and calcite were still observable in Cast Stone sliced samples. A slightly decreased intensity for the quartz peak at $272-\theta$ and an increased intensity for the calcite peak at 29 2- $\theta$ were found only in the sliced Cast Stone sample (top-H1) collected at the outermost rim of the monolith compared to two other slices collected at more interior regions. The XRD patterns for vertically sliced Cast Stone samples showed similar intensities for quartz and calcite after 90 days of leaching compared to the unleached Cast Stone, although the peaks for most of the other Cast Stone mineral phases disappeared.

The XRD patterns of the sliced DuraLith samples after 90 days of leaching showed no changes in peak intensity for the major minerals, quartz, and anhydrite, irrespective of location in the sliced monolith. The SEM/EDS analyses of the sliced Cast Stone and DuraLith waste forms also showed no significant changes in chemical compositions or morphologies compared to unleached waste forms. This indicated that any chemical changes are very minor in the bulk samples, even after 90 days of leaching, and are not resolvable using the SEM/EDS technique. This does not mean that there is no leaching of the DuraLith waste forms; rather it means that the leaching/dissolution is congruent such that the mass leached has the same chemical composition as the bulk waste form. 



\subsection{Oxidation and Carbonation Studies}

\subsection{Introduction}

Based on Phase-I screening test results, the most likely chemical-degradation processes that may occur within waste forms are oxidation and carbonation. To determine the effects of oxidation and carbonation degradation on waste forms, additional testing with the EPA 1313 and 1315 methods was performed on Phase I archived Cast Stone and DuraLith samples. In addition, FBSR waste form encapsulated in Geopolymer-7 binder available from SRNL was included in these tests.

An environmental chamber that exposes either intact waste form monoliths or waste form powders to different gas mixtures was used to produce enhanced oxidizing or carbonation conditions. Using a mixture of $5 \% \mathrm{CO}_{2}$ and $95 \% \mathrm{~N}_{2}$ (g) in the chamber accelerates the carbonation reaction on the exposed surfaces of the waste forms. In a separate chamber, a mixture of $22 \% \mathrm{O}_{2}$ and $78 \% \mathrm{~N}_{2}$ (g) was used to accelerate oxidation reactions on the exposed surfaces. Those conditions represent slightly enhanced carbonation and oxidation conditions compared to those found in the underground disposal facility. Following exposure to the $\mathrm{CO}_{2}$ - or $\mathrm{O}_{2}$-rich atmospheres for 14 days, waste form monoliths (right cylinders) that contained Tc were subjected to EPA 1315 leach testing with the standard leachant replacement intervals.

For other carbonation and oxidation testing, all three waste forms were disaggregated into $<0.3 \mathrm{~mm}-$ sized samples. These waste form granules were subjected to the same weathering conditions defined above. Following exposure to one of the two atmospheres for 14 days, the waste form granules were subjected to leach testing with the EPA 1313 method (pH effects) at a liquid-to-solid ratio of $10 \mathrm{~mL} / \mathrm{g}$ with extraction times of 1 hour, 3 days, and 7 days to investigate leaching/dissolution rates. These EPA 1313 method data were compared to EPA 1315 method data collected on waste forms subjected to weathering so that additional data on the impacts of carbonation and oxidation on each waste form could be obtained. Additionally, a series of EPA 1313 tests for waste forms created in Phase I (Cast Stone and DuraLith) without additional accelerated carbonation or oxidation were also conducted as a function of reaction times up to 7 days in contrast to the Phase-I testing using particle less than a $0.3-\mathrm{mm}$ size fraction that stopped after the prescribed 1-day reaction. All of these experiments were conducted to address specific comments from the review panel for Phase-I testing results.

\subsection{Materials and Methods}

\subsubsection{Materials}

Cast Stone and DuraLith (Batch \#2) waste form monoliths (2-in. diameter by 4-in. height) archived during Phase-I testing, FBSR encapsulated in Geopolymer-7 binder, and newly prepared DuraLith monoliths (2-in. diameter by 4-in, height) were used for the accelerated weathering tests. To fit into the controlled atmosphere chambers, the archived Phase-I monoliths were cut to about a quarter of their original height, which yielded monoliths (2-in. diameter by 1-in. height) that were reacted in the atmosphere chambers. Other samples were prepared by crushing one monolith of each waste form and separating particle sizes less than $0.3 \mathrm{~mm}$ using a sieve. 


\subsubsection{Environmental Atmosphere Chamber}

The accelerated oxidation or carbonation weathering chambers used to incubate either the small monoliths or granule samples of each waste form were described in Section 5.2.2. For the carbonation weathering tests, the chamber was continually refreshed with an atmosphere mixture of $5 \% \mathrm{CO}_{2}$ and $95 \% \mathrm{~N}_{2}$ gases under ambient temperature and pressure with $100 \%$ relative humidity conditions. For the oxidation weathering tests, the waste forms were bathed in a mixture of $22 \% \mathrm{O}_{2}$ and $78 \% \mathrm{~N}_{2}$ gases (with no $\mathrm{CO}_{2}$ ). The special gas mixtures were flushed through the chamber for 14 days. After exposure to the $\mathrm{CO}_{2}$ or $\mathrm{O}_{2}$ atmospheres, the monolith samples were tested with the EPA 1315 method, which was described in Section 7. The leachate solutions collected from these tests were analyzed for 1) pH, 2) EC, 3) alkalinity, and 4) the concentration of Tc, major cations, and RCRA-listed metals. The details on analytical methods can be also found in previous sections.

Powder samples prepared from each waste form and reacted inside the chamber were tested with the EPA 1313 method. The details of the EPA 1313 method are described below. The EPA 1315 methodology used for the small monoliths is described in Section 7.2.2.

\subsubsection{EPA Method 1313}

The EPA Method 1313 (Liquid-Solid Partitioning as a Function of Extract $\mathrm{pH}$ ) is a static test method where a set of parallel extraction experiments are conducted in pre-determined amounts of dilute acid or base in DIW to produce fixed $\mathrm{pH}$ conditions ( $\mathrm{pH}$ range from 4 to 12 ) at a liquid-to-solid ratio (10 $\mathrm{mL} / \mathrm{g}$ ) (EPA 2009a). Because the measured $\mathrm{pH}$ of the leachate solutions for Cast Stone and DuraLith powder samples without adding acid is high $(\mathrm{pH} \approx 12$ to 13$)$ and this condition is germane to the field condition, only one $\mathrm{pH}$ condition without adjusting $\mathrm{pH}$ levels using acid or base was used for the modified EPA 1313 testing for these accelerated weathering tests. These EPA 1313 tests were performed by mixing $10 \mathrm{~g}$ of $<0.3-\mathrm{mm}$ sized weathered material with $100 \mathrm{~mL}$ of DIW. A sample of each waste form that had not been exposed to the oxidation or carbonation atmospheres was also tested as a baseline. All slurries of the granular waste forms, either weathered or unreacted, were placed on a platform shaker and allowed to mix at room temperature $\left(23 \pm 2^{\circ} \mathrm{C}\right)$ up to a total of 7 days. At various contact times of 1 hour, 3 days, and 7 days for the weathered samples and 1, 2, 5, and 7 days for the unreacted samples, one container of each waste form was removed from the shaker and processed. The slurry was centrifuged, and the supernate solution was filtered with a syringe filter $(0.45-\mu \mathrm{m}$ polypropylene membrane). The filtrate was used to measure $\mathrm{pH}, \mathrm{EC}$, alkalinity, Tc, and major cation concentrations. The results are discussed in Section 8.3.2.

\subsection{Results and Discussion}

\subsubsection{EPA 1315 Method After Weathering}

The $\mathrm{pH}$ and Tc diffusivity results from the EPA 1315 leach tests for Cast Stone after the 14-day weathering in either the $\mathrm{CO}_{2} / \mathrm{N}_{2}$ or $\mathrm{O}_{2} / \mathrm{N}_{2}$ gas mixtures are shown in Figure 8.1. For the $\mathrm{CO}_{2}(\mathrm{~g})$ reacted Cast Stone, the first few leachate $\mathrm{pH}$ values were much lower (pH ranged from 6 to 7 ) than the value of 11.0 found for the unweathered leachates. The decrease in $\mathrm{pH}$ was caused by carbonation reactions that formed carbonic acid and coated the Cast Stone monoliths with calcite that was subsequently partially dissolved as bicarbonate ions in the leachates. The $\mathrm{pH}$ in the carbonated Cast Stone leachates gradually 
increased to close to 9.0 as the leaching time increased to 90 days (Table 8.1). The calculated Tc diffusivity for the carbonated Cast Stone monoliths after $\mathrm{CO}_{2} / \mathrm{N}_{2}$ gas reaction was higher than the Tc diffusivity for the unreacted Cast Stone monoliths (Figure 8.1, left). However, the diffusivity of Tc measured in carbonated Cast Stone gradually increased as the leaching time increased up to 30 days, while Tc diffusivity of the unreacted Cast Stone showed a generally decreasing trend as the leaching time increased. The initial large increase in Tc diffusivity in the carbonated Cast Stone monolith may be related to increased porosity or pore volume in the reacted Cast Stone as we found from the pore structure analysis, which is presented in Section 5. The decrease in the Tc diffusivity for carbonated Cast Stone at longer leach times when the $\mathrm{pH}$ has increased towards 9 (close to 72 days leaching time) is also related to porosity or pore structure changes. When the $\mathrm{pH}$ of the leachate increased towards 9 as the leaching time increased, precipitation inside the Cast Stone monolith could be possible and the newly formed $\mathrm{CaCO}_{3}$ started to plug pores, which reduced the Tc diffusivity. Decreased $\mathrm{pH}$ after 72 days leaching time was also found in carbonated Cast Stone. However, the relative effect of $\mathrm{CaCO}_{3}$ precipitation, which can reduce porosity, is smaller than the increase in porosity caused by Ca dissolution of the C-S-H gel needed to supply the Ca for the carbonation reactions. Thus, the net cumulative effect on Tc diffusivity is about a 2-3 order of magnitude higher Tc diffusivity in the carbonated Cast Stone compared to unreacted Cast Stone after 90 days of leaching.
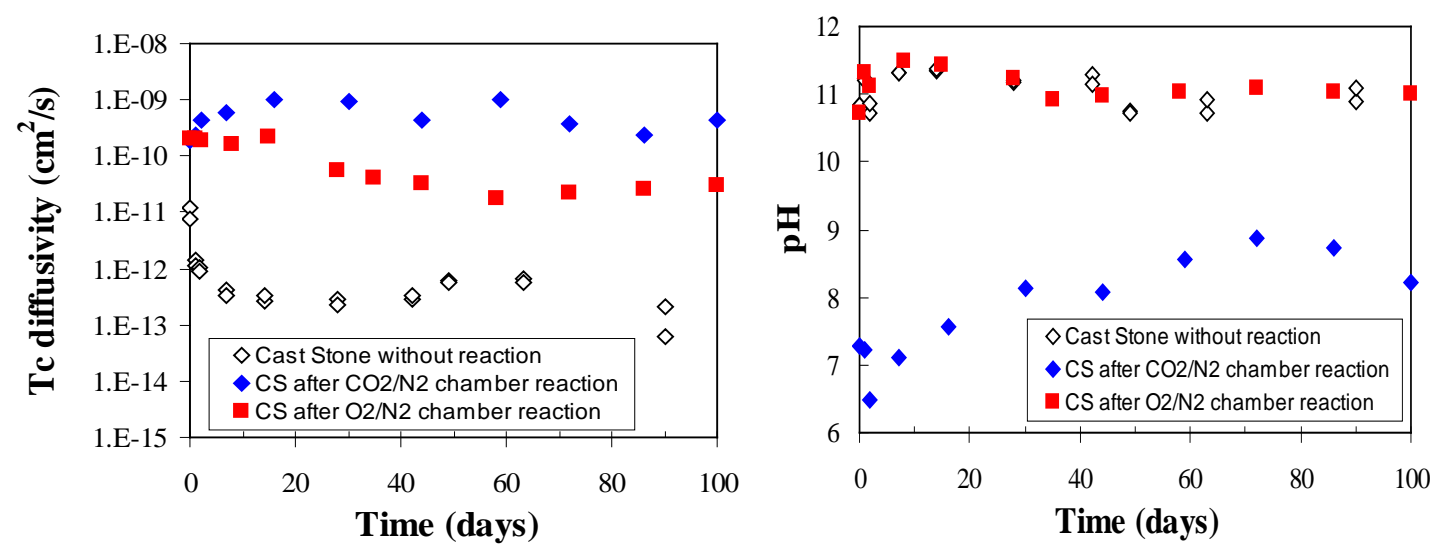

Figure 8.1. Diffusivity of Tc and Measured pHs for Cast Stone Leachates Before and After Reaction Inside $\mathrm{CO}_{2} / \mathrm{N}_{2}$ or $\mathrm{O}_{2} / \mathrm{N}_{2}$ Chamber Using the EPA 1315 Method

The Method 1315 leachates from the Cast Stone monolith reacted with elevated concentrations of $\mathrm{O}_{2}$ (g) did not show any changes in $\mathrm{pH}$ compared to those for the Cast Stone monoliths leached with no gas reaction during the Phase-I testing (Figure 8.1, right). The measured Tc diffusivity for the Cast Stone monolith after enhanced $\mathrm{O}_{2}(\mathrm{~g})$ reaction also showed increased Tc diffusivity compared to the unreacted Cast Stone monolith. However, when the Tc diffusivity for the enhanced $\mathrm{O}_{2}$ (g) reacted Cast Stone is compared to the carbonated Cast Stone, the enhanced $\mathrm{O}_{2}(\mathrm{~g})$ reacted Tc diffusivity is lower than Tc diffusivity for the carbonated Cast Stone monolith (Figure 8.1, left). The initial high Tc diffusivity found for the enhanced $\mathrm{O}_{2}(\mathrm{~g})$ reacted Cast Stone resulted from the elevated $\mathrm{O}_{2}$ content permeating into the surface of the monolith and likely re-oxidizing Tc(IV) formed from the reaction with BFS. Such Tc(IV) re-oxidation upon contact with oxygen was also found by Shuh et al. (2000) for the Saltstone waste form used at DOE's Savannah River Site, which uses a very similar dry blend mix. As shown previously in 
Table 8.1. Values of pH, EC, Alkalinity, Tc/Re Diffusivity, and Tc/Re LI of Waste Forms Measured by the EPA 1315 Method after $\mathrm{CO}_{2} / \mathrm{N}_{2}$ or $\mathrm{O}_{2} / \mathrm{N}_{2}$ Chamber Reaction

\begin{tabular}{|c|c|c|c|c|c|c|c|}
\hline \multicolumn{2}{|c|}{$\begin{array}{c}\text { Waste Forms with } \\
\text { Reactions }\end{array}$} & \multirow{2}{*}{$\begin{array}{c}\begin{array}{c}\text { Times } \\
\text { (day) }\end{array} \\
0.08\end{array}$} & \multirow{2}{*}{$\frac{\mathrm{pH}}{7.29}$} & \multirow{2}{*}{$\begin{array}{c}\begin{array}{c}\mathrm{EC} \\
(\mathrm{mS} / \mathrm{cm})\end{array} \\
0.169\end{array}$} & \multirow{2}{*}{$\begin{array}{c}\begin{array}{c}\text { Tc Diffusivity } \\
\left(\mathrm{cm}^{2} / \mathrm{s}\right)\end{array} \\
1.86 \mathrm{E}-10\end{array}$} & \multirow{2}{*}{$\begin{array}{c}\text { Tc } \\
(\mathrm{LI}) \\
9.73\end{array}$} & \multirow{2}{*}{$\begin{array}{c}\begin{array}{c}\text { Alkalinity } \\
\left(\mathrm{mg} / \mathrm{L} \text { as } \mathrm{CaCO}_{3}\right.\end{array} \\
\mathrm{ND}\end{array}$} \\
\hline \multirow{23}{*}{ Cast Stone } & \multirow{11}{*}{$\begin{array}{l}\mathrm{CO}_{2} / \\
\mathrm{N}_{2}\end{array}$} & & & & & & \\
\hline & & 1.0 & 7.23 & 0.708 & $2.28 \mathrm{E}-10$ & 9.64 & ND \\
\hline & & 2.0 & 6.47 & 0.422 & $4.26 \mathrm{E}-10$ & 9.37 & ND \\
\hline & & 7.0 & 7.12 & 0.911 & $6.14 \mathrm{E}-10$ & 9.21 & 27.9 \\
\hline & & 16.0 & 7.57 & 0.669 & 1.03E-09 & 8.99 & 33.0 \\
\hline & & 30.0 & 8.12 & 0.552 & $9.64 \mathrm{E}-10$ & 9.02 & 63.5 \\
\hline & & 44.0 & 8.09 & 0.305 & $4.52 \mathrm{E}-10$ & 9.35 & 51.5 \\
\hline & & 59.0 & 8.57 & 0.178 & 1.03E-09 & 8.99 & 58.4 \\
\hline & & 72.0 & 8.87 & 0.123 & $3.88 \mathrm{E}-10$ & 9.41 & 57.9 \\
\hline & & 86.0 & 8.73 & 0.0992 & 2.39E-10 & 9.62 & 53.5 \\
\hline & & 100.0 & 8.23 & 0.145 & 4.34E-10 & 9.36 & 69.9 \\
\hline & \multirow{12}{*}{$\begin{array}{l}\mathrm{O}_{2} / \\
\mathrm{N}_{2}\end{array}$} & 0.08 & 10.7 & 0.148 & $1.98 \mathrm{E}-10$ & 9.70 & 44.9 \\
\hline & & 1.0 & 11.3 & 0.508 & 2.02E-10 & 9.70 & 159 \\
\hline & & 2.0 & 11.1 & 0.318 & $1.90 \mathrm{E}-10$ & 9.72 & 83.1 \\
\hline & & 8.0 & 11.5 & 0.757 & $1.68 \mathrm{E}-10$ & 9.78 & 171 \\
\hline & & 15.0 & 11.4 & 0.677 & $2.24 \mathrm{E}-10$ & 9.65 & 149 \\
\hline & & 28.0 & 11.2 & 0.676 & $5.48 \mathrm{E}-11$ & 10.3 & 204 \\
\hline & & 35.0 & 10.9 & 0.302 & $4.23 \mathrm{E}-11$ & 10.4 & 72 \\
\hline & & 44.0 & 11.0 & 0.285 & $3.21 \mathrm{E}-11$ & 10.5 & 95.6 \\
\hline & & 58.0 & 11.0 & 0.327 & $1.71 \mathrm{E}-11$ & 10.8 & 108 \\
\hline & & 72.0 & 11.1 & 0.334 & $2.18 \mathrm{E}-11$ & 10.7 & 107 \\
\hline & & 86.0 & 11.0 & 0.285 & 2.65E-11 & 10.6 & 92.9 \\
\hline & & 100.0 & 11.0 & 0.263 & 3.13E-11 & 10.5 & 87.8 \\
\hline \multirow{22}{*}{$\begin{array}{l}\text { DuraLith } \\
\text { Batch \#2 }\end{array}$} & \multirow{11}{*}{$\begin{array}{c}\mathrm{CO}_{2} / \\
\mathrm{N}_{2}\end{array}$} & 0.08 & 9.57 & 0.326 & $9.15 \mathrm{E}-10$ & 9.04 & 57.1 \\
\hline & & 1.0 & 9.78 & 0.659 & $3.11 \mathrm{E}-10$ & 9.51 & 123 \\
\hline & & 2.0 & 9.80 & 0.38 & $3.42 \mathrm{E}-10$ & 9.47 & ND \\
\hline & & 7.0 & 9.92 & 1.05 & $2.85 \mathrm{E}-10$ & 9.55 & 158 \\
\hline & & 14.0 & 10.1 & 0.854 & $1.45 \mathrm{E}-10$ & 9.84 & 130 \\
\hline & & 28.0 & 10.0 & 1.09 & $1.66 \mathrm{E}-10$ & 9.78 & 184 \\
\hline & & 42.0 & 10.2 & 0.611 & $1.08 \mathrm{E}-10$ & 9.97 & 153 \\
\hline & & 49.0 & 9.93 & NM & $1.16 \mathrm{E}-10$ & 9.93 & 85.8 \\
\hline & & 63.0 & 9.81 & 0.418 & $8.74 \mathrm{E}-11$ & 10.1 & 131 \\
\hline & & 77.0 & 9.81 & 0.344 & 5.91E-11 & 10.2 & 123 \\
\hline & & 91.0 & 9.90 & 0.299 & $4.41 \mathrm{E}-11$ & 10.4 & 114 \\
\hline & \multirow{11}{*}{$\begin{array}{l}\mathrm{O}_{2} / \\
\mathrm{N}_{2}\end{array}$} & 0.08 & 10.4 & 0.196 & $1.24 \mathrm{E}-09$ & 8.91 & 42.2 \\
\hline & & 1.0 & 10.6 & 0.310 & $2.82 \mathrm{E}-10$ & 9.55 & 78.6 \\
\hline & & 2.0 & 10.5 & 0.226 & $6.32 \mathrm{E}-10$ & 9.20 & 53.7 \\
\hline & & 7.0 & 10.5 & NM & 1.99E-09 & 8.70 & 126 \\
\hline & & 14.0 & 10.5 & NM & 5.66E-09 & 8.25 & 143 \\
\hline & & 28.0 & 9.93 & 0.924 & $1.08 \mathrm{E}-08$ & 7.97 & 178 \\
\hline & & 42.0 & 9.81 & 0.640 & 3.47E-11 & 10.5 & 150 \\
\hline & & 49.0 & 9.64 & 0.266 & $2.21 \mathrm{E}-11$ & 10.7 & 80.9 \\
\hline & & 63.0 & 9.35 & 0.376 & $2.48 \mathrm{E}-11$ & 10.6 & 115 \\
\hline & & 77.0 & 9.25 & 0.308 & $2.47 \mathrm{E}-11$ & 10.6 & 107 \\
\hline & & 91.0 & 9.37 & 0.256 & $1.56 \mathrm{E}-11$ & 10.8 & 95.6 \\
\hline
\end{tabular}


Table 8.1. (contd)

\begin{tabular}{|c|c|c|c|c|c|c|c|}
\hline \multicolumn{2}{|c|}{$\begin{array}{c}\text { Waste Forms with } \\
\text { Reactions }\end{array}$} & \multirow{2}{*}{$\begin{array}{c}\text { Times } \\
\text { (day) }\end{array}$} & \multirow{2}{*}{$\frac{\mathrm{pH}}{9.31}$} & \multirow{2}{*}{$\begin{array}{c}\begin{array}{c}\mathrm{EC} \\
(\mathrm{mS} / \mathrm{cm})\end{array} \\
2.42\end{array}$} & \multirow{2}{*}{$\begin{array}{c}\begin{array}{c}\text { Re Diffusivity } \\
\left(\mathrm{cm}^{2} / \mathrm{s}\right)\end{array} \\
4.49 \mathrm{E}-09\end{array}$} & \multirow{2}{*}{$\begin{array}{c}\mathrm{Re} \\
(\mathrm{LI}) \\
8.35\end{array}$} & \multirow{2}{*}{$\begin{array}{c}\begin{array}{c}\text { Alkalinity } \\
\left(\mathrm{mg} / \mathrm{L} \text { as } \mathrm{CaCO}_{3}\right)\end{array} \\
1420\end{array}$} \\
\hline \multirow{20}{*}{$\begin{array}{c}\text { Geo-7 } \\
\text { encapsulated } \\
\text { FBSR } \\
\text { Monolith }\end{array}$} & \multirow{11}{*}{$\begin{array}{l}\mathrm{CO}_{2} / \\
\mathrm{N}_{2}\end{array}$} & & & & & & \\
\hline & & 1.0 & 10.7 & 2.82 & 9.67E-09 & 8.01 & 1440 \\
\hline & & 2.0 & 10.8 & 1.88 & $1.31 \mathrm{E}-08$ & 7.88 & 886 \\
\hline & & 7.0 & 11.3 & 3.54 & 4.22E-09 & 8.37 & 869 \\
\hline & & 14.0 & 11.7 & 3.54 & 1.13E-09 & 8.90 & 1850 \\
\hline & & 28.0 & 11.5 & 1.53 & $1.83 \mathrm{E}-11$ & 10.7 & 6540 \\
\hline & & 42.0 & 11.3 & $\mathrm{NM}$ & $6.95 \mathrm{E}-12$ & 11.2 & 3530 \\
\hline & & 49.0 & 11.0 & 0.392 & $6.51 \mathrm{E}-12$ & 11.2 & 179 \\
\hline & & 63.0 & 10.9 & 0.399 & $3.97 \mathrm{E}-12$ & 11.4 & 196 \\
\hline & & 77.0 & 10.7 & 0.288 & 2.95E-12 & 11.5 & 190 \\
\hline & & 91.0 & 10.4 & 0.253 & NM & NM & 110 \\
\hline & \multirow{9}{*}{$\begin{array}{l}\mathrm{O}_{2} / \\
\mathrm{N}_{2}\end{array}$} & 0.08 & 11.9 & 3.35 & 8.83E-09 & 8.05 & 1290 \\
\hline & & 1.0 & 12.2 & 6.51 & 5.36E-09 & 8.27 & 2330 \\
\hline & & 2.0 & 12.0 & 3.76 & 3.40E-09 & 8.47 & 1420 \\
\hline & & 7.0 & 12.3 & 8.07 & 1.52E-09 & 8.82 & 2700 \\
\hline & & 14.0 & 12.1 & $\mathrm{NM}$ & 1.02E-09 & 8.99 & 2300 \\
\hline & & 28.0 & 11.9 & 3.07 & $6.13 \mathrm{E}-11$ & 10.2 & 1040 \\
\hline & & 42.0 & 11.5 & 1.47 & $2.22 \mathrm{E}-11$ & 10.7 & 536 \\
\hline & & 49.0 & 11.3 & 0.579 & $1.54 \mathrm{E}-11$ & 10.8 & 224 \\
\hline & & 63.0 & 10.9 & 0.497 & $1.16 \mathrm{E}-11$ & 10.9 & 220 \\
\hline
\end{tabular}

ND indicates "not determined.” NM indicates "not measured."

Section 3, Tc speciation in Cast Stone is closely related with curing and storage times. The Cast Stone monoliths from the Phase-I project that were used in the weathering studies discussed in this section had been stored for many more months than Cast Stone waste forms used in Phase-I and Phase-II studies discussed in Pierce et al. (2010) and Sundaram et al. (2011). The longer storage time likely allowed more slow dissolution of BFS and reduction of Tc(VII) to Tc(IV) inside the Cast Stone monolith. However, the 14-day oxidizing weathering step using elevated $\mathrm{O}_{2}$ (g) concentrations appears to have re-oxidized Tc(IV) present at and near the surface of the monolith so that when the weathered Cast Stone monolith was placed in the leachant, Tc(VII) present in near surface pore water easily diffused out. However, after reacting with DIW in the first leachant exchange cycles (about 20 days leaching time), Tc diffusivity started to decrease. Because we do not have any data yet for Tc oxidation states for these weathered Cast Stone monoliths after $\mathrm{O}_{2}(\mathrm{~g})$ reaction, we can only hypothesize about why the Tc diffusivity starts to decrease after 20 days of leaching but we believe that the explanation for the initial increased Tc diffusivity after oxidative weathering is correct.

The Tc diffusivity results and measured $\mathrm{pH}$ values for EPA 1315 method leachates from the carbonated DuraLith (Batch \#2) monolith are shown in Figure 8.2. Even though the DuraLith monolith was carbonated for the same 14-day period as the Cast Stone monolith, the carbonated DuraLith leachate $\mathrm{pH}$ values were not significantly different from those of DuraLith leachates for unweathered monoliths (Figure 8.2, right). It would appear that DuraLith has more caustic $\mathrm{pH}$ buffering materials present so that the $\mathrm{pH}$ values in the carbonated DuraLith leachates are still high (around 10.0) even after 91 days leaching time. At the first leaching time, the carbonated DuraLith leachate $\mathrm{pH}$ was about 9.5, and the $\mathrm{pH}$ values gradually increased as the leaching time increased as was found in carbonated Cast Stone leachates. 
The $\mathrm{O}_{2}$ (g) reacted DuraLith leachate pHs were initially similar to those for unreacted DuraLith leachates, but the pHs started to decrease as the leaching time increased so that the $\mathrm{pH}$ values of $\mathrm{O}_{2}$ reacted DuraLith leachates showed similar or slightly lower $\mathrm{pH}$ values than those of the carbonated DuraLith after 30 days of leaching time.
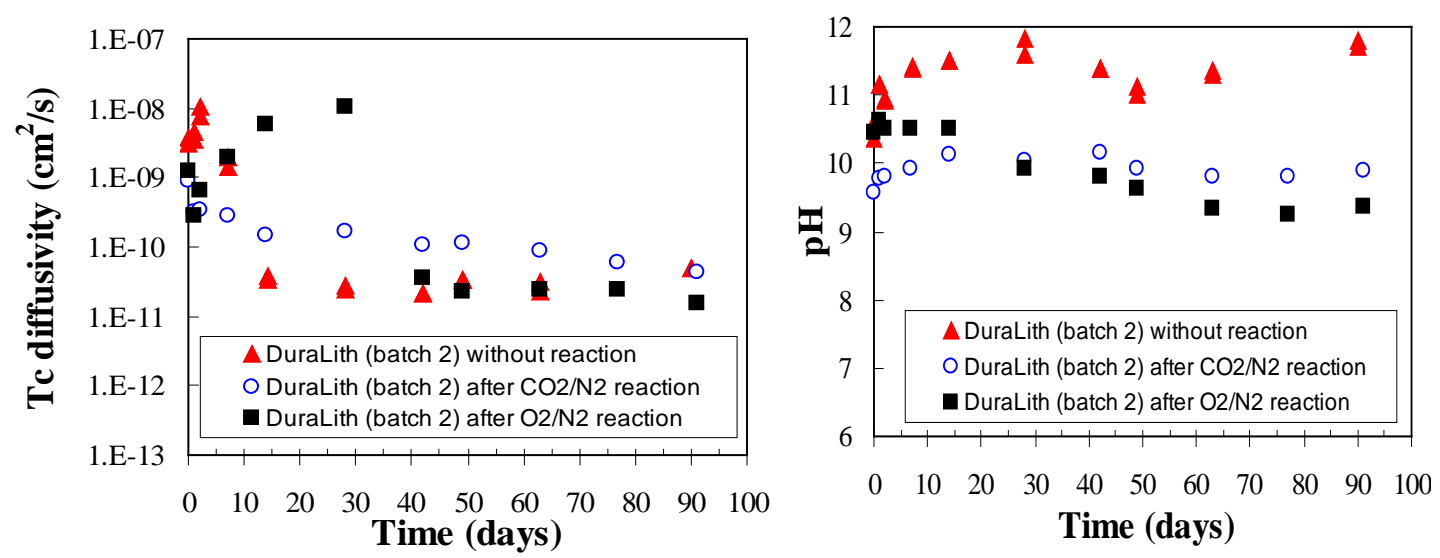

Figure 8.2. Diffusivity of Tc and Measured pHs for DuraLith (Batch \#2) Before and After Reaction Inside a $\mathrm{CO}_{2} / \mathrm{N}_{2}$ or $\mathrm{O}_{2} / \mathrm{N}_{2}$ Chamber Using the EPA 1315 Method

The measured Tc diffusivities for the carbonated DuraLith monolith were slightly lower than those for DuraLith monoliths not subjected to weathering before being leached during Phase-I testing (Pierce et al. 2010). Lower Tc diffusivities were especially evident for the carbonated DuraLith leachates at early leaching times (less than 10 days). The initially high Tc diffusivity for the unreacted DuraLith may have been caused by rapid dissolution of small fragments or debris present in the Method 1315 Phase I tests (Pierce et al. 2010). For the carbonated DuraLith monolith as the leaching time increased beyond 7 days, Tc diffusivity became slightly greater than for the unweathered DuraLith monoliths (Figure 8.2, left). However, this increase in Tc diffusivity for carbonated DuraLith versus the unreacted DuraLith was not as noticeably higher than that found in the carbonated versus unreacted Cast Stone data set. After about 90 days leaching time, the cumulative Tc diffusivity was about the same for both carbonated and unreacted DuraLith. Therefore, there was little difference in cumulative Tc diffusivity between the unreacted and carbonated monoliths despite there being subtle differences in the individual interval leachate Tc diffusivity values.

The measured Tc diffusivity for oxidized DuraLith monoliths showed increased Tc diffusivity up to 30 days of leaching time compared to unweathered monoliths. However, Tc diffusivity for the oxidized DuraLith monolith dropped abruptly at about 40 days of leaching time and was similar to the cumulative Tc diffusivity found in unreacted DuraLith through 90 days of leaching time. The initial increase in Tc diffusivity for the oxidized DuraLith monolith is thought to result from reoxidation of reduced Tc(IV) in DuraLith during the elevated $\mathrm{O}_{2}$ (g) reaction. After the newly oxidized Tc present at the surface and near surface of oxygenated DuraLith was removed, Tc diffusivity for oxidized DuraLith started to follow the same trend as found for the unreacted DuraLith as the leaching time increased.

Geo-7 encapsulated FBSR (both monolith and $<0.3 \mathrm{~mm}$ crushed) samples were also weathered in the $\mathrm{CO}_{2} / \mathrm{N}_{2}$ environmental chamber. After $\sim 2$ to 3 days of reaction, many white crystals had formed on the surface of the FBSR monolith. One type of growth was $\sim 2 \mathrm{~mm}$ in diameter and $\sim 1 \mathrm{~mm}$ height. This 
crystal appeared to have formed in large surface pores or damaged areas on the monolith as seen in Figure 8.3 , left. A second type of growth was $\sim 1 \mathrm{~mm}$ in diameter with flat square shapes. This type of growth covered most of the surface of the Geo-7 encapsulated FBSR monolith. When the chamber was opened after 14 days, these growths were sampled and analyzed using XRD. Both types of growths were identified as nahcolite $\left(\mathrm{NaHCO}_{3}\right)$ as seen in XRD pattern (Figure 8.3, right). None of the common calcium carbonate minerals (calcite, aragonite, and vaterite) were observed in these XRD patterns for both white precipitates. When the Geo-7 encapsulated FBSR monolith was placed into DIW to start the EPA 1315 leach test, the growths dissolved within the first 2 hours.
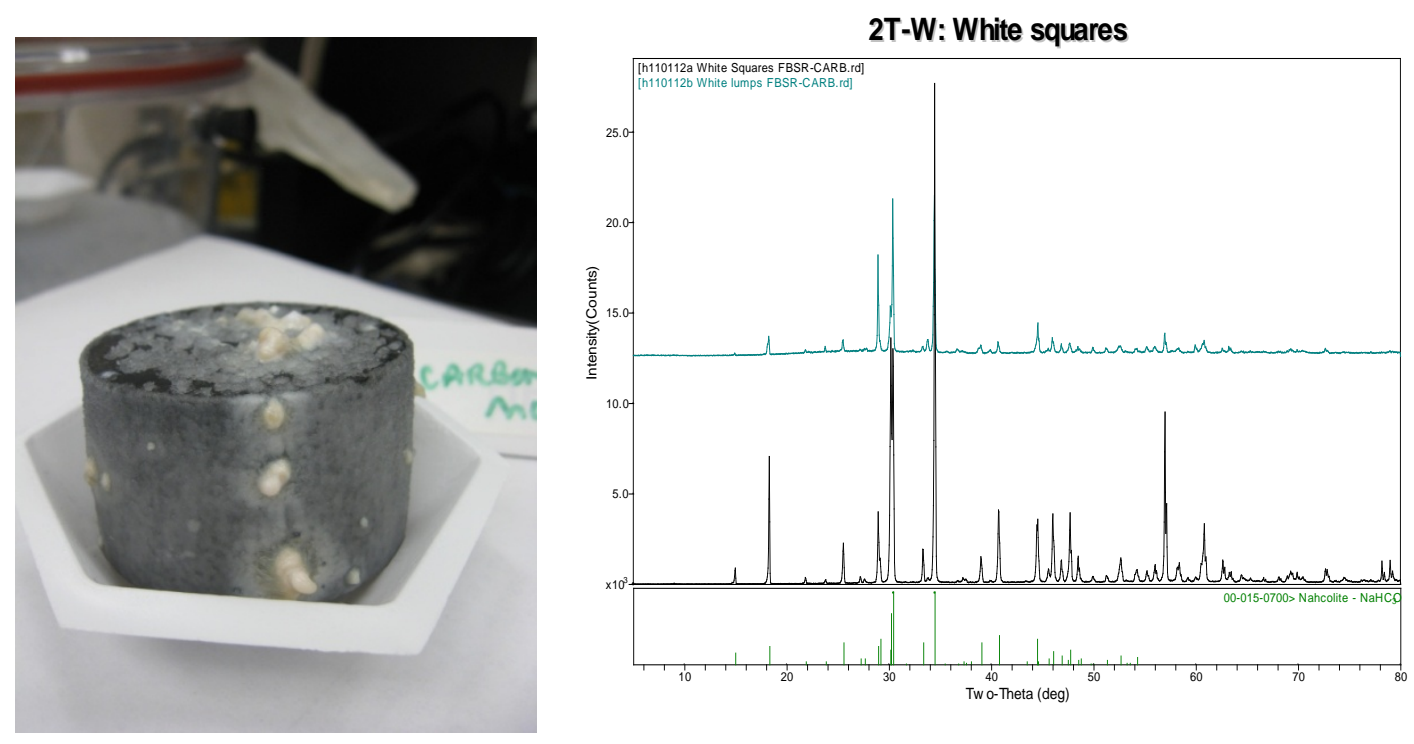

Figure 8.3. (Left) Reacted FBSR Monolith with $\mathrm{CO}_{2} / \mathrm{N}_{2}$ (g) Inside a Chamber and (right) XRD Patterns of Collected Two White Precipitates, White Lumps (top) and White Squares (middle) from the Reacted FBSR Surfaces and Reference XRD Pattern (bottom) of $\mathrm{NaHCO}_{3}$, Nahcolite

The results of Re diffusivity from the EPA 1315 testing and the leachate $\mathrm{pH}$ values for the carbonated or oxidized Geo-7 encapsulated FBSR monolith are shown in Figure 8.4. The initial Re diffusivities for both the carbonated and oxidized FBSR monoliths were similar or slightly higher than those for a Geo-7 encapsulated FBSR monolith that was leached without any weathering. However, the Re diffusivity for the carbonated FBSR monolith decreased as the leaching time increased after 10 days. Once the nearsurface Re was leached, Re within the interior of the monolith appears to leach out more slowly, even if there was enhanced carbonation reaction. The same decreasing trend of Re diffusivity was also found in the Geo-7 encapsulated FBSR monolith after the $\mathrm{O}_{2}(\mathrm{~g})$ reaction as the leaching times increased. Also, both the $\mathrm{CO}_{2}(\mathrm{~g})$ and the $\mathrm{O}_{2}$ (g) reacted Geo-7 encapsulated FBSR monolith showed a gradually decreasing mass at each collection time as the leaching time increased. Because of decreasing Re diffusivity as the leaching time increased, the observed mass loss for the monolith is likely caused by dissolution of the Geo-7 binding material and not the FBSR product, itself.

Although the pHs of carbonated Geo-7 encapsulated FBSR at early leaching stages were lower than those of oxidized and unreacted FBSR, the difference in $\mathrm{pH}$ values among the three FBSR monoliths became minor as the leaching time increased (Figure 8.4, right). This finding suggests that large amounts of pH-buffering materials are present in the Geo-7 encapsulated FBSR sample. The pH buffering material 
is likely in the Geo-7 binder as evidenced by the high concentrations of $\mathrm{Na}$ and $\mathrm{Si}$ found in leachates (see Appendix A-3) as leaching times increased. The measured mass of the Geo-7 encapsulated FBSR monolith decreased at each collection interval, suggesting continuous dissolution of the Geo-7 encapsulated FBSR monolith, likely dissolution of the Geo-7 binder itself.
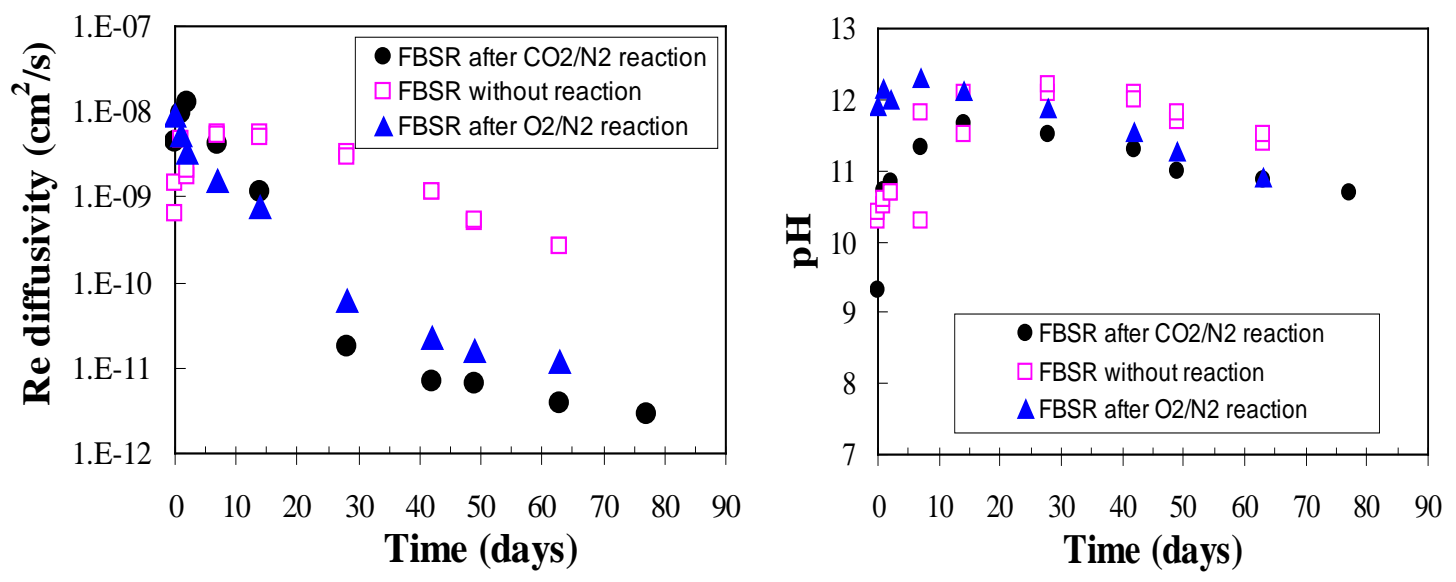

Figure 8.4. Diffusivity of Re and Measured pHs for the FBSR Monolith Before and After Reaction Inside a $\mathrm{CO}_{2} / \mathrm{N}_{2}$ or $\mathrm{O}_{2} / \mathrm{N}_{2}$ Chamber Using the EPA 1315 Method

\subsubsection{EPA 1313 Method Analysis}

The measured pHs and Tc concentrations in EPA 1313 method filtrates from Cast Stone waste forms after different reaction times are shown in Figure 8.5. Concentrations of Tc in filtrates from both the carbonated and oxidized Cast Stone granular samples were lower than for unreacted Cast Stone filtrates. However, Tc concentrations for the carbonated Cast Stone filtrates were also slightly lower than for the filtrates from the oxidized Cast Stone (Figure 8.5, left). The concentrations of leached Tc slowly increased as EPA 1313 method leaching times increased and reached equilibrium after 7 days leaching for all three Cast Stone waste forms. The $\mathrm{pH}$ values for the oxygen-treated and untreated Cast Stone filtrates were very similar and were quite alkaline ( $\mathrm{pH} 12.0$, see Figure 8.5, right). The carbonate treated Cast Stone filtrate $\mathrm{pH}$ values were much lower (between $\mathrm{pH} 7$ and 8), which is consistent with EPA 1315 leachate results previously discussed, especially at early stage leaching (see Figure 8.1). The EC and alkalinity values for Method 1313 filtrates for the oxidized Cast Stone samples were significantly larger than for the carbonated and unreacted Cast Stone filtrates (Table 8.2). 

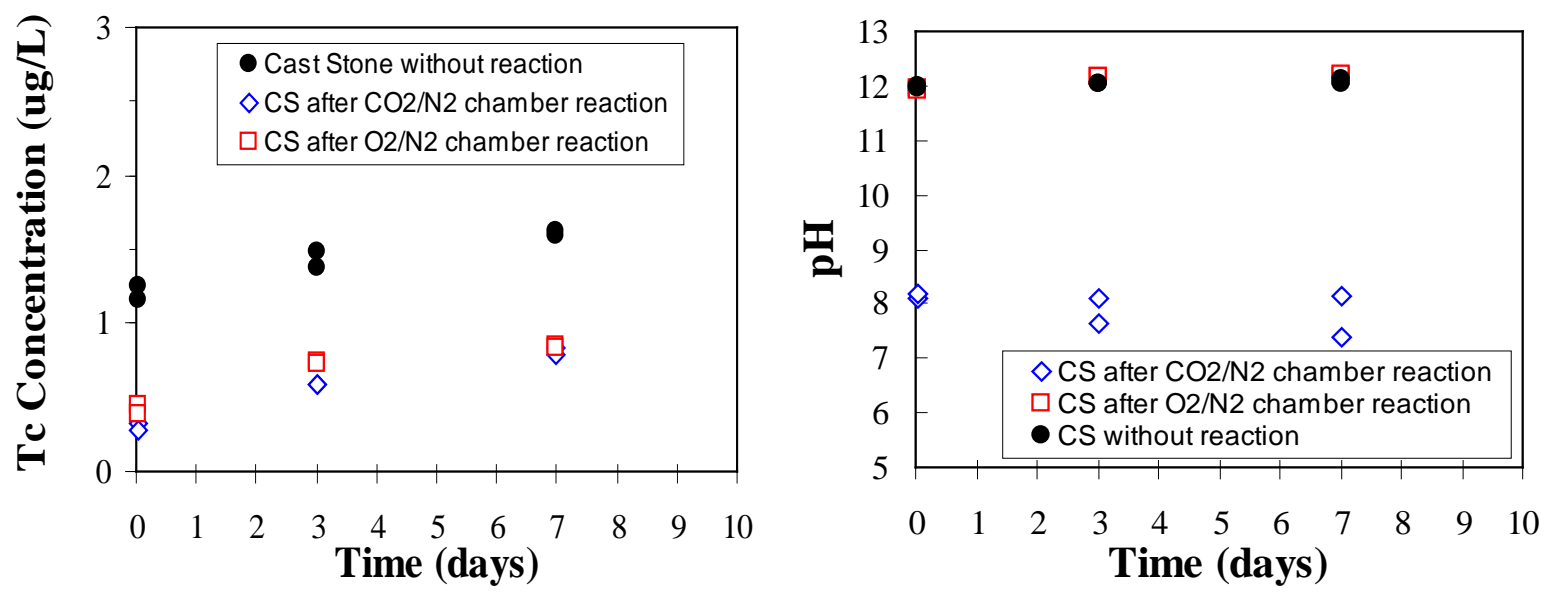

Figure 8.5. $\quad$ Concentrations of Leached Tc (left) and Measured pHs (right) for Cast Stone Before and After Reaction Inside a $\mathrm{CO}_{2} / \mathrm{N}_{2}$ or $\mathrm{O}_{2} / \mathrm{N}_{2}$ Chamber Using the EPA 1313 Method as a Function of Time

Table 8.2. Values of pH, EC, Alkalinity, Tc/Re Diffusivity, and Tc/Re LI of Waste Forms Measured by the EPA 1313 Method After $\mathrm{CO}_{2} / \mathrm{N}_{2}$ or $\mathrm{O}_{2} / \mathrm{N}_{2}$ Chamber Reactions

\begin{tabular}{|c|c|c|c|c|c|c|}
\hline \multicolumn{2}{|c|}{$\begin{array}{c}\text { Waste Forms } \\
\text { With/Without Reactions }\end{array}$} & \multirow{2}{*}{$\begin{array}{c}\begin{array}{c}\text { Times } \\
\text { (day) }\end{array} \\
0.042\end{array}$} & \multirow{2}{*}{$\frac{\mathrm{pH}}{8.12}$} & \multirow{2}{*}{$\begin{array}{c}\begin{array}{c}\mathrm{EC} \\
(\mathrm{mS} / \mathrm{cm})\end{array} \\
1.34\end{array}$} & \multirow{2}{*}{$\begin{array}{c}\begin{array}{c}\text { Tc Concentration } \\
(\mu \mathrm{g} / \mathrm{L})\end{array} \\
0.325\end{array}$} & \multirow{2}{*}{$\begin{array}{c}\begin{array}{c}\text { Alkalinity } \\
\left(\mathrm{mg} / \mathrm{L} \text { as } \mathrm{CaCO}_{3}\right)\end{array} \\
90.5\end{array}$} \\
\hline \multirow{18}{*}{ Cast Stone } & \multirow{6}{*}{$\mathrm{CO}_{2} / \mathrm{N}$} & & & & & \\
\hline & & 0.042 & 8.20 & 1.83 & 0.285 & 48.1 \\
\hline & & 3.0 & 7.64 & 2.46 & 0.582 & 76.5 \\
\hline & & 3.0 & 8.08 & 2.53 & 0.582 & 77.1 \\
\hline & & 7.0 & 7.40 & 2.74 & 0.842 & 112 \\
\hline & & 7.0 & 8.15 & 2.58 & 0.794 & 101 \\
\hline & \multirow{6}{*}{$\mathrm{O}_{2} / \mathrm{N}_{2}$} & 0.042 & 12.0 & 2.46 & 0.447 & 258 \\
\hline & & 0.042 & 11.9 & 2.23 & 0.382 & 309 \\
\hline & & 3.0 & 12.2 & 4.51 & 0.740 & 973 \\
\hline & & 3.0 & 12.2 & 4.24 & 0.731 & 941 \\
\hline & & 7.0 & 12.2 & 4.82 & 0.853 & 1100 \\
\hline & & 7.0 & 12.2 & 4.73 & 0.835 & 1280 \\
\hline & \multirow{6}{*}{$\begin{array}{l}\text { No } \\
\mathrm{CO}_{2} \\
/ \mathrm{O}_{2}\end{array}$} & 0.042 & 11.9 & $\mathrm{NM}^{(\mathrm{a})}$ & 1.16 & 711 \\
\hline & & 0.042 & 12.0 & NM & 1.25 & 709 \\
\hline & & 3.0 & 12.0 & NM & 1.38 & 775 \\
\hline & & 3.0 & 12.0 & NM & 1.48 & 784 \\
\hline & & 7.0 & 12.1 & NM & 1.59 & 856 \\
\hline & & 7.0 & 12.1 & NM & 1.63 & 912 \\
\hline \multirow{10}{*}{$\begin{array}{l}\text { DuraLith } \\
\text { Batch \#2 }\end{array}$} & \multirow{6}{*}{$\begin{array}{c}\mathrm{CO}_{2} / \mathrm{N} \\
2\end{array}$} & 0.042 & 9.73 & 2.89 & 3.00 & 637 \\
\hline & & 0.042 & 9.76 & 2.71 & 2.71 & 599 \\
\hline & & 3.0 & 9.86 & 3.86 & 2.76 & 1130 \\
\hline & & 3.0 & 9.83 & 4.03 & 2.77 & 1200 \\
\hline & & 7.0 & 9.9 & 3.97 & 2.82 & 1260 \\
\hline & & 7.0 & 9.9 & 3.89 & 2.67 & 1210 \\
\hline & \multirow{4}{*}{$\mathrm{O}_{2} / \mathrm{N}_{2}$} & 0.042 & 10.8 & 1.46 & 1.74 & 214 \\
\hline & & 0.042 & 10.8 & 1.35 & 1.59 & 210 \\
\hline & & 3.0 & 10.9 & 3.36 & 2.66 & 692 \\
\hline & & 3.0 & 10.9 & 3.26 & 2.63 & 666 \\
\hline
\end{tabular}


Table 8.2 (contd)

\begin{tabular}{|c|c|c|c|c|c|c|}
\hline \multicolumn{2}{|c|}{$\begin{array}{c}\text { Waste Forms } \\
\text { With/Without Reactions }\end{array}$} & \multirow{2}{*}{$\begin{array}{c}\begin{array}{c}\text { Times } \\
\text { (day) }\end{array} \\
7.0\end{array}$} & \multirow{2}{*}{$\frac{\mathrm{pH}}{10.9}$} & \multirow{2}{*}{$\begin{array}{c}\begin{array}{c}\mathrm{EC} \\
(\mathrm{mS} / \mathrm{cm})\end{array} \\
3.81\end{array}$} & \multirow{2}{*}{$\begin{array}{c}\begin{array}{c}\text { Tc Concentration } \\
(\mu \mathrm{g} / \mathrm{L})\end{array} \\
2.73\end{array}$} & \multirow{2}{*}{$\begin{array}{c}\begin{array}{c}\text { Alkalinity } \\
\left(\mathrm{mg} / \mathrm{L} \text { as } \mathrm{CaCO}_{3}\right)\end{array} \\
847\end{array}$} \\
\hline & & & & & & \\
\hline & & 7.0 & 10.9 & 3.74 & 2.64 & 867 \\
\hline & & 0.042 & 12.0 & 6.25 & 2.97 & 1013 \\
\hline & No & 0.042 & 12.0 & 6.16 & 2.95 & 1067 \\
\hline & & 3.0 & 11.3 & NM & 2.90 & NM \\
\hline & $\mathrm{CO}_{2}$ & 3.0 & 11.3 & NM & 2.91 & NM \\
\hline & $/ \mathrm{O}_{2}$ & 7.0 & 11.3 & 5.22 & 3.14 & 1660 \\
\hline & & 7.0 & 11.3 & 5.19 & 3.05 & 1610 \\
\hline \multicolumn{2}{|c|}{$\begin{array}{c}\text { Waste Forms } \\
\text { with/without Reactions }\end{array}$} & $\begin{array}{c}\text { Times } \\
\text { (day) }\end{array}$ & $\mathrm{pH}$ & $\begin{array}{c}\mathrm{EC} \\
(\mathrm{mS} / \mathrm{cm}) \\
\end{array}$ & $\begin{array}{c}\text { Re Concentration } \\
(\mu \mathrm{g} / \mathrm{L})\end{array}$ & $\begin{array}{c}\text { Alkalinity } \\
\left(\mathrm{mg} / \mathrm{L} \text { as } \mathrm{CaCO}_{3}\right) \\
\end{array}$ \\
\hline \multirow{14}{*}{$\begin{array}{c}\text { Geo-7 } \\
\text { encapsulated } \\
\text { FBSR }\end{array}$} & \multirow{6}{*}{$\begin{array}{l}\mathrm{CO}_{2} / \mathrm{N} \\
2\end{array}$} & 0.042 & 9.39 & 12.0 & 1120 & 11100 \\
\hline & & 0.042 & 9.45 & 11.3 & 1120 & 9030 \\
\hline & & 3.0 & 9.46 & 12.7 & 1750 & 9240 \\
\hline & & 3.0 & 9.42 & 12.7 & 1800 & 9850 \\
\hline & & 7.0 & 9.45 & 12.6 & 1890 & 9140 \\
\hline & & 7.0 & 9.45 & 12.3 & 1850 & 8770 \\
\hline & \multirow{6}{*}{$\mathrm{O}_{2} / \mathrm{N}_{2}$} & 0.042 & 11.9 & 12.0 & 1640 & 7620 \\
\hline & & 0.042 & 11.9 & 12.4 & 1730 & 7690 \\
\hline & & 3.0 & 11.9 & 12.4 & 1830 & 7690 \\
\hline & & 3.0 & 12.0 & 12.8 & 1840 & 7340 \\
\hline & & 7.0 & 12.0 & 12.8 & 2380 & 7410 \\
\hline & & 7.0 & 11.9 & 13.5 & 2530 & 7840 \\
\hline & No & 1.0 & 12.2 & 19.2 & 3410 & 12700 \\
\hline & $\begin{array}{l}\mathrm{CO}_{2} \\
/ \mathrm{O}_{2}\end{array}$ & 1.0 & 12.2 & 19.0 & 3500 & 12900 \\
\hline
\end{tabular}

The EPA 1313 method filtrate results for Tc concentrations and $\mathrm{pH}$ values for unreacted and both carbonated and oxidized DuraLith waste forms are shown in Figure 8.6. The Tc concentration in the filtrate from the carbonated DuraLith (Batch \#2) was similar to the Tc concentration in the filtrates for the unreacted DuraLith (Batch \#2), suggesting no impact from carbonation of the DuraLith waste form. Although the Tc concentration in the EPA 1313 method filtrates from the oxidized DuraLith after 1 hour reaction was lower than those of carbonated and unreacted DuraLith at the same reaction time (1 hour), Tc concentration in the EPA 1313 filtrate after 3 days reaction increased was similar to those of the carbonated and unreacted DuraLith filtrates. The carbonated DuraLith filtrate $\mathrm{pH}$ values were lower than the filtrate $\mathrm{pH}$ values for the unreacted DuraLith and oxidized DuraLith (Figure 8.6, right), which are the same trends as found in leachates from EPA 1315 testing for unreacted and reacted DuraLith waste forms. 

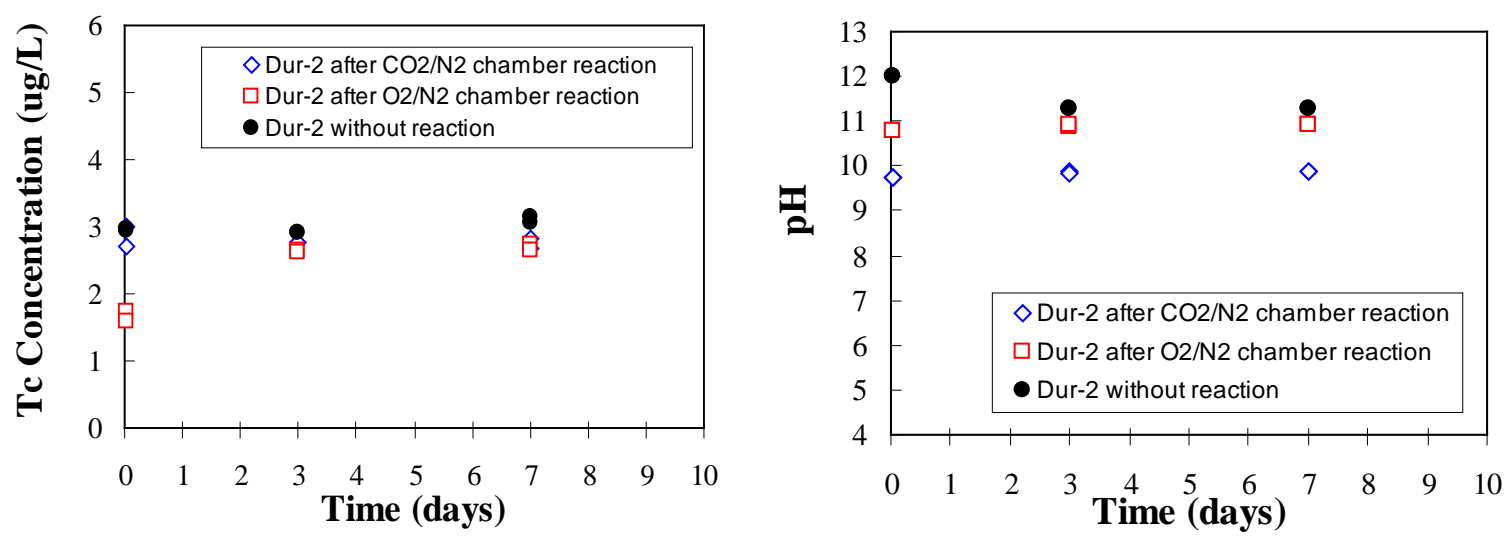

Figure 8.6. Concentrations of Leached Tc (left) and pHs (right) for DuraLith Before and After Reaction Inside a $\mathrm{CO}_{2} / \mathrm{N}_{2}$ or $\mathrm{O}_{2} / \mathrm{N}_{2}$ Chamber Using the EPA 1313 Method as a Function of Time

The EPA 1313 method filtrate Re concentrations and $\mathrm{pH}$ values for the carbonated Geo-7 encapsulated FBSR granular samples are shown in Figure 8.6. The filtrate Re concentrations from the carbonated or oxidized Geo-7 encapsulated FBSR waste form increased as leaching times increased, while the $\mathrm{pHs}$ were relatively constant for the different leaching times. The Re concentrations in the filtrates from the carbonated and oxidized FBSR samples were much lower than the Re concentration for filtrates from the unreacted Geo-7 encapsulated FBSR sample. However, the pHs and Re concentration for reacted Geo-7 encapsulated FBSR are similar to those found in the EPA Method 1315 test previously described.
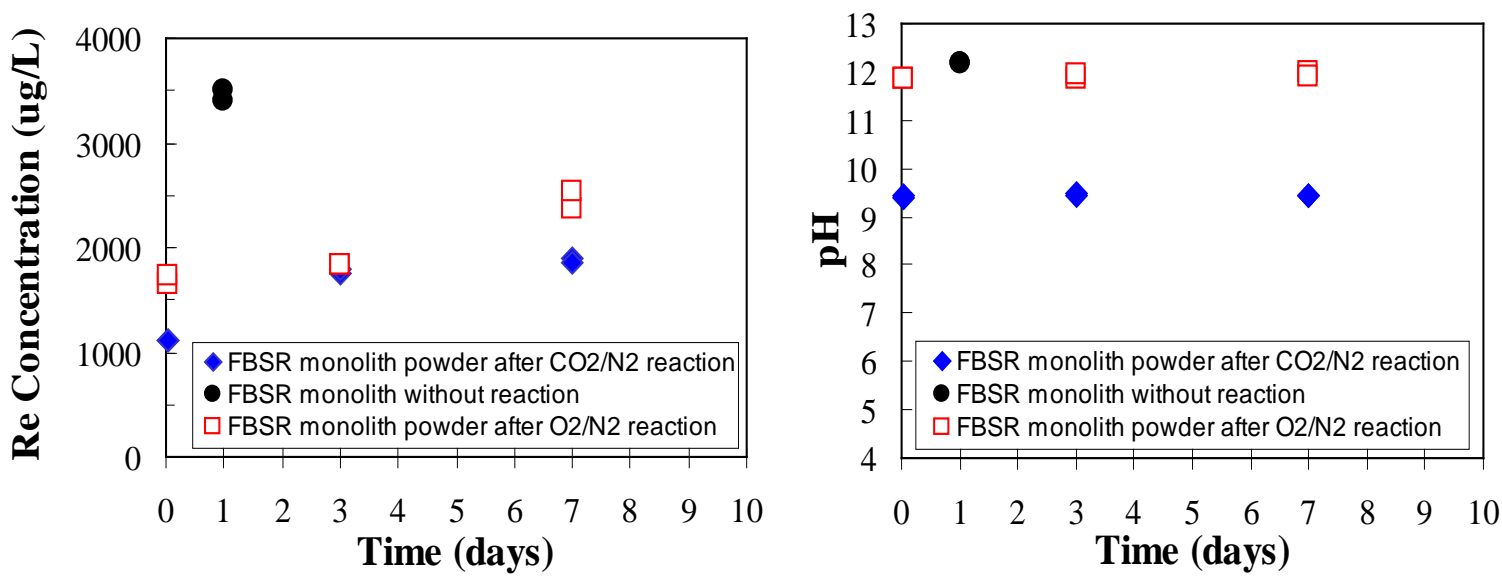

Figure 8.7. Concentrations of leached Re (left) and Measured pHs (right) for FBSR Monolith Powder Before and After Reaction Inside a $\mathrm{CO}_{2} / \mathrm{N}_{2}$ or $\mathrm{O}_{2} / \mathrm{N}_{2}$ Chamber Using the EPA 1313 Method as Functions of Time

\subsection{Conclusions}

Different weathering processes-enriched $\mathrm{CO}_{2}(\mathrm{~g})$ and $\mathrm{O}_{2}(\mathrm{~g})$ atmospheres - to promote carbonation and oxidation, respectively were performed inside environmental chambers for three waste forms. 
Carbonated Cast Stone waste form leachates exhibited lower $\mathrm{pH}$ values than unreacted Cast Stone leachates. Increased Tc diffusivity values for carbonated Cast Stone monoliths in comparison to unweathered Cast Stone were observed especially at short leaching times. This may have resulted from increased porosity after the carbonation reaction as determined by pore structure analysis. The diffusivity of Tc from the carbonated Cast Stone was constant or slowly decreased as the leaching times increased. For the oxidized Cast Stone, the leachate $\mathrm{pHs}$ were not changed from the $\mathrm{pH}$ values observed for unreacted Cast Stone, but Tc diffusivity also increased for the first 40 days of the 90-day leach test. Because $\mathrm{O}_{2}(\mathrm{~g})$ is a strong oxidant, the increased exposure to $\mathrm{O}_{2}(\mathrm{~g})$ likely re-oxidized reduced $\mathrm{Tc}(\mathrm{IV})$ species near the surface of the Cast Stone monolith, thus causing the early enhanced Tc diffusivity. Once the near-surface impacts of the oxidation treatment dissipated in the leach tests by subsequent leachant renewals, the latter Tc diffusivity values dropped back to those observed for unweathered Cast Stone waste forms. The slow re-oxidation process and the limited reduction capacity of the remaining reducing agents (i.e., BFS) in the Cast Stone should be considered in future long-term predictions for the performance of the Cast Stone waste form. The slow diffusion of oxygen into waste forms can re-oxidize Tc and enhance its diffusion properties.

The Tc diffusivity and leachate $\mathrm{pHs}$ for the carbonated DuraLith waste form after $\mathrm{CO}_{2}(\mathrm{~g})$ reaction were lower than values for the unreacted DuraLith, but based on changes in $\mathrm{pH}$, the degree of $\mathrm{CO}_{2}(\mathrm{~g})$ reaction in the DuraLith was not as large as that found in Cast Stone tests. Data for the impacts of subjecting the DuraLith to enriched $\mathrm{O}_{2}$ (g) atmospheres showed higher Tc diffusivity up to 30 days of leaching because of the reoxidation of Tc(IV) formed during the weathering of the waste form by the elevated oxygen contact. However, the increased early stage Tc diffusivity for oxidized DuraLith dropped off and showed similar Tc diffusivity to those found in unreacted DuraLith as the leaching time increased. Generally, carbonated DuraLith monoliths continued to show higher Tc diffusivity than those found in both unreacted and oxidized DuraLith through 70 days leaching time.

The Geo7 encapsulated FBSR monolith after carbonation or after oxidation showed decreasing Re diffusivity as the leaching time increased, while the leachate pHs were similar to those measured in leachates from unreacted Geo7 encapsulated FBSR monoliths. Thus there did not seem to be any significant effects on Re leaching caused by short-term enhanced weathering.

EPA 1313 testing for the three waste forms (Cast Stone, DuraLith, and Geo7 encapsulated FBSR) after reaction inside a $\mathrm{CO}_{2}(\mathrm{~g})$ or $\mathrm{O}_{2}(\mathrm{~g})$ chamber showed similar results to those obtained from the EPA 1315 method leachates. Additional EPA 1313 testing with extended reaction times beyond 7 days are recommended because the EPA 1313 testing through 7 days showed that Tc concentrations were still increasing, although $\mathrm{pH}$ levels in the filtrates from the various waste forms appear to have reached steady state values.

The pore structure and the Tc oxidation state of the waste forms need to be further analyzed both before and after enhanced weathering and before and after subsequent water leaching to augment our understanding of the impacts of weathering before and after water leaching so that predictive long-term models of radionuclide leachability out of the various waste forms can be developed. 


\subsection{Summary and Recommendations}

Activities performed to date in the radionuclide retention mechanisms subtask of the Phase-II secondary waste testing program have included:

- Measuring technetium speciation/oxidation states in unleached waste forms

- Measuring the reductive capacity of dry ingredients and final solid waste forms

- Analyzing the pore structures of waste forms before and after enhanced weathering

- Performing flow-through column leach tests using the EPA 1314 method

- Extending EPA 1315 leach testing to 90 days for waste forms available from Phase I studies

- Conducting additional enhanced weathering tests using $\mathrm{CO}_{2}(\mathrm{~g})$ or $\mathrm{O}_{2}(\mathrm{~g})$ reactions and then subjecting the weathered waste forms to EPA 1315 water leach tests

- Extending EPA 1313 method leach tests of unreacted and weathered waste forms to longer water contact times.

Although Tc speciation and oxidation-state distributions are predicted to be the same in each of the different liquid waste simulants, the Tc oxidation states in the final solid waste forms varied, depending on the types of waste form prepared (especially those that were sensitive to types and amounts of reductants present in the starting dry blend mix) and the waste form curing (or aging) times. Waste forms considered in this subtask were Cast Stone, DuraLith, Ceramicrete, and FBSR encapsulated in a Geo-7 matrix.

BFS added as one of the dry ingredients in preparing Cast Stone worked as a reductant to form reduced Tc(IV) species if the aging/curing time was long enough for the BFS to dissolve so that measurable amounts of electrons were released. That is, slow dissolution of the BFS during aging allowed more of the Tc trapped in the Cast Stone (likely in the pore water) to be reduced. In contrast, adding reductants, such as $\mathrm{Na}_{2} \mathrm{~S}, \mathrm{SnF}_{2}$, or $\mathrm{SnCl}_{2}$, used in preparing DuraLith and Ceramicrete effectively and swiftly reduced Tc(VII) to Tc(IV) even after short reaction times (3 days). The measured reductive capacities for the individual dry blend ingredients showed high reduction capacities for the $\mathrm{SnF}_{2}$ and $\mathrm{SnCl}_{2}$ compared to all other dry blend ingredients. Because $\mathrm{SnF}_{2}$ and $\mathrm{SnCl}_{2}$ are used in both DuraLith and Ceramicrete, the reducing capacities of these two cured waste forms are considerably larger than the reducing capacity of cured Cast Stone and Geo7-encapsulated FBSR. The measured reductive capacity values were obtained with two methods, one based on Ce(IV) as the oxidant and another based on $\mathrm{Cr}(\mathrm{VI})$ as the oxidant. In almost all cases, the Ce(IV) method yielded larger reducing capacity values than those from the $\mathrm{Cr}(\mathrm{VI})$ method and can be used as an upper bound for the reductive capacity of the waste forms. The Ce(IV) method subjects the solids to a strong acid (low $\mathrm{pH}$ ) condition that dissolves much more of the solids than are dissolved by the $\mathrm{Cr}(\mathrm{VI})$ method, which relies on a neutral $\mathrm{pH}$ condition.

Pore structure analysis showed that Cast Stone is a relatively highly porous material (less dense) when compared to the other waste forms. Carbonation reactions appear to change the pore structure of Cast Stone more than in other waste forms. Accelerated carbonation weathering of Cast Stone via reaction with enhanced $\mathrm{CO}_{2}(\mathrm{~g})$ increased the Tc diffusivity from Cast Stone over at least 90 days of water leaching of monoliths. However, carbonation reactions did not increase Tc diffusivity from DuraLith or Geo-7 encapsulated FBSR waste form monoliths using the EPA 1315 method. Increased Tc diffusivity in 
carbonated Cast Stone seemed to be constant or slowly decrease as leaching times increased. Cast Stone monoliths subjected to accelerated oxidation using elevated concentrations of $\mathrm{O}_{2}$ (g) also exhibited increased Tc diffusivity compared to unreacted Cast Stone over most of the short leaching times studied. Both carbonated and oxidized Geo7 encapsulated FBSR showed lower Re diffusivity values compared to unreacted Geo-7 encapsulated FBSR.

Waste form samples subjected to EPA 1313 testing with extended reaction times up to 7 days showed that Tc concentrations in filtrates were still increasing after reacting for 7 days, while $\mathrm{pH}$ values appeared to reach steady-state values for all three waste forms tested (Cast Stone, DuraLith, and Geo-7 encapsulated FBSR). Therefore, future EPA 1313 testing should be extended beyond 7 days to find the point at which Tc concentrations reach equilibrium.

The flow-through column leaching test using the EPA 1314 method for different waste forms showed slightly higher Tc concentrations in the column effluents from DuraLith than effluents from Cast Stone, which is consistent with Phase-I EPA 1313 and 1315 results. Rhenium concentrations in the EPA 1314 column effluents from the Geo-7 encapsulated FBSR waste form were higher, as expected, because of the higher concentrations in the waste simulant used in the FBSR preparation.

The EPA 1315 method leach test on Cast Stone and DuraLith monoliths from the Phase-I project that had been stored for several months were performed for extended times (up to 90 days). The results showed that the Tc diffusivity for the Cast Stone followed a trend of slow decrease in Tc diffusivity with time. After subjecting other Cast Stone monoliths to enhanced weathering (carbonation for 14 days), there was increased Tc release, which probably resulted from dissolution of C-S-H or portlandite in the Cast Stone that dominated the porosity changes caused by calcium carbonate precipitation. However, after 30 days of accelerated carbonation there was a reduced net porosity observed using pore structure analysis for the same Cast Stone and this reduced porosity resulted in decreasing Tc diffusivity in Cast Stone as the leaching times increased. This was because the amount of calcite precipitation in a relatively later stage of carbonation started to dominate over the C-S-H or portlandite dissolution reactions, which tend to increase porosity. Another factor that could be lowering the Tc diffusivity values over time is a lowered chemical gradient between Tc concentrations inside the Cast Stone monolith as the Tc source is depleted.

The results obtained in this subtask help fill existing data gaps and should support a down-selection process for identifying one or more secondary waste forms that should be studied further. Additional recommendations for continued mechanism studies are listed below:

1. Additional long-term Tc speciation and oxidation-state investigations should be conducted with spectroscopic techniques to monitor Tc oxidation evolution in the different waste forms as a function of curing/storage as well as after different times of accelerated weathering and water leaching times. Because re-oxidation of Tc(IV) species occurs when the waste form is exposed to atmospheric oxygen, a predictive relationship between the Tc oxidation state and Tc diffusivity (or LI) as a function of aging and weathering times should be developed for each waste form type for long-term performance assessment of waste forms disposed of in the IDF repository.

2. The reductive capacity of the reductants added to form different waste forms should be measured with the Ce(IV) method to estimate the upper bound reductive capacity of the reductants. Measurement of residual reductive capacity should also be performed after varying accelerated weathering exposures using the carbonation and oxygenation treatments. The kinetics of how soon the reductants can lose 
their reductive capacity because of $\mathrm{O}_{2}$ (g) diffusion is a key data gap that needs to be addressed. The long-term reduction capacity measurement for the reductants can help understand and predict the potential re-oxidation of Tc species and the changes in reductive capacity of waste forms in a longterm performance assessment when they are exposed to oxic or suboxic conditions.

3. More scientific and detailed studies of waste form pore structure and their changes before and after carbonation reactions and the relationship of the pore structure changes with permeability changes should be conducted to develop the predictive model for Tc leachability variations caused by pore structure changes due to physicochemical reactions. Longer term carbonation investigations are required to evaluate the overall effects on waste form physical properties, especially for the Cast Stone waste form. Pore-size distribution analysis using Hg-porosimeter techniques should be included to provide more data.

4. Longer-term flow-through column leach testing (EPA 1314) and additional waste form weathering studies using the elevated $\mathrm{CO}_{2}(\mathrm{~g})$ and $\mathrm{O}_{2}(\mathrm{~g})$ mixtures should be conducted. The weathered waste forms should be also tested with the EPA 1313 and 1315 test methods for longer time periods. 



\subsection{References}

Angus MJ and FP Glasser. 1985. “The Chemical Environment in Cement Matrices.” Materials Research Society Symposium Proceedings 50:547-556.

Barrett EP, LG Joyner, and PP Halenda. 1951. "The Determination of Pore Volume and Area Distribution in Porous Substances.” Journal of the American Chemical Society 73(1):373-380. DOI:10.1021/ja01145a126.

Bethke C and S Yeakel. 2009. The Geochemist’s Workbench, Release 8.0, Reference Manual. Hydrogeology Program, Urbana, Illinois.

Biino GG and P Gröning. 1998. "Cleavage Mechanism and Surface Chemical Characterization of Phengitic Muscovite and Muscovite as Constrained by X-ray Photoelectron Spectroscopy.” Physics and Chemistry of Minerals 25(2):168-181. DOI: 10.1007/s002690050100.

Brunauer S, PH Emmett, and E Teller. 1938. “Adsorption of Gases in Multimolecular Layers.” Journal of the American Chemical Society 60(2):309-319. DOI:10.1021/ja01269a023.

Cai R, WB Lindquist, W Um, KW Jones. 2009. "Tomographic Analysis of Reactive Flow-Induced Pore Structure Changes in Column Experiments.” Advances in Water Resources 32(9):1396-1403.

DOI: 10.1016/j.advwatres.2009.06.006.

Cooke GA, LL Lockrem, BA Clark, and R Westburg. 2008. Cast Stone Technology for Treatment and Disposal of Iodine Rich Caustic Waste Demonstration-Final Report. RPP-RPT-26725, Rev 0-A, CH2M Hill Hanford Group, Inc., Richland, Washington.

Cooke GA, JB Duncan, LMD Guthrie, and LL Lockrem. 2009. “Assessment of Pertechnetate Getters, Reductants, and Stabilization.” Presented at the DOE Technical Exchange, Denver, Colorado, Washington River Protection Solutions, LLC, Richland, Washington. Available at: RPP-1231-VA.

Crank J. 1986. Mathematics of Diffusion. Second Edition, pp. 424. Oxford University Press, London, United Kingdom.

EPA-U.S. Environmental Protection Agency. 1984. “Determination of Inorganic Anions.” EPA Method 300.0A, in Test Method for the Determination of Inorganic Anions in Water by Ion Chromatography. EPA-600/4-84-0 17, U.S. Environmental Protection Agency, Washington, D.C.

EPA-U.S. Environmental Protection Agency. 2000a. "Inductively Coupled Plasma-Atomic Emission Spectrometry.” EPA Method 6010B, in Test Methods for Evaluating Solid Waste, Physical/Chemical Methods. SW-846, U.S. Environmental Protection Agency, Washington, D.C. Accessed May 11, 2011 at: http://www.epa.gov/epaoswer/hazwaste/test/sw846.htm.

EPA-U.S. Environmental Protection Agency. 2000b. “Inductively Coupled Plasma-Mass Spectrometry.” EPA Method 6020, in Test Methods for Evaluating Solid Waste, Physical/Chemical Methods. SW-846, U.S. Environmental Protection Agency, Washington, D.C. Accessed May 11, 2011 at: http://www.epa.gov/epaoswer/hazwaste/test/sw846.htm. 
EPA-U.S. Environmental Protection Agency. 2009a. "Leaching Test (Liquid-Solid Partitioning as a Function of Extract pH) of Constituents in Solid Materials Using a Parallel Batch Extraction Test.” Draft Method 1313. U.S. Environmental Protection Agency, Washington, D.C.

EPA-U.S. Environmental Protection Agency. 2009b. "Leaching Test (Liquid-Solid Partitioning as a Function of Liquid-Solid Ratio) of Constituents in Solid Materials Using an Up-Flow Percolation Column.” Draft Method 1314. U.S. Environmental Protection Agency, Washington, D.C.

EPA-U.S. Environmental Protection Agency. 2009c. "Mass Transfer Rates of Constituents in Monolith or Compacted Granular Materials Using a Semi-Dynamic Tank Leaching Test.” Draft Method 1315. U.S. Environmental Protection Agency, Washington, D.C.

EPA-U.S. Environmental Protection Agency. 2009d. "Leaching Test (Liquid-Solid Partitioning as a Function of Liquid to Solid Ratio) of Constituents in Solid Materials Using a Parallel Batch Extraction Test.” Draft Method 1316. U.S. Environmental Protection Agency, Washington, D.C.

Garrels RM and CL Christ. 1965. Solutions, Minerals, and Equilibria. Freeman, Cooper and Co., San Francisco, California.

Gilliam TM, RD Spence, WD Bostick, and LL Shoemaker. 1990. “Solidification/Stabilization of Technetium in Cement-Based Grouts.” Journal of Hazardous Materials 24(2-3):189-197. DOI: $\underline{10.1016 / 0304-3894(90) 87009-7}$.

Gregg SJ and KSW Sing. 1982. Adsorption, Surface Area, and Porosity. Second Edition. Academic Press, Inc., Orlando, Florida.

Hochella MF Jr. 1988. “Auger Electron and X-ray Photoelectron Spectroscopies.” In: Spectroscopic Methods in Mineralogy and Geology (FC Hawthorne, Editor). Reviews in Mineralogy 18:573-637.

Hochella MF Jr. 1990. “Atomic Structure, Microtopography, Compound and Reactivity of Mineral Surfaces.” In: Mineral-Water Interface Geochemistry (MF Hochella Jr. and AF White, Editors). Reviews in Mineralogy 23:87-132.

Jantzen CM. 2003. Characterization and Performance of Fluidized Bed Steam Reforming (FBSR) Product as a Final Waste Form (U). WSRC-MS-2003-00595 Revision 0, Westinghouse Savannah River Company, Aiken, South Carolina.

Jantzen CM, JC Marra, and JM Pareizs. 2004. Analysis of Raw Materials for Fluidized Bed Steam. SRNL-ITB-2004-0004, Savannah River National Laboratory, Aiken, South Carolina.

Josephson GB, GF Piepel, and JH Westsik Jr. 2010. Selection of Secondary Waste Test Compositions. Pacific Northwest National Laboratory, Richland, Washington.

Kaplan DI, T Hang, and SE Aleman. 2005. Estimated Duration of the Reduction Capacity Within a High-Level Waste Tank(U). WSRC-RP-2005-01674, Revision 0, Westinghouse Savannah River Company, Aiken, South Carolina.

Langmuir D. 1997. Aqueous Environmental Geochemistry. Prentice Hall, Upper Saddle River, New Jersey. 
Lee W and B Batchelor. 2003. "Reductive Capacity of Natural Reductants.” Environmental Science \&Technology 37(3):535-541. DOI: 10.1021/es025830m.

Liu Y, J Terry, and SS Jurisson. 2008. "Pertechnetate Immobilization with Amorphous Iron Sulfide.” Radiochimica Acta 96:823-833. DOI:10.1524/ract.2008.1528.

Liu Y, J Terry, and SS Jurisson. 2009. "Potential Interferences on the Pertechnetate-Sulfide Immobilization Reaction.” Radiochimica Acta 97:33-41. DOI:10.1524/ract.2009.1569.

Lockrem LL. 2005. Hanford Containerized Cast Stone Facility Task 1 - Process Testing and Development, Final Report. RPP-RPT-26742, Rev 0, Fluor Hanford, Richland, Washington.

Lockrem LL, GA Cooke, BA Clark, and R Westburg. 2008. Cast Stone Technology for Treatment \& Disposal of Iodine Rich Caustic Waste Demonstration Final Report. CH2M Hill Hanford Group, Inc., Richland, Washington (RPP-RPT-26725, Rev. 0-A; link is to Rev 0, Rev 0-A; included all authors).

Lukens WW, JJ Bucher, NM Edelstein, and DK Shuh. 2002. "Products of Pertechnetate Radiolysis in Highly Alkaline Solution: Structure of $\mathrm{TcO}_{2} \mathrm{xH}_{2} \mathrm{O}$.” Environmental Science \& Technology 36(5):1124-1129. DOI: 10.1021/es015653+.

Lukens WW, JJ Bucher, DK Shuh, and NM Edelstein. 2005. "Evolution of Technetium Speciation in Reducing Grout.” Environmental Science \& Technology 39(20):8064-8070. DOI: 10.1021/es050155c.

Newville M. 2001. “IFEFFIT: Interactive XAFS Analysis and FEFF Fitting.” Journal of Synchrotron Radiation 8(2)::322-324. DOI:10.1107/S0909049500016964.

Nordstrom DK and JL Munoz. 1985. Geochemical Thermodynamics. The Benjamin/Cummings Publishing Co., Inc., Menlo Park, California.

NRC-U.S. Nuclear Regulatory Commission. 1991. Technical Position on Waste Form, Rev. 1. Final Waste Classification and Waste Form Technical Position Papers. U.S. Nuclear Regulatory Commission, Washington, DC.

Olson AL, NR Soelberg, DW Marshall, and GL Anderson. 2004. Fluidized Bed Steam Reforming of INEEL SBW Using THORsm Mineralizing Technology. INEEL/EXT-04-02564, Idaho National Engineering and Environmental Laboratory, Idaho Falls, Idaho.

PNNL-Pacific Northwest National Laboratory. 1998. Inductively Coupled Plasma Mass Spectrometric (ICP-MS) Analysis. PNNL-AGG-415, Pacific Northwest National Laboratory, Richland, Washington.

Perera DS, Z Aly, ER Vance, and M Mizumo. 2005. “Immobilization of Pb in a Geopolymer Matrix.” Journal of the American Ceramic Society 88(9):2586-2588. DOI:10.1111/j.1551-2916.2005.00438.X.

Pierce EM, W Um, KJ Cantrell, MM Valenta, JH Westsik, Jr., RJ Serne, and KE Parker. 2010. Secondary Waste Form Screening Test Results-Cast Stone and Alkali Alumino-Silicate Geopolymer. PNNL-19505, Pacific Northwest National Laboratory, Richland, Washington. 
Pires RP, JH Westsik Jr., RJ Serne, SV Mattigod, EC Golovich, MM Valenta, and KE Parker. 2011. Secondary Waste Form Screening Test Results - THOR ${ }^{\circledR}$ Fluidized Bed Steam Reforming Product in a Geopolymer Matrix. PNNL-20551, Pacific Northwest National Laboratory, Richland, Washington.

Ravel B and M Newville. 2005. "ATHENA, ARTEMIS, HEPHAESTUS: Data Analysis for X-ray Absorption Spectroscopy using IFEFFIT.” Journal of Synchrotron Radiation 12:537-541.

Rehr JJ, MM de Leon, S Zabinsky, and RC Albers. 1991. “Theoretical X-ray absorption fine structure standards.” J. Am. Chem. Soc. 113:5135-5140.

Roberts KA and DI Kaplan. 2009. Reduction Capacity of Saltstone and Saltstone Components. SRNL-STI-2009-00637, Rev 0, Savannah River National Laboratory, Aiken, South Carolina.

Russell RL, MJ Schweiger, JH Westsik, PR Hrma, DE Smith, AB Gallegos, MR Telander, and SG Pitman. 2006. Low Temperature Waste Immobilization Testing. PNNL-16052, Rev. 1, Pacific Northwest National Laboratory, Richland, Washington.

Shuh DV, NM Edelstein, CJ Burns, WW Lukens, JJ Bucher, MG Fickes, and BL Scott. 2000. Research Program to Investigate the Fundamental Chemistry of Technetium. Final Report of U.S. Department of Energy, EMSP-60296, Lawrence Berkeley National Laboratory, Berkeley, California.

Singh D, AS Wagh, JC Cunnane, and JL Mayberry. 1997. "Chemically Bonded Phosphate Ceramics for Low-Level Mixed-Waste Stabilization.” Journal of Environmental Science and Health Part A 32:527-541.

Smith RW and JC Walton. 1993. "The Role of Oxygen Diffusion in the Release of Technetium from Reducing Cementitious Waste Forms.” Materials Research Society Symposium Proceedings 1993, pp. 247-253.

Sundaram SK, J Chun, W Um, KE Parker, C-W Chung, JH Westsik, Jr., ME Valenta, ML Kimura, SG Pitman, and CA Burns. 2011. Secondary Waste Form Development and Optimization-Cast Stone. PNNL-20159, Pacific Northwest National Laboratory, Richland, Washington.

Teo BK. 1986. EXAFS: Basic Principles and Data Analysis. Springer-Verlag, Berlin.

USGS-U.S. Geological Survey. 2004. “Alkalinity and Acid Neutralizing Capacity.” In: National Field Manual for the Collection of Water-Quality Data, Second Edition. SA Rounds and FD Wilde, Editors.

Accessed May 11, 2011 at:

http://water.usgs.gov/owq/FieldManual/Chapter6/section6.6/html/section6.6.htm.

WAC—Washington State Administrative Code. 2000. "Land Disposal Restrictions.” WAC 173-303-140. Washington State Administrative Code, Olympia, Washington.

Wagh AS. 2004. Chemically Bonded Phosphate Ceramics: Twenty-First Century Materials with Diverse Applications. Elsevier, Amsterdam, The Netherlands.

Webb PA and Orr C. 1997. Analytical Methods in Fine Particle Technology. Micromeritics Instrument Corporation, Norcross, Georgia. 


\section{Appendix A}

Appendix A-1: Additional XPS Results for FBSR samples

Appendix A-2: Additional Test Results from EPA Methods 1313, 1314, and 1315

Appendix A-3: SEM/EDS for 90-Day Leached Cast Stone and DuraLith Sliced Samples 



\section{Appendix A-1}

\section{Additional Results from XPS for High Energy Resolution Photoemission Spectra of FBSR Powder and FBSR Milled Powder}

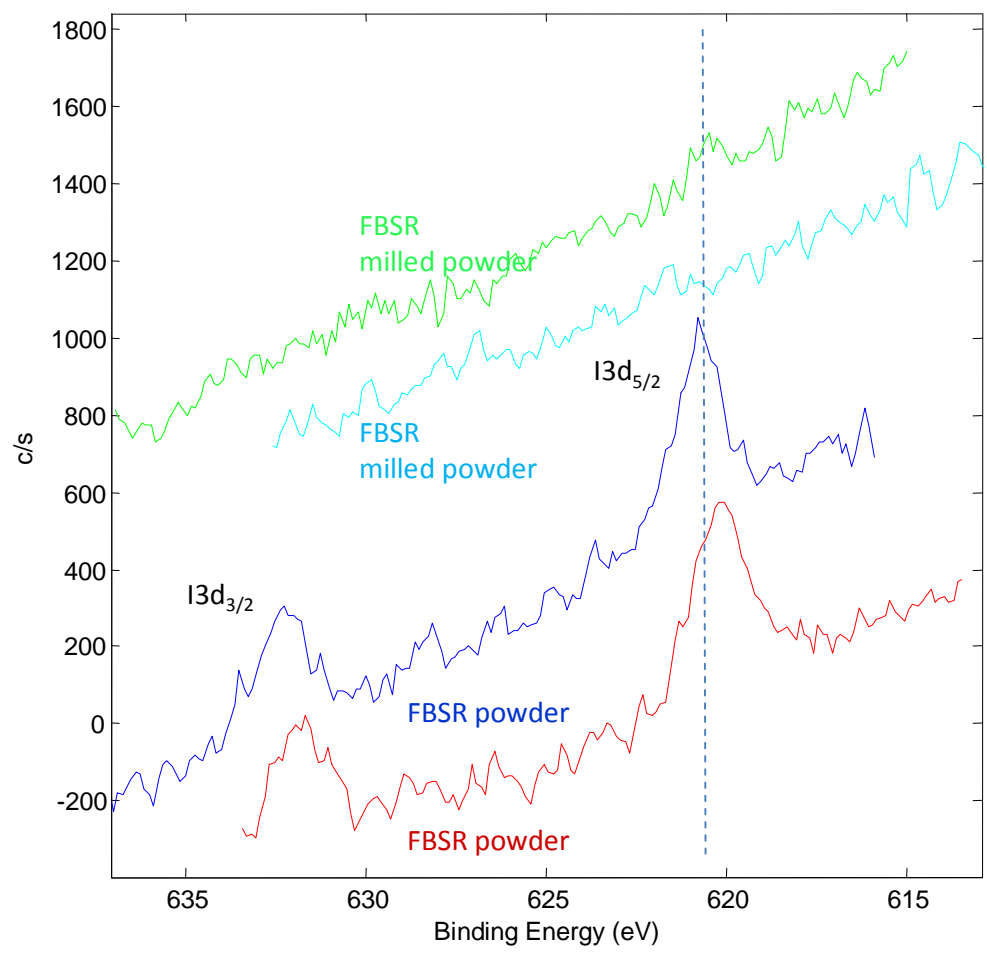

Figure A.1. High Energy Resolution Photoemission Spectra of the I 3d Region for FBSR Powder and FBSR Milled Powder (counts/second) 


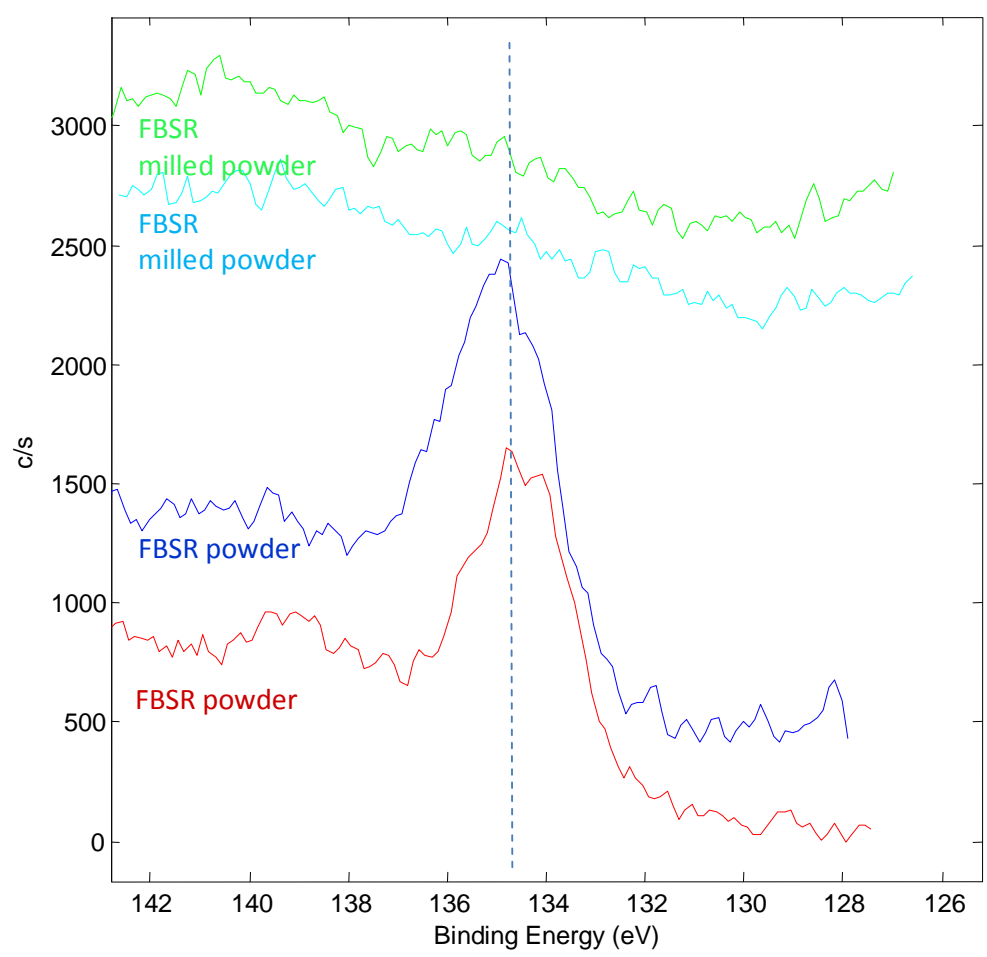

Figure A.2. High Energy Resolution Photoemission Spectra of the P 2p Region for FBSR Powder and FBSR Milled Powder

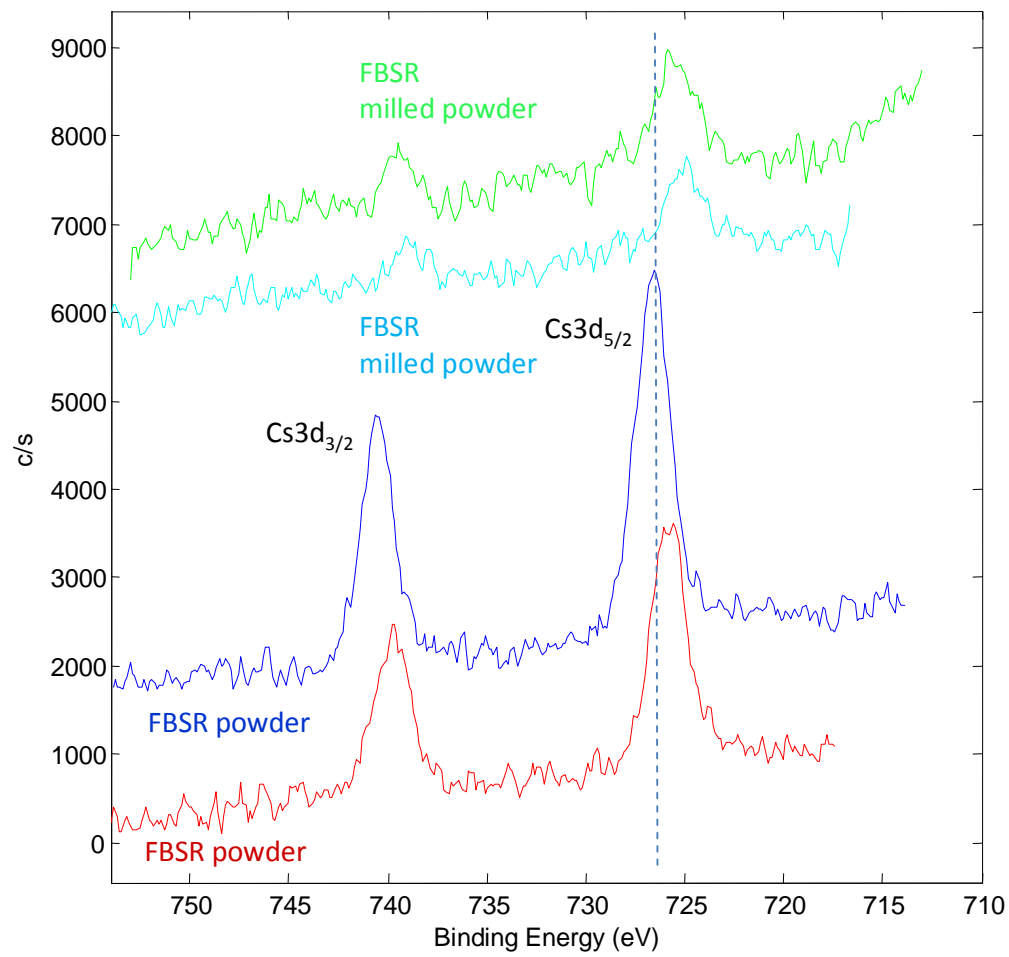

Figure A.3. High Energy Resolution Photoemission Spectra of the Cs 3d Region for FBSR Powder and FBSR Milled Powder 


\section{Appendix A-2 - Additional Test Results from EPA Methods 1313, 1314, and 1315}

Table A.1. Concentration of Major Cations Measured in Leachate from Method 1315 After $\mathrm{CO}_{2} / \mathrm{N}_{2}$ or $\mathrm{O}_{2} / \mathrm{N}_{2}$ Chamber Reaction

\begin{tabular}{|c|c|c|c|c|c|c|c|c|c|c|}
\hline \multicolumn{2}{|c|}{$\begin{array}{c}\text { Waste Forms with } \\
\text { Reactions }\end{array}$} & $\begin{array}{l}\text { Time } \\
\text { (days) }\end{array}$ & $\begin{array}{c}\mathrm{Na} \\
(\mu \mathrm{g} / \mathrm{L})\end{array}$ & $\begin{array}{c}\mathrm{Ca} \\
(\mu \mathrm{g} / \mathrm{L})\end{array}$ & $\begin{array}{c}\mathrm{K} \\
(\mu \mathrm{g} / \mathrm{L})\end{array}$ & $\begin{array}{c}\mathrm{Al} \\
(\mu \mathrm{g} / \mathrm{L})\end{array}$ & $\begin{array}{c}\mathrm{Si} \\
(\mu \mathrm{g} / \mathrm{L})\end{array}$ & $\begin{array}{c}\mathrm{Mg} \\
(\mu \mathrm{g} / \mathrm{L})\end{array}$ & $\begin{array}{c}\mathrm{S} \\
(\mu \mathrm{g} / \mathrm{L})\end{array}$ & $\begin{array}{c}\mathrm{Fe} \\
(\mu \mathrm{g} / \mathrm{L})\end{array}$ \\
\hline \multirow{21}{*}{ ast Stone } & \multirow{10}{*}{$\begin{array}{l}\mathrm{CO}_{2} / \\
\mathrm{N}_{2}\end{array}$} & 0.08 & $2.84 \mathrm{E}+04$ & $3.84 \mathrm{E}+03$ & ND & ND & ND & $5.33 \mathrm{E}+02$ & $1.69 \mathrm{E}+04$ & ND \\
\hline & & 1.0 & $9.82 E+04$ & $2.75 E+04$ & $3.71 \mathrm{E}+03$ & ND & $2.15 E+03$ & $3.20 \mathrm{E}+03$ & $6.45 E+04$ & ND \\
\hline & & 2.0 & $6.10 \mathrm{E}+04$ & $1.66 \mathrm{E}+04$ & $3.13 E+03$ & ND & $2.03 E+03$ & $1.78 \mathrm{E}+03$ & $4.11 \mathrm{E}+04$ & ND \\
\hline & & 7.0 & $1.30 \mathrm{E}+05$ & $3.85 E+04$ & $4.31 \mathrm{E}+03$ & ND & $3.89 \mathrm{E}+03$ & $4.14 \mathrm{E}+03$ & $1.07 \mathrm{E}+05$ & ND \\
\hline & & 16.0 & $1.02 \mathrm{E}+05$ & $3.10 \mathrm{E}+04$ & $1.42 \mathrm{E}+04$ & ND & $4.31 \mathrm{E}+03$ & $3.14 \mathrm{E}+03$ & $8.96 \mathrm{E}+04$ & ND \\
\hline & & 30.0 & $8.19 \mathrm{E}+04$ & $3.46 \mathrm{E}+04$ & $6.57 \mathrm{E}+03$ & ND & $5.33 \mathrm{E}+03$ & $3.19 \mathrm{E}+03$ & $7.04 \mathrm{E}+04$ & ND \\
\hline & & 44.0 & $4.40 \mathrm{E}+04$ & $1.81 \mathrm{E}+04$ & $7.78 \mathrm{E}+03$ & ND & $4.82 \mathrm{E}+03$ & $1.60 \mathrm{E}+03$ & $3.33 \mathrm{E}+04$ & ND \\
\hline & & 59.0 & $2.96 \mathrm{E}+04$ & $1.33 E+04$ & $1.06 \mathrm{E}+04$ & ND & $5.05 E+03$ & $9.72 \mathrm{E}+02$ & NR & ND \\
\hline & & 72.0 & $2.17 E+04$ & $1.10 \mathrm{E}+04$ & $4.97 E+03$ & $2.30 \mathrm{E}+02$ & $4.43 E+03$ & $7.48 \mathrm{E}+02$ & $4.42 E+03$ & ND \\
\hline & & 86.0 & $1.66 \mathrm{E}+04$ & $1.02 E+04$ & $3.08 E+03$ & $2.09 \mathrm{E}+02$ & $4.22 \mathrm{E}+03$ & $6.73 \mathrm{E}+02$ & ND & ND \\
\hline & \multirow{11}{*}{$\mathrm{O}_{2} / \mathrm{N}_{2}$} & 0.08 & $2.16 \mathrm{E}+04$ & ND & ND & $5.50 \mathrm{E}+02$ & $1.31 \mathrm{E}+03$ & $1.61 \mathrm{E}+02$ & ND & ND \\
\hline & & 1.0 & $5.83 E+04$ & $7.91 \mathrm{E}+02$ & $4.04 \mathrm{E}+03$ & $1.97 \mathrm{E}+03$ & $6.37 \mathrm{E}+03$ & $3.12 \mathrm{E}+02$ & $4.75 E+03$ & ND \\
\hline & & 2.0 & $3.45 E+04$ & $1.97 \mathrm{E}+03$ & ND & $1.21 \mathrm{E}+03$ & $4.58 \mathrm{E}+03$ & ND & ND & ND \\
\hline & & 8.0 & $7.20 \mathrm{E}+04$ & $6.64 \mathrm{E}+03$ & $5.08 \mathrm{E}+03$ & $2.54 \mathrm{E}+03$ & $9.80 \mathrm{E}+03$ & $3.70 \mathrm{E}+02$ & $5.10 \mathrm{E}+03$ & ND \\
\hline & & 15.0 & $5.79 E+04$ & $1.08 \mathrm{E}+04$ & $5.23 E+03$ & $3.04 \mathrm{E}+03$ & $1.13 \mathrm{E}+04$ & $1.67 \mathrm{E}+02$ & $4.53 E+03$ & ND \\
\hline & & 28.0 & $5.24 \mathrm{E}+04$ & $1.80 \mathrm{E}+04$ & $5.80 \mathrm{E}+03$ & $3.04 \mathrm{E}+03$ & $1.18 \mathrm{E}+04$ & ND & $4.55 \mathrm{E}+03$ & ND \\
\hline & & 35.0 & $2.18 \mathrm{E}+04$ & $1.16 \mathrm{E}+04$ & ND & $1.74 \mathrm{E}+03$ & $7.19 \mathrm{E}+03$ & $5.93 \mathrm{E}+01$ & ND & ND \\
\hline & & 44.0 & $2.45 \mathrm{E}+04$ & $1.25 \mathrm{E}+04$ & $6.20 \mathrm{E}+03$ & $2.08 \mathrm{E}+03$ & $7.53 \mathrm{E}+03$ & $7.26 \mathrm{E}+01$ & $4.33 E+03$ & ND \\
\hline & & 58.0 & $2.60 \mathrm{E}+04$ & $1.19 \mathrm{E}+04$ & $6.64 \mathrm{E}+03$ & $2.30 \mathrm{E}+03$ & $8.46 \mathrm{E}+03$ & $6.49 \mathrm{E}+01$ & $5.30 \mathrm{E}+03$ & ND \\
\hline & & 72.0 & $2.16 \mathrm{E}+04$ & $1.20 \mathrm{E}+04$ & $7.30 \mathrm{E}+03$ & $2.23 \mathrm{E}+03$ & $7.95 E+03$ & 7.13E+01 & $4.45 \mathrm{E}+03$ & ND \\
\hline & & 86.0 & $1.80 \mathrm{E}+04$ & $1.81 \mathrm{E}+04$ & ND & $1.97 \mathrm{E}+03$ & $7.33 \mathrm{E}+03$ & $5.65 \mathrm{E}+01$ & NR & ND \\
\hline
\end{tabular}


Table A.1. (contd)

\begin{tabular}{|c|c|c|c|c|c|c|c|c|c|c|}
\hline \multicolumn{2}{|c|}{$\begin{array}{c}\text { Waste Forms with } \\
\text { Reactions }\end{array}$} & $\begin{array}{l}\text { Time } \\
\text { (days) }\end{array}$ & $\begin{array}{c}\mathrm{Na} \\
(\mu \mathrm{g} / \mathrm{L})\end{array}$ & $\begin{array}{c}\mathrm{Ca} \\
(\mu \mathrm{g} / \mathrm{L})\end{array}$ & $\begin{array}{c}\mathrm{K} \\
(\mu \mathrm{g} / \mathrm{L}) \\
\end{array}$ & $\begin{array}{c}\mathrm{Al} \\
(\mu \mathrm{g} / \mathrm{L})\end{array}$ & $\begin{array}{c}\mathrm{Si} \\
(\mu \mathrm{g} / \mathrm{L})\end{array}$ & $\begin{array}{c}\mathrm{Mg} \\
(\mu \mathrm{g} / \mathrm{L})\end{array}$ & $\begin{array}{c}\mathrm{S} \\
(\mu \mathrm{g} / \mathrm{L})\end{array}$ & $\begin{array}{c}\mathrm{Fe} \\
(\mu \mathrm{g} / \mathrm{L})\end{array}$ \\
\hline \multirow{22}{*}{$\begin{array}{l}\text { DuraLith } \\
\text { Batch \#2 }\end{array}$} & \multirow{11}{*}{$\begin{array}{c}\mathrm{CO}_{2} / \\
\mathrm{N}_{2}\end{array}$} & 0.08 & $3.39 \mathrm{E}+04$ & ND & $8.22 \mathrm{E}+04$ & ND & ND & $5.14 \mathrm{E}+02$ & $6.46 \mathrm{E}+03$ & ND \\
\hline & & 1.0 & $5.78 \mathrm{E}+04$ & ND & $1.28 \mathrm{E}+05$ & ND & ND & ND & $1.06 \mathrm{E}+04$ & ND \\
\hline & & 2.0 & $3.82 E+04$ & ND & $9.13 E+04$ & ND & ND & ND & $6.89 E+03$ & ND \\
\hline & & 7.0 & $8.65 E+04$ & ND & $1.90 \mathrm{E}+05$ & ND & ND & ND & $2.02 \mathrm{E}+04$ & ND \\
\hline & & 14.0 & $7.21 \mathrm{E}+04$ & ND & $1.67 \mathrm{E}+05$ & ND & ND & ND & $1.66 \mathrm{E}+04$ & ND \\
\hline & & 28.0 & $1.04 \mathrm{E}+05$ & ND & $2.35 \mathrm{E}+05$ & ND & ND & ND & ND & ND \\
\hline & & 42.0 & $5.43 \mathrm{E}+04$ & ND & $1.20 \mathrm{E}+05$ & ND & ND & ND & ND & ND \\
\hline & & 49.0 & $2.21 \mathrm{E}+04$ & ND & $5.20 \mathrm{E}+04$ & $1.94 \mathrm{E}+03$ & ND & ND & ND & ND \\
\hline & & 63.0 & $3.38 \mathrm{E}+04$ & ND & 7.37E+04 & $1.97 \mathrm{E}+03$ & ND & ND & ND & ND \\
\hline & & 77.0 & $2.75 E+04$ & ND & $5.99 \mathrm{E}+04$ & $2.07 \mathrm{E}+03$ & ND & ND & ND & ND \\
\hline & & 91.0 & $2.34 \mathrm{E}+04$ & ND & $5.08 \mathrm{E}+04$ & $1.99 \mathrm{E}+03$ & ND & ND & ND & ND \\
\hline & \multirow{11}{*}{$\mathrm{O}_{2} / \mathrm{N}_{2}$} & 0.08 & $2.02 \mathrm{E}+04$ & ND & $4.36 \mathrm{E}+04$ & ND & ND & ND & ND & ND \\
\hline & & 1.0 & $2.74 \mathrm{E}+04$ & ND & $6.28 \mathrm{E}+04$ & ND & ND & ND & ND & ND \\
\hline & & 2.0 & $1.98 \mathrm{E}+04$ & ND & $4.77 \mathrm{E}+04$ & ND & ND & ND & ND & ND \\
\hline & & 7.0 & $5.52 \mathrm{E}+04$ & ND & $1.26 \mathrm{E}+05$ & $1.23 \mathrm{E}+03$ & $7.14 \mathrm{E}+03$ & ND & ND & ND \\
\hline & & 14.0 & $6.67 \mathrm{E}+04$ & ND & $1.50 \mathrm{E}+05$ & $1.54 \mathrm{E}+03$ & $9.72 E+03$ & ND & ND & ND \\
\hline & & 28.0 & $7.29 \mathrm{E}+04$ & ND & $1.62 \mathrm{E}+05$ & $1.08 \mathrm{E}+03$ & $1.11 \mathrm{E}+04$ & ND & ND & ND \\
\hline & & 42.0 & $4.80 \mathrm{E}+04$ & ND & $1.08 \mathrm{E}+05$ & ND & $1.12 \mathrm{E}+04$ & ND & ND & ND \\
\hline & & 49.0 & $2.10 \mathrm{E}+04$ & ND & $4.75 \mathrm{E}+04$ & ND & $7.12 \mathrm{E}+03$ & ND & ND & ND \\
\hline & & 63.0 & $3.64 \mathrm{E}+04$ & ND & $6.34 \mathrm{E}+04$ & ND & $1.02 \mathrm{E}+04$ & ND & ND & ND \\
\hline & & 77.0 & $3.22 \mathrm{E}+04$ & ND & $5.23 E+04$ & ND & $1.11 \mathrm{E}+04$ & ND & ND & ND \\
\hline & & 91.0 & $2.88 \mathrm{E}+04$ & ND & $4.26 \mathrm{E}+04$ & ND & $1.15 \mathrm{E}+04$ & ND & ND & ND \\
\hline
\end{tabular}


Table A.1. (contd)

\begin{tabular}{|c|c|c|c|c|c|c|c|c|c|c|}
\hline \multicolumn{2}{|c|}{$\begin{array}{c}\text { Waste Forms with } \\
\text { Reactions }\end{array}$} & $\begin{array}{l}\text { Time } \\
\text { (days) }\end{array}$ & $\begin{array}{c}\mathrm{Na} \\
(\mu \mathrm{g} / \mathrm{L})\end{array}$ & $\begin{array}{c}\mathrm{Ca} \\
(\mu \mathrm{g} / \mathrm{L})\end{array}$ & $\begin{array}{c}\mathrm{K} \\
(\mu \mathrm{g} / \mathrm{L})\end{array}$ & $\begin{array}{c}\mathrm{Al} \\
(\mu \mathrm{g} / \mathrm{L})\end{array}$ & $\begin{array}{c}\mathrm{Si} \\
(\mu \mathrm{g} / \mathrm{L})\end{array}$ & $\begin{array}{c}\mathrm{Mg} \\
(\mu \mathrm{g} / \mathrm{L})\end{array}$ & $\begin{array}{c}\mathrm{S} \\
(\mu \mathrm{g} / \mathrm{L})\end{array}$ & $\begin{array}{c}\mathrm{Fe} \\
(\mu \mathrm{g} / \mathrm{L})\end{array}$ \\
\hline \multirow{20}{*}{$\begin{array}{c}\text { Geo-7 } \\
\text { encapsulated } \\
\text { FBSR } \\
\text { Monolith }\end{array}$} & \multirow{11}{*}{$\begin{array}{c}\mathrm{CO}_{2} / \\
\mathrm{N}_{2}\end{array}$} & 0.08 & $6.35 E+05$ & $\mathrm{ND}$ & $6.53 \mathrm{E}+03$ & ND & $2.46 \mathrm{E}+04$ & $5.24 \mathrm{E}+01$ & $4.83 \mathrm{E}+03$ & $3.70 \mathrm{E}+02$ \\
\hline & & 1 & $7.41 \mathrm{E}+05$ & ND & $1.25 \mathrm{E}+04$ & $7.25 \mathrm{E}+02$ & $3.02 E+05$ & $8.62 E+01$ & $2.08 \mathrm{E}+04$ & $1.11 \mathrm{E}+03$ \\
\hline & & 2 & $4.59 E+05$ & ND & $8.82 E+03$ & $1.90 \mathrm{E}+02$ & $1.81 \mathrm{E}+05$ & $4.41 \mathrm{E}+01$ & $1.14 \mathrm{E}+04$ & $3.45 \mathrm{E}+02$ \\
\hline & & 7 & $9.37 \mathrm{E}+05$ & $5.28 \mathrm{E}+02$ & $1.59 \mathrm{E}+04$ & $2.68 \mathrm{E}+02$ & $4.64 \mathrm{E}+05$ & $1.46 \mathrm{E}+02$ & $2.15 E+04$ & $1.11 \mathrm{E}+03$ \\
\hline & & 14.0 & $8.16 \mathrm{E}+05$ & ND & ND & ND & $4.83 E+05$ & $6.04 \mathrm{E}+02$ & ND & $3.57 E+03$ \\
\hline & & 28.0 & $2.86 \mathrm{E}+05$ & ND & ND & ND & $2.06 \mathrm{E}+05$ & $9.26 \mathrm{E}+02$ & ND & $3.95 E+03$ \\
\hline & & 42.0 & $1.53 \mathrm{E}+05$ & ND & ND & $9.32 \mathrm{E}+02$ & $1.11 \mathrm{E}+05$ & $7.72 \mathrm{E}+02$ & ND & $3.39 E+03$ \\
\hline & & 49.0 & $6.57 \mathrm{E}+04$ & ND & ND & ND & $4.22 \mathrm{E}+04$ & ND & ND & $1.70 \mathrm{E}+03$ \\
\hline & & 63.0 & $7.11 \mathrm{E}+04$ & ND & ND & $9.73 E+02$ & $5.04 \mathrm{E}+04$ & $2.17 \mathrm{E}+02$ & ND & $3.32 E+03$ \\
\hline & & 77.0 & $5.41 \mathrm{E}+04$ & ND & ND & $9.66 \mathrm{E}+02$ & $3.80 \mathrm{E}+04$ & ND & ND & $2.18 \mathrm{E}+03$ \\
\hline & & 91.0 & $4.76 \mathrm{E}+04$ & ND & $1.92 \mathrm{E}+04$ & $1.03 \mathrm{E}+03$ & $2.94 \mathrm{E}+04$ & $2.50 \mathrm{E}+02$ & ND & $1.60 \mathrm{E}+03$ \\
\hline & $\mathrm{O}_{2} / \mathrm{N}_{2}$ & 0.08 & $5.46 \mathrm{E}+05$ & ND & ND & ND & $1.71 \mathrm{E}+05$ & $6.45 \mathrm{E}+02$ & ND & $4.23 \mathrm{E}+03$ \\
\hline & & 1.0 & $1.09 \mathrm{E}+06$ & ND & ND & ND & $2.59 \mathrm{E}+05$ & $9.84 \mathrm{E}+02$ & ND & $5.58 \mathrm{E}+03$ \\
\hline & & 2.0 & $6.08 \mathrm{E}+05$ & ND & ND & ND & $1.84 \mathrm{E}+05$ & $6.79 E+02$ & ND & $2.78 \mathrm{E}+03$ \\
\hline & & 7.0 & $1.33 \mathrm{E}+06$ & ND & $2.77 E+04$ & $9.48 \mathrm{E}+02$ & NR & $1.49 E+03$ & $1.69 \mathrm{E}+04$ & $6.07 E+03$ \\
\hline & & 14.0 & $9.27 \mathrm{E}+05$ & ND & $1.74 \mathrm{E}+04$ & $1.21 \mathrm{E}+03$ & $3.14 \mathrm{E}+05$ & $1.59 \mathrm{E}+03$ & ND & $5.55 \mathrm{E}+03$ \\
\hline & & 28.0 & $4.90 \mathrm{E}+05$ & ND & ND & $1.38 \mathrm{E}+03$ & $1.67 \mathrm{E}+05$ & $1.61 \mathrm{E}+03$ & ND & $5.92 \mathrm{E}+03$ \\
\hline & & 42.0 & $2.35 E+05$ & ND & ND & $1.57 \mathrm{E}+03$ & $1.10 \mathrm{E}+05$ & $1.06 \mathrm{E}+03$ & ND & $4.42 E+03$ \\
\hline & & 49.0 & $8.11 \mathrm{E}+04$ & ND & ND & $1.58 \mathrm{E}+03$ & $3.92 \mathrm{E}+04$ & $4.03 \mathrm{E}+02$ & ND & $1.68 \mathrm{E}+03$ \\
\hline & & 63.0 & $9.26 \mathrm{E}+04$ & ND & ND & $1.37 \mathrm{E}+03$ & $4.19 \mathrm{E}+04$ & $5.55 \mathrm{E}+02$ & ND & $2.22 \mathrm{E}+03$ \\
\hline
\end{tabular}

ND indicates "not detected" below quantification level.

NR indicates sample values not reportable. 
Table A.2. Concentrations of RCRA Metals Measured in Leachate from Method 1315 After $\mathrm{CO}_{2} / \mathrm{N}_{2}$ or $\mathrm{O}_{2} / \mathrm{N}_{2}$ Chamber Reaction

\begin{tabular}{|c|c|c|c|c|c|c|c|c|c|}
\hline \multicolumn{2}{|c|}{$\begin{array}{c}\text { Waste Forms with } \\
\text { Reactions }\end{array}$} & $\begin{array}{l}\text { Time } \\
\text { (days) }\end{array}$ & $\begin{array}{c}\text { As } \\
(\mu \mathrm{g} / \mathrm{L})\end{array}$ & $\begin{array}{c}\mathrm{Cd} \\
(\mu \mathrm{g} / \mathrm{L})\end{array}$ & $\begin{array}{c}\mathrm{Cr} \\
(\mu \mathrm{g} / \mathrm{L})\end{array}$ & $\begin{array}{c}\mathrm{Pb} \\
(\mu \mathrm{g} / \mathrm{L})\end{array}$ & $\begin{array}{c}\mathrm{Ag} \\
(\mu \mathrm{g} / \mathrm{L})\end{array}$ & $\begin{array}{c}\mathrm{Hg} \\
(\mu \mathrm{g} / \mathrm{L})\end{array}$ & $\begin{array}{c}\mathrm{Cu} \\
(\mu \mathrm{g} / \mathrm{L})\end{array}$ \\
\hline & \multirow{10}{*}{$\mathrm{CO}_{2} / \mathrm{N}_{2}$} & 0.08 & ND & ND & $1.86 \mathrm{E}+00$ & ND & ND & ND & ND \\
\hline & & 1.0 & ND & ND & $2.11 \mathrm{E}+00$ & ND & ND & ND & ND \\
\hline & & 2.0 & ND & ND & $1.80 \mathrm{E}+00$ & ND & ND & ND & ND \\
\hline & & 7.0 & ND & ND & $2.95 E+00$ & ND & ND & ND & ND \\
\hline & & 16.0 & ND & ND & ND & ND & ND & ND & ND \\
\hline & & 30.0 & ND & ND & ND & ND & ND & ND & ND \\
\hline & & 44.0 & ND & ND & ND & ND & ND & ND & ND \\
\hline & & 59.0 & ND & ND & $1.39 \mathrm{E}+00$ & 6.61E-01 & ND & ND & ND \\
\hline & & 72.0 & ND & ND & ND & ND & ND & NR & ND \\
\hline & & 86.0 & ND & ND & ND & ND & ND & NR & ND \\
\hline \multirow[t]{22}{*}{ Cast Stone } & & 0.08 & ND & ND & $2.01 \mathrm{E}+00$ & ND & ND & ND & ND \\
\hline & & 1.0 & ND & ND & $3.98 \mathrm{E}+00$ & ND & ND & ND & ND \\
\hline & & 2.0 & ND & ND & $3.24 \mathrm{E}+00$ & ND & ND & ND & ND \\
\hline & & 8.0 & ND & ND & $5.61 \mathrm{E}+00$ & ND & ND & ND & ND \\
\hline & & 15.0 & ND & 4.16E-01 & ND & $2.28 \mathrm{E}+00$ & ND & ND & $8.91 \mathrm{E}+02$ \\
\hline & $\mathrm{O}_{2} / \mathrm{N}_{2}$ & 28.0 & ND & ND & $5.24 \mathrm{E}+00$ & ND & ND & ND & ND \\
\hline & & 35.0 & ND & ND & $3.12 \mathrm{E}+00$ & ND & ND & ND & ND \\
\hline & & 44.0 & ND & ND & ND & ND & ND & ND & ND \\
\hline & & 58.0 & ND & ND & ND & ND & ND & ND & ND \\
\hline & & 72.0 & ND & ND & ND & ND & ND & ND & ND \\
\hline & & 86.0 & ND & NR & & NR & ND & NR & NR \\
\hline & & 0.08 & ND & ND & ND & ND & ND & NR & ND \\
\hline & & 1.0 & ND & ND & ND & ND & ND & NR & ND \\
\hline & & 2.0 & ND & ND & ND & ND & ND & NR & ND \\
\hline & & 7.0 & ND & ND & ND & ND & ND & NR & ND \\
\hline & & 14.0 & ND & ND & ND & ND & ND & NR & ND \\
\hline & $\mathrm{CO}_{2} / \mathrm{N}_{2}$ & 28.0 & ND & ND & ND & ND & ND & ND & ND \\
\hline & & 42.0 & ND & ND & ND & ND & ND & ND & ND \\
\hline & & 49.0 & ND & ND & ND & ND & ND & NM & ND \\
\hline & & 63.0 & ND & ND & ND & ND & ND & NM & ND \\
\hline & & 77.0 & ND & ND & ND & ND & ND & NM & ND \\
\hline & & 91.0 & ND & ND & ND & ND & ND & NM & ND \\
\hline \multirow{11}{*}{ Batch \#2 } & \multirow{11}{*}{$\mathrm{O}_{2} / \mathrm{N}_{2}$} & 0.08 & ND & ND & ND & ND & ND & ND & ND \\
\hline & & 1.0 & ND & ND & ND & ND & ND & ND & ND \\
\hline & & 2.0 & ND & ND & ND & ND & ND & ND & ND \\
\hline & & 7.0 & ND & ND & ND & ND & ND & ND & ND \\
\hline & & 14.0 & ND & ND & ND & ND & ND & ND & ND \\
\hline & & 28.0 & ND & ND & ND & ND & ND & NM & ND \\
\hline & & 42.0 & ND & ND & ND & ND & ND & $\mathrm{NM}$ & ND \\
\hline & & 49.0 & ND & ND & ND & ND & ND & $\mathrm{NM}$ & ND \\
\hline & & 63.0 & ND & ND & ND & ND & ND & ND & ND \\
\hline & & 77.0 & ND & ND & ND & ND & ND & ND & ND \\
\hline & & 91.0 & ND & ND & ND & ND & ND & ND & ND \\
\hline
\end{tabular}


Table A.2. (contd)

\begin{tabular}{|c|c|c|c|c|c|c|c|c|c|}
\hline \multicolumn{2}{|c|}{$\begin{array}{l}\text { Waste Forms with } \\
\text { Reactions }\end{array}$} & $\begin{array}{l}\text { Time } \\
\text { (days) }\end{array}$ & $\begin{array}{c}\text { As } \\
(\mu \mathrm{g} / \mathrm{L})\end{array}$ & $\begin{array}{c}\mathrm{Cd} \\
(\mu \mathrm{g} / \mathrm{L})\end{array}$ & $\begin{array}{c}\mathrm{Cr} \\
(\mu \mathrm{g} / \mathrm{L})\end{array}$ & $\begin{array}{c}\mathrm{Pb} \\
(\mu \mathrm{g} / \mathrm{L})\end{array}$ & $\begin{array}{c}\mathrm{Ag} \\
(\mu \mathrm{g} / \mathrm{L})\end{array}$ & $\begin{array}{c}\mathrm{Hg} \\
(\mu \mathrm{g} / \mathrm{L})\end{array}$ & $\begin{array}{c}\mathrm{Cu} \\
(\mu \mathrm{g} / \mathrm{L})\end{array}$ \\
\hline \multirow{20}{*}{$\begin{array}{c}\text { Geo-7 } \\
\text { encapsulated } \\
\text { FBSR } \\
\text { Monolith }\end{array}$} & \multirow{11}{*}{$\mathrm{CO}_{2} / \mathrm{N}_{2}$} & 0.08 & ND & ND & ND & ND & ND & NR & ND \\
\hline & & 1 & $8.02 \mathrm{E}+02$ & ND & ND & ND & ND & NR & ND \\
\hline & & 2 & ND & ND & ND & ND & ND & NR & ND \\
\hline & & 7 & 7.67E+02 & ND & ND & ND & ND & NR & ND \\
\hline & & 14.0 & ND & ND & ND & ND & ND & ND & ND \\
\hline & & 28.0 & ND & ND & ND & ND & ND & ND & ND \\
\hline & & 42.0 & ND & ND & ND & ND & ND & ND & ND \\
\hline & & 49.0 & ND & ND & ND & ND & ND & NM & ND \\
\hline & & 63.0 & ND & ND & ND & ND & ND & NM & ND \\
\hline & & 77.0 & ND & ND & ND & ND & ND & NM & ND \\
\hline & & 91.0 & ND & ND & ND & ND & ND & ND & ND \\
\hline & \multirow{9}{*}{$\mathrm{O}_{2} / \mathrm{N}_{2}$} & 0.08 & ND & ND & ND & ND & ND & $1.58 \mathrm{E}+01$ & ND \\
\hline & & 1.0 & ND & ND & ND & ND & ND & ND & ND \\
\hline & & 2.0 & ND & ND & ND & ND & ND & ND & ND \\
\hline & & 7.0 & ND & ND & ND & ND & ND & NM & ND \\
\hline & & 14.0 & ND & ND & ND & ND & ND & ND & ND \\
\hline & & 28.0 & ND & ND & ND & ND & ND & NM & ND \\
\hline & & 42.0 & ND & ND & ND & ND & ND & NM & ND \\
\hline & & 49.0 & ND & ND & ND & ND & ND & NM & ND \\
\hline & & 63.0 & ND & ND & ND & ND & ND & ND & ND \\
\hline
\end{tabular}

ND indicates "not detected" below quantification level.

NR indicates sample values not reportable. 
Table A.3. Concentrations of Major Cations Measured in Leachate from Method 1313 After $\mathrm{CO}_{2} / \mathrm{N}_{2}$ or $\mathrm{O}_{2} / \mathrm{N}_{2}$ Chamber Reaction

\begin{tabular}{|c|c|c|c|c|c|c|c|c|c|c|}
\hline \multicolumn{2}{|c|}{$\begin{array}{l}\text { Waste Forms With } \\
\text { Reactions }\end{array}$} & $\begin{array}{c}\begin{array}{c}\text { Time } \\
\text { (days) }\end{array} \\
0.042\end{array}$ & $\begin{array}{c}\begin{array}{c}\mathrm{Na} \\
(\mu \mathrm{g} / \mathrm{L})\end{array} \\
2.50 \mathrm{E}+05\end{array}$ & $\begin{array}{c}\begin{array}{c}\mathrm{Ca} \\
(\mu \mathrm{g} / \mathrm{L})\end{array} \\
1.12 \mathrm{E}+05\end{array}$ & $\begin{array}{c}\begin{array}{c}\mathrm{K} \\
(\mu \mathrm{g} / \mathrm{L})\end{array} \\
1.56 \mathrm{E}+04\end{array}$ & $\begin{array}{c}\begin{array}{c}\mathrm{Al} \\
(\mu \mathrm{g} / \mathrm{L})\end{array} \\
\mathrm{ND}\end{array}$ & $\begin{array}{c}\begin{array}{c}\mathrm{Si} \\
(\mu \mathrm{g} / \mathrm{L})\end{array} \\
3.11 \mathrm{E}+03\end{array}$ & $\begin{array}{c}\begin{array}{c}\mathrm{Mg} \\
(\mu \mathrm{g} / \mathrm{L})\end{array} \\
1.43 \mathrm{E}+04\end{array}$ & $\begin{array}{c}\begin{array}{c}\mathrm{S} \\
(\mu \mathrm{g} / \mathrm{L})\end{array} \\
2.32 \mathrm{E}+05\end{array}$ & $\begin{array}{c}\begin{array}{c}\mathrm{Fe} \\
(\mu \mathrm{g} / \mathrm{L})\end{array} \\
\mathrm{ND}\end{array}$ \\
\hline \multirow{8}{*}{ Cast Stone } & \multirow{4}{*}{$\mathrm{CO}_{2} / \mathrm{N}_{2}$} & 0.042 & $2.27 \mathrm{E}+05$ & $1.06 \mathrm{E}+05$ & $1.17 \mathrm{E}+04$ & ND & $3.20 \mathrm{E}+03$ & $1.34 \mathrm{E}+04$ & $2.21 E+05$ & ND \\
\hline & & 3.0 & $3.18 \mathrm{E}+05$ & $1.59 \mathrm{E}+05$ & $1.12 \mathrm{E}+04$ & ND & $5.80 \mathrm{E}+03$ & $2.04 \mathrm{E}+04$ & $3.33 E+05$ & ND \\
\hline & & 7.0 & $3.51 \mathrm{E}+05$ & $1.78 \mathrm{E}+05$ & $1.13 \mathrm{E}+04$ & ND & $8.42 E+03$ & $2.24 \mathrm{E}+04$ & $3.63 E+05$ & ND \\
\hline & & 7.0 & $3.39 E+05$ & $1.65 \mathrm{E}+05$ & $1.03 E+04$ & ND & $8.13 E+03$ & $2.09 E+04$ & $3.37 \mathrm{E}+05$ & ND \\
\hline & \multirow{4}{*}{$\mathrm{O}_{2} / \mathrm{N}_{2}$} & 0.042 & $2.37 \mathrm{E}+05$ & $6.66 \mathrm{E}+03$ & $1.63 E+04$ & $1.32 \mathrm{E}+04$ & $8.25 \mathrm{E}+03$ & ND & $2.08 \mathrm{E}+04$ & $2.31 \mathrm{E}+02$ \\
\hline & & 3.0 & $3.92 E+05$ & $1.16 \mathrm{E}+04$ & $2.80 \mathrm{E}+04$ & $1.62 E+04$ & $1.74 \mathrm{E}+04$ & ND & $3.23 E+04$ & $1.51 \mathrm{E}+02$ \\
\hline & & 7.0 & $4.47 E+05$ & $1.57 \mathrm{E}+04$ & $3.34 \mathrm{E}+04$ & $1.68 \mathrm{E}+04$ & $2.25 \mathrm{E}+04$ & ND & $3.98 E+04$ & ND \\
\hline & & 7.0 & $4.53 \mathrm{E}+05$ & $1.64 \mathrm{E}+04$ & $3.28 E+04$ & $1.62 \mathrm{E}+04$ & $2.18 \mathrm{E}+04$ & $1.36 \mathrm{E}+02$ & $3.71 E+04$ & ND \\
\hline \multirow{8}{*}{$\begin{array}{l}\text { DuraLith } \\
\text { Batch \#2 }\end{array}$} & \multirow{3}{*}{$\mathrm{CO}_{2} / \mathrm{N}_{2}$} & 0.042 & $2.66 \mathrm{E}+05$ & ND & $4.66 \mathrm{E}+05$ & ND & ND & $6.06 \mathrm{E}+02$ & $6.74 \mathrm{E}+04$ & ND \\
\hline & & 0.042 & $2.51 E+05$ & ND & $4.37 \mathrm{E}+05$ & ND & ND & $5.23 E+02$ & $5.89 E+04$ & ND \\
\hline & & 3.0 & $3.85 E+05$ & ND & $6.53 \mathrm{E}+05$ & ND & ND & $5.76 \mathrm{E}+02$ & $6.83 \mathrm{E}+04$ & ND \\
\hline & \multirow{5}{*}{$\mathrm{O}_{2} / \mathrm{N}_{2}$} & 0.042 & $1.03 E+05$ & ND & $1.89 \mathrm{E}+05$ & ND & ND & ND & $2.95 \mathrm{E}+04$ & ND \\
\hline & & 3.0 & $2.85 E+05$ & ND & $5.17 \mathrm{E}+05$ & ND & $1.98 \mathrm{E}+04$ & ND & $5.45 E+04$ & ND \\
\hline & & 3.0 & $2.77 \mathrm{E}+05$ & ND & $5.06 \mathrm{E}+05$ & ND & $1.86 \mathrm{E}+04$ & ND & $5.44 \mathrm{E}+04$ & ND \\
\hline & & 7.0 & $3.46 \mathrm{E}+05$ & ND & $5.84 \mathrm{E}+05$ & ND & $2.74 \mathrm{E}+04$ & ND & $5.48 \mathrm{E}+04$ & ND \\
\hline & & 7.0 & $3.53 E+05$ & ND & $5.97 \mathrm{E}+05$ & ND & $2.71 \mathrm{E}+04$ & ND & $5.25 E+04$ & ND \\
\hline
\end{tabular}


Table A.3. (contd)

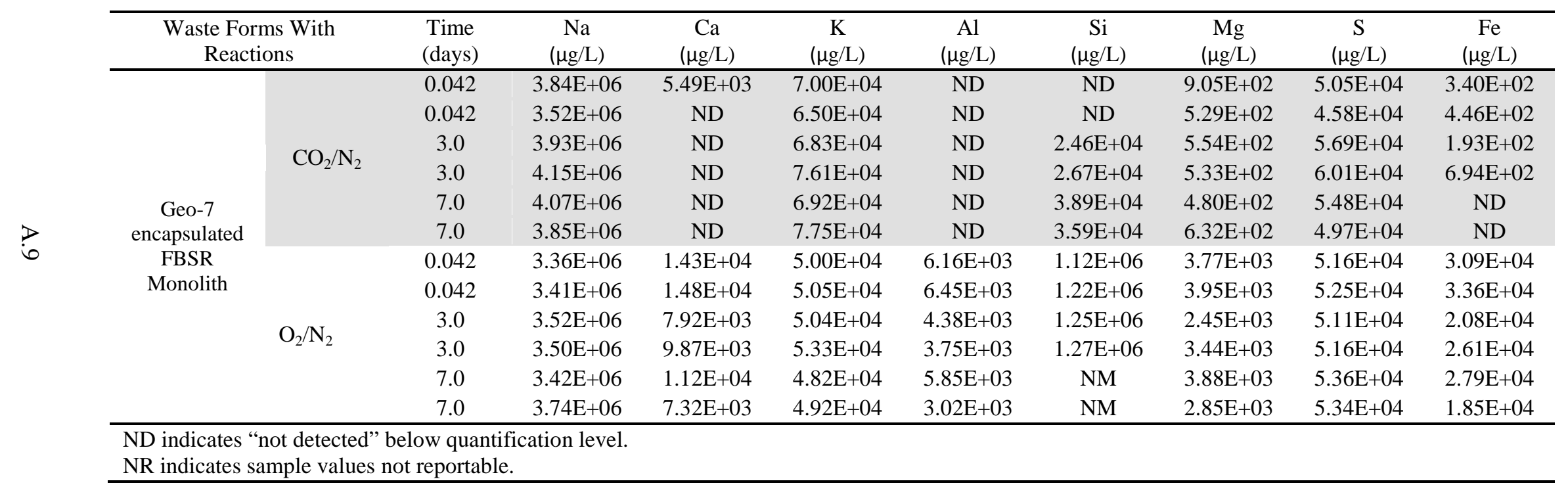


Table A.4. Concentrations of RCRA Metals Measured in Leachate from Method 1313 After $\mathrm{CO}_{2} / \mathrm{N}_{2}$ or $\mathrm{O}_{2} / \mathrm{N}_{2}$ Chamber Reaction

\begin{tabular}{|c|c|c|c|c|c|c|c|c|c|}
\hline \multicolumn{2}{|c|}{$\begin{array}{l}\text { Waste Forms With } \\
\text { Reactions }\end{array}$} & $\begin{array}{l}\text { Time } \\
\text { (days) }\end{array}$ & $\begin{array}{c}\text { As } \\
(\mu \mathrm{g} / \mathrm{L})\end{array}$ & $\begin{array}{c}\mathrm{Cd} \\
(\mu \mathrm{g} / \mathrm{L})\end{array}$ & $\begin{array}{c}\mathrm{Cr} \\
(\mu \mathrm{g} / \mathrm{L})\end{array}$ & $\begin{array}{c}\mathrm{Pb} \\
(\mu \mathrm{g} / \mathrm{L})\end{array}$ & $\begin{array}{c}\mathrm{Ag} \\
(\mu \mathrm{g} / \mathrm{L})\end{array}$ & $\begin{array}{c}\mathrm{Hg} \\
(\mu \mathrm{g} / \mathrm{L})\end{array}$ & $\begin{array}{c}\mathrm{Cu} \\
(\mu \mathrm{g} / \mathrm{L})\end{array}$ \\
\hline \multirow{12}{*}{ Cast Stone } & \multirow{6}{*}{$\mathrm{CO}_{2} / \mathrm{N}_{2}$} & 0.042 & ND & 4.03E-01 & $1.80 \mathrm{E}+00$ & ND & ND & $9.93 \mathrm{E}+00$ & $7.29 \mathrm{E}+00$ \\
\hline & & 0.042 & ND & ND & $1.93 E+00$ & ND & ND & $8.55 E+00$ & $5.81 E+00$ \\
\hline & & 3.0 & ND & 5.29E-01 & $2.67 \mathrm{E}+00$ & ND & ND & $3.45 \mathrm{E}+00$ & $7.26 \mathrm{E}+00$ \\
\hline & & 3.0 & ND & 5.59E-01 & $2.20 \mathrm{E}+00$ & ND & ND & $4.27 \mathrm{E}+00$ & $7.37 \mathrm{E}+00$ \\
\hline & & 7.0 & ND & $6.75 \mathrm{E}-01$ & $3.03 E+00$ & ND & ND & ND & $9.61 \mathrm{E}+00$ \\
\hline & & 7.0 & ND & $6.44 \mathrm{E}-01$ & $3.18 \mathrm{E}+00$ & ND & ND & $6.60 \mathrm{E}+00$ & $8.86 \mathrm{E}+00$ \\
\hline & \multirow{6}{*}{$\mathrm{O}_{2} / \mathrm{N}_{2}$} & 0.042 & ND & ND & $3.28 \mathrm{E}+00$ & ND & ND & 7.81E-01 & $2.60 \mathrm{E}+00$ \\
\hline & & 0.042 & ND & ND & $3.15 E+00$ & ND & ND & ND & $3.24 \mathrm{E}+00$ \\
\hline & & 3.0 & ND & ND & $1.10 \mathrm{E}+01$ & ND & ND & $1.41 \mathrm{E}+00$ & $4.44 \mathrm{E}+00$ \\
\hline & & 3.0 & ND & ND & $1.06 \mathrm{E}+01$ & ND & ND & $1.34 \mathrm{E}+00$ & $4.58 \mathrm{E}+00$ \\
\hline & & 7.0 & ND & ND & $1.43 \mathrm{E}+01$ & ND & ND & $1.42 \mathrm{E}+00$ & $7.19 \mathrm{E}+00$ \\
\hline & & 7.0 & ND & ND & $1.38 \mathrm{E}+01$ & ND & ND & $1.09 \mathrm{E}+00$ & $4.76 \mathrm{E}+00$ \\
\hline \multirow{12}{*}{$\begin{array}{l}\text { DuraLith } \\
\text { Batch \#2 }\end{array}$} & \multirow{6}{*}{$\mathrm{CO}_{2} / \mathrm{N}_{2}$} & 0.042 & ND & ND & ND & ND & ND & ND & ND \\
\hline & & 0.042 & ND & ND & ND & ND & ND & NR & ND \\
\hline & & 3.0 & ND & ND & ND & ND & ND & NR & ND \\
\hline & & 3.0 & ND & ND & ND & ND & ND & NR & ND \\
\hline & & 7.0 & ND & ND & ND & ND & ND & NR & ND \\
\hline & & 7.0 & ND & ND & ND & ND & ND & NR & ND \\
\hline & \multirow{6}{*}{$\mathrm{O}_{2} / \mathrm{N}_{2}$} & 0.042 & ND & ND & ND & ND & ND & ND & ND \\
\hline & & 0.042 & ND & ND & $\mathrm{ND}$ & ND & ND & NR & ND \\
\hline & & 3.0 & ND & ND & ND & ND & ND & NR & ND \\
\hline & & 3.0 & ND & ND & ND & ND & ND & NR & ND \\
\hline & & 7.0 & ND & ND & ND & ND & ND & NR & ND \\
\hline & & 7.0 & ND & ND & ND & ND & ND & NR & ND \\
\hline \multirow{12}{*}{$\begin{array}{c}\text { Geo-7 } \\
\text { encapsulated } \\
\text { FBSR } \\
\text { Monolith }\end{array}$} & \multirow{6}{*}{$\mathrm{CO}_{2} / \mathrm{N}_{2}$} & 0.042 & $1.60 \mathrm{E}+03$ & ND & ND & ND & ND & NR & ND \\
\hline & & 0.042 & $1.53 E+03$ & ND & ND & ND & ND & NR & ND \\
\hline & & 3.0 & $1.68 E+03$ & ND & ND & ND & ND & NR & ND \\
\hline & & 3.0 & $1.85 \mathrm{E}+03$ & ND & ND & ND & ND & NR & ND \\
\hline & & 7.0 & $1.63 E+03$ & ND & ND & ND & ND & NR & ND \\
\hline & & 7.0 & $1.83 E+03$ & ND & ND & ND & ND & NR & ND \\
\hline & \multirow{6}{*}{$\mathrm{O}_{2} / \mathrm{N}_{2}$} & 0.042 & ND & ND & ND & ND & ND & ND & ND \\
\hline & & 0.042 & ND & ND & ND & ND & ND & ND & ND \\
\hline & & 3.0 & ND & ND & ND & ND & ND & ND & ND \\
\hline & & 3.0 & ND & ND & ND & ND & $3.62 \mathrm{E}+01$ & ND & ND \\
\hline & & 7.0 & ND & ND & ND & ND & NM & ND & ND \\
\hline & & 7.0 & ND & ND & ND & ND & NM & ND & ND \\
\hline
\end{tabular}

ND indicates "not detected" below quantification level.

NR indicates sample values not reportable. 
Table A.5. Concentrations of Major Cations Measured in Leachate from Method 1314

\begin{tabular}{|c|c|c|c|c|c|c|c|c|c|c|}
\hline Waste Forms & $\begin{array}{c}\text { Cumulative LS } \\
\text { Ratio } \\
\end{array}$ & $\mathrm{pH}$ & $\begin{array}{c}\mathrm{Na} \\
(\mu \mathrm{g} / \mathrm{L})\end{array}$ & $\begin{array}{c}\mathrm{Ca} \\
(\mu \mathrm{g} / \mathrm{L})\end{array}$ & $\begin{array}{c}\mathrm{K} \\
(\mu \mathrm{g} / \mathrm{L}) \\
\end{array}$ & $\begin{array}{c}\mathrm{Al} \\
(\mu \mathrm{g} / \mathrm{L})\end{array}$ & $\begin{array}{c}\mathrm{Si} \\
(\mu \mathrm{g} / \mathrm{L})\end{array}$ & $\begin{array}{c}\mathrm{Mg} \\
(\mu \mathrm{g} / \mathrm{L})\end{array}$ & $\begin{array}{c}\mathrm{S} \\
(\mu \mathrm{g} / \mathrm{L}) \\
\end{array}$ & $\begin{array}{c}\mathrm{Fe} \\
(\mu \mathrm{g} / \mathrm{L})\end{array}$ \\
\hline \multirow{13}{*}{ Cast Stone } & 0.129 & 12.7 & $5.20 \mathrm{E}+06$ & $6.18 \mathrm{E}+03$ & $3.22 \mathrm{E}+05$ & $1.37 \mathrm{E}+05$ & $7.43 \mathrm{E}+04$ & ND & $1.07 \mathrm{E}+06$ & $1.38 \mathrm{E}+04$ \\
\hline & 0.452 & 12.8 & $4.86 \mathrm{E}+06$ & $7.24 \mathrm{E}+03$ & $2.96 \mathrm{E}+05$ & $1.41 \mathrm{E}+05$ & $6.07 \mathrm{E}+04$ & ND & $1.03 E+06$ & $7.94 \mathrm{E}+03$ \\
\hline & 0.943 & 12.7 & $2.51 \mathrm{E}+06$ & $5.11 \mathrm{E}+03$ & $1.49 \mathrm{E}+05$ & $9.65 E+04$ & $5.10 \mathrm{E}+04$ & ND & $2.03 E+05$ & $5.19 \mathrm{E}+02$ \\
\hline & 1.47 & 12.6 & $1.73 E+06$ & $5.43 \mathrm{E}+03$ & $1.07 \mathrm{E}+05$ & $6.93 \mathrm{E}+04$ & $4.67 \mathrm{E}+04$ & ND & $1.22 \mathrm{E}+05$ & ND \\
\hline & 2.01 & 12.5 & $1.13 \mathrm{E}+06$ & $5.61 \mathrm{E}+03$ & $7.23 E+04$ & $4.25 E+04$ & $3.86 \mathrm{E}+04$ & ND & $6.52 \mathrm{E}+04$ & ND \\
\hline & 3.60 & 12.3 & $6.44 \mathrm{E}+05$ & $1.12 \mathrm{E}+04$ & $5.35 E+04$ & $2.32 E+04$ & $3.13 E+04$ & ND & $4.68 \mathrm{E}+04$ & ND \\
\hline & 4.13 & 11.9 & $3.19 \mathrm{E}+05$ & ND & $4.51 E+04$ & $1.18 \mathrm{E}+04$ & $1.91 \mathrm{E}+04$ & ND & $3.67 E+04$ & ND \\
\hline & 8.89 & 11.8 & $6.78 \mathrm{E}+04$ & $9.23 E+04$ & $2.55 E+04$ & $5.61 \mathrm{E}+03$ & $8.59 E+03$ & ND & $2.57 \mathrm{E}+04$ & ND \\
\hline & 9.43 & 11.6 & $3.32 \mathrm{E}+04$ & $9.25 E+04$ & ND & $5.00 \mathrm{E}+03$ & $6.99 \mathrm{E}+03$ & ND & $2.10 \mathrm{E}+04$ & ND \\
\hline & 9.70 & 8.70 & $2.02 E+04$ & $3.24 \mathrm{E}+04$ & ND & $4.75 E+03$ & ND & ND & $1.89 \mathrm{E}+04$ & ND \\
\hline & 14.0 & 11.8 & $9.83 E+03$ & $1.35 \mathrm{E}+05$ & ND & $4.87 E+03$ & ND & ND & $1.68 \mathrm{E}+04$ & ND \\
\hline & 16.6 & 11.7 & $1.13 \mathrm{E}+04$ & $1.32 \mathrm{E}+05$ & ND & $4.40 \mathrm{E}+03$ & $6.21 \mathrm{E}+03$ & ND & $1.06 \mathrm{E}+04$ & ND \\
\hline & 22.9 & 11.7 & $8.57 \mathrm{E}+03$ & $1.34 \mathrm{E}+05$ & ND & $4.41 \mathrm{E}+03$ & $5.99 \mathrm{E}+03$ & $4.55 \mathrm{E}+01$ & $9.40 E+03$ & ND \\
\hline \multirow{10}{*}{$\begin{array}{c}\text { DuraLith Batch } \\
\text { \#2 }\end{array}$} & 0.119 & 12.8 & $2.90 \mathrm{E}+06$ & $1.07 \mathrm{E}+04$ & $5.78 E+06$ & $1.42 E+03$ & $1.02 \mathrm{E}+05$ & ND & $1.36 \mathrm{E}+06$ & $1.56 \mathrm{E}+02$ \\
\hline & 0.392 & 12.2 & $2.62 \mathrm{E}+06$ & $4.89 \mathrm{E}+03$ & $5.10 \mathrm{E}+06$ & $2.25 \mathrm{E}+03$ & $1.61 \mathrm{E}+05$ & ND & $1.02 \mathrm{E}+06$ & $1.37 \mathrm{E}+02$ \\
\hline & 0.884 & 12.4 & $1.68 \mathrm{E}+06$ & $2.13 E+03$ & $2.97 \mathrm{E}+06$ & $3.94 \mathrm{E}+03$ & $2.11 E+05$ & ND & $3.59 \mathrm{E}+05$ & ND \\
\hline & 1.39 & 12.4 & $1.13 \mathrm{E}+06$ & $1.13 \mathrm{E}+03$ & $1.86 \mathrm{E}+06$ & $5.18 \mathrm{E}+03$ & $2.53 E+05$ & ND & $1.09 \mathrm{E}+05$ & ND \\
\hline & 1.89 & 12.3 & $1.07 \mathrm{E}+06$ & $7.10 \mathrm{E}+02$ & $1.71 \mathrm{E}+06$ & $6.06 \mathrm{E}+03$ & $2.49 \mathrm{E}+05$ & ND & $6.53 \mathrm{E}+04$ & ND \\
\hline & 3.40 & 12.0 & $7.64 \mathrm{E}+05$ & $6.30 \mathrm{E}+02$ & $1.21 \mathrm{E}+06$ & $6.27 E+03$ & $1.55 \mathrm{E}+05$ & ND & $3.34 \mathrm{E}+04$ & ND \\
\hline & 3.90 & 12.3 & $6.33 E+05$ & $7.79 \mathrm{E}+02$ & $9.69 \mathrm{E}+05$ & $6.74 \mathrm{E}+03$ & $1.36 \mathrm{E}+05$ & ND & $2.62 E+04$ & ND \\
\hline & 8.43 & 12.1 & $4.32 \mathrm{E}+05$ & ND & $6.80 \mathrm{E}+05$ & $7.86 \mathrm{E}+03$ & $9.00 \mathrm{E}+04$ & ND & $1.56 \mathrm{E}+04$ & ND \\
\hline & 8.98 & 12.0 & $3.29 E+05$ & ND & $5.27 \mathrm{E}+05$ & $8.78 E+03$ & $6.67 E+04$ & ND & $1.17 \mathrm{E}+04$ & ND \\
\hline & 9.78 & 11.9 & $3.37 \mathrm{E}+05$ & ND & $5.32 \mathrm{E}+05$ & $8.76 \mathrm{E}+03$ & $6.71 \mathrm{E}+04$ & $4.79 \mathrm{E}+01$ & $1.21 \mathrm{E}+04$ & $1.39 \mathrm{E}+02$ \\
\hline \multirow{11}{*}{ FBSR } & 0.233 & 13.0 & $7.35 E+07$ & $3.52 E+05$ & $1.21 \mathrm{E}+06$ & $5.73 \mathrm{E}+05$ & $3.51 \mathrm{E}+07$ & $8.78 E+04$ & $9.47 \mathrm{E}+05$ & $7.20 \mathrm{E}+05$ \\
\hline & 0.617 & 12.9 & $4.32 \mathrm{E}+07$ & $2.21 \mathrm{E}+05$ & $7.80 \mathrm{E}+05$ & $2.57 \mathrm{E}+05$ & $2.16 \mathrm{E}+07$ & $7.10 \mathrm{E}+04$ & $5.80 \mathrm{E}+05$ & $4.22 \mathrm{E}+05$ \\
\hline & 1.13 & 12.8 & $2.35 \mathrm{E}+07$ & ND & $4.80 \mathrm{E}+05$ & $6.26 \mathrm{E}+04$ & $1.07 \mathrm{E}+07$ & $4.05 E+04$ & $3.04 \mathrm{E}+05$ & $1.71 \mathrm{E}+05$ \\
\hline & 1.69 & 12.7 & $1.46 \mathrm{E}+07$ & ND & $3.39 E+05$ & $2.47 \mathrm{E}+04$ & $6.20 \mathrm{E}+06$ & $2.72 E+04$ & $1.84 \mathrm{E}+05$ & $2.30 \mathrm{E}+05$ \\
\hline & 2.26 & 12.5 & $4.57 \mathrm{E}+06$ & $1.53 \mathrm{E}+04$ & $8.56 \mathrm{E}+04$ & $1.19 \mathrm{E}+04$ & $2.20 \mathrm{E}+05$ & $3.50 \mathrm{E}+04$ & $3.89 E+04$ & $1.25 \mathrm{E}+05$ \\
\hline & 3.91 & 12.4 & $1.84 \mathrm{E}+06$ & $9.02 \mathrm{E}+03$ & $4.58 E+04$ & $1.17 \mathrm{E}+04$ & $7.78 \mathrm{E}+05$ & $2.82 E+04$ & $8.88 \mathrm{E}+03$ & $7.66 \mathrm{E}+04$ \\
\hline & 4.46 & 12.2 & $9.52 E+05$ & ND & $3.19 E+04$ & $5.68 \mathrm{E}+03$ & $4.70 \mathrm{E}+05$ & $8.74 \mathrm{E}+03$ & $3.73 E+03$ & $2.44 \mathrm{E}+04$ \\
\hline & 9.40 & 11.7 & $4.25 E+05$ & ND & ND & $3.21 \mathrm{E}+03$ & $2.20 \mathrm{E}+05$ & $2.02 \mathrm{E}+03$ & $3.55 E+03$ & $6.88 \mathrm{E}+03$ \\
\hline & 10.1 & 11.6 & $2.32 \mathrm{E}+05$ & $9.25 \mathrm{E}+02$ & $4.91 \mathrm{E}+03$ & $2.78 \mathrm{E}+03$ & $1.31 \mathrm{E}+05$ & $1.02 \mathrm{E}+03$ & ND & $4.02 E+03$ \\
\hline & 10.6 & 11.4 & $2.10 \mathrm{E}+05$ & $9.88 \mathrm{E}+02$ & $4.00 \mathrm{E}+03$ & $2.78 \mathrm{E}+03$ & $1.23 \mathrm{E}+05$ & $8.08 \mathrm{E}+02$ & ND & $3.51 E+03$ \\
\hline & 11.0 & 11.4 & $1.77 \mathrm{E}+05$ & $5.98 \mathrm{E}+02$ & $3.55 E+03$ & $2.94 \mathrm{E}+03$ & $9.67 \mathrm{E}+04$ & $6.66 \mathrm{E}+02$ & ND & $3.19 E+03$ \\
\hline
\end{tabular}


Table A.6. Concentration of RCRA Metals Measured in Leachate from Method 1314

\begin{tabular}{|c|c|c|c|c|c|c|c|c|c|}
\hline Waste Forms & $\begin{array}{c}\text { Cumulative LS } \\
\text { Ratio }\end{array}$ & $\mathrm{pH}$ & $\begin{array}{c}\text { As } \\
(\mu \mathrm{g} / \mathrm{L})\end{array}$ & $\begin{array}{c}\mathrm{Cd} \\
(\mu \mathrm{g} / \mathrm{L})\end{array}$ & $\begin{array}{c}\mathrm{Cr} \\
(\mu \mathrm{g} / \mathrm{L})\end{array}$ & $\begin{array}{c}\mathrm{Pb} \\
(\mu \mathrm{g} / \mathrm{L})\end{array}$ & $\begin{array}{c}\mathrm{Ag} \\
(\mu \mathrm{g} / \mathrm{L})\end{array}$ & $\begin{array}{c}\mathrm{Hg} \\
(\mu \mathrm{g} / \mathrm{L})\end{array}$ & $\begin{array}{c}\mathrm{Cu} \\
(\mu \mathrm{g} / \mathrm{L})\end{array}$ \\
\hline \multirow{13}{*}{ Cast Stone } & 0.129 & 12.7 & $1.76 \mathrm{E}+02$ & $1.14 \mathrm{E}+01$ & $8.72 \mathrm{E}+01$ & $1.17 \mathrm{E}+01$ & ND & NR & $2.06 \mathrm{E}+02$ \\
\hline & 0.452 & 12.8 & $1.42 \mathrm{E}+02$ & $1.02 \mathrm{E}+01$ & $9.40 \mathrm{E}+01$ & $8.33 E+00$ & ND & NR & $6.08 \mathrm{E}+01$ \\
\hline & 0.943 & 12.7 & $5.82 \mathrm{E}+01$ & $1.84 \mathrm{E}+00$ & $4.51 \mathrm{E}+01$ & $3.16 \mathrm{E}+00$ & ND & NR & $8.83 \mathrm{E}+00$ \\
\hline & 1.47 & 12.6 & $3.71 \mathrm{E}+01$ & $1.28 \mathrm{E}+00$ & $5.87 \mathrm{E}+01$ & ND & ND & NR & $6.60 \mathrm{E}+00$ \\
\hline & 2.01 & 12.5 & $1.90 \mathrm{E}+01$ & ND & $2.89 \mathrm{E}+01$ & ND & ND & NR & ND \\
\hline & 3.60 & 12.3 & $6.66 \mathrm{E}+00$ & ND & $4.87 \mathrm{E}+01$ & ND & ND & NR & ND \\
\hline & 4.13 & 11.9 & ND & ND & $9.59 \mathrm{E}+01$ & ND & ND & NR & ND \\
\hline & 8.89 & 11.8 & ND & ND & $6.96 \mathrm{E}+00$ & ND & ND & NR & ND \\
\hline & 9.43 & 11.6 & ND & ND & $1.51 \mathrm{E}+01$ & ND & ND & NR & ND \\
\hline & 9.70 & 8.70 & ND & ND & $4.18 \mathrm{E}+01$ & ND & ND & NR & ND \\
\hline & 14.0 & 11.8 & ND & ND & $5.13 \mathrm{E}+00$ & $1.96 \mathrm{E}+00$ & ND & NR & ND \\
\hline & 16.6 & 11.7 & NR & ND & $6.21 \mathrm{E}+00$ & ND & ND & ND & ND \\
\hline & 22.9 & 11.7 & NR & ND & $3.77 \mathrm{E}+00$ & ND & ND & ND & ND \\
\hline \multirow{10}{*}{ DuraLith Batch \#2 } & 0.119 & 12.8 & ND & $1.62 \mathrm{E}+00$ & $1.76 \mathrm{E}+01$ & ND & ND & $7.36 \mathrm{E}+00$ & $4.14 \mathrm{E}+01$ \\
\hline & 0.392 & 12.2 & ND & $9.16 \mathrm{E}-01$ & $1.68 \mathrm{E}+00$ & $3.71 E+00$ & ND & $6.58 \mathrm{E}+00$ & $2.11 \mathrm{E}+01$ \\
\hline & 0.884 & 12.4 & ND & ND & $2.76 \mathrm{E}+00$ & 9.55E-01 & ND & $1.29 \mathrm{E}+01$ & $1.27 \mathrm{E}+01$ \\
\hline & 1.39 & 12.4 & ND & ND & $3.05 E+00$ & 6.18E-01 & ND & $1.16 \mathrm{E}+00$ & 4.33E+00 \\
\hline & 1.89 & 12.3 & ND & ND & $2.94 \mathrm{E}+00$ & ND & ND & $3.88 \mathrm{E}+01$ & $2.88 \mathrm{E}+00$ \\
\hline & 3.40 & 12.0 & ND & ND & $5.37 \mathrm{E}+00$ & ND & ND & $3.10 \mathrm{E}+00$ & ND \\
\hline & 3.90 & 12.3 & ND & ND & $6.91 \mathrm{E}+00$ & $6.06 \mathrm{E}-01$ & ND & $7.73 \mathrm{E}+00$ & ND \\
\hline & 8.43 & 12.1 & ND & ND & $2.85 \mathrm{E}+00$ & ND & ND & $1.02 \mathrm{E}+00$ & ND \\
\hline & 8.98 & 12.0 & ND & ND & $5.06 \mathrm{E}+00$ & $1.37 \mathrm{E}+00$ & ND & ND & ND \\
\hline & 9.78 & 11.9 & ND & ND & $2.59 \mathrm{E}+01$ & $2.59 \mathrm{E}+00$ & ND & ND & ND \\
\hline
\end{tabular}


Table A.6. (contd)

\begin{tabular}{|c|c|c|c|c|c|c|c|c|c|}
\hline Waste Forms & $\begin{array}{c}\text { Cumulative LS } \\
\text { Ratio }\end{array}$ & $\mathrm{pH}$ & $\begin{array}{c}\text { As } \\
(\mu \mathrm{g} / \mathrm{L})\end{array}$ & $\begin{array}{c}\mathrm{Cd} \\
(\mu \mathrm{g} / \mathrm{L})\end{array}$ & $\begin{array}{c}\mathrm{Cr} \\
(\mu \mathrm{g} / \mathrm{L})\end{array}$ & $\begin{array}{c}\mathrm{Pb} \\
(\mu \mathrm{g} / \mathrm{L})\end{array}$ & $\begin{array}{c}\mathrm{Ag} \\
(\mu \mathrm{g} / \mathrm{L})\end{array}$ & $\begin{array}{c}\mathrm{Hg} \\
(\mu \mathrm{g} / \mathrm{L})\end{array}$ & $\begin{array}{c}\mathrm{Cu} \\
(\mu \mathrm{g} / \mathrm{L})\end{array}$ \\
\hline \multirow{11}{*}{ FBSR } & 0.233 & 13.0 & $2.87 E+04$ & $4.09 \mathrm{E}+03$ & $7.70 \mathrm{E}+03$ & $1.67 \mathrm{E}+04$ & ND & NR & $1.79 E+03$ \\
\hline & 0.617 & 12.9 & $1.84 \mathrm{E}+04$ & $2.26 \mathrm{E}+03$ & $3.83 E+03$ & $7.42 \mathrm{E}+03$ & ND & NR & $1.04 \mathrm{E}+03$ \\
\hline & 1.13 & 12.8 & $1.10 \mathrm{E}+04$ & $1.00 \mathrm{E}+03$ & $1.16 \mathrm{E}+03$ & $1.70 \mathrm{E}+03$ & ND & NR & $5.01 \mathrm{E}+02$ \\
\hline & 1.69 & 12.7 & $7.83 \mathrm{E}+03$ & $1.38 E+03$ & $1.02 \mathrm{E}+03$ & $1.78 \mathrm{E}+03$ & ND & NR & $6.04 \mathrm{E}+02$ \\
\hline & 2.26 & 12.5 & $1.23 \mathrm{E}+03$ & $8.03 E+02$ & $5.84 \mathrm{E}+02$ & $7.29 E+02$ & ND & NR & $5.20 \mathrm{E}+02$ \\
\hline & 3.91 & 12.4 & ND & $4.72 \mathrm{E}+02$ & $4.47 \mathrm{E}+02$ & $3.53 \mathrm{E}+02$ & ND & NR & $3.05 E+02$ \\
\hline & 4.46 & 12.2 & ND & ND & $2.06 \mathrm{E}+02$ & ND & ND & NR & $1.26 \mathrm{E}+02$ \\
\hline & 9.40 & 11.7 & ND & ND & $9.20 \mathrm{E}+01$ & ND & ND & NR & ND \\
\hline & 10.1 & 11.6 & ND & ND & $6.97 \mathrm{E}+01$ & ND & ND & NR & ND \\
\hline & 10.6 & 11.4 & ND & ND & $6.93 \mathrm{E}+01$ & ND & ND & NR & ND \\
\hline & 11.0 & 11.4 & ND & ND & $6.17 \mathrm{E}+01$ & ND & ND & NR & ND \\
\hline $\begin{array}{l}\text { Cumulative LS rat } \\
\text { ND indicates "not } \\
\text { NR indicates samp }\end{array}$ & $\begin{array}{l}\text { ates cumulativ } \\
\text { d” below quan } \\
\text { s not reportab }\end{array}$ & $\begin{array}{l}\text { olid r } \\
\text { level }\end{array}$ & & & & & & & \\
\hline
\end{tabular}




\section{Appendix A-3}

\section{SEM/EDS for 90-Day Leached Cast Stone and DuraLith Sliced Samples}

Cast Stone (Top-V1) (EDS was collected at red-cross mark location; $K$ and $L$ indicate K-energy and L-energy of each element, respectively; ZAF is for element correction, absorption, and fluorescence)

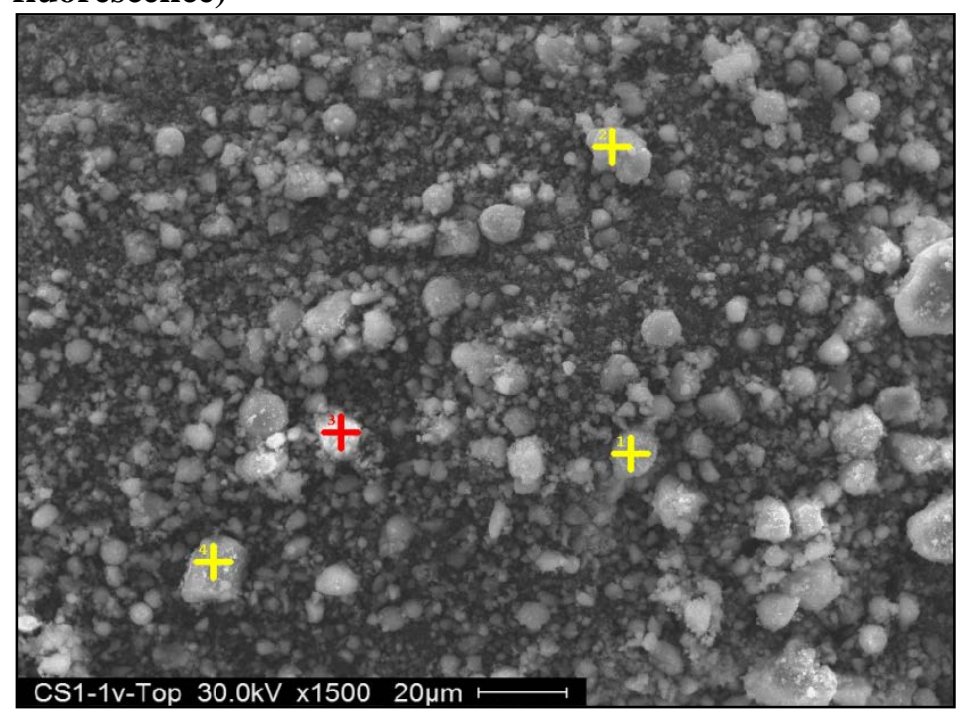

\begin{tabular}{||l|l|l|}
\hline Element & Wt\% & At\% \\
\hline OK & 38.85 & 53.79 \\
\hline FK & 00.81 & 00.95 \\
\hline NaK & 02.64 & 02.55 \\
\hline $\boldsymbol{M g K}$ & 02.43 & 02.21 \\
\hline AlK & 15.97 & 13.11 \\
\hline SiK & 26.22 & 20.68 \\
\hline SK & 00.39 & 00.27 \\
\hline KK & 00.19 & 00.11 \\
\hline CaK & 07.51 & 04.15 \\
\hline TiK & 03.53 & 01.63 \\
\hline FeK & 01.37 & 00.54 \\
\hline WL & 00.07 & 00.01 \\
\hline Matrix & Correction & ZAF \\
\hline \hline
\end{tabular}

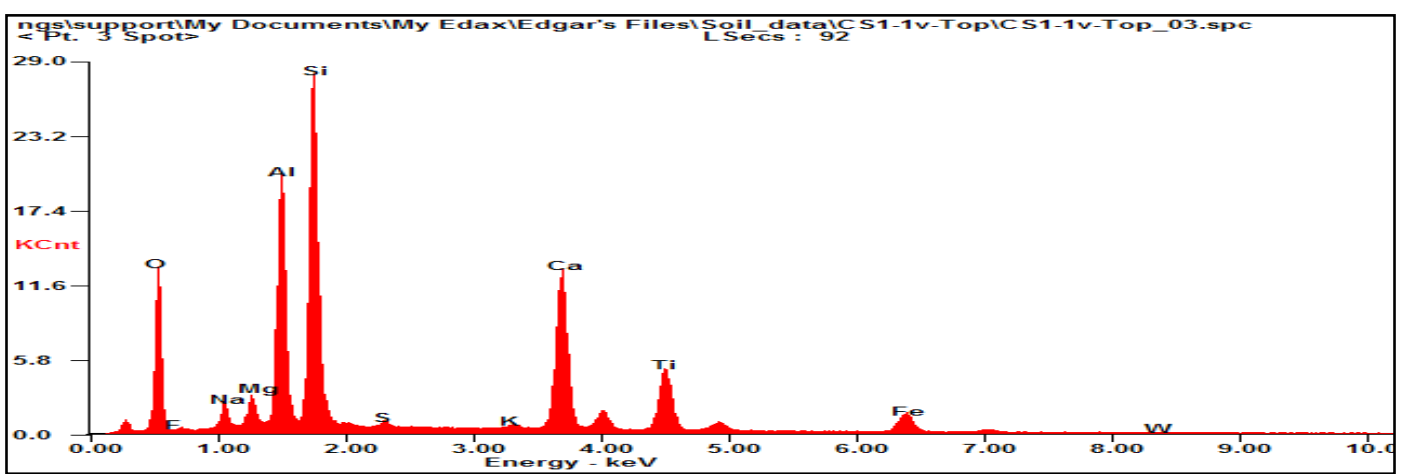


Cast Stone (bottom-H1) (EDS was collected at red-cross marked location; ; K and L indicate Kenergy and L-energy of each element, respectively; ZAF is for element correction, absorption, and fluorescence)

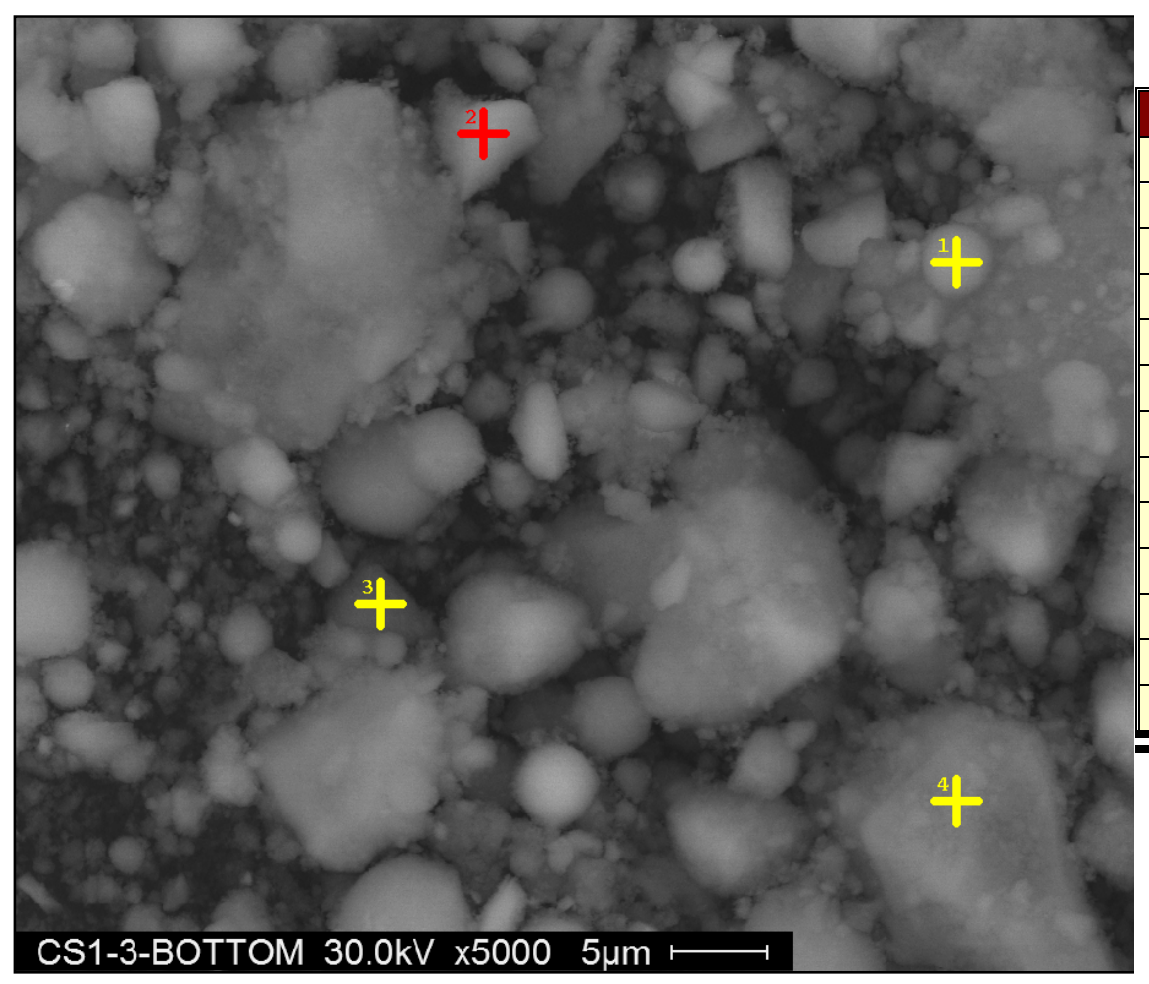

\begin{tabular}{|l|l|l|}
\hline Element & Wt\% & At\% \\
\hline OK & 46.22 & 61.69 \\
\hline FK & 00.83 & 00.94 \\
\hline NaK & 01.46 & 01.36 \\
\hline $\boldsymbol{M g K}$ & 02.74 & 02.41 \\
\hline $\boldsymbol{A l K}$ & 10.93 & 08.65 \\
\hline SiK & 21.11 & 16.05 \\
\hline SK & 00.77 & 00.51 \\
\hline KK & 00.22 & 00.12 \\
\hline CaK & 15.02 & 08.00 \\
\hline TiK & 00.35 & 00.16 \\
\hline FeK & 00.31 & 00.12 \\
\hline WL & 00.02 & 00.00 \\
\hline Matrix & Correction & ZAF \\
\hline \hline
\end{tabular}

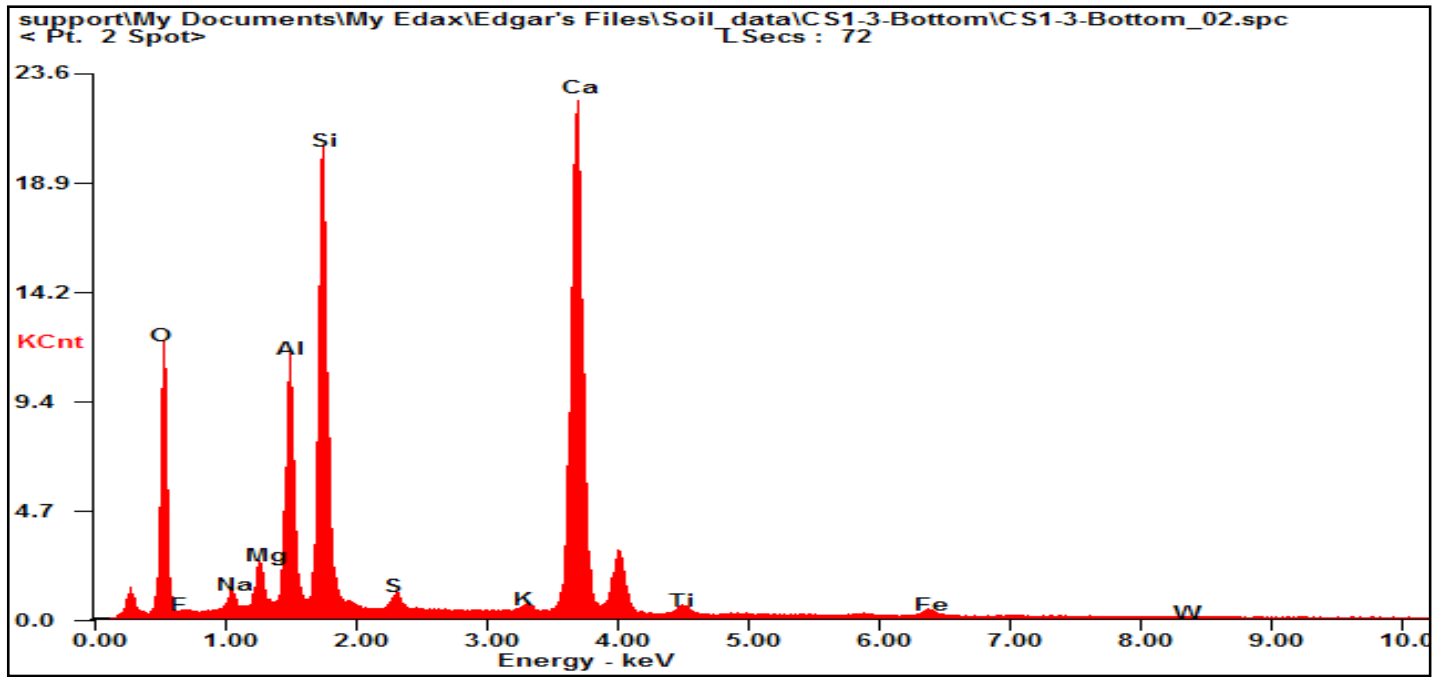


Cast Stone (bottom-H3) (EDS was collected at red-cross marked location; K and L indicate Kenergy and L-energy of each element, respectively; ZAF is for element correction, absorption, and fluorescence)

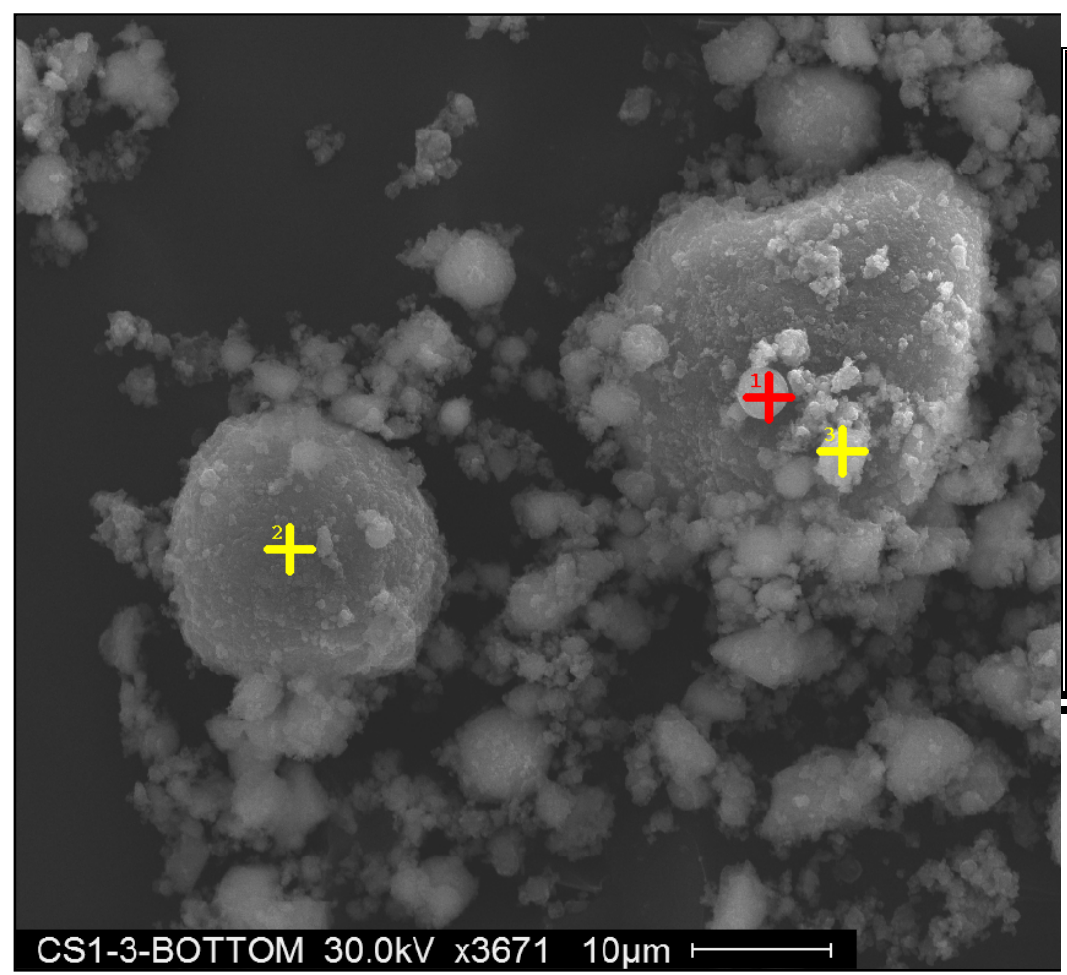

\begin{tabular}{||l|l|l|}
\hline Element & Wt\% & At\% \\
\hline OK & 42.34 & 56.36 \\
\hline FK & 00.66 & 00.74 \\
\hline NaK & 03.71 & 03.43 \\
\hline $\boldsymbol{M g K}$ & 00.88 & 00.77 \\
\hline AlK & 13.96 & 11.02 \\
\hline SiK & 32.35 & 24.53 \\
\hline SK & 00.51 & 00.34 \\
\hline KK & 00.38 & 00.21 \\
\hline CaK & 04.04 & 02.15 \\
\hline TiK & 00.29 & 00.13 \\
\hline FeK & 00.85 & 00.32 \\
\hline WL & 00.04 & 00.00 \\
\hline Matrix & Correction & ZAF \\
\hline \hline
\end{tabular}

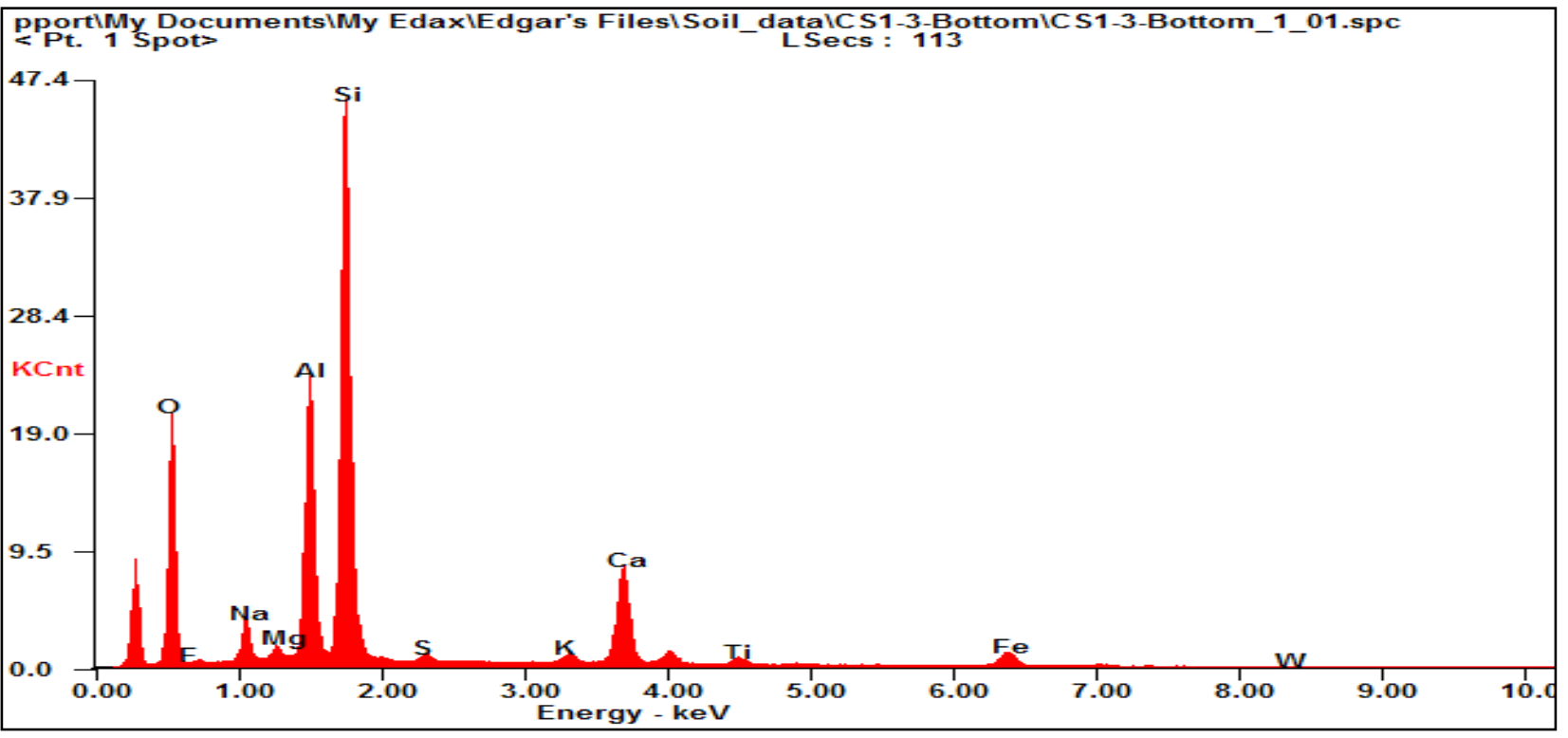


DuraLith-B2C1 Bottom. EDS was collected at yellow-cross marked location; $K$ and $L$ indicate $K-$ energy and L-energy of each element, respectively; ZAF is for element correction, absorption, and fluorescence)

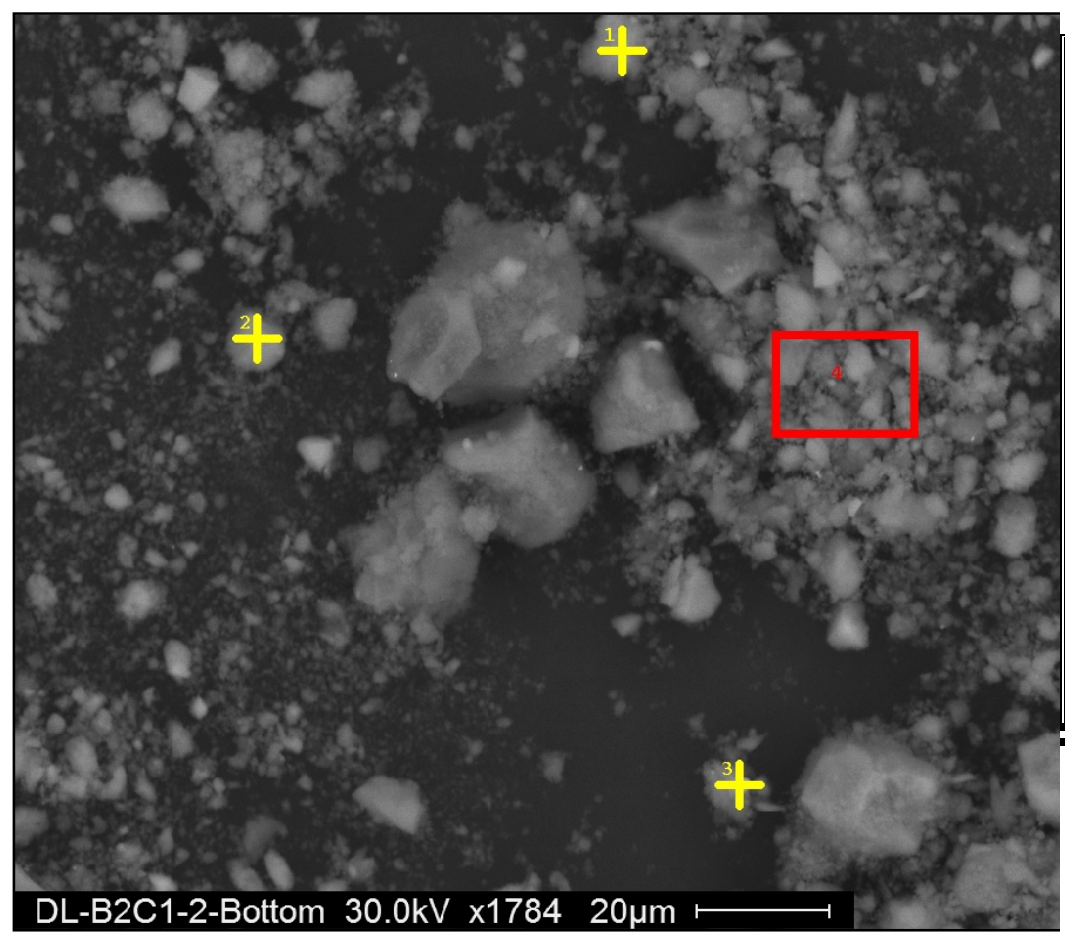

\begin{tabular}{||l|l|l|}
\hline Element & Wt\% & At\% \\
\hline OK & 42.02 & 56.63 \\
\hline FK & 00.16 & 00.18 \\
\hline NaK & 02.44 & 02.29 \\
\hline MgK & 01.58 & 01.41 \\
\hline AlK & 10.79 & 08.62 \\
\hline SiK & 33.45 & 25.68 \\
\hline SK & 00.11 & 00.07 \\
\hline KK & 06.01 & 03.31 \\
\hline CaK & 03.07 & 01.65 \\
\hline TiK & 00.30 & 00.13 \\
\hline FeK & 00.06 & 00.02 \\
\hline WL & 00.00 & 00.00 \\
\hline Matrix & Correction & ZAF \\
\hline \multicolumn{2}{|l}{} \\
\hline \hline & & \\
\hline & \multicolumn{2}{|l}{} \\
\hline
\end{tabular}

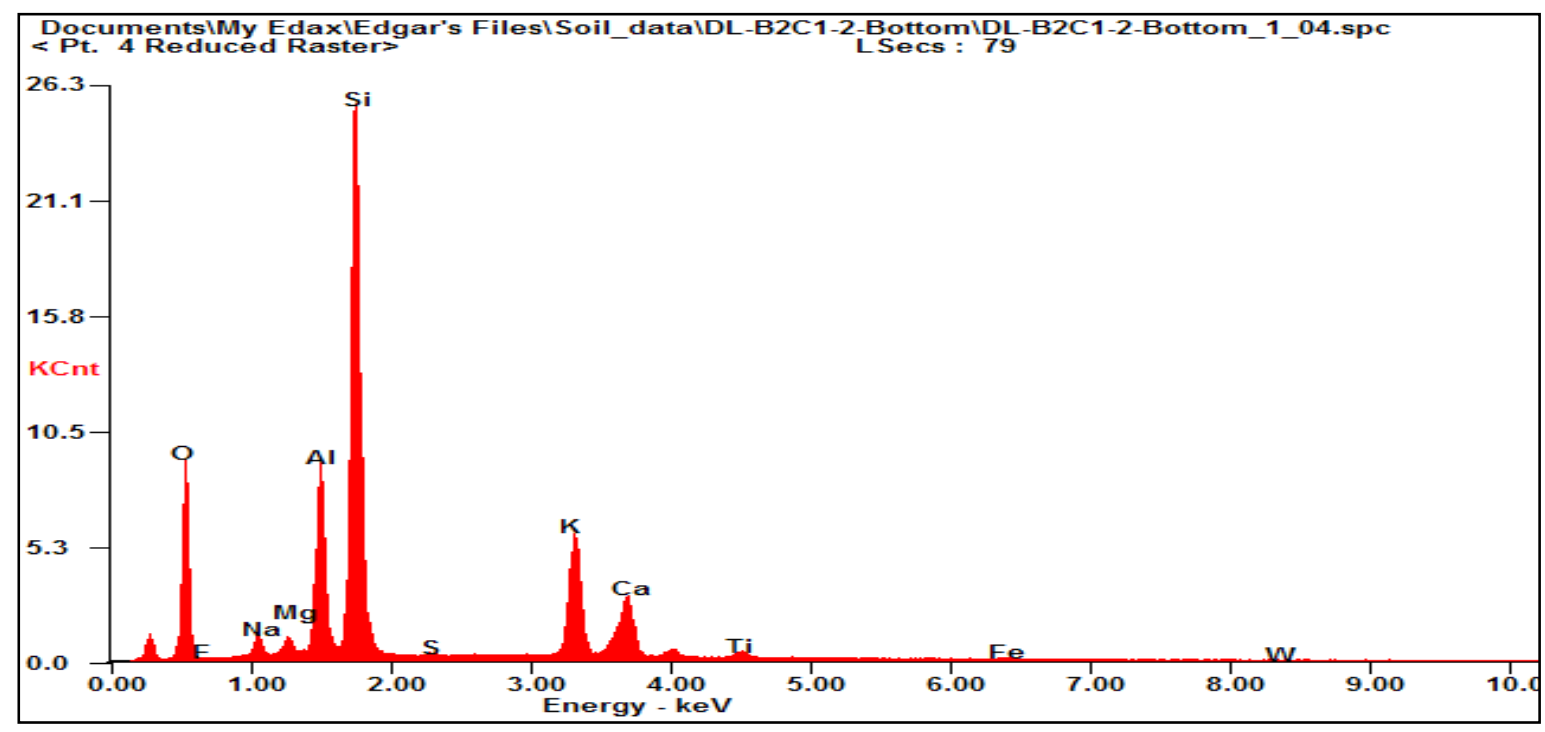





\section{Distribution}

No. of

Copies

\section{OFFSITE}

3 Civil \& Environmental Engineering Vanderbilt University

2301 Vanderbilt Place

Nashville, TN 37235-1831

ATTN: D. Kosson

KG Brown

AC Garrabrants

4 Savannah River National Laboratory P.O. Box 616

Aiken, SC 29802

ATTN: D Kaplan

$$
\begin{aligned}
& \text { G Flash } \\
& \text { C Jantzen } \\
& \text { C Langton }
\end{aligned}
$$

EM Pierce

Building 1505, MS 6038

Oak Ridge National Laboratory

P.O. Box 2008

Oak Ridge, TN 37831-6038
No. of

\section{Copies}

\section{ONSITE}

6 U.S. Department of Energy

$\begin{array}{ll}\text { BM Mauss } & \text { H6-60 } \\ \text { J Morse } & \text { A5-11 } \\ \text { RD Hildebrand } & \text { A6-38 } \\ \text { RW Lober } & \text { H6-60 }\end{array}$

DOE Public Reading Room (2)

CH2M HILL Plateau Remediation Company

LL Lehman H8-51

2 Washington River Protection Solutions

MA Melvin E6-30

KE Smith E6-30

20 Pacific Northwest National Laboratory

PR Bredt

K6-50

KJ Cantrell

K6-81

J Chun

K6-24

C-W Chung

K6-24

SV Mattigod

K3-62

KE Parker

K3-62

LM Peurrung

K9-09

N Qafoku

P7-54

RJ Serne

K6-81

G Wang

P7-54

W Um (3)

P7-54

MM Valenta

P7-54

JH Westsik, Jr (5) 




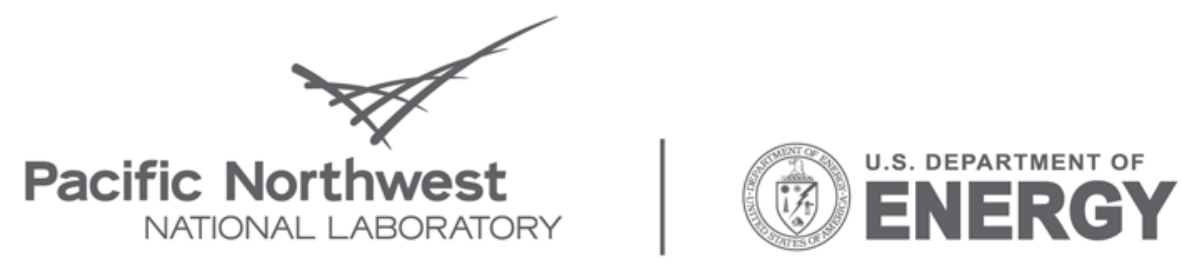

Proudly Operated by Battelle Since 1965

902 Battelle Boulevard

P.O. Box 999

Richland, WA 99352

1-888-375-PNNL (7665)

www.pnl.gov 